\title{
Conservation Genetics and Hybridisation of the Forbes' Parakeet (Cyanoramphus forbesi) in the Chatham Islands
}

\author{
Chi-hang Chan \\ A thesis presented to Victoria University of Wellington \\ in fulfilment of the requirements for the degree of \\ Doctor of Philosophy in Zoology \\ Victoria University of Wellington \\ 2006
}




\section{Abstract}

This study describes the isolation and characterisation of microsatellite loci in Forbes' parakeet (Cyanoramphus forbesi). These molecular markers are used to assess the status of interspecific hybridisation between Forbes' parakeets and Chatham Island Red-crowned parakeets ( $C$. novaezelandiae chathamensis) on Mangere and Little Mangere Islands in the Chatham Islands group. The evolution of these microsatellite loci in parrots is also investigated.

Forbes' parakeets are facing the problem of genetic introgression due to extensive hybridisation with Chatham Island Red-crowned parakeets. Hybrids show a spectrum of crown morphologies between the parent species (Nixon 1982), but identification of hybrids based on morphology alone is not foolproof. Mitochondrial DNA studies by Boon (2000) showed that Forbes' parakeet is a distinct lineage, basal to all other New Zealand parakeets but several Forbes' morphotypes have Chatham Island Redcrowned parakeet haplotype. However, mitochondrial DNA markers only probe the maternally inherited lineages and cannot tell the whole story.

The microsatellite markers used in this study show that interspecific hybridisation between Forbes parakeet and Chatham Island Red-crowned parakeet is more extensive than previously expected. Microsatellite data combined with results from scoring mitochondrial DNA haplotypes show that crown morphology alone under-represents the proportion of hybrids in the population, and that a large number of cryptic hybrids $(77.9 \%)$ show Forbes' parakeet morphotypes. A three factor scoring system is suggested in which a parakeet must pass both genetic (microsatellites and mitochondrial) and morphological criteria to be considered a "pure" Forbes' parakeet. Using this system, $17.8 \%, 1.2 \%$, and $81.0 \%$ of the 
Mangere Island parakeet population are "pure" Forbes' parakeets, "pure" Chatham Island Red-crowned parakeets, and interspecific hybrids respectively.

The results of this study have implications for the future conservation of Forbes' parakeet. Because interspecific hybridisation makes no positive contribution to the long-term survival of Forbes' parakeets, conservation measures to limit contact between the two species should be taken to control further hybridisation of parakeets on Mangere Island.

The microsatellite loci isolated in this study are found to evolve following the patterns best described by either the Stepwise Mutation Model (SMM; Ohta \& Kimura 1973) or the Two-Phase Model (TPM; Di Rienzo et al. 1994) at population level. By mapping the evolutionary changes in repeat motif variations to a parrot phylogeny, it is suggested that these loci may evolve through a more complex model than sole repeat number changes. 


\section{Acknowledgements}

First of all, I would like to express sincere gratitude to the most important people in my academic career, my supervisors Dr. Geoffrey Chambers, Prof. Charles Daugherty, and Dr. Hilary Aikman (DoC). Without your continued support and contribution, this project would never have completed. Especially my principal supervisor, Dr. Geoffrey Chambers, your being always available, always understanding, your help and encouragement in various aspects of life are very much appreciated.

The success should also be shared with Kaye Ballantyne, Prof. David Lambert (Massey), Dr. Oliver Berry (Massey), Dr. Elizabeth MacAvoy, Dr. James Sainsbury, and Dr. Wee-Ming Boon, who offered huge amounts of assistance during these years. I would also like to thank Dr. Jonatham Gardner, Dr. Cristina Yumi Miyaki, and Dr. Mary Morgan-Richards for comments on this thesis.

I am also thankful to all the staff and students at the VUW School of Biological Sciences, for their company and for sharing the fun over the years, especially Dr. Smita Apte, Dr. Ann Wood, Dr. Rod Lea, Dr. Jonathan Gardner, Margo van Bekkum, Adele Whyte, Hayley Lawrence, Lorna McGibbon, Mary Murray, Delwyn Carter, Merrin Woods, Carolina Davies, Anasuya Vishvanath, Mark Johnson, Bruce Dudley, Xiaochen (Jenny) Kong, Tim Sargent, Nicola Davidson, Tongrak Kitwattanachai, Sam Court, Rachel Procter, Bruce Norris and Dr. Leon Huynen (Massey).

Last, but certainly not least, I am deeply impressed by the love, care, support and encouragement from my parents, and my partner Susanna Chui-shan Leung. I owe them everything in my life. 


\section{Table of Contents}

Abstract i

Acknowledgements iii

Table of Contents iv

Chapter 1 Introduction

1.1 Overview 1

1.2 Hybridisation between Species 1

1.3 Birds, Parrots, and Parakeets 5

1.4 Molecular Markers in Conservation Genetics Studies 13

1.5 The Biology of Microsatellites 14

$\begin{array}{ll}1.6 & 19\end{array}$

$\begin{array}{lll}1.7 & \text { Structure of this Thesis } & 19\end{array}$

$\begin{array}{lll}1.8 & \text { References } & 21\end{array}$

Chapter 2 Development of Microsatellite Loci for Forbes' Parakeet (Cyanormphus forbesi) by Hybridisation Selection using Enriched Membranes

2.1 Introduction 40

2.2 Methods 42

2.3 Results 53

2.4 Discussion 54

2.5 References 56

$\begin{array}{ll}\text { Appendix } 2.1 & 60\end{array}$

$\begin{array}{ll}\text { Appendix } 2.2 & 66\end{array}$

$\begin{array}{ll}\text { Appendix 2.3 } & 72\end{array}$ 
Chapter 3 Microsatellite DNA Studies Revealed Extensive Hybridisation between Parakeets on Mangere Island

3.1 Introduction 80

3.2 Methods 81

3.3 Results 88

3.4 Discussion 104

3.5 References 111

Appendix $3.1 \quad 121$

Appendix $3.2 \quad 131$

$\begin{array}{ll}\text { Appendix } 3.3 & 138\end{array}$

Chapter 4 Microsatellite Evolution in Parrots

4.1 Introduction 169

4.2 Methods 170

4.3 Results 174

4.4 Discussion 182

4.5 References 187

Chapter 5 Does Crown Plumage Directly Reflect the Hybridisation Status of Parakeets? A Preliminary Study in Red-crowned Parakeets (Cyanoramphus novaezelandiae novaezelandiae) and Yellowcrowned Parakeets (C. auriceps) on New Zealand Mainland

$\begin{array}{lll}5.1 & \text { Introduction } & 197 \\ 5.2 & \text { Methods } & 199 \\ 5.3 & \text { Results } & 201 \\ 5.4 & \text { Discussion } & 207 \\ 5.5 & \text { References } & 210\end{array}$


Chapter 6 Conservation of Forbes' Parakeet - Present and Outlook

$\begin{array}{lll}6.1 & \text { Summary } & 213\end{array}$

6.2 Present Status of Forbes' Parakeet 214

$\begin{array}{lll}6.3 & \text { Conservation Considerations } & 217\end{array}$

6.4 Future Research 222

$\begin{array}{lll}6.5 & \text { References } & 224\end{array}$

This project is funded by the New Zealand Department of Conservation and Victoria University of Wellington

Chan C-H (2006) Conservation genetics and hybridisation of the Frobes' parakeet (Cyanoramphus forbesi) in the Chatham Islands. PhD thesis, Victoria University of Wellington, Wellington, New Zealand.

Z 


\section{Chapter 1: Introduction}

\subsection{Overview}

This thesis investigates the role of interspecific hybridisation in the recent history of Forbes' parakeet (Cyanoramphus forbesi), a small green parrot found on Mangere and Little Mangere Islands in the Chatham Islands group of New Zealand. Insights were gained through the study of morphological markers, microsatellite and mitochondrial DNA genetic markers in the Mangere Island parakeet population. The effect of hybridisation to the genetic diversity in the population, and the relationship between genetic makeup (biparental and female lineages) and morphologic features in parakeets were investigated. Based on the information obtained, conservation strategies to enhance the long-term genetic integrity of Forbes' parakeets are discussed. The markers developed also allowed the study of microsatellite evolution in parrots and investigation of evolution in parrots from a nuclear DNA perspective.

This chapter introduces the concepts underlying this study. Because hybridisation and the biology of microsatellite DNA have been popular topics in recent years, a large number of quality reviews about these topics have been published in the literature. The aim of this chapter is to provide a summary of findings and theories formulated to date without extensive replication of published reviews. A full reference list is provided for more detailed information about the topics.

\subsection{Hybridisation between Species}

\subsubsection{Definition of Hybridisation}

Numerous definitions exist for "hybridisation" between taxa. Due to the controversy over the definition of species (see Sites \& Crandall 1997; 
Avise \& Walker 2000; Hendry et al. 2000), a definition of "hybridisation" that does not involve the application of particular species concepts is preferred in this study. Thus, hybridisation can be defined as "the interbreeding of individuals from what are believed to be genetically distinct populations, regardless of taxonomic status of such populations" (Rhymer \& Simberloff 1996).

\subsubsection{How Common Is Hybridisation Among Vertebrates?}

Hybridisation, natural and human induced, is common in both plants and animals. Hybridisation is particularly common in birds: Grant \& Grant (1992) estimated that $9.2 \%$ of all known bird species had bred with another species and produced hybrid offspring. In birds it was estimated the average hybridisable species pair diverged from a common ancestor about 22 million years ago (Prager \& Wilson 1975), which is similar to that of frogs (21 million years), but remarkably different from placental mammals (only 2 to 3 million years; Wilson et al. 1974). A suggestion is that the very slow rate of anatomical evolution in birds might have caused the slow rate of loss of interspecific hybridisation potential (Prager \& Wilson 1975).

\subsubsection{Barriers to Hybridisation}

For a healthy and fertile interspecific hybrid offspring to be produced successfully in nature, both pre- and post-zygotic barriers that contribute to reproductive isolation need to be overcome. Recent research involving various model organisms shows that pre-zygotic factors, such as gamete incompatibility and mating behaviour, seem to play a more important role in preventing hybridisation (Rahman et al. 2001; Wolf et al. 2001) compared to post-zygotic factors, such as offspring inviability and sterility (Coyne 1992). Presently, very little is known about how genes interact to 
cause reproductive isolation, and how various genotypes determine the pattern of fitnesses.

At the population level, the barrier to hybridisation can be physical as well as genetical (reviewed by Barton \& Hewitt 1985). The movement of alleles across the hybrid zone is proportional to the gradient of change in allele frequencies. A greater flux usually occurs when the gradient is shallow. When an allele flux meets a physical or genetical barrier, a sharp step builds up. Gene flow may be impeded at the barrier by: 1) environmental factors that reduce density or dispersal; or 2) reduction in density caused by lowered fitness in a cline maintained by dispersal / selection balance; or 3) the inability of an allele to recombine into a new genetic background.

\subsubsection{Fitness of Hybrids}

Hybrid progeny may have inferior, superior or similar fitness relative to their parents, for example, see Arnold \& Hodges (1995), Barton (2001), and Burke \& Arnold (2001). Hybridisation results in recombinant genotypes that are new in the environment. In some cases, these new genotypes may confer adaptive advantages to the individual, but in most cases, they have neutral or negative impacts, for example, reduced fertility (Burke \& Arnold 2001). The reduction of fitness of hybrids is known as 'hybrid breakdown', and can be caused by unfavourable interactions between the genomes of parent species (Burton 1990; Breeuwer \& Werren 1995; Burke et al. 1998). For instance, hybrid sterility was found to result from a large number of genetic incompatibilities in Drosophila flies (Coyne \& Orr 1989; Cabot et al. 1994; Palopoli \& Wu 1994; Perez \& Wu 1995; True et al. 1996). Haldane (1922) suggested that the heterogametic sex hybrids will be more affected by genetic defects. This bias has since been found to arise from interactions between chromosomes, rather than 
defects traceable to the sex chromosomes alone (Coyne 1985; Hollocher \& Wu 1996). This indicates the incompatibility factors are likely to be recessive (True et al. 1996). Hybrid infertility was also found to be more common than hybrid inviability in the heterogametic sex in Drosophila and mammals (Orr 1993; Wu \& Davis 1993).

Conversely, some hybrids can be fitter than parental species, such as between some members of the fish Gambusia and the finch Geospiza (Grant \& Grant 1992; Scribner 1993; see also reviews by Arnold \& Hodges 1995; Burke \& Arnold 2001). Hybrid vigour often occurs if the parental species are inbred. New variants that are more adapted to new environments can sometimes be produced through hybridisation (Lewontin \& Birch 1966). As Arnold \& Hodges (1995) have pointed out, the fitness of hybrids is mostly estimated relative to their parents, and hybrid genotypes usually show a wide range of fitness that is difficult to estimate accurately unless hybrid classes can be precisely defined. Hybrid zones, narrow regions where genetically distinct populations meet, mate, and produce hybrids (reviewed by Barton \& Hewitt 1985), have become useful situations for the study of hybridisation and gene flow across species.

\subsubsection{Hybridisation, Evolution, and Conservation}

Negative impacts of genetic introgression through hybridisation, especially the threat of extinction of parental species through competition with hybrids, have been well documented. For example, the Seychelles turtle dove (Stereptopelia picturata rostrata) and the Red-eyed dove ( $S$. semitorguata australis) have both been extensively hybridised with introduced species (see Rhymer \& Simberloff 1996; Huxel 1999; Wolf et al. 2001). When genetic introgression takes place from a more abundant species to a rare species, the likelihood of extinction of genotypes in the latter increases. The threat of extinction of endangered species through 
hybridisation creates negative attitudes towards hybridisation, and consequently the benefits of hybridisation are less well described.

On the positive side, Lewontin \& Birch (1966) suggested that introgression of genes through hybridisation could lead to rapid adaptive evolution of a population. Hybridisation can also be a source of genetic diversity that stimulates the diversification of populations (Anderson \& Stebbins 1954; Dowling \& Secor 1997), and / or triggers speciation (see Wiegand 1935; Orr 1995; Rieseberg et al. 1996). Hybridisation may also be a useful tool in conserving endangered populations. For example, interbreeding with the closely related Texas Puma (Puma concolor stanleyana) was encouraged to restore genetic diversity in the highly endangered Florida Panther (P. c. coryi; Hedrick 1995; Land \& Lacy 2000).

\subsubsection{Hybrid Morphologies}

Hybrids can exhibit a wide range of morphologies. Some hybrids resemble their parental species or show phenotypes intermediate between parental species, for example, in Colaptes flickers and in Cerion snails (Moore 1987; Woodruff \& Gould 1987), while others may show novel or extreme phenotypes, which are more commonly observed in plants (for examples, see Rieseberg et al. 1999; Rieseberg et al. 2003). Therefore, it is sometimes difficult to identify hybrids using phenotypic characters alone.

\subsection{Birds, Parrots, and Parakeets}

\subsubsection{Birds (Aves)}

Over 9000 avian species have been identified to date (May 1992) but the phylogenetic relationships among bird orders have not been totally resolved (Cracraft 2001; Harrison et al. 2004). While mitochondrial phylogenies generally support a bird-crocodilian relationship (Hedges 
1994), discovery of fossils of feathered dinosaurs pointed at feathered, ground-living, bipedal dinosaurs as ancestors of birds (Qiang et al. 1998). It appears that birds with pronounced plumage dichromatism, generalised feeding habits, large and fragmented geographical ranges, and good dispersal capabilities usually show higher species diversity (Owens et al. 1999).

Two contrasting hypotheses have been proposed regarding the early evolution of avian species. Molecular clock studies suggested all modern avian orders originated in the Cretaceous, diverged about 100 million years ago or earlier, and many of these lineages survived the CretaceousTertiary mass extinction event (Hedges et al. 1996; Cooper \& Penny 1997; Rambaut \& Bromham 1998). The fossil record however, suggests that most lineages of birds were exterminated at the Cretaceous-Tertiary boundary mass extinctions and that explosive evolution events followed. Thus one, or at most a few, surviving lineages may have given rise to all modern birds (Feduccia 1995, 2003).

Hybridisation and the high levels of sexual dimorphism in birds can cause biases in taxonomy, especially in earlier work that mostly relies on morphological features to identify species (Sibley 1957). One possible explanation of the observed pattern of frequent interspecific hybridisation in birds (Grant \& Grant 1992) is the slow evolution of postmating isolating factors in birds, and consequently, a small scope for reinforcement of premating isolation (Grant \& Grant 1997).

\subsubsection{Parrots (Psittaciformes)}

More than 330 species of parrots inhabit the world (Forshaw 1989). Using morphological data, Burton (1974) suggested pigeons (Columbiformes) as the closest relative to parrots. However, the phylogenetic association of 
parrots remains unclear, except that they are part of the Neoaves group (Harrison et al. 2004). Based on anatomical features, Smith (1975) proposed division of parrots into four different groups: Platycercinae; Loriinae; Arinae; and Psittacinae. It was also noted by Smith (1975) that subdividing the parrot group was difficult because parrots comprised a homogenous order of birds, substantial differences among morphological characters were hard to find, and the subdivisions had to be made using features such as branching of arteries. Using DNA hybridisation techniques, Sibley \& Ahlquist (1990) suggested that Australasian, African, and American parrots form three subgroups. The Australasian subgroup was found to be the ancestral lineage in mitochondrial DNA studies (Miyaki et al. 1998). The phylogeny of parrots is being gradually resolved with various genetic markers (Ovenden et al. 1987; Christidis et al. 1991; Birt et al. 1992; Triggs \& Daugherty 1996; Miyaki et al. 1998; Boon et al. 2000; Kearvell et al. 2003; Groombridge et al. 2004; Ribas \& Miyaki 2004; Tavares et al. 2004; de Kloet \& de Kloet 2005).

\subsubsection{Parrots of New Zealand}

Three large parrots, the Kakapo (Strigops habroptilus), Kea (Nestor notabilis), and Kaka ( $N$. meridionalis), and the smaller Cyanoramphus parakeets make up the parrot biota of New Zealand.

Based on data from the mitochondrial DNA control region, Boon (2000) almost completely revised the taxonomy of the Cyanoramphus complex. According to Boon (2000), the Cyanoramphus parakeets living in the New Zealand region comprise nine species and subspecies: The Antipodes Island Green parakeet (Cyanoramphus unicolor), Orange-fronted parakeet (C. malherbi), Yellow-crowned parakeet (C. auriceps), Forbes' parakeet (C. forbesI), Red-crowned parakeet (C. novaezelandiae novaezelandiae), Chatham Island Red-crowned parakeet (C. n. chathamensis), Kermadec 
parakeet (C. n. cyanurus), Reischek's parakeet (C. hochstetteri), and Norfolk Island parakeet (C. cooki).

The New Zealand Cyanoramphus parakeets are believed to have radiated out from New Caledonia during the last 500,000 years. Mitochondrial cytochrome $b$ sequence analysis (Boon 2000) suggested that the Eunmyphicus parakeets from New Caledonia shared the most recent common ancestor with Cyanoramphus parakeets about 2.5 million years ago.

The Cyanoramphus genus is unique in having dispersed successfully for long distances over water. Cyanoramphus parakeets have been used as subjects in a number of studies, for example, the controversial taxonomy of the Orange-fronted parakeet (Holyoak 1974; Taylor et al. 1986; Triggs \& Daugherty 1996; Taylor 1998; Boon et al. 2000; Kearvell et al. 2003), the intelligence of the Yellow-crowned parakeets (Funk 2002), hybridisation between Red-crowned parakeets (C. n. novaezelandiae) and Yellowcrowned parakeets (Veitch 1979; Butler 1986), and between Chatham Island Red-crowned parakeets (C. n. chathamensis) and Forbes' parakeets (Taylor 1975). This thesis focuses on Forbes' parakeet, and its hybridisation with Chatham Island Red-crowned parakeets.

\subsubsection{Forbes' Parakeet and Chatham Island Red-crowned Parakeet}

Forbes' parakeet is a highly threatened parrot confined to Mangere and Little Mangere Islands in the Chatham Islands group (Figure 1.1). The Chatham Island Red-crowned parakeet, on the other hand, can be found on the main Chatham Island, Pitt Island, and South-East Island. Chatham Island Red-crowned parakeets are also seen visiting Mangere and Little Mangere Islands, and some breed there too. 
Taylor (1975) suggested feeding habits and territoriality differences between Forbes' and Chatham Island Red-crowned parakeets based on field observations: Forbes' parakeets generally prefer forest habitats to open vegetation, while the Chatham Island Red-crowned parakeets were seen to be resident on scattered patches of grass, scrub and herbs. About 10 breeding Forbes' parakeet pairs were observed by Taylor (1975). The number of parakeets on Mangere Island was estimated at $821(95 \% \mathrm{Cl}=411-1231)$ in year 2003 (Terry Greene, NZ Department of Conservation, per. comm.).

Figure 1.1 Location of Mangere Island and South-East Island (Rangatira) in the Chatham Islands group.

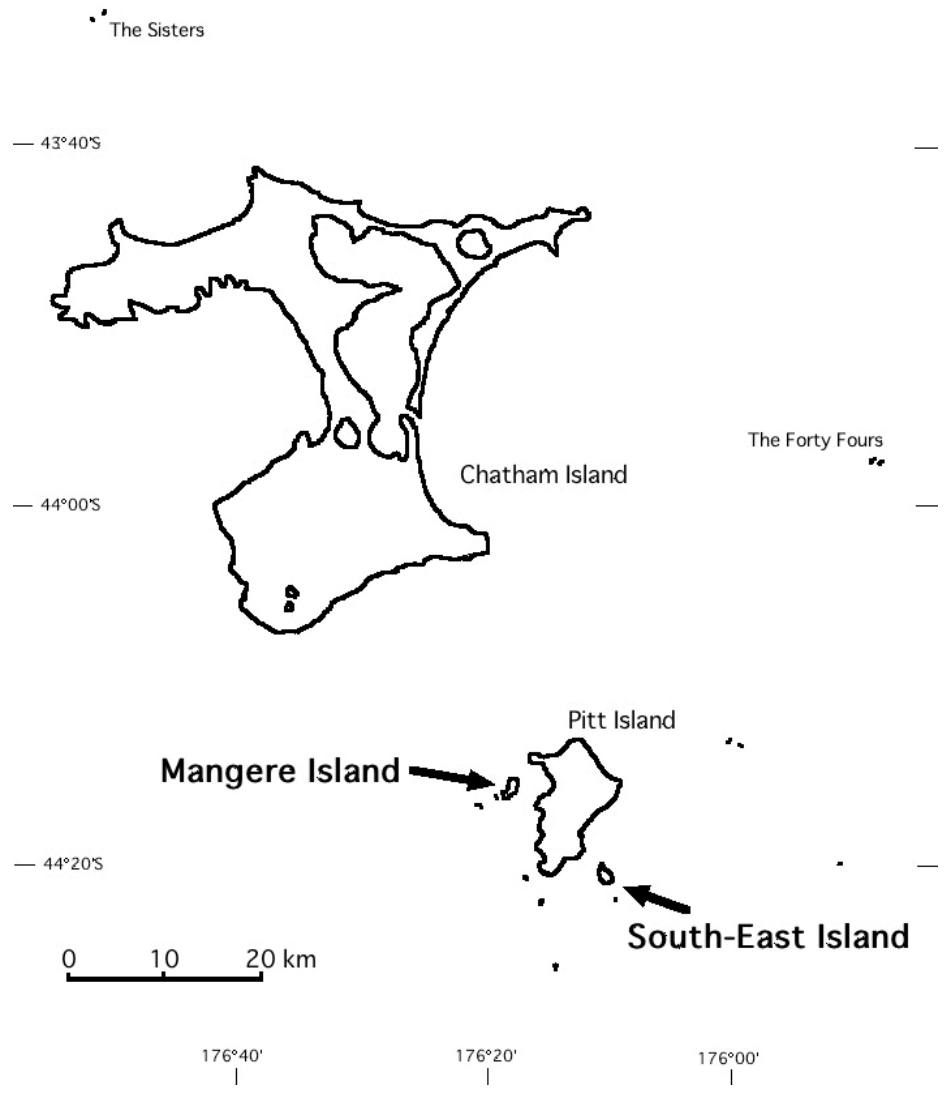


Morphologically, a Forbes' parakeet is identified by a yellow crown with red frontal band that does not extend to the eyes. Forbes' parakeets differ from Yellow-crowned parakeets by having yellowish cheeks and are generally larger in size. The Chatham Island Red-crowned parakeets have only red crown plumage and hybrids between the two species can show a range of crown colourations intermediate between the two parental species (Nixon 1982). In a 1999 census (Tertia Thurley, NZ Department of Conservation, pers. comm.) on Mangere Island, 66 parakeets were banded. Based on the morphological identification scale developed by Nixon (1982), it was estimated that $90 \%$ were Forbes' parakeets, $3 \%$ were Chatham Island Red-crowned parakeets, and 7\% were hybrids.

\subsubsection{Previous Genetic Work in Forbes' Parakeets}

Using allozyme electrophoresis, Triggs \& Daugherty (1996) suggested elevation of Forbes' parakeet from subspecific status of Yellow-crowned parakeet ( $C$. auriceps forbesi) to full species status ( $C$. forbesi). Further work with the mitochondrial control region DNA sequences (Boon 2000; Boon et al. 2001) revealed three distinct haplotypes among the Mangere Island Forbes' parakeet samples. Haplogroups 1 and 2 respectively sit within, and basal to, a Red-crowned parakeet clade. These were suggested to represent results of past hybridisations between Forbes' parakeets and Chatham Island Red-crowned parakeets (C. $n$. chathamensis) retaining Red-crowned parakeet haplotypes. Haplogroup 3 is basal to all other New Zealand parakeets, and was suggested to represent the ancestral true Forbes' parakeet lineage. Haplogroup 3 Forbes' parakeets also represent the most ancestral living Cyanoramphus parakeet lineage in New Zealand.

The elevation to species level of Forbes' parakeet (Triggs \& Daugherty 1996; Boon 2000) has led to the increase in conservation concern of this 
species. Identification of hybrids has been based purely on crown morphology, while the accuracy of morphological markers in predicting the actual genetic makeup of the birds has not been previously studied. The work presented in this thesis will explore the relationship between crown plumage colouration and the genetics of the birds via the use of molecular markers.

\subsubsection{Hybridisation in the Mangere Island Parakeet Population}

The history of hybridisation between Forbes' parakeets and Chatham Island Red-crowned parakeets has not been documented. It is generally believed that Forbes' parakeet was the more abundant speices on Mangere and Little Mangere Islands, while Chatham Island Red-crowned parakeets occupied the main Chatham Island, Pitt Island and South-East Island. However, there may be Chatham Island Red-crowned parakeets on Mangere and Little Mangere Islands as well. The Forbes' parakeet population is therefore surrounded by the more abundant Chatham Island Red-crowned parakeets. The proximity between Mangere Island and Pitt Island means parakeets can fly freely between these islands, and between Pitt and South-East Islands. Forbes' parakeets and Chatham Island Redcrowned parakeets can, in principal, freely interact because of a lack of a geographic barrier.

Despite Taylor (1975) suggesting that habitat preferences exist between the two species of parakeets on Mangere Island, there is no evidence of differences in mating behaviour between the two species. It is also believed that forest clearence by humans on Mangere Island may have driven Forbes' parakeets from forests and encouraged their breeding with Chatham Island Red-crowned parakeets on Mangere Island. 
Genetically, there appears to be very little post-zygotic isolation between these two closely related species. The abundance of hybrids observed by Taylor (1975) also suggested hybrids and backcrosses are not inferior in fitness compared to the parent species.

The lack of pre- and post-zygotic reproductive isolation between Forbes' and Chatham Island Red-crowned parakeets could probably explain the widespread hybridisation observed at present. This widespread hybridisation, if uncontrolled, is likely to continue in the future because hybrids and backcrosses have at least equal fitness compared to the parental species. The consequence is extensive mixing and slow extinction of parental genotypes in the population, constituting a major threat to the existence of the rare Forbes' parakeet.

\subsubsection{Conservation of Forbes' Parakeet}

Hybridisation challenges the definition of species under the Biological Species Concept (Mayr 1942), which define species as groups of interbreeding or potentially interbreeding natural populations reproductively isolated from other such populations. While Forbes' parakeets and Chatham Island Red-crowned parakeets are considered separate species, they interbreed to form hybrids.

Aimed at identifying 'populations possessing genetic attributes significant for the present and future generations of the species in question', the Evolutionarily Significant Unit (ESU) concept was first proposed by Ryder (1986) in order to provide a rational basis for setting priorities in conservation that reflects the underlying genetic diversity, and without entering debates surrounding species concepts. Various different criteria have been suggested to define ESUs (reviewed in Fraser and Bernatchez 2001). For example, Moritz (1994) defined ESUs as 'reciprocally 
monophyletic for mtDNA alleles and show significant divergence of allele frequencies at nuclear loci', whereas Crandall et al. (2000) recommended ecological data and genetic variation of adaptive significance be taken into account in establishing ESUs.

In this thesis, microsatellite markers are used to examine nuclear DNA divergence between Forbes' parakeets and Chatham Island Red-crowned parakeets. Along with morphological differences examined by Nixon (1982) and mitochondrial DNA divergence established by Boon (2000), whether Mangere Island parakeets form distinct ESUs will be discussed.

\subsection{Molecular Markers in Conservation Genetics Studies}

\subsubsection{Molecular Methods in Population Genetics}

Molecular methods have been regularly employed to solve population biology problems for around 40 years. The first widely used molecular tool was electrophoresis of protein markers (Harris 1966; Hubby \& Lewontin 1966; Lewontin \& Hubby 1966). With recent advances in molecular biology, such as DNA sequencing (Sanger et al. 1977) and the Polymerase Chain Reaction (PCR; Saiki et al. 1985; Mullis \& Faloona 1987), DNA-based markers have gained in popularity. A wide range of DNA-based techniques is now available for the study of ecological and evolutionary problems, such as parentage, individual and species identification, genetic bottlenecks, sex assignment, migration, and phylogenetic relationships etc. (see Amos \& Hoelzel 1992; Burke 1994; Lambert 1995; Lambert \& Millar 1995; Sunnucks 2000; Blouin 2003).

\subsubsection{Molecular Genetics in Avian Biology}

Molecular genetic techniques have made substantial contributions in studying ecology and evolution in birds, especially in the study of mating 
systems, population structure, gene flow, and phylogenetic relationships (see Avise 1996). Techniques which use PCR allow large quantities of specific DNA product to be amplified from a small amount of DNA template (see Arnheim et al. 1990). These techniques are particularly useful in studies of species such as birds, which can be difficult to capture and handle, because non-destructive and even non-invasive samples can be taken from materials such as feathers and faeces. Non-invasive sampling has its limitations in terms of the quality and quantity of recoverable DNA, but it does cause minimal damage to the organism (Taberlet et al. 1999). A leading example of such PCR-based molecular tools is the use of microsatellite DNA markers. These have been proven to be useful in studying various aspects of genetic relationships in birds, such as the monitoring of genetic variability, and detection of extra-pair fertilisation (Ellegren 1992).

Another popular marker is mitochondrial DNA. Due to the rapid evolution of mitochondrial DNA (Brown et al. 1979), mitochondrial DNA sequencing provides a very useful tool for studying phylogenetic relationships (Barton \& Jones 1983). Studies of mitochondrial DNA sequence variations can also provide useful information about the population structure, for example, the identification of four haplogroups within the Mangere Island Cyanoramphus parakeet population (Boon et al. 2000).

\subsection{The Biology of Microsatellites}

\subsubsection{What are Microsatellites?}

Repeat sequences in DNA were first discovered in mouse, and later found in a wide range of organisms (Waring \& Britten 1966; Britten \& Kohne 1968). Following recommendations by Chambers \& MacAvoy (2000), repeat sequences in DNA can be classified into four classes: mononucleotide tracts, microsatellites, minisatellites, and the larger 
satellites. Microsatellites are defined as short segments of $2-6$ nucleotides repeated in more or less uniform tracts with a minimum length of 8 nucleotides.

Repeat number mutations in microsatellite loci are considered as selectively neutral (Tachida \& lizuka 1992; Michalakis \& Veuille 1996; Schlötterer 2000), fitting neutral theory prediction (Kimura 1968, 1986). Microsatellites are non-randomly distributed in genomes (see $\mathrm{Li}$ et al. 2002, 2004), their polymorphisms can be affected by their location, and presence of other linked genes (Slatkin 1995; Thuillet et al. 2004).

\subsubsection{Patterns of Microsatellite Evolution}

Microsatellites evolve mostly through changes in number of repeat units. Slipped-strand mispairing, or slippage synthesis, is believed to be the major mechanism that generates the observed patterns of microsatellite evolution (Levinson \& Gutman 1987; Schlötterer \& Tautz 1992). Allele frequency distribution spectra of microsatellites tend to differ between loci, and there is no consensus to the best description of the distributions (Jarne \& Lagoda 1996; Chambers \& MacAvoy 2000). One of the most frequently used predictions of their distributions is the Stepwise Mutation Model (SMM; Ohta \& Kimura 1973) which assumes that the repeat number changes through increase or decrease of one repeat unit at a time (with equal probability), and that alleles may mutate towards other allelic states already present. Some loci, however, are better described by the Infinite Allele Model (IAM; Kimura \& Crow 1964), which predicts that mutations can involve any number of repeat units. Which of these models provides the best description of microsatellite allele distributions? Computer simulations by Shriver et al. (1993) showed that microsatellites generally evolve via SMM, while showing some deviations towards IAM, suggesting neither of these models accurately describes the patterns in all 
microsatellite loci. Di Rienzo et al. (1994) proposed the Two-phase mutation Model (TPM) based on their survey of microsatellite allele frequencies in the human population of Sardinia. The TPM predicts that the majority of mutations are one repeat unit mutations (similar to SMM), but larger jumps of more than one repeat occur occasionally.

\subsubsection{The Rise and Fall of a Microsatellite}

Microsatellite repeats are believed to arise from genomic regions where simple repetitive sequences are already abundant (Tautz et al. 1986). Through phylogenetic studies, Messier et al. (1996) proposed that a microsatellite locus can be created through a single substitution event in a region of cryptic simplicity. Further studies using data in the Human Gene Mutation Database suggested that both substitution and insertion events are likely to contribute to the origin of short tandem repeats (Zhu et al. 2000b). However, the types of repeat that arise seem to be determined by the pattern of subsequent slippage events (Gordon 1997).

There is also debate regarding whether a minimum number of repeat units or nucleotides has to be reached before changes in number of repeat units can take place by slippage. Through DNA sequencing studies in the $\square-$ globin pseudogene of primates, Messier et al. (1996) suggested that the minimum number of repeat units required for slippage to occur is $4-5$ repeats for dinucleotides, and 2 repeats for tetranucleotide units. An alternative suggestion, from studies in yeast (Saccharomyces cerevisiae), is that a minimum of 8 nucleotides, regardless of the type of repeat, is required (Rose \& Falush 1998). Using a maximum likelihood method, Sibly et al. (2001) also showed that no slippage can occur in dinucleotide microsatellites under 5 repeats. However, another study in yeast $(S$. cerevisiae) suggested that there is no critical minimum of repeats required for microsatellite expansion (Pupko \& Graur 1999). 
Studies in yeast have shown that stability of microsatellite tracts is dependent on the DNA mismatch repair system (Strand et al. 1993, 1995; Sia et al. 1997). The pattern of microsatellite evolution, however, remains controversial. While some studies have suggested that longer repeat units, such as tetranucloetide repeats, have higher mutation rates compared with shorter dinucleotide units (Weber \& Wong 1993; Primmer \& Ellegren 1998), other studies have suggested the reverse (Chakraborty et al. 1997). It appears that, regardless of length of repeat units, mutation rate differs between loci, alleles, and species (Brinkmann et al. 1998; Kruglyak et al. 1998; Ellegren 2000a), and that these variations may be directly attributed to differences between slippage rates (Kruglyak et al. 1998). There also seems to be a general pattern that loci with larger numbers of repeat units tend to have a higher mutation rate (Wierdl et al. 1997; Primmer et al. 1998; Falush \& Iwasa 1999; Ellegren 2000b; Beck et al. 2003).

Ideas concerning the pattern of microsatellite mutation also vary. The majority of observations support the hypothesis that increases in number of repeats occur more frequently than decreases (Primmer et al. 1996, 1998; Primmer \& Ellegren 1998; Falush \& Iwasa 1999; Twerdi et al. 1999; but see Beck et al. 2003). Microsatellites do not expand indefinitely, and there also appears to be an upper limit constraint on allele size (Garza et al. 1995; Lehmann et al. 1996; Zhivotovsky et al. 1997). The majority of studies favour the idea that loci with large numbers of repeat units tend to undergo deletions while loci with fewer repeat units tend to increase in size (Wierdl et al. 1997; Ellegren 2000b; Harr \& Schlötterer 2000; Xu et al. 2000; but see Falush \& Iwasa 1999; Harr et al. 2002). Long repeats were also shown to have a relatively short existence time in Drosophila melanogaster (Harr \& Schlötterer 2000). An excellent analogy to the present consensus pattern is a model based on the "Snakes and Ladders" 
board game (Chambers \& MacAvoy 2000), in which ladders (increase in repeat units) are more frequently encountered at lower numbered squares (loci with few repeats), and snakes (dramatic decrease in repeat units) are more abundant at the larger numbered squares (loci with large number of repeats).

Interruptions within the repetitive tract appear to stabilise a microsatellite (Jin et al. 1996; Petes et al. 1997; Taylor et al. 1999; but see Bichara et al. 1995). These interruptions may be removed during slippage of adjacent bases and the stabilised microsatellite may only be a transition state (Harr et al. 2000). However, the "death" of a microsatellite can occur if a deletion of the repeat units follows the introduction of the interruption (Taylor et al. 1999).

\subsubsection{The Use of Microsatellites in Population Genetics}

Microsatellite markers are widely used in population genetics, especially in studies of population structure, breeding behaviour, and kinship analysis (see Ellegren 1992; Chambers \& MacAvoy 2000; Blouin 2003). Recent studies have also used microsatellites to study phylogenetic relationships (see Zhu et al. 2000a).

Microsatellites appear to be very convenient tools for assessing the genetic differences between Forbes' parakeets, Chatham Island Redcrowned parakeets, and their hybrids without invasive sampling of the population. The reproducibility of microsatellite data also makes this method robust, and allows inclusion of data collected subsequent to this study. 


\subsection{The Aims of this Study}

Through the development and use of microsatellite genetic markers in parakeets, the following questions will be addressed:

1) What is the extent of hybridisation in Forbes' parakeet as judged by nuclear genetic markers?

2) Is Forbes' parakeet in danger of losing its genetic integrity?

3) Are other genetic markers (mitochondrial DNA control region haplotypes) and morphological markers (such as crown plumage morphology) directly correlated to hybridisation in birds?

4) What is the pattern of microsatellite evolution between parrots?

5) What are the implications to future directions in conserving Forbes' parakeet?

\subsection{Structure of this Thesis}

\subsubsection{Introduction}

This chapter introduces the background information this thesis is based on, including the role of hybridisation in the evolution of a population, the biology of parrots and parakeets, and the evolution and application of microsatellite molecular markers. 
1.7.2 Chapter 2: Development of Microsatellite Loci for Forbes' Parakeet (Cyanoramphus forbesi) by Hybridisation Selection using Enriched Membranes

This chapter describes the process of isolating Forbes' parakeet microsatellite loci. The microsatellite isolation work was carried out at Institute of Molecular BioSciences, Massey University, Palmerston North. The characterization of the loci was performed at the Institute of Molecular Systematics, School of Biological Sciences, Victoria University of Wellington, Wellington.

\subsubsection{Chapter 3: Microsatellite DNA Studies Reveal Extensive} Hybridisation between Parakeets on Mangere Island In this chapter, microsatellite loci isolated from Forbes' parakeets are used to assess the hybridisation status between Forbes' parakeets and Chatham Island Red-crowned parakeets. A system is developed to identify true Forbes' parakeets based on morphological, nuclear and mitochondrial DNA data.

\subsubsection{Chapter 4: Microsatellite Evolution in Parrots}

The possible use of microsatellite flanking sequences to build phylogenies, and the evolution of microsatellites in parrots are investigated in this chapter. Implications are drawn on the evolution of microsatellite repeat motifs and the origin of microsatellites. 
1.7.5 Chapter 5: Does Crown Plumage Directly Reflect the Hybridisation Status of Parakeets? A Preliminary Study in Red-crowned Parakeets (Cyanoramphus novaezelandiae novaezelandiae) and Yellow-crowned Parakeets (C. auriceps) on the New Zealand Mainland

The use of the isolated Forbes' parakeet microsatellite markers in other species of New Zealand parakeets is investigated in this chapter. Microsatellite and mitochondrial DNA data are used to address whether yellow feathers on the crown of a Red-crowned parakeet indicate a hybridisation history.

1.7.6 Chapter 6: Conservation of Forbes' Parakeet - Present and Outlook

Based on the data obtained in the previous chapters, implications to the conservation of Forbes' parakeets are discussed in this chapter.

\subsection{References}

Amos B, Hoelzel AR (1992) Applications of molecular genetic techniques to the conservation of small populations. Biological Conservation, 61, 133 $-144$

Anderson E, Stebbins GL Jr (1954) Hybridization as an evolutionary stimulus. Evolution, 8, $377-388$.

Arnheim N, White T, Rainey WE (1990) Application of PCR: Organismal and population biology. BioScience, 40, 174-182.

Arnold ML, Hodges SA (1995) Are natural hybrids fit or unfit relative to their parents? TREE, 10, $67-71$. 
Avise JC (1996) Three fundamental contributions of molecular genetics to avian ecology and evolution. Ibis, 138, 16-25.

Avise JC, Walker D (2000) Abandon all species concepts? A respond. Conservation Genetics, 1, 77 - 80.

Barton NH (2001) The role of hybridization in evolution. Molecular Ecology, 10, $551-568$.

Barton NH, Hewitt GM (1985) Analysis of hybrid zones. Annu. Rev. Ecol. Syst., 16, $113-148$.

Barton N, Jones JS (1983) Mitochondrial DNA: New clues about evolution. Nature, 306, 317 - 318.

Beck NR, Double MC, Cockburn A (2003) Microsatellite evolution at two hypervariable loci revealed by extensive avian pedigrees. Mol. Biol. Evol., 20, $54-61$.

Bichara M, Schumacher S, Fuchs RPP (1995) Genetic instability within monotonous runs of $\mathrm{CpG}$ sequences in Escherichia coli. Genetics, 140, $897-907$.

Birt TP; Friesen VL; Green JM; Montevecchi WA, Davidson WS (1992) Cytochrome- $b$ sequence variation among parrots. Hereditas, 117, 67 72.

Blouin MS (2003) DNA-based methods for pedigree reconstruction and kinship analysis in natural populations. TREE, 18, 503-511. 
Boon WM (2000) Molecular systematics and conservation of the Cyanoramphus parakeet complex and the evolution of parrots. PhD Thesis, Victoria University of Wellington, Wellington, New Zealand.

Boon WM, Kearvell JC, Daugherty CH, Chambers GK (2000) Molecular systematics of New Zealand Cyanoramphus parakeets: Conservation of Orange-fronted and Forbes' Parakeets. Bird Conservation International, 10, $211-239$.

Boon WM, Kearvell JC, Daugherty CH, Chambers GK (2001) Molecular systematics and conservation of kakariki (Cyanoramphus spp.): Science for Conservation 176. Department of Conservation, Wellington.

Breeuwer JAJ, Werren JH (1995) Hybrid breakdown between two haplodiploid species: The role of nuclear and cytoplasmic genes. Evolution, 49, 705 - 717.

Brinkmann B, Klintschar M, Neuhuber F, Hühne J, Rolf B (1998) Mutation rate in human microsatellites: Influence of the structure and length of the tandem repeat. Am. J. Hum. Genet., 62, $1408-1415$.

Britten RJ, Kohne DE (1968) Repeated sequences in DNA. Science, 161, $529-540$.

Brown WM, George M Jr, Wilson AC (1979) Rapid evolution of animal mitochondrial DNA. Proc. Natl. Acad. Sci., 76, 1967 - 1971.

Burke JM, Arnold ML (2001) Genetics and the fitness of hybrids. Ann. Rev. Genet., 35, $31-52$. 
Burke JM, Voss TJ, Arnold ML (1998) Genetic interactions and natural selection in Louisiana Iris hybrids. Evolution, 52, $1304-1310$.

Burke T (1994) Spots before the eyes: Molecular ecology. TREE, 9, 355 357.

Burton PJK (1974) Jaw and tongue features in Psittaciformes and other orders with special reference to the anatomy of the Tooth-billed pigeon (Didunculus strigirostris). J. Zool. Lond., 174, 255 - 276.

Burton RS (1990) Hybrid breakdown in developmental time in the copepod Tigriopus californicus. Evolution, 44, 1814-1822.

Butler DJ (1986) Hybrid parakeet on mainland. Notornis, 33, 58 - 62.

Cabot EL, Davis AW, Johnson NA, Wu Cl (1994) Genetics of reproductive isolation in the Drosophila simulans clade: Complex epistasis underlying hybrid male sterility. Genetics, 137, $175-189$.

Chakraborty R, Kimmel M, Stivers DN, Davison LJ, Deka R (1997) Relative mutation rates at di-, tri-, and tetranucleotide microsatellite loci. Proc. Natl. Acad. Sci. USA, 94, 1041 - 1046.

Chambers GK, MacAvoy ES (2000) Microsatellites: Consensus and controversy. Comparative Biochemistry and Physiology B, 126, 455 476.

Christids L, Schodde R, Shaw DD, Maynes SF (1991) Relationships among the Australo-Papuan parrots, lorikeets, and cockatoos (Aves: Psittaciformes): Protein evidence. Condor, 93, $302-317$. 
Cooper A, Penny D (1997) Mass survival of birds across CretaceousTertiary boundary: Molecular evidence. Science, 275, 1109-1113.

Coyne JA (1985) The genetic basis of Haldane's rule. Nature, 314, 736 738.

Coyne JA (1992) Genetics and speciation. Nature, 355, 511 - 515.

Coyne JA, Orr HA (1989) Patterns of speciation in Drosophila. Evolution, 43, $362-381$.

Cracraft J (2001) Avian evolution, Gondwana biogeography and the Cretaceous-Tertiary mass extinction event. Proc. R. Soc. Lond. B, 268, $459-469$.

Crandall KA, Bininda-Emonds ORP, Mace GM, Wayne RK (2000) Considering evolutionary processes in conservation biology. TREE, 15, $290-295$.

de Kloet RS, de Kloet SR (2005) The evolution of the spindlin gene in birds: Sequence analysis of an intron of the spindlin $\mathrm{W}$ and $\mathrm{Z}$ gene reveals four major division of the Psittaciformes. Molecular Phylogenetics and Evolution, 36, $706-721$.

Di Rienzo A, Peterson AC, Garza JC, Valdes AM, Slatkin M, Freimer NB (1994) Mutational processes of simple-sequence repeat loci in human populations. Proc. Natl. Acad. Sci. USA, 91, 3166-3170.

Dowling TE, Secor CL (1997) The role of hybridization and introgression in the diversification of animals. Annu. Rev. Ecol. Syst., 28, 593-619. 
Ellegren H (1992) Polymerase-Chain-Reaction (PCR) analysis of microsatellites - a new approach to studies of genetic relationships in birds. Auk, 109, $886-895$.

Ellegren H (2000a) Microsatellite mutations in the germline: Implications for evolutionary inference. TIG, 16, 551-558.

Ellegren $H$ (2000b) Heterogeneous mutation processes in human microsatellite DNA sequences. Nature Genetics, 24, 400 - 402.

Falush D, Iwasa $Y$ (1999) Size-dependent mutability and microsatellite constraints. Mol. Biol. Evol., 16, $960-966$.

Feduccia A (1995) Explosive evolution in Tertiary birds and mammals. Science, 267, $637-638$.

Feduccia A (2003) 'Big bang' for tertiary birds? TREE, 18, 172 - 176.

Forshaw JM (1989) Parrots of the world, 3rd edn. Lansdowne Editions, Melbourne.

Fraser DJ, Bernatchez L (2001) Adaptive evolutionary conservation: Towards a unified concept for defining conservation units. Molecular Ecology, 10, $2741-2752$.

Funk MS (2002) Problem solving skills in young Yellow-crowned parakeets (Cyanoramphus auriceps). Anim Cogn, 5, 167-176.

Garza JC, Slatkin M, Freimer NB (1995) Microsatellite allele frequencies in humans and chimpanzees, with implications for constraints on allele size. Mol. Biol. Evol., 12, $594-603$. 
Gordon AJE (1997) Microsatellite birth register. J. Mol. Evol., 45, 337 338.

Grant PR, Grant BR (1992) Hybridization of bird species. Science, 256, $193-197$.

Grant PR, Grant BR (1997) Genetics and the origin of bird species. Proc. Natl. Acad. Sci. USA, 94, $7768-7775$.

Groombridge JJ, Jones CG, Nichols RA, Carlton M, Bruford MW (2004) Molecular phylogeny and morphological change in the Psittacula parakeets. Molecular Phylogenetics and Evolution, 31, 96- 108.

Harr B, Schlötterer C (2000) Long microsatellite alleles in Drosophila melanogaster have a downward mutation bias and short persistence times, which causes their genome-wide underrepresentation. Genetics, $155,1213-1220$.

Harr B, Zangerl B, Schlötterer C (2000) Removal of microsatellite interruptions by DNA replication slippage: Phylogenetic evidence from Drosophila. Mol. Biol. Evol., 17, 1001 - 1009.

Harr B, Todorova J, Schlötterer C (2002) Mismatch repair-driven mutational bias in D. melanogaster. Molecular Cell, 10, 199-205.

Harris H (1966) Enzyme polymorphisms in man. Proc. R. Soc. Lond. B, $164,298-310$. 
Harrison GL, McLenachan PA, Phillips MJ, Slack KE, Cooper A, Penny D (2004) Four new avian mitochondrial genomes help get to basic evolutionary questions in the late Cretaceous. Mol. Biol. Evol., 21, 974 983.

Hedges SB (1994) Molecular evidence for the origin of birds. Proc. Natl. Acad. Sci. USA, 91, $2621-2624$.

Hedges SB, Parker PH, Sibley CG, Kumar S (1996) Continental breakup and the ordinal diversification of birds and mammals. Nature, 381, 226 229.

Haldane JBS (1922) Sex ratio and unisexual sterility in hybrid animals. J. Genet., 12, 101 - 109.

Hedrick PW (1995) Gene flow and genetic restoration: The Florida Panther as a case study. Conservation Biology, 9, 996 - 1007.

Hendry AP, Vamosi SM, Latham SJ, Heilbuth JC, Day T (2000) Questioning species realities. Conservation Genetics, 1, 67 - 76.

Hollocher $\mathrm{H}, \mathrm{Wu} \mathrm{Cl}$ (1996) The genetics of reproductive isolation in the Drosophila simulans clade: $X$ vs. autosomal effects and male vs. female effects. Genetics, 143, $1243-1255$.

Holyoak DT (1974) Cyanoramphus malherbi, is it a colour morph of $C$. auriceps? Bulletin British Ornithologists' Club, 94, 4-9.

Hubby JL, Lewontin RC (1966) A molecular approach to the study of genic heterozygosity in natural populations. I. The number of alleles at different loci in Drosophila pseudoobscura. Genetics, 54, 577 - 594. 
Huxel GR (1999) Rapid displacement of native species by invasive species: Effects of hybridization. Biological Conservation, 89, 143-152.

Jarne P, Lagoda JL (1996) Microsatellites, from molecules to populations and back. TREE, 11, $424-429$.

Jin L, Macaubas C, Hallmayer J, Kimura A, Mignot E (1996) Mutation rate varies among alleles at a microsatellite locus: Phylogenetic evidence. Proc. Natl. Acad. Sci. USA, 93, $15285-15288$.

Kearvell JC, Grant AD, Boon WM (2003) The Orange-fronted Parakeet (Cyanoramphus malherbi) is a distinct species: A review of recent research into its taxonomy and systematic relationship within the genus Cyanoramphus. Notornis, 50, $27-35$.

Kimura M (1968) Evolutionary rate at the molecular level. Nature, 217, $624-626$.

Kimura M (1986) DNA and the neutral theory. Phil. Trans. R. Soc. Lond. $B, 312,343-354$.

Kimura M, Crow JF (1964) The number of alleles that can be maintained in a finite population. Genetics, 49, $725-738$.

Kruglyak S, Durrett RT, Schug MD, Aquadro CF (1998) Equilibrium distributions of microsatellite repeat length resulting from a balance between slippage events and point mutations. Proc. Natl. Acad. Sci. USA, 95, $10774-10778$.

Lambert DM (1995) The new science of molecular ecology. New Zealand Journal of Ecology, 19, 93 - 96. 
Lambert DM, Millar CD (1995) DNA science and conservation. Pacific Conservation Biology, 2, 21 - 38.

Land ED, Lacy RC (2000) Introgression level achieved through Florida Panther genetic restoration. Endangered Species Update, 17, 100-105.

Lehmann T, Hawley WA, Collins FH (1996) An evaluation of evolutionary constraints on microsatellite loci using null alleles. Genetics, 144, 1155 1163.

Levinson G, Gutman GA (1987) Slipped-strand mispairing: A major mechanism for DNA sequence evolution. Mol. Bio. Evol., 4, $203-221$.

Lewontin RC, Birch LC (1966) Hybridization as a source of variation for adaptation to new environments. Evolution, 20, $315-336$.

Lewontin RC, Hubby JL (1966) A molecular approach to the study of genic heterozygosity in natural populations. II. Amount of variation and degree of heterozygosity in natural populations of Drosophila pseudoobscura. Genetics, 54, $595-609$.

Li YC, Korol AB, Fahima T, Beiles A, Nevo E (2002) Microsatellites: Genomic distribution, putative functions and mutational mechanisms: A review. Molecular Ecology, 11, 2453 - 2465.

Li YC, Korol AB, Fahima T, Nevo E (2004) Microsatellites within genes: Structure, function, and evolution. Mol. Biol. Evol., 21, 991 - 1007.

May RM (1992) How many species inhibit the earth? Scientific American, Oct, $18-24$. 
Mayr E (1942) Systematics and the origin of species. Columbia University Press, New York.

Messier W, Li SH, Stewart CB (1996) The birth of microsatellites. Nature, $381,483$.

Michalakis Y, Veuille M (1996) Length variation of CAG/CAA trinucleotide repeats in natural populations of Drosophila melanogaster and its relation to the recombination rate. Genetics, 143, 1713-1725.

Miyaki CY, Matioli SR, Burke T, Wajntal A (1998) Parrot evolution and paleogeographical events: Mitochondrial DNA evidence. Mol. Biol.Evol., $15,544-551$.

Moore WS (1987) Random mating in the northern Flicker hybrid zone: Implications for the evolution of bright and contrasting plumage patterns in birds. Evolution, 41, $539-546$.

Moritz C (1994) Defining 'Evolutionarily Significant Units' for conservation. TREE, 9, $373-375$.

Mullis KB, Faloona FA (1987) Specific synthesis of DNA in vitro via a polymerase-catalyzed chain reaction. Methods in Enzymology, 155, 335 350.

Nixon AJ (1982) Aspects of the ecology and morphology of Cyanoramphus parakeets and hybrids from Mangere Island, Chatham Islands. MSc thesis, Victoria University of Wellington, Wellington, New Zealand. 
Ohta T, Kimura M (1973) A model of mutation appropriate to estimate the number of electrophoretically detectable alleles in a finite population. Genet. Res., 22, $201-204$.

Orr HA (1993) Haldane's rule has multiple genetic causes. Nature, 361, $532-533$.

Orr HA (1995) The population genetics of speciation: The evolution of hybrid incompatibilities. Genetics, 139, $1805-1813$.

Ovenden JR, Mackinlay AG, Crozier RH (1987) Systematics and mitochondrial genome evolution of Australian Rosellas (Aves: Platycercidae). Mol. Biol. Evol., 4, 526 - 543.

Owens IPF, Bennett PM, Harvey PH (1999) Species richness among birds: Body size, life history, sexual selection or ecology? Proc. R. Soc. Lond. B, 266, $933-939$.

Palopoli MF, Wu Cl (1994) Genetics of hybrid male sterility between Drosophila sibling species: a complex web of epistasis is revealed in interspecific studies. Genetics, 138, $329-341$.

Perez DE, Wu Cl (1995) Further characterization of the Odysseus locus of hybrid sterility in Drosophila: One gene is not enough. Genetics, 140, 201 $-206$.

Petes TD, Greenwell PW, Dominska M (1997) Stabilization of microsatellite sequences by variant repeats in the yeast Saccharomyces cerevisiae. Genetics, 146, $491-498$. 
Prager EM, Wilson AC (1975) Slow evolutionary loss of potential for interspecific hybridization in birds: A manifestation of slow regulatory evolution. Proc. Nat. Acad. Sci. USA, 72, $200-204$.

Primmer CR, Ellegren H (1998) Patterns of molecular evolution in avian microsatellites. Mol. Biol. Evol., 15, $997-1008$.

Primmer CR, Ellegren H, Saino N, Møller AP (1996) Directional evolution in germline microsatellite mutations. Nature Genetics, 13, $391-393$.

Primmer CR, Saino N, Møller AP, Ellegren H (1998) Unraveling the processes of microsatellite evolution through analysis of germ line mutations in Barn Swallows Hirundo rustica. Mol. Biol. Evol., 15, 1047 1054.

Pupko T, Graur D (1999) Evolution of microsatellites in the yeast Saccharomyces cerevisiae: Role of the length and number of repeated units. J. Mol. Evol., 48, 313-316.

Qiang J, Currie PJ, Norell MA, Shu-An J (1998) Two feathered dinosaurs from northeastern China. Nature, 393, $753-761$.

Rahman MA, Uehara T, Pearse JS (2001) Hybrids of two closely related tropical sea urchins (Genus Echinometra): Evidence against postzygotic isolating mechanisms. Biol. Bull., 200, 97 - 106.

Rambaut A, Bromham L (1998) Estimating divergence dates from molecular sequences. Mol. Biol. Evol., 15, 442 - 448.

Rhymer JM, Simberloff D (1996) Extinction by hybridization and introgression. Annu. Rev. Ecol. Syst., 27, 83-109. 
Ribas CC, Miyaki CY (2004) Molecular systematics in Aratinga parakeets: Species limits and historical biogeography in the 'solstitialis' group, and the systematic position of Nandayus nenday. Molecular Phylogenetics and Evolution, 30, $663-675$.

Rieseberg LH, Archer MA, Wayne RK (1999) Transgressive segregation, adaptation and speciation. Heredity, 83, 363-372.

Rieseberg LH, Sinervo B, Linder R, Ungerer MC, Arias DM (1996) Role of gene interactions in hybrid speciation: Evidence from ancient and experimental hybrids. Science, 272, $741-745$.

Rieseberg LH, Widmer A, Arntz AM, Burke JM (2003) The genetic architecture necessary for transgressive segregation is common in both natural and domesticated populations. Phil. Trans. R. Soc. Lond. B, 358, $1141-1147$.

Rose O, Falush D (1998) A threshold size for microsatellite expansion. Mol. Biol. Evol., 15, $613-615$.

Ryder OA (1986) Species conservation and systematics: The dilemma of subspecies. TREE, 1, 9-10.

Saiki RK, Scharf S, Faloona F, Mullis KB, Horn GT, Erlich HA, Arnheim N (1985) Enzymatic amplification of $\square$-globin genomic sequences and restriction site analysis for diagnosis of sickle cell anemia. Science, 230, $1350-1354$.

Sanger F, Nicklen S, Coulson AR (1977) DNA sequencing with chainterminating inhibitors. Proc. Natl. Acad. Sci. USA, 74, $5463-5467$. 
Schlötterer C (2000) Evolutionary dynamics of microsatellite DNA. Chromosoma, 109, $365-371$.

Schlötterer C, Tautz D (1992) Slippage synthesis of simple sequence DNA. Nucleic Acids Research, 20, 211-215.

Scribner KT (1993) Hybrid zone dynamics are influenced by genotypespecific variation in life-history traits: Experimental evidence from hybridizing Gambusia species. Evolution, 47, $632-646$.

Shriver MD, Jin L, Chakraborty R, Boerwinkle E (1993) VNTR allele frequency distributions under the stepwise mutation model: A computer simulation approach. Genetics, 134, 983-993.

Sia EA, Kokoska RJ, Dominska M, Greenwell P, Petes TD (1997) Microsatellite instability in yeast: Dependence on repeat unit size and DNA mismatch repair genes.

Sibley CG (1957) The evolutionary and taxonomic significance of sexual dimorphism and hybridization in birds. Condor, 59, 166- 191.

Sibley CG, Ahlquist JE (1990) Phylogeny and Classification of Birds: A study in molecular evolution, Yale University Press, New Haven.

Sibly RM, Whittaker JC, Talbot M (2001) A maximum-likelihood approach to fitting equilibrium models of microsatellite evolution. Mol. Biol. Evol., 18, $413-417$.

Sites JW Jr, Crandall KA (1997) Testing species boundaries in biodiversity studies. Conservation Biology, 11, 1289 - 1297. 
Slatkin M (1995) Hitchhiking and associative overdominance at a microsatellite locus. Mol. Biol. Evol., 12, 473 - 480.

Smith GA (1975) Systematics of parrots. Ibis, 117, $18-68$.

Strand M, Prolla TA, Liskay RM, Petes TD (1993) Destabilization of tracts of simple repetitive DNA in yeast by mutations affecting DNA mismatch repair. Nature, 365, 274-276.

Strand M, Earley MC, Crouse GF, Petes TD (1995) Mutations in the MSH3 gene preferentially lead to deletions within tracts of simple repetitive DNA in Saccharomyces cerevisiae. Proc. Natl. Acad. Sci. USA, 92, $10418-$ 10421.

Sunnucks P (2000) Efficient genetic markers for population biology. TREE, 15, $199-203$.

Taberlet P, Waits LP, Luikart G (1999) Noninvasive genetic sampling: Look before you leap. TREE, 14, 323-327.

Tachida H, lizuka M (1992) Persistence of repeated sequence that evolve by replication slippage. Genetics, 131, $471-478$.

Tautz D, Trick M, Dover GA (1986) Cryptic simplicity in DNA is a major source of genetic variation. Nature, 322, $652-656$.

Tavares ES, Yamashita C, Miyaki CY (2004) Phylognetic relationships among some Neotropical parrot genera (Psittacidae) based on mitochondrial sequences. Auk, 121, $230-242$. 
Taylor JS, Durkin JMH, Breden F (1999) The death of a microsatellite: A phylogenetic perspective on microsatellite interruptions. Mol. Biol. Evol., $16,567-572$.

Taylor RH (1975) Some ideas on speciation in New Zealand parakeets. Notornis, 22, $110-121$.

Taylor $\mathrm{RH}$ (1998) A reappraisal of the Orange-fronted Parakeet (Cyanoramphus sp.) - species or colour morph? Notornis, 45, 49 - 63.

Taylor RH, Heatherbell EG, Heatherbell EM (1986) The Orange-fronted Parakeet (Cyanoramphus malherbi) is a colour morph of the Yellowcrowned Parakeet (C. auriceps). Notornis, 33, 17- 22.

Thuillet AC, Bataillon T, Sourdille P, David JL (2004) Factors affecting polymorphism at microsatellite loci in bread wheat [Triticum aestivum (L.) Thell]: Effects of mutation processes and physical distance from the centromere. Theor. Appl. Genet., 108, 368 - 377.

Triggs SJ, Daugherty CH (1996) Conservation and genetics of New Zealand parakeets. Bird Conservation International, 6, 89 - 101.

True JR, Weir BS, Laurie CC (1996) A genome-wide survey of hybrid incompatibility factors by the introgression of marked segments of Drosophila mauritiana chromosomes into Drosophila simulans. Genetics, $142,819-837$.

Twerdi CD, Boyer JC, Farber RA (1999) Relative rates of insertion and deletion mutations in a microsatellite sequence in cultured cells. Proc. Natl. Acad. Sci. USA, 96, $2875-2879$. 
Veitch CR (1979) Parakeet hybridisation. Notornis, 26, 395.

Waring M, Britten RJ (1966) Nucleotide sequence repetition: A rapidly reassociating fraction of mouse DNA. Science, 154, $791-794$.

Weber JL, Wong C (1993) Mutation of human short tandem repeats. Human Molecular Genetics, 2, 1123 - 1128.

Wiegand KM (1935) A taxonomist's experience with hybrids in the wild. Science, 81, 161 - 166.

Wierdl M, Dominska M, Petes TD (1997) Microsatellite instability in yeast: Dependence on the length of the microsatellite. Genetics, 146, 769- 779.

Wilson AC, Maxson LR, Sarich VM (1974) Two types of molecular evolution. Evidence from studies of interspecific hybridization. Proc. Nat. Acad. Sci. USA, 71, $2843-2847$.

Wolf DE, Takebayashi N, Rieseberg LH (2001) Predicting the risk of extinction through hybridization. Conservation Biology, 15, 1039 - 1053.

Woodruff DS, Gould SJ (1987) Fifty years of interspecific hybridization: Genetics and morphometrics of a controlled experiment on the land snail Cerion in the Florida Keys. Evolution, 41, 1022 - 1045.

Wu Cl, Davis AW (1993) Evolution of postmating reproductive isolation: The composite nature of Haldane's rule and its genetic bases. Am. Nat., $142,187-212$. 
Xu X, Peng M, Fang Z, Xu X (2000) The direction of microsatellite mutations is dependent upon allele length. Nature Genetics, 24, $396-$ 399.

Zhivotovsky LA, Feldman MW, Grishechkin SA (1997) Biased mutations and microsatellite variation. Mol. Biol. Evol., 14, 926 - 933.

Zhu Y, Queller DC, Strassmann JE (2000a) A phylogenetic perspective on sequence evolution in microsatellite loci. J. Mol. Evol., 50, 324 - 338.

Zhu Y, Strassmann JE, Queller DC (2000b) Insertions, substitutions, and the origin of microsatellites. Genet. Res., 76, $227-236$. 


\section{Chapter 2: Development of Microsatellite Loci for Forbes' Parakeet (Cyanoramphus forbesi) by Hybridisation Selection using Enriched Membranes}

\section{$2.1 \quad$ Introduction}

Microsatellites have been reported to occur at relatively low frequency in birds (Primmer et al. 1997) compared with other organisms, such as mammals and invertebrates. A possible explanation for the low microsatellite abundance is a general reduction in genome size in avian species, which was suggested to be an adaptation to the requirements of flight (Hughes \& Hughes 1995). The convenience of cross-species utility of microsatellite markers (Moore et al. 1991; Primmer et al. 1996) has made loci isolated from closely related species attractive candidates for this study. However, microsatellite loci isolated from other New Zealand parrots (Kakapo, Robertson et al. 2000; and Kaka, Sainsbury et al. 2004) did not amplify readily from Forbes' parakeet DNA (James Sainsbury and Margo van Bekkum, Victoria University of Wellington, pers. comm.), making isolation of microsatellite loci from Forbes' parakeet necessary.

One of the most commonly used methods for developing microsatellite markers is the use of hybridisation selection (see Zane et al. 2002). Briefly, this method involves fragmentation of the genome of the species of interest using restriction enzymes, cloning these fragments in competent bacterial cells through the use of plasmids, and screening resultant libraries with radioactively labelled microsatellite oligonucleotide sequences. Positive colonies are selected, plasmids isolated and primers designed based on their insert sequences. 
This basic method is generally effective in species which have many microsatellites, and numerous studies using this technique have been reported over the past decade in journals such as Conservation Genetics and Molecular Ecology. However, in the case of species like birds with relatively few microsatellites, a very large number of colonies must be screened in order to find a satisfactory number of positive clones.

Enrichment techniques have been developed to increase the efficiency of the hybridisation selection technique. The enrichment steps enhance the number of microsatellites in the candidate inserts by selection prior to cloning. This increases the chance of finding microsatellite loci among the limited number of colonies that is feasible to screen.

Various enrichment techniques were developed to increase the representation of microsatellites in libraries, e.g. through the use of singlestranded uracil DNA (Ostrander et al. 1992), random amplified polymorphic DNA (RAPD; Ender et al. 1996; Lunt et al. 1999), vectorette PCR (Lench et al. 1996), and the more popular hybridisation selection methods (Kandpal et al. 1994).

For this study, a simple and straightforward hybridisation selection enrichment protocol using nylon membranes was selected to enrich Forbes' parakeet DNA templates for microsatellites. The protocol was a modification of Armour et al. (1994) and Berry et al. (2003). The enrichment process involved digesting the parakeet DNA with Sau 3AI restriction enzyme, selection of suitably sized fragments, ligating the fragments to synthetic SAU linkers to allow PCR amplification and hence increase template numbers, followed by hybridisation of the amplified templates to nylon membranes with bound microsatellite probes. The bound fragments of candidate microsatellites recovered from the membranes were expected to have a higher abundance of microsatellites. 
These microsatellite-enriched fragment pools were used to construct libraries for screening.

\subsection{Methods}

\subsubsection{Extraction of DNA and Preparation of Template for Enrichment}

Samples from banded parakeets on Mangere Island were collected by Department of Conservation field staff in the form of blood stored in liquid nitrogen.

Parakeet DNA was extracted from blood samples from the populations on Mangere Island and South-East Island using the phenol / chloroform method modified from Sambrook et al. (1989). For each sample, $1 \mu \mathrm{l}$ of blood was added to $400 \mu \mathrm{l}$ of SET buffer $(0.1 \mathrm{M}$ Tris-HCl pH 8.0, $0.1 \mathrm{M}$ $\mathrm{NaCl}, 1.0 \mathrm{mM}$ EDTA) pre-mixed with $0.5 \%$ SDS, mixed, followed by the addition of $20 \mu \mathrm{l}$ of Proteinase $\mathrm{K}$ solution (Roche) at $20 \mathrm{mg} / \mathrm{ml}$. The mixture was incubated in a Hybaid rotating incubator at $55^{\circ} \mathrm{C}$ overnight.

Following incubation, $400 \mu \mathrm{l}$ of phenol was added to the reaction, which was mixed on a rotating platform for $30 \mathrm{~min}$, then centrifuged at 13000 rpm for $5 \mathrm{~min}$ to allow phase separation. The upper aqueous phase was transferred to a fresh plastic microcentrifuge tube, to which $400 \mu \mathrm{l}$ of phenol:chloroform:isoamyl alcohol (25:24:1) was added, followed by 30 min mixing and a $5 \mathrm{~min}$ spin at $13000 \mathrm{rpm}$. The lower organic phase was removed and $400 \mu \mathrm{l}$ of chloroform:isoamyl alcohol (24:1) was added. The reaction was allowed mixing for $30 \mathrm{~min}$ prior to $5 \mathrm{~min}$ centrifugation. To precipitate the DNA, the top phase was recovered and transferred to a new microcentrifuge tube, mixed with $1 / 10^{\text {th }}$ volume of $3 \mathrm{M} \mathrm{NaOAc} \mathrm{pH} 5.2$, followed by addition of $2 x$ volume of cold absolute ethanol. The reaction was allowed to precipitate for $3 \mathrm{hrs}$ at $4^{\circ} \mathrm{C}$ before centrifugation at 13000 rpm for $30 \mathrm{~min}$. After centrifugation, the supernatant was removed and 1 
$\mathrm{ml}$ of $70 \%$ ethanol was added to wash the pellet. The ethanol used in this wash step was removed by a $15 \mathrm{~min}$ spin at $13000 \mathrm{rpm}$ and the pellet was allowed to air dry at room temperature. The DNA was redissolved in $20 \mu \mathrm{l}$ $1 \mathrm{mM}$ Tris- $\mathrm{HCl} \mathrm{pH} 8.0$ buffer.

Samples from five individuals (birds ID: D172010, D172029, D172031, D175194, and D175197; Appendix 3.2) with Forbes' parakeet morphology from the Mangere parakeet population were chosen as the source of templates for enrichment.

\subsubsection{Genomic DNA Fragmentation and Size Selection of Template}

Fragmentation of template DNA from each sample was carried out by digesting $5 \mu \mathrm{l}$ of purified genomic DNA with $5 \mathrm{U}$ of Sau $3 A$ l restriction endonuclease (Roche) in a $15 \mu \mathrm{l}$ reaction containing $1 \times$ SuRE/Cut buffer $A$ (Roche) and $30 \mu \mathrm{g}$ RNase A (Sigma). The reaction was incubated at $37^{\circ} \mathrm{C}$ in a water bath overnight.

Digested genomic DNA between $500 \mathrm{bp}$ to $1 \mathrm{~kb}$ in size was selected, taking into account the ease of subsequent cloning, sequencing and primer design requirements. Size separation of fragments was performed by electrophoresis of the genomic DNA on a 1.2\% LE agarose (Roche) gel with Ethidium Bromide ( $\mathrm{EtBr})$ in 1x TA buffer at $100 \mathrm{~V}$ for $30 \mathrm{~min}$. Fragment sizes were determined by comparing to $1 \mathrm{~kb}$ DNA ladder standards (Invitrogen). Agarose slices containing the DNA of desired sizes were excised using sterile scalpel blades on an UV transilluminator. DNA was extracted from the agarose gel slice using High Pure PCR Product Purification Kit (Roche) following the manufacturer's protocol. DNA was eluted by $25 \mu$ l elution buffer provided with the kit. 
The eluted DNA was quantified with a DyNA Quant 200 fluorometer (Hoefer) following manufacturer's instructions. Eluted DNA concentrations were: $11 \mathrm{ng} / \mu \mathrm{l}$ (sample D172010), $10 \mathrm{ng} / \mu \mathrm{l}$ (sample D172029), $21 \mathrm{ng} / \mu \mathrm{l}$ (sample D172031), $11 \mathrm{ng} / \mu \mathrm{l}$ (sample D175194), and $17 \mathrm{ng} / \mu \mathrm{l}$ (sample D175197).

\subsubsection{Preparation of SAU Linkers}

Synthetic oligonucleotide SAU linkers (Royle et al. 1992) were prepared in 10 replicate $10 \mu \mathrm{l}$ reactions, each containing $5 \mu \mathrm{g}$ of SAULA (5' GCGGTACCCGGGAAGCTTGG $\left.3^{\prime}\right), \quad 5 \mu \mathrm{g}$ of SAULB (5' GATCCCAAGCTTCCCGGGTACCGC 3'), and 1x REACT 1 buffer (Invitrogen). The solution was heated to $95^{\circ} \mathrm{C}$ for $40 \mathrm{sec}$ in an OmnGene thermocycler (Hybaid), followed by $65^{\circ} \mathrm{C}-15 \mathrm{~min}, 60^{\circ} \mathrm{C}-15 \mathrm{~min}, 50^{\circ} \mathrm{C}-$ $15 \mathrm{~min}, 45^{\circ} \mathrm{C}-15 \mathrm{~min}, 40^{\circ} \mathrm{C}-15 \mathrm{~min}$, and then held at room temperature.

\subsubsection{Ligation of Template DNA to SAU Linkers}

A $40 \mu$ l ligation reaction was set up containing $2.75 \mu \mathrm{g}$ of SAU linkers, 40 $\mathrm{ng}$ of DNA from each of the five samples, $1 \mathrm{x}$ ligase buffer (Roche), $0.5 \mathrm{mM}$ ATP (Roche), and $1 \cup \mathrm{T}_{4}$ DNA ligase (Roche). The reaction was incubated at $16^{\circ} \mathrm{C}$ overnight. Unligated linkers were removed by running the reaction through a High Pure PCR Products Purification Kit (Roche) following the manufacturer's protocol. Elution of ligation products was carried out using $25 \mu \mathrm{l}$ elution buffer.

\subsubsection{Pre-enrichment PCR}

To increase the amount of DNA template for enrichment hybridisation, the ligation products were PCR amplified with SAULA as primer. PCR was carried out in 12 replicates of $25 \mu \mathrm{l}$, each containing $1 \mu \mathrm{l}$ of gDNA 
fragments-SAU linkers, $0.5 \mu \mathrm{M}$ SAULA primer, 1x PCR buffer (Qiagen), 3 $\mathrm{mM} \mathrm{MgCl} 2,0.8 \mathrm{mM}$ dNTPs (Roche), and $1 \mathrm{U}$ Taq DNA polymerase (Qiagen). The reaction was run on a Hybaid OmnGene thermocycler through $94^{\circ} \mathrm{C}-4 \mathrm{~min}, 30 \times\left(58^{\circ} \mathrm{C}-1 \mathrm{~min}, 70^{\circ} \mathrm{C}-2 \mathrm{~min}, 94^{\circ} \mathrm{C}-1 \mathrm{~min}\right)$, followed by a final $4 \mathrm{~min}$ extension at $70^{\circ} \mathrm{C}$. The reaction was checked by running $2 \mu \mathrm{l}$ aliquots of PCR products on a 1\% LE agarose gel with $\mathrm{EtBr}$ in 1x TA buffer at $100 \mathrm{~V}$ for $30 \mathrm{~min}$, and the PCR products visualized under UV light.

The PCR products were pooled and precipitated by mixing with $30 \mu \mathrm{l}$ of $3 \mathrm{M} \mathrm{NaOAc} \mathrm{pH} 5.2$ and $660 \mu \mathrm{l}$ cold absolute ethanol, allowed to stand at $4^{\circ} \mathrm{C}$ overnight, followed by centrifugation at $13000 \mathrm{rpm}$ for $30 \mathrm{~min}$. The supernatant was removed after centrifugation, and the DNA pellet was washed with $1 \mathrm{ml}$ of $70 \%$ ethanol. After centrifugation at $13000 \mathrm{rpm}$ for 15 min and removal of the supernatant, the pellet was air-dried. The PCR amplified size-selected DNA template was resuspended with $15 \mu \mathrm{l}$ of 1 $\mathrm{mM}$ Tris- $\mathrm{HCl} \mathrm{pH}$ 8.0, and quantified with a Hoefer DyNA Quant 200 fluorometer. The concentration was $350 \mathrm{ng} / \mu \mathrm{l}$.

\subsubsection{Preparation of Probes for Enrichment Hybridisations}

The three complementary pairs of $(\text { GATA })_{7}$ and $(\text { TATC })_{7},(\text { AAAG })_{7}$ and $(\mathrm{TTTC})_{7},(\mathrm{CA})_{15}$ and $(\mathrm{GT})_{15}$ were phosphorylated to facilitate their ligation to the other member in the pair. The phosphorylation reaction was carried out by heating a $50 \mu \mathrm{l}$ mixture of $2 \mu \mathrm{g}$ of each oligo in a pair, $1 \mathrm{x}$ ligase buffer (Roche), and $1 \mathrm{mM} \mathrm{ATP} \mathrm{(Roche)} \mathrm{to} 70^{\circ} \mathrm{C}$ for $5 \mathrm{~min}$, followed immediately by chilling on ice and the addition of $30 \mathrm{U}$ of $\mathrm{T}_{4}$ Polynucleotide Kinase (Roche). The phosphorylation reaction was incubated at $37^{\circ} \mathrm{C}$ for $45 \mathrm{~min}$ and the enzyme was then heat inactivated at $65^{\circ} \mathrm{C}$ for $20 \mathrm{~min}$. 
The phosphorylated oligo-pairs were ligated to form "lig-concatemers" in a $65 \mu \mathrm{l}$ reaction containing $50 \mu \mathrm{l}$ phosphorylated oligo-pairs, 1x ligase buffer (Roche), and $1 \mathrm{U} \mathrm{T}_{4}$ ligase (Roche). The ligation reaction was incubated at $16^{\circ} \mathrm{C}$ overnight.

The ligation product was then size-fractionated by electrophoresis on a $1.2 \% \mathrm{LE}$ agarose gel with $\mathrm{EtBr}$, run in $1 \mathrm{x} \mathrm{TA}$ buffer at $100 \mathrm{~V}$ for $30 \mathrm{~min}$. DNA fragments were visualized under UV light and gel slices containing fragments $>200$ bp were excised with scalpel blades, extracted with High Pure PCR Products Purification Kit (Roche) following manufacturer's instructions and eluted in $25 \mu \mathrm{l}$ of the elution buffer provided in the kit.

Primer-free PCRs were set up in 8 replicates for each probe to generate giant probes. Each $25 \mu \mathrm{l}$ reaction contained $1 \mu \mathrm{l}$ of "lig-concatemer" template, 1x PCR buffer (Qiagen), $6.7 \mathrm{mM} \mathrm{MgCl}_{2}, 0.8 \mathrm{mM}$ dNTPs (Roche), and $2 \mathrm{U}$ of Taq DNA polymerase (Qiagen). The reaction was run on a Hybaid OmnGene thermocycler for $95^{\circ} \mathrm{C}-2 \mathrm{~min}, 30 \times\left(55^{\circ} \mathrm{C}-1 \mathrm{~min}, 72^{\circ} \mathrm{C}\right.$ $-2 \mathrm{~min}, 95^{\circ} \mathrm{C}-1 \mathrm{~min}$ ), and $72^{\circ} \mathrm{C}-5 \mathrm{~min}$. The reaction was checked by running $2 \mu \mathrm{l}$ aliquots on a $1 \%$ LE agarose gel with $\mathrm{EtBr}$ in $1 \times$ TA buffer at $100 \mathrm{~V}$ for $30 \mathrm{~min}$. Smears extending from the wells to about $100 \mathrm{bp}$ were observed. Replicates of each probe were pooled.

Each giant probe was precipitated by addition of $20 \mu \mathrm{l}$ of $3 \mathrm{M} \mathrm{NaOAc} \mathrm{pH}$ $5.2,440 \mu \mathrm{l}$ of cold absolute ethanol, and centrifuged at $13000 \mathrm{rpm}$ for 30 min after an overnight incubation at $4^{\circ} \mathrm{C}$. The supernatant was removed and the pellet washed with $1 \mathrm{ml} 70 \%$ ethanol, the wash was subsequently removed after $15 \mathrm{~min}$ of centrifugation at $13000 \mathrm{rpm}$. The giant probe DNA pellet was resuspended in $25 \mu \mathrm{l}$ of $1 \mathrm{mM}$ Tris- $\mathrm{HCl} \mathrm{pH} 8.0$ after airdrying. The DNA solution was quantified with a DyNA Quant 200 fluorometer (Hoefer), which gave concentration estimates of 
$(\mathrm{GATA})_{7} /(\mathrm{TATC})_{7}$ at $270 \mathrm{ng} / \mu \mathrm{l},(\mathrm{AAAG})_{7} /(\mathrm{TTTC})_{7}$ at $609 \mathrm{ng} / \mu \mathrm{l}$, and $(\mathrm{CA})_{15} /(\mathrm{GT})_{15}$ at $560 \mathrm{ng} / \mu \mathrm{l}$.

\subsubsection{Membrane Enrichment}

The giant probe was denatured by treatment with $\mathrm{NaOH}$. For each probe, 10 replicate $9 \mu \mathrm{l}$ reactions were set up, each containing $1 \mu \mathrm{g}$ of giant probe, $200 \mathrm{mM} \mathrm{NaOH}$, and $2 \mathrm{mM}$ EDTA. The denaturing reaction was incubated at $37^{\circ} \mathrm{C}$ for $30 \mathrm{~min}$, and then partially neutralised by the addition

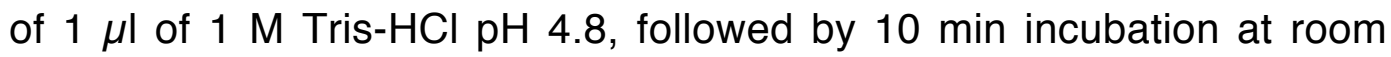
temperature.

Each replicate of denatured giant probes was dotted on Hybond-N membranes (Amersham Pharmacia Biotech) cut into $3 \mathrm{~mm}^{2}$ squares. The membranes were allowed to air dry, and were wrapped with plastic wrap prior to cross-linking by placing on a standard UV transilluminator for 50 sec per side.

Membranes holding the same probe were grouped together and prehybridised in $1.3 \mathrm{ml}$ of Church and Gilbert hybridisation solution (Church \& Gilbert 1984) with $1 \% \mathrm{BSA}$ at $65^{\circ} \mathrm{C}$ for 3 hours in a rotating Hybaid oven.

While the membranes were pre-hybridising, PCR amplified DNA fragments-SAU linkers were denatured. Each reaction was set up in $9 \mu \mathrm{l}$ triplicates, containing $1 \mu \mathrm{g}$ of DNA fragments-SAU linkers, $200 \mathrm{mM} \mathrm{NaOH}$, and $2 \mathrm{mM}$ EDTA. These were allowed to incubate at $37^{\circ} \mathrm{C}$ for $1 \mathrm{hr}$ before neutralisation with $1 \mu \mathrm{l}$ of $1 \mathrm{M}$ Tris- $\mathrm{HCl} \mathrm{pH} \mathrm{4.8,} \mathrm{and} \mathrm{a} \mathrm{further} \mathrm{incubation} \mathrm{of}$ $10 \mathrm{~min}$ at room temperature.

The pre-hybridisation solution was removed from the tube containing the membranes, and a mixture of neutralised denatured template DNA and 
$200 \mu \mathrm{l}$ of fresh Church and Gilbert solution (Church \& Gilbert 1984) with $1 \%$ BSA was added to the tube. The tube was incubated at $65^{\circ} \mathrm{C}$ overnight, rotating in a Hybaid oven.

The hybridisation solution was removed after the incubation and the membranes were washed 3 times at $65^{\circ} \mathrm{C}$ for 10 min with $600 \mu \mathrm{l}$ prewarmed $2 x$ SSC and $0.1 \%$ SDS solution, followed by a rinse with $5 x$ SSC at room temperature. The membranes with captured DNA fragments-SAU linkers were allowed to air dry.

Microsatellite enriched DNA was recovered from the membranes by adding $100 \mu \mathrm{l}$ of $50 \mathrm{mM} \mathrm{KOH}$ with $0.01 \%$ SDS, followed by incubation at room temperature for $10 \mathrm{~min}$ with occasional flicking. After incubation, $100 \mu \mathrm{l}$ of $50 \mathrm{mM}$ Tris- $\mathrm{HCl} \mathrm{pH} 7.5$ with $0.01 \%$ SDS was added to neutralise the reactions, and the membranes were removed from the tubes.

DNA was precipitated by the addition of $20 \mu \mathrm{l}$ of $3 \mathrm{M} \mathrm{NaOAc} \mathrm{pH} 5.2,0.5 \mathrm{ml}$ of cold absolute ethanol, and $2 \mu \mathrm{l}$ of linear polyacrylamide (Gillard \& Strauss 1990), followed by a $10 \mathrm{~min}$ chill on ice, and a $30 \mathrm{~min}$ centrifugation at $13000 \mathrm{rpm}$ at $4^{\circ} \mathrm{C}$. The supernatant was removed from the tube and the pellet was washed with $0.5 \mathrm{ml} 70 \%$ ethanol. The pellet was allowed to air dry after centrifugation at $13000 \mathrm{rpm}$ for $15 \mathrm{~min}$ and the removal of the wash solution. The dried pellet was resuspended in $10 \mu \mathrm{l}$ of $1 \mathrm{mM}$ Tris- $\mathrm{HCl} \mathrm{pH} 8.0$.

\subsubsection{PCR Amplification of Membrane Enriched DNA}

To increase the amount of insert DNA for subsequent library constructions, PCR amplifications were set up in 4 replicates using the recovered DNA from the previous step as template. In each reaction, $1 \mu \mathrm{l}$ of the recovered enriched DNA template was used, to which 1x PCR 
buffer (Qiagen), $3 \mathrm{mM} \mathrm{MgCl}$, $0.8 \mathrm{mM}$ dNTPs (Roche), $0.5 \mu \mathrm{M}$ SAULA primer, and $1 \cup$ Taq DNA polymerase (Qiagen) were added. The reaction was cycled through $95^{\circ} \mathrm{C}-5 \mathrm{~min}, 30 \times\left(67^{\circ} \mathrm{C}-1 \mathrm{~min}, 72^{\circ} \mathrm{C}-2 \mathrm{~min}, 95^{\circ} \mathrm{C}-\right.$ $1 \mathrm{~min}), 72^{\circ} \mathrm{C}-4 \mathrm{~min}$ in an OmnGene thermocycler (Hybaid).

The reaction was checked by electrophoresis of $1 \mu \mathrm{l}$ aliquots of products on a $1 \%$ LE agarose gel with EtBr in $1 \times$ TA buffer, run at $100 \mathrm{~V}$ for $30 \mathrm{~min}$. Fragments of $500 \mathrm{bp}$ to $1 \mathrm{~kb}$ were visualised under UV light.

Following manufacturer's protocol, High Pure PCR Product Purification Kit (Roche) was used to purify PCR products. The purified product was eluted with $50 \mu$ l of elution buffer provided in the kit.

\subsubsection{Removal of SAU Linkers from Enriched DNA}

The SAU linkers were removed from the amplified enriched DNA by an overnight digestion at $37^{\circ} \mathrm{C}$ with $10 \mathrm{U}$ of $\mathrm{Sau} 3 A /$ restriction endonuclease (Roche) in a $60 \mu \mathrm{l}$ reaction containing $1 \times$ SuRE/Cut buffer A (Roche) and $50 \mu \mathrm{l}$ of purified PCR products of enriched DNA. The reaction was run through High Pure PCR Products Purification Kit (Roche) following manufacturer's instructions to remove the SAU linkers, and the enriched DNA template was eluted with $25 \mu$ of elution buffer.

The purified enriched DNA template was quantified in a Hoefer DyNA Quant 200 fluorometer. The concentrations of GATA, AAAG, and CA enriched templates were $57 \mathrm{ng} / \mu \mathrm{l}, 71 \mathrm{ng} / \mu \mathrm{l}$, and $55 \mathrm{ng} / \mu \mathrm{l}$ respectively.

\subsubsection{Preparation of Plasmids for Library Construction}

Plasmid pUC18 DNA (500 ng; Roche) was digested in a $30 \mu$ reaction with $20 \mathrm{U}$ of Bam HI (Roche) in 1x SuRE/Cut Buffer B (Roche). The 
reaction was incubated at $37^{\circ} \mathrm{C}$ overnight. After the incubation, $2 \mathrm{U}$ of shrimp alkaline phosphatase (Amersham Pharmacia Biotech) was added to dephosphorylate the cut ends of the plasmid, and the reaction was allowed a further 2 hours' incubation at $37^{\circ} \mathrm{C}$.

The reaction was run on a 1\% LE agarose gel with EtBr in 1x TA buffer for $30 \mathrm{~min}$ at $100 \mathrm{~V}$. A gel fragment containing the linear plasmid was cut out and the plasmid DNA was extracted with High Pure PCR Products Purification Kit (Roche), and eluted in $25 \mu$ elution buffer. The purified plasmid DNA solution was found to have a concentration of $18 \mathrm{ng} / \mu \mathrm{l}$.

\subsubsection{Ligation of Inserts into Plasmids}

Ligation reaction was set up for the three different types of amplified enriched DNA. Each ligation reaction was set up with 1x ligase buffer (Roche), $1 \mathrm{mM}$ ATP (Roche), $50 \mathrm{ng}$ of digested and dephosphorylated pUC18 DNA, $90 \mathrm{ng}$ of amplified enriched DNA template, and $1 \mathrm{U}$ of $\mathrm{T}_{4}$ DNA ligase (Roche). The reaction was incubated at $16^{\circ} \mathrm{C}$ overnight.

\subsubsection{Transformation of Competent Cells and Making Glycerol Stocks of} Transformed Cells

Insert-containing pUC18 plasmid was diluted 5-fold with TE buffer $\mathrm{pH} 7.5$, and $1.5 \mu \mathrm{l}$ of the dilution was used to transform Max Efficiency DH5 competent Escherichia coli cells (Invitrogen) according to manufacturer's instructions. Each of the transformation reactions was plated out onto 10 LB agar plates with $100 \mu \mathrm{g} / \mathrm{ml}$ of ampicillin, $40 \mu \mathrm{g} / \mathrm{ml} \mathrm{IPTG,} 40 \mu \mathrm{g} / \mathrm{ml} \mathrm{X-gal.}$ The plates were incubated at $37^{\circ} \mathrm{C}$ overnight.

For each probe used, three 96 well plates were prepared with $20 \mu \mathrm{l}$ of sterile glycerol, $80 \mu \mathrm{l}$ of LB, and $50 \mathrm{ng} / \mu \mathrm{l}$ of ampicillin in each well. Using 
sterile technique, white colonies were transferred from the agar plates with sterile toothpicks into the wells containing glycerol growth medium. A total of 288 colonies were transferred for each type of enriched template. The 96 well plates were incubated at $37^{\circ} \mathrm{C}$ overnight in a shaking incubator.

\subsubsection{Transfer of Colonies, and Cross-linking of DNA onto Membranes}

A sterile "hedgehog" transfer device was used to transfer colonies from the glycerol stock plates to Hybond-N membranes (Amersham Pharmacia Biotech) placed on large LB agar plates with $100 \mu \mathrm{g} / \mathrm{ml}$ ampicillin, and was incubated at $37^{\circ} \mathrm{C}$ overnight.

The membranes were then placed on a piece of $3 \mathrm{~mm}$ filter paper (Whatman) pre-wetted with 2x SSC and 5\% SDS for 2 min to lyse colonies. The DNA liberated was cross-linked to the membrane by a 40 sec microwave treatment on high setting.

\subsubsection{Hybridisation of Membranes with Radioactive Probes}

For each of the three different probes, the three membranes containing cross-linked plasmid DNA from the previous step were grouped and prehybridised at $65^{\circ} \mathrm{C}$ for $2 \mathrm{hrs}$ with shaking in a $125 \mathrm{ml}$ solution which contained 0.3 $\mathrm{M} \mathrm{Na}_{2} \mathrm{HPO}_{4} \mathrm{pH}$ 7.2, $1.2 \mathrm{mM}$ EDTA pH 8.0, and 0.1\% SDS.

Individual reactions were set up using Megaprime DNA Labelling System (Amersham Pharmacia Biotech) to incorporate $\square^{32} \mathrm{P}$-dCTP into $5 \mathrm{ng}$ of each type of giant probes following the manufacturer's protocol. Unincorporated radioactive nucleotides were removed by passing the reactions through $1 \mathrm{ml}$ Sephadex G50 columns, with centrifugation at $2250 \mathrm{rpm}$ for $4 \mathrm{~min}$ to help the solution move through the columns. The procedure was repeated with new columns. The eluted probes were then 
boiled at $100^{\circ} \mathrm{C}$ in a waterbath for $5 \mathrm{~min}$ and immediately put on ice for 5 $\min$.

The radioactive probe was added to the membranes in the prehybridisation solution (see above), and the hybridisation reaction was incubated at $65^{\circ} \mathrm{C}$ with shaking overnight.

After the overnight incubation, the membrane was rinsed twice for $30 \mathrm{sec}$ with a wash solution containing $2 x$ SSC and $0.1 \%$ SDS, and then washed with fresh wash solution at $50^{\circ} \mathrm{C}$ for $15 \mathrm{~min}$. The membrane was allowed to air dry, and was exposed to Fuji Super Rx film (Fujifilm) at $-80^{\circ} \mathrm{C}$ for 17 hrs with an intensifying screen. The autoradiograph was developed, washed and allowed to air dry.

\subsubsection{Characterization of Plasmid DNA from Positive Colonies}

Positive colonies were identified from the autoradiographs. The corresponding colony was picked from the glycerol stock and allowed to grow at $37^{\circ} \mathrm{C}$ with shaking overnight in $10 \mathrm{ml}$ liquid LB medium containing $100 \mu \mathrm{g} / \mathrm{ml}$ ampicillin. Plasmid DNA was extracted from these minipreps using QIAprep Spin Miniprep Kit (Qiagen) according to manufacturer's instructions. The plasmid DNA was eluted by $50 \mu \mathrm{l}$ of elution buffer provided in the kit.

The recovered plasmid was sequenced with BigDye Terminator Cycle Sequencing Kit (Applied Biosystems) on a Perkin-Elmer model 480 thermocycler using either Forward (5' CCCAGTCACGACGTTGTAAAACG 3') or Reverse (5' AGCGGATAACAATTTCACACAGG 3') universal sequencing primers, and the fluorescently labelled products were separated on a 5\% polyacrylamide gel (Long Ranger Singel Pack, BMA) by an $\mathrm{ABI}$ Prism 377 sequencer (Applied Biosystems). DNA sequence 
data were acquired and analysed by the Sequencing Analysis software (Applied Biosystems).

2.2.16 Optimisation of PCRs for Amplification of Microsatellites Loci in Genomic DNA

Primers were designed using the software OLIGO (version 4.0 for Macintosh; Molecular Biology Insights, http://www.oligo.net) based on the insert sequences from positive clones that contained well-placed microsatellites with enough flanking region (minimum 50 bases on each side) for primers to be designed. The loci were named (Cfor) after the focal speices of this study, Cyanoramphus forbesi.

PCR reaction for amplification of microsatellite loci in genomic DNA was optimised on a Perkin-Elmer model 480 thermocycler, by modification of a protocol by Henegariu et al. (1997). The optimised reaction contained 1x PCR buffer (Qiagen), $2 \mathrm{mM} \mathrm{MgCl}, 50 \mathrm{mM} \mathrm{KCl,} 0.1 \mathrm{mM}$ dNTPs (Roche), $0.4 \mu \mathrm{M}$ of each primer (0.8 $\mu \mathrm{M}$ each for Cfor2021), and $1 \mathrm{U}$ Taq DNA polymerase (Qiagen). In a $12.5 \mu$ l reaction, about $10 \mathrm{ng}$ of parakeet genomic DNA was used as starting template. The reaction was cycled through $94^{\circ} \mathrm{C}-4 \mathrm{~min}, 30 \times\left(94^{\circ} \mathrm{C}-30 \mathrm{sec}, \mathrm{T}_{\mathrm{a}}-1 \mathrm{~min}, 65^{\circ} \mathrm{C}-1 \mathrm{~min}\right), 65^{\circ} \mathrm{C}$ $-3 \mathrm{~min}\left(\mathrm{~T}_{\mathrm{a}}\right.$ are given in Table 2.1).

The PCR product was analysed on a 1\% LE agarose gel containing EtBr, run at $100 \mathrm{~V}$ for $40 \mathrm{~min}$.

\subsection{Results}

\subsubsection{Development of Primers for Amplification of Microsatellite Loci}

A total of 47 strong positive signals were detected on autoradiographs. Among these, 10 were from screening with $(\text { GATA })_{n} /(\text { TATC })_{n}$ probe, 13 
from the $(A A A G)_{n} /(T T T C)_{n}$ probe, and 24 from the $(C A)_{n} /(G T)_{n}$ probe. All 47 inserts were sequenced, and primers were designed for 14 microsatellite loci (Table 2.1; Appendix 2.1). Among the remaining inserts sequenced, 8 were found to be false positives, 21 had microsatellite repeat arrays too close to one of the restriction sites and did not contain enough space for primers to be designed, and 4 appeared to be identical copies of other inserts identified. PCR conditions were successfully optimised in 9 loci among the 14 loci for which primers were designed (Table 2.1).

\subsection{Discussion}

\subsubsection{Membrane Enrichment Methodology}

This method was proven to be effective in isolating microsatellite loci in this study. Eight polymorphic and one monomorphic microsatellite loci were successfully developed and characterized from Forbes' parakeets. The membrane enrichment method used in this study seems to have a similar efficiency as the other enrichment methods when compared with similar studies in New Zealand parrots: Robertson et al. (2000) isolated 7 polymorphic loci in kakapo (Strigops habroptilus) using a protocol based on White \& Powell (1997), and Sainsbury et al. (2004) isolated 6 polymorphic loci in kaka (Nestor meridionalis) using a protocol developed by Grist et al. (1993) and Cooper et al. (1997).

Using the same membrane enrichment protocol, Berry et al. (2003) isolated 15 polymorphic microsatellite loci in New Zealand skinks, about double that isolated from Forbes' parakeets in this study. It is likely that the low number of loci isolated in this study is due to the low abundance of microsatellites in parrots. 
Table 2.1 Characteristics of microsatellite loci isolated from Forbes' parakeet (Cyanoramphus forbesi). For each locus, the primers designed, the repeat motif as first isolated, the size of the first isolated PCR product, and the annealing temperature $\left(T_{a}\right)$ of the PCR are presented.

\begin{tabular}{|c|c|c|c|c|}
\hline Locus & Primer sequences $5^{\prime}-3^{\prime}$ & $\begin{array}{l}\text { Repeat motif } \\
\text { (first isolated) }\end{array}$ & $\begin{array}{l}\text { Size } \\
\text { (bp) }\end{array}$ & $\begin{array}{c}\mathrm{T}_{\mathrm{a}} \\
\left({ }^{\circ} \mathrm{C}\right)\end{array}$ \\
\hline Cfor0405 & $\begin{array}{l}\text { CS004: TCCCTGAGCAATAACCAC } \\
\text { CS005: ATAAAACGGGAAAATAGA }\end{array}$ & $(\mathrm{CA})_{3} \mathrm{CG}(\mathrm{CA})_{4}$ & 88 & - \\
\hline Cfor0607 & $\begin{array}{l}\text { CS006: GGCACGACCCAGGCAATC } \\
\text { CS007: CATCCTTGGCAGTGTTCG }\end{array}$ & $\begin{array}{l}(\text { TTTC })_{2} \text { GTTCTC }(\text { TTTC })_{2} \\
\text { CTTC }(\text { TTTC })_{5} \text { TTCC }(\text { TC })_{4}\end{array}$ & 283 & - \\
\hline Cfor0809 & $\begin{array}{l}\text { CS008: GGATTTGTTCTAAGGGTTGT } \\
\text { CS009: AAGGTTTTGTGGAGGCTGTG }\end{array}$ & $\begin{array}{l}(\text { GATA })_{4} \text { GATG }(\text { GATA })_{2} \\
(\text { GA })_{2}(\text { GATA })_{3}\end{array}$ & 187 & 63 \\
\hline Cfor1011 & $\begin{array}{l}\text { CS010: GCCTCAATGACTCCTCTC } \\
\text { CS011: TGCCTGCTTTTGTTTATT }\end{array}$ & $(\mathrm{CA})_{11} \mathrm{CG}(\mathrm{CA})_{6}$ & 227 & - \\
\hline Cfor1213 & $\begin{array}{l}\text { CS012: AGGCTGCCCAGAGAAGCT } \\
\text { CS013: CTATGACATGATTACGAA }\end{array}$ & $\begin{array}{l}(\mathrm{CTAT})_{14} \mathrm{CAT}(\mathrm{CTAT})_{5} \\
(\mathrm{CTAC})_{8}(\mathrm{CTAT})_{2}\end{array}$ & 287 & - \\
\hline Cfor1415 & $\begin{array}{l}\text { CS014: TTTTTGTTAGCCACTGTT } \\
\text { CS015: GGGTATACGTTTCTTTTA }\end{array}$ & $(\mathrm{TG})_{16}$ & 215 & 53 \\
\hline Cfor1617 & $\begin{array}{l}\text { CS016: GGCACGACCCAGGCAATC } \\
\text { CS017: CCCGCATCCCCACTCCAG }\end{array}$ & $\begin{array}{l}(\mathrm{CTTT})_{2} \mathrm{CGTTCT}(\mathrm{CTTT})_{2} \\
\text { CCTT }(\mathrm{CTTT})_{5}\end{array}$ & 217 & 61 \\
\hline Cfor1819 & $\begin{array}{l}\text { CS018: AGGGGAGATGAACTGAGG } \\
\text { CS019: CCCAGGTAAGTGTTTCAA }\end{array}$ & $(\mathrm{CA})_{9}$ & 184 & 58 \\
\hline Cfor2021 & $\begin{array}{l}\text { CS020: ACTTCTGCTATCCAAACC } \\
\text { CS021: TCTGCTTGAGTGTGTCTT }\end{array}$ & $(\mathrm{TG})_{2} \mathrm{G}(\mathrm{TG})_{9}$ & 239 & 60 \\
\hline Cfor2223 & $\begin{array}{l}\text { CS022: CTCACTTTGCTCTGTTCGTA } \\
\text { CS023: CCTTGCTTCTTTGGATAATA }\end{array}$ & $(\mathrm{CA})_{6} \mathrm{CG}(\mathrm{CA})_{8}$ & 217 & 60 \\
\hline Cfor2425 & $\begin{array}{l}\text { CS024: TTCAGATAAAGAGAGCAG } \\
\text { CS025: AAGGAGCCCAGTTCATGC }\end{array}$ & $(\mathrm{CA})_{15}$ & 200 & - \\
\hline Cfor2627 & $\begin{array}{l}\text { CS126: GAATCCATCCCACCAACACA } \\
\text { CS127: AGAAGGCAGTGAAGGGATGT }\end{array}$ & $(\mathrm{TG})_{20}$ & 170 & 59 \\
\hline Cfor2829 & $\begin{array}{l}\text { CS028: AATGTTTGCTCCACTTGC } \\
\text { CS029: CCTGCGGGCTGAATGTGC }\end{array}$ & $\begin{array}{l}(A A A G)_{4} \ldots(A G)_{4} \ldots \\
(A A A G)_{4}\end{array}$ & 219 & 63 \\
\hline Cfor3031 & $\begin{array}{l}\text { CS030: TGCATGTGCAAAGAGTCC } \\
\text { CS131: CATGCTCATACCCTCACTCA }\end{array}$ & $(\mathrm{GT})_{11}$ & 239 & 57 \\
\hline
\end{tabular}

A number of positive clones identified in this study contained microsatellites which were too close to the restriction site to allow development of primers. This greatly reduced the effectiveness of the 
method in obtaining amplifiable polymorphic microsatellites. Using other restriction endonuclease and plasmid combinations may help improve the yield of clones which microsatellites are centrally located in the inserts.

More detailed analyses of the Mangere and South-East Islands parakeet populations and characterization of the loci are presented in the next two chapters.

2.4.2 Is Enrichment Necessary in Isolating Microsatellite Loci from Forbes' Parakeet?

Prior to the construction and screening of enriched libraries described in this chapter, non-enriched Forbes' parakeet genomic libraries were constructed and screened for microsatellites. However, none of the 30 positive colonies selected from the non-enriched libraries contained microsatellites (see Appendix 2.2 for methods and results).

It appears an enrichment step is essential in isolating microsatellites from organisms with low microsatellite density, such as birds (Primmer et al. 1997). The difficulties in isolating microsatellites also explain why a lot of effort has been put into development of enrichment protocols (see Zane et al. 2002).

\section{$2.5 \quad$ References}

Armour JAL, Neumann R, Gobert S, Jeffreys AJ (1994) Isolation of human simple repeat loci by hybridization selection. Hum. Mol. Genet., 3, $599-$ 605.

Berry O, Gleeson DM, Sarre SD (2003) Microsatellite DNA markers for New Zealand skinks. Conservation Genetics, 4, 411 - 414. 
Church GM, Gilbert W (1984) Genomic sequencing. Proc. Natl. Acad. Sci. USA, 81, 1991 - 1995.

Cooper SJB, Bull CM, Gardner MG (1997) Characterization of microsatellite loci from the socially monogamous lizard Tiliqua rugosa using a PCR-based isolation technique. Molecular Ecology, 6, 793 - 795.

Ender A, Schwenk K, Ständler T, Streit B, Schierwater B (1996) RAPD identification of microsatellites in Daphnia. Molecular Ecology, 5, 437 441.

Gaillard C, Strauss F (1990) Ethanol precipitation of DNA with linear polyacrylamide as carrier. Nucleic Acids Research, 18, 378.

Grist SA, Firgaira FA, Morley AA (1993) Dinucleotide repeat polymorphisms isolated by the polymerase chain reaction. BioTechniques, 15, $304-309$.

Henegariu O, Heerema NA, Dlouhy SR, Vance GH, Vogt PH (1997) Multiplex PCR: Critical parameters and step-by-step protocol. BioTechniques, 23, $504-511$.

Hughes AL, Hughes MK (1995) Small genomes for better flyers. Science, 377, 391.

Kandpal RP, Kandpal G, Weissman SM (1994) Construction of libraries enriched for sequence repeats and jumping clones, and hybridization selection for region-specific markers. Proc. Natl. Acad. Sci. USA, 91, $88-$ 92. 
Lench NJ, Norris A, Bailey A, Booth A, Markham AF (1996) Vectorette $P C R$ isolation of microsatellite repeat sequences using anchored dinucleotide repeat primers. Nucleic Acids Research, 24, 2190-2191.

Lunt DH, Hutchinson WF, Carvalho GR (1999) An efficient method for PCR-based isolation of microsatellite arrays (PIMA). Molecular Ecology, 8, $891-894$.

Moore SS, Sargeant LL, King TJ, Mattick JS, Georges M, Hetzel DJS (1991) The conservation of dinucleotide microsatellites among mammalian genomes allows the use of heterologous PCR primer pairs in closely related species. Genomics, 10, $654-660$.

Ostrander EA, Jong PM, Rine J, Duyk G (1992) Construction of smallinsert genomic DNA libraries highly enriched for microsatellite repeat sequences. Proc. Natl. Acad. Sci. USA, 89, $3419-3423$.

Primmer CR, Møller AP, Ellegren H (1996) A wide-range survey of crossspecies microsatellite amplification in birds. Molecular Ecology, 5, $365-$ 378.

Primmer CR, Raudsepp T, Chowdhary BP, Møller AP, Ellegren H (1997) Low frequency of microsatellites in the avian genome. Genome Research, 7, $471-482$.

Robertson BC, Minot EO, Lambert DM (2000) Microsatellite primers for the kakapo (Strigops habroptilus) and their utility in other parrots. Conservation Genetics 1, 93 - 95. 
Royle NJ, Hill MC, Jeffreys AJ (1992) Isolation of telomere junction fragments by anchored polymerase chain reaction. Proc. R. Soc. Lond. B, 247, $57-67$.

Sainsbury JP, MacAvoy ES, Chambers GK (2004) Characterization of microsatellite loci in the Kaka, Nestor meridionalis. Molecular Ecology Notes, 4, $623-625$.

Sambrook J, Fritsch EF, Maniatis T (1989) Molecular Cloning: $A$ Laboratory Manual, 2nd edn. Cold Spring Harbor Laboratory Press, New York.

White G, Powell W (1997) Isolation and characterization of microsatellite loci in Swietenia humilis (Meliaceae): an endangered tropical hardwood species. Molecular Ecology, 6, $851-860$.

Zane L, Bargelloni L, Patarnello T (2002) Strategies for microsatellite isolation: A review. Molecular Ecology, 11, 1- 16. 
Appendix 2.1 Sequences of Microsatellite Loci with PCR Primers Designed

Regions of inserts with reliable sequence are listed with primers designed set in bold.

PCR optimised loci (locus name - PCR product size):

Cfor0809 - 187 bp

CTAGCTCGGTACCCGGGGACCTTTCTGTAGCAAAACACCAACTGTCA TTGTATGGATTTGTTCTAAGGGTTGTCAGCTCTGGAAGAGTGCAGCC ATTTCACAACCAGGAGGTGGGTGGGTGGACGGGTAGGTAGGTAGAT GGATAGATAGATAGATAGATGGATAGATAGAGAGATAGATAGATAGA TGGAGTGTTGGGTAGAGACAGAAATAGAGAGAGCACAGCCTCCACA AAACCTTGTTTCAAGTACCCTCATTTATAACTTGGGTTTTGTAGGTTTT CTTGCCTTTGGAAGGGGACTTCATGTATCTTCACACCGTTCCTGAGA GTGGCAGTATTTGCACAGTGTTAATGTCTCAGGCCTGATC

Cfor1415-215 bp

GATCCCTGTTTTTTGTTAGCCACTGTTTGAAAACCTTGTTAGCTTAGT GTCGGGCACTCATTAAACTTTCAACTTACACAAGTTGCCTCCCAGCTC TGACAGATTGTCTGTGCCACAGTGTGTATATGCGTGAGCATGTGTTT GTGTGTGTGTGTGTGTGTGTGTGTGTGTGTGACTTATTGACCTGTAT GCAAGGCAAGTCACCGTAAAAGAAACGTATACCCCTTTTCACCCGA CAGATC 
Cfor1617-217 bp

GATCAGATACGGGGAGAGACACGGAGAAGAGAAAAGCTCCGTGCTG GCACGACCCAGGCAATCGGGTGACCTCTTTCTTCCTTTCTTTCGTTC

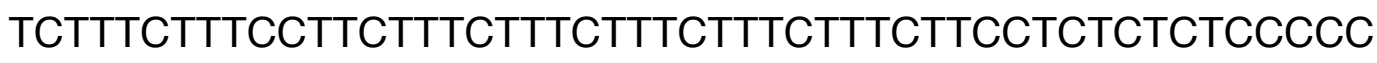
TTTCCTTCTCTTTCTCCTCGTCTCCTCGCTGCCCTCCTTCTCCTCGCC GCTGGTGAGGCTGGTCCCTCACCCCGGTTGGTGGTGCCCCCACCGC GGCTCTCCTGGAGTGGGGATGCGGGGGTCCCCAGCAGCGTCGGGG CTGGGGGGGCTGGTGGTGCCCGCAGGAGGTTGCTTGGAGGAAGAC AGCGTTCAGCTGGAGAGCAGGAGCCATTACACACG

Cfor1819- 184 bp CTAGAGGACCCCCATGTCTTGGTGTCCCCAGGGACATGGTTGCTTGC ATCCCTTGCCCATGGTGTCCAGGGGAGATGAACTGAGGTTTAAGGT GGGTGCTTGGGAATTGACCAGCTCTGAGTAGAGCTGGGCACAGCAC AGGACCATCCCAAGGGCTGTCCATGTAGCAATCACACACACACACAC ACACCCCTTATTTAGAATCCCTATCATTTCCCAGTCTACGGGCTGTGT TGAAACACTTACCTGGGTATGCCAGGGGCATCACTGGATGCTCAGC TCCATGCCCATCCCTCCTGGTGCTCACCTCCCTCCATCCGGAGCTGC TCAATCCCGCTGCTTCACTTCACTCCCCATCCTGCTGCTCTGACACA GCCACCCCATGTCACTCACCCAGCCCAGGTCACCTCAGGGGATGGC AGAGAGCTGGCGGCTGCCTCAGGACACGGCTATTCCTGCCACCTCC GTGATC 
Cfor2021 - 239 bp

GATCTGTCAACCGAGTAGCCCTGAACTACGAAGTGAAATTACAGTAC TTCTGCTATCCAAACCCCCCTGAATTGCGAGGTGTGCGGTGTGGTGT GTGTGTGTGTGTGTGTTGCACGGCGGTGTAACAATGTGCTGGCACC GCGTCAGGGCTGGAAGCGCCGCAGACCCCGTATAACGCCAAATGAG GCTTGTCTTGTTTTGTTATTCAGATTTCTACTCTTCCATTAAAAACAGC CTTACAATAACCAATGATAAAGGTCTGATTTAAGACACACTCAAGCA GAGCAATTCAGAGCTTAGGACAGTGATC

Cfor2223 - $217 b p$

GATAGTGGGGTATTAACGAAGCGGAAGTTGCTTCTCCTGCTCACTTT GCTCTGTTCGTAAACAAAGGGACTCTGTTCCTTTATCTTATGATTTCTT CACAGAGGAACAGGCAAACATGCATAGAAAGGAGGAGACAGGGAGA TGGAGCTTACTGATTTTTTTCAGTGAAAGGACTGATTTTTCCCACCTTTT ACATACACACACACACACGCACACACACACACACATTTCAATTTAGTA TTATCCAAAGAAGCAAGGACATTTCATATCAGCTGGGGACTTGGCCT GACAAAGGTGAAGGTGATC

Cfor2627 - 170 bp

CTAGAGGATCCATCCCACCAACACACATAGTTCTTTCCCTGCTGCTA CGCTGCAGCCAGGGGTGGGGAGAGTGTGTGTGTGTGTGTGTGTGTG TGTGTGTGTGTGTGTGTGCACATGTTTCCAAAAGATTCGTCTGCTTTC AAAAATCACCAGGCACATCCCTTCACTGCCTTCTGGAGCCTGACCCT TGCACGCTGCTTGGGCAAGACAAAGGAAACCTTGCAAATGCCACTGA TC 
Cfor2829 - 219 bp

CTAGTACAAATGTTTGCTCCACTTGCACAGAGAGAATATTGAAAGAAA GAAAGAAAGAGAGAGAGAGAGAAAGAGAGAGAAAGAAAGAAAAAGA AAGAAAGGAAGAAAGAATGAAAGAAAGAAAAAGAAAGAAAGGAAGGA AGAAAGAAAGAAAGAGAAAGAAAGAAAGAAAGAGAGAAAGAAAGAGC ATGTGGTTAGTTTTTAGAAGTGCACATTCAGCCCGCAGGCTCTTGCT GGTCGCTGCCGCCCGCCCCAGTTCTGCCGGGTCCTTACCCTACAGC TGTGGTACTGCCACAGCAGCTGGGTCAGGGCCACGATC

Cfor3031 - 239 bp

CTAGAGGAGCCCGTCGGGAGTGCGTGCAGGAGCCCGTCCACGGGG TGCATGTGCAAAGAGTCCCTCGGAGGGGTGTGTGTGCAACAGACTG CCCGGAGGGGGGTGTGCAAATGTCCCTGGGGCCATGTGTGAACGC GTGCCCGAAAGCGGCGTGTGTAAGAACGTGGTGGGGTGAGTGCATG TGCGGCGTCCCGTTGGGGTGGGTGTGTGTGTGTGTGTGTGTGTAAA AGTGCTTGTCCAGGGGACGGGTGTGTAAGAGCCGGTTGAGTGAGGG TATGAGCATGATC

Non-optimised loci (Amplification of genomic DNA failed):

Cfor0405

AGCCAGTCCCTGAGCAATAACCACCTTGGAAGCCACACACGCACAC ACACCCCCCCCCTTTCAATTTTTCTTTCCTTCTATTTTCCCGTTTTATA TAGCTTGAAGCATGAACAATTAGAATGGCAATAAAATATTCCTTTGGC TGATTCAAAGGGGGAACCCGGGAAGTTTGGGCACTGGGACCGGGG GTTTCCGGGGAAGGGGAA 
Cfor0607

AGATACGGGGAGAGACACGGAGAAGAGAAAAGCTCCGTGCTGGCAC GACCCAGGCAATCGGGTGACCTCTTTCTTCCTTTCTTTCGTTCTCTTT CTTTCCTTCTTTCTTTCTTTCTTTCTTTCTTCСTCTCTCTCССССТTTCC TTCTCTTTCTCCTCGTCTCCTCGCTGCCСTCCTTCTCCTCGCCGCTGG TGAGGCTGGTCCCTCACCCCGGTTGGTGGTGCCCCCACCGCGGCTC TGTCTGACATGGCCTTCAACACCACCAGGGATGGAGCATTCACAACA AGGCTCTGTCCGACCTGGCCTCGAACACTGCCAAGGATGGAGCATT CACAACCCATTCCAGTGCCTCACCAACCTCACAGTAAATAATTTCTTC CTTATATCTTACCTGAACTTCCCCTGTTTAAGCTTGAACCTGTTACCC CTTGTCCTGTCACTACAGTCCCTGATGAAGAGTCCCTCCCCAGCATC CCTATAGGCCCCCTTCAGATACTGGAAGGCTGCTATGAGGTCCCCAC GCAGCCTTCTCTTCTCAGCTGAACAGCCCCAACTTTCTCAGCCTATCT TCATACGGGAGTT

Cfor1011

AGCCTCAATGACTCCTCTCACTCCCAAGCTATAGGACAGGCCCTGCA ATACCAAATACAAATACTCAATCCCTTTGCTATCTTCTCCTCAATGCCC AGACATCACACACACACACACACACACACGCACACACACACAAACCC CTTAACTCTTTACAACTCTACACGCTTTGTGCCTTCACATCTCCCAAG CCAGCAGCAGCATGTGAAAAATAAACAAAAGCAGGCATGCTGAGAG ACGGCTCAAAGATGCACCTTTAACTTACCAAGGGC 
Cfor1213

CACAGGCTGCCCAGAGAAGCTGTGGCTGCCCCATCCCTGGCATGCA TGCATGCATCTATCTATCTATCTATCTATCTATCTATCTATCTATCTATC TATCTATCTATCTATCATCTATCTATCTATCTATCTATCTACCTACCTAC СТАССТАССТАССТАССТАССТАТСТАТСТААТСТАТСАТСТTТСТTСТ CTGAAATGTCCCAATTGTACAATGTTTAGCTGCTCCGTGTTGAAACCT GTTGAGGATCCCCGGGTACCGAGCTCGAATTCGTAATCATGTCATAG CTGTTTCCTGTGTGAAATTGTTATCCGCTCACAATTCCACACAACATA CGAGCCGGAAGCATAAAGTGTAAAGCCTGGGGTGCCTAATGAGTGA GCTAACTCACATTAATTGCGTTGCGCTCACTGGCCGCTTTCCAGTCG GGAAA

Cfor2425

GATTTGTTCAGATAAAGAGAGCAGTTTCTAGAGTTCAGGTTTGAAGA TACACACACACACACACACACACAACACACAGAGAGCTTCAAGTGTT CAGGTTTGAAGACAAACACACACATAGACACACACACACAGAGCTTC CTCCCСTCTCTGTGTTTCCATCCCCATCAGAGGCTGGGCTCAGGCTG CATGAACTGGGCTCCTTTCAGACTCACAGAATCAACCAGGTTGGTAA AGCCCTTTAAGCTCATCCAGTCCAACCATTCCCAGCACTGCCAAGGC CACCCCTAACCCNTGGCACTGAGGCCTCGTCTCCACGGTGTGTGAG CACTTGCAGAGCCAGTGCCCGCAGCCCTGCCCTGGGCAGCCTGTTC CAATGCCTGAGCACCCT 


\section{Appendix 2.2 Libraries Without Enrichment - Random Genomic DNA Sequences from Forbes' Parakeet}

\section{Methods}

Preparation of Insert and Plasmid DNA

DNA was extracted from five random Mangere Island parakeet blood samples as described in section 2.2.1. From each sample, $5 \mu \mathrm{l}$ of DNA was digested in a $15 \mu \mathrm{l}$ reaction with $5 \mathrm{U}$ of restriction enzyme Sau3 Al (Roche), 1x SuRE/Cut buffer A (Roche), and $0.5 \mu$ RNase A. The reaction was incubated in a $37^{\circ} \mathrm{C}$ heating incubator overnight.

DNA fragments between $300 \mathrm{bp}$ to $800 \mathrm{bp}$ were size-selected and purified as described in section 2.2.2. The pool of size-selected fragments from the five samples were mixed.

Plasmid pBlueScript (Stratagene) was digested in a $30 \mu \mathrm{l}$ reaction with 20 $\mathrm{U}$ of Bam HI (Roche) in 1x SuRE/Cut Buffer B (Roche). The reaction was incubated at $37^{\circ} \mathrm{C}$ overnight. After the incubation, $2 \mathrm{U}$ of shrimp alkaline phosphatase (Amersham Pharmacia Biotech) was added, and the reaction was allowed a further 2 hours' incubation at $37^{\circ} \mathrm{C}$. The digested product was separated by agarose gel electrophoresis, and the linear plasmid was excised from the gel, followed by purification with High Pure PCR Products Purification Kit (Roche).

The insert and plasmid DNA were quantified on an agarose gel. The insert was found to be $20 \mathrm{ng} / \mu \mathrm{l}$. The Bam $\mathrm{HI}$ cut plasmid was at a concentration of $30 \mathrm{ng} / \mu \mathrm{l}$. 


\section{Ligation of Inserts to Plasmids and Transformation}

Using the protocol described in section 2.2.11, Sau3 Al digested insert was ligated into Bam $\mathrm{HI}$ cut plasmid. Library Efficiency $\mathrm{DH} 5 \square$ competent E. coli cells (Invitrogen) were transformed following manufacturer's protocol. The transformed cells were plated out on 10 LB plates as described in section 2.2.12. The plates were left to incubate at $37^{\circ} \mathrm{C}$ overnight.

An average of 70 colonies grew on each plate. The colonies were lifted onto Hybond-N nylon membranes (Amersham Pharmacia Biotech) following manufacturer's protocol. Each membrane was then baked $80^{\circ} \mathrm{C}$ for 2 hours to crosslink the DNA.

\section{Preparation of Microsatellite Probes and Hybridisation}

Hybridisation was performed as described in section 2.2.14, except the probes used were a mixture of $(C A)_{12}$ and $(G A)_{12}$ oligonucleotides radioactively labelled in a $50 \mu \mathrm{l}$ reaction, incubated for 1 hour at $37^{\circ} \mathrm{C}$, containing $25 \cup$ Terminal Deoxynucleotide Transferase (TdT; Amersham Pharmacia Biotech), 1x TdT buffer (Amersham Pharmacia Biotech), $5 \mu$ l $\square^{32} \mathrm{P}-\mathrm{dCTP}$, and $25 \square \mathrm{mol}$ of each of the oligonucleotides.

\section{Isolation and Characterization of Positive Inserts}

Colonies that gave positive signals on the autoradiographs were identified and picked from the agar plates. These colonies were allowed to grow overnight at $37^{\circ} \mathrm{C}$ with shaking in LB medium with $100 \mu \mathrm{g} / \mathrm{ml}$ ampicillin. Plasmid DNA was extracted from the cultures using QIAprep Spin Miniprep Kit (Qiagen) according to manufacturer's instructions. The recovered plasmid was sequenced as described in section 2.2.15. Sequences obtained were searched for homology to published sequences 
at the Genbank/EMBL/DDBJ databases (http://www.ncbi.nlm.nih.gov) using the nucleotide BLAST tool.

\section{Results}

\section{Positive Colonies}

The screening of the non-enriched library yielded 30 positive colonies, of which, 17 were successfully sequenced. Only 9 of the inserts were longer than $100 \mathrm{bp}$ (see Sequences section in this appendix).

\section{Characterization of Insert Sequences}

None of the insert sequences contained microsatellites. A search on the Genbank/EMBL/DDBJ databases did not return any matches to over $50 \%$ of the length of the insert sequences (as at January 2005). The sequences isolated represent novel random nuclear genetic fragments from Cyanoramphus forbesi.

\section{Sequences}

Clone \#1 - 173 nt

TCCCCCGGGCTGCAGGAATTCGATATCAAGCTTATCGATTGGGTGGA AGACAACTTCCTTCTGCAAGTAACAGAGGAGCCGACAAGGAGAGGT GCCATGCTTGACCTTGTGCTCACCAACAGGGAAGGGCTCGTTGAGAA TGTGGTACTCCAGGGCAGCCGTGGATGCAGTGA 
Clone \#2 - $283 \mathrm{nt}$

TCCCCCGGGCTGCAGGAATTCGATATCAAGCTTATCGAATACCCAGC CCAGCACGGGCAACTGAGGTACCAGCACGAGCATTGGTGGTTCAGT GGTAGAATTCTCGCCTGCCACGCGGGAGGCCCGGGTTCAATTCCCG GCCAATGCAAAGCTTTGCTTTTATTCTGTCCTGGGTTCAGCAGAAAAA GTCTTTTTTCTCCTTCTTACCAATCATTCACAGTCTAGGAGGTTCCTC CAGTGCATTGATGATAACTTCTTAATGCAAATGGTGGACATACCAACT

Clone \#3-181 nt TCAGATATTAGGAAAAATGTCTTTACTGAAAGGACTGTCAATCATTGA AGCAGGCTGCCCAAGGAAGTGATGGCCTCACCATCCCTGGAGGTAT TTAAAAGATGTGTAGATACGGTACTTAGGGACATGGCTTAGTGGTGG ACTTGGCAACAGCTGGGCTCGATACCGTCGACCTCGAGGG

Clone \#4 - $270 \mathrm{nt}$ TCTTGTTTTTACGAGGTGCCCGGGCAGCAGTGAGGTGCGCAGTCCA ACAGCATCATGGTGCTGCACGGGACCTGGCTGCTAACAATGTGCCC GAGAGGTGTGAATGCGGCAGCGTCCGGGAGGCTCCAAATGGGTAAC AACACATGAAGGGAAAACCACCCCGGCTGCCCTCAAACCTGAGCTG CCTCCTCCTGCTCCCСTCCTCCCCGCACCTGCCTTTCGTTTTCCTCAT GCATGGAAGGTATTAATCACCCAGCTCGCTTTACTGGC

Clone \#5- $153 \mathrm{nt}$ TCCTTTGCTTAAACAAAAGTATTGTCTGCTGTAGGCACTGTAAGCACT GAGGAACTGTACTGTTGCCCTGCACCTCTCTCTGCACGCAAGGCTGC AGAGCTTTCTGCTCAGTTCCTCAGCTCTGGGGAGCACATCCAGCGCA CAACGGTGGGA 
Clone \#6- $138 \mathrm{nt}$ TCATGTTACATCATGTTATAGCATCATGTCATATCATATAACCTCATTT CATTTCCTTTTCATTGCATTTGGTTTCTTTTCTTCACCTCGTCATTTTCT СТССТССТССТСТСТССАСАAАТАТАССАТTTССТАТСА

Clone \#7-356 nt

TCCTGCAGGAAAGCTACTCTCTTCCTAATTACCCTGCAATTGCCAGGT TCAAAATGTAATTTATGAGCAGCATAGATAGAATGGCCACATTAGTCC ATTATTTCATGATAATCTTTTCTACTCTTGCTTTCAGAAAGGAAGGATT TTGCAGCTCTCGTTGCATTGGCACTGTCAGCAGTTCCTCTGTGCAGT GATGCTATACAACTGCACTGGAAAGATACTCCCCCAAAAATGTAGAG CAGTCACCTAACAGCAAGGTATTACAGAAGGAGGGAGGTACTGTGAG GTACACTTAAACAAATAAAGCATGACCTGGTGGGCTGCCTCAGACAC TGTTGACCACATTTGGAAACAGA

Clone \#8- $140 \mathrm{nt}$

TATGATAGGAAATGGTATATTTGTGGAGAGAGGAGGAGGAGAGAAAA TGACGAGGTGAAGAAAAGAAACCAAATGCAATGAAAAGGAAATGAAA TGAGGTTATATGATATGACATGATGCTATAACATGATGTAACATGA 
Clone \#9- $356 \mathrm{nt}$

TCTGTTTCCAAATGTGGTCAACAGTGTCTGAGGCAGCCCACCAGGTC ATGCTTTATTTGTTTAAGTGTACCTCACAGTACCTCCCTCCTTCTGTAA TACCTTGCTGTTAGGTGACTGCTCTACATTTTTGGGGGAGTATCTTTC CAGTGCAGTTGTATAGCATCACTGCACAGAGGAACTGCTGACAGTGC CAATGCAACGAGAGCTGCAAAATCCTTCCTTTCTGAAAGCAAGAGTA GAAAAGATTATCATGAAATAATGGACTAATGTGGCCATTCTATCTATG CTGCTCATAAATTACATTTTGAACCTGGCAATTGCAGGGTAATTAGGA AGAGAGTAGCTTTCCTGCAGGA 


\section{Appendix 2.3 Characterization of Variable Microsatellite Loci in Forbes' Parakeet (Cyanoramphus forbesi) and their Use in Other Parrots}

Manuscript submitted to Conservation Genetics, in press.

Chi-hang Chan ${ }^{1}$, Kaye N. Ballantyne ${ }^{1}$, David M. Lambert ${ }^{2}$ \& Geoffrey K. Chambers $^{1}$

${ }^{1}$ Institute for Molecular Systematics, School of Biological Sciences, Victoria University of Wellington, PO Box 600, Wellington, New Zealand. ${ }^{2}$ Allan Wilson Centre for Molecular Ecology and Evolution, Institute of Molecular BioSciences, Massey University, Private Bag 102904, North Shore Mail Centre, Auckland, New Zealand.

Keywords: microsatellite, Cyanoramphus forbesi, hybridisation

Forbes' parakeet (Cyanoramphus forbesi) is endemic to Mangere and Little Mangere Islands, in the Chatham Islands group of New Zealand. They are known to hybridise with Chatham Island Red-Crowned parakeets (C. novaezelandiae chathamensis). Their hybrid offspring and various backcrosses exhibit a range of crown colour patterns intermediate between those of the parent species.

A previous analysis of the entire mitochondrial DNA control region divided Forbes' parakeet into three haplotype groups (Boon et al. 2001), with the major differences between the three haplogroups lying within the first $300 \mathrm{bp}$ from the 5 '-end of the sequence. Haplogroup 3 consists of birds that are genetically distinct from other Cyanoramphus species whereas haplogroups 1 and 2 are much more closely related to Chatham Island Red-Crowned parakeets and believed to have arisen from past inter- 
specific hybridisation. In this study, we isolated nuclear microsatellite DNA markers for measuring genetic variation in the Forbes' parakeet population to monitor its hybridisation with $C$. $n$. chathamensis.

Blood and feather samples were collected from a complex parakeet population on Mangere Island, which is thought to comprise of a mixture of Forbes' parakeets, Chatham Island Red-Crowned parakeets and their hybrids. DNA was extracted from blood samples using a phenol/chloroform method (Sambrook et al. 1989) or from feathers using DNeasy Tissue Kit (Qiagen). Microsatellite loci were isolated, characterised and developed from a library enriched by use of nylon membranes (Armour et al. 1994; Berry et al. 2003). Purified genomic DNA from five randomly chosen birds with Forbes' parakeets morphotype was digested with Sau 3AI (Roche), and the 500-1000bp gel-isolated fragments were ligated to SAU linkers (Royle et al. 1992) at $16^{\circ} \mathrm{C}$ for 17 hours. Pre-enrichment PCR was performed using $0.5 \mu \mathrm{M}$ SAULA primer (5' GCGGTACCCGGGAAGCTTGG 3'), 1x PCR buffer (Qiagen), $3 \mathrm{mM}$ $\mathrm{MgCl}_{2}, 0.8 \mathrm{mM}$ dNTPs, $1 \cup$ Taq polymerase (Qiagen). The reactions were cycled through $94^{\circ} \mathrm{C}-4 \mathrm{~min} ; 30 \times\left(58^{\circ} \mathrm{C}-1 \mathrm{~min}, 70^{\circ} \mathrm{C}-2 \mathrm{~min}, 94^{\circ} \mathrm{C}-1\right.$ $\mathrm{min}) ; 70^{\circ} \mathrm{C}-4 \mathrm{~min}$ on a Hybaid OmnGene thermocycler. Hybond-N membranes (Amersham Pharmacia Biotech) cut into $3 \mathrm{~mm}^{2}$ squares, saturated with $(\mathrm{CA} / \mathrm{GT})_{n},(\mathrm{AAAG/TTTC})_{n}$, or (GATA/CTAT) $)_{n}$ solutions were used to select for pre-enriched fragments containing microsatellite DNA as described in Berry et al. (2003).

The enriched fragments were PCR amplified under the same conditions as the pre-enrichment PCR except that the annealing temperature was increased to $67^{\circ} \mathrm{C}$ and the number of cycles was increased to 35 . The SAU linkers were removed by digestion with Sau 3AI (Roche) and products recovered by purification with High Pure PCR Products Purification kit (Roche). The Sau $3 A /$ digest fragments were ligated into 
pUC18 plasmids and transformed into competent Escherichia coli, strain DH5a cells. Colonies were lifted on Hybond-N membranes (Amersham Pharmacia Biotech) and screened with $\square^{32} P$-labelled $(C A)_{n},(A A A G)_{n}$, or $(\text { GATA })_{n}$ probes following the protocol in Berry et al. (2003). The membranes were exposed on Fuji Super RX film (Fujifilm) with an intensifying screen for $17 \mathrm{~h}$. Plasmid were isolated from 47 positive candidate colonies identified from autoradiographs using QIAprep Miniprep kit (Qiagen) and their avian inserts were cycle sequenced with BigDye Terminator Cycle Sequencing Kit (Applied Biosystems) and products were run on an ABI Prism 377 sequencer (Applied Biosystems).

Fourteen sets of PCR primers were designed based on recovered DNA sequences using OLIGO (version 4.0 for Macintosh; Molecular Biology Insights, http://www.oligo.net), and we were able to optimise amplification conditions for 9 sets of primers in 12 randomly chosen parakeet DNA samples. Candidate loci were amplified in 1x PCR buffer (Qiagen), $2 \mathrm{mM}$ $\mathrm{MgCl}_{2}, 50 \mathrm{mM} \mathrm{KCl}, 0.1 \mathrm{mM}$ dNTPs, $1 \mu \mathrm{M}$ Fluorescein-12-dUTP (Roche; for genotyping reactions only), $0.4 \mu \mathrm{M}$ each primer $(0.8 \mu \mathrm{M}$ each for Cfor2021), and $1 \cup$ Taq DNA polymerase (Qiagen). The reactions were run on a Perkin-Elmer model 480 thermocycler for an initial denaturation at $94^{\circ} \mathrm{C}-4 \mathrm{~min}$, followed by $30 \times\left(94^{\circ} \mathrm{C}-30 \mathrm{sec}, \mathrm{T}_{\mathrm{a}}-1 \mathrm{~min}, 65^{\circ} \mathrm{C}-1 \mathrm{~min}\right)$, and a final extension of $65^{\circ} \mathrm{C}-3 \mathrm{~min}\left(\mathrm{~T}_{\mathrm{a}}\right.$ are given in Table 1$)$. Genotyping and sequencing were performed on an $\mathrm{ABI}$ Prism 377 sequencer (Applied Biosystems).

A total of 250 parakeets from Mangere Island were screened to examine variability at each of the loci. All loci, except Cfor2223, were found to be polymorphic in the Mangere Island parakeet population (Table 1). The monomorphic locus, Cfor2223, could be amplified with primers ( $F$ : CTCACTTTGCTCTGTTCGTA and R: CCTTGCTTCTTTTGGATAATA) at $T_{a}$ 
$=60^{\circ} \mathrm{C}$, and a $217 \mathrm{bp}$ allele with repeat motif $(\mathrm{CA})_{6} \mathrm{CG}(\mathrm{CA})_{8}$ was observed in Forbes' parakeet.

Observed and expected heterozygosity values were calculated using the Microsatellite Analyser software (version M3.15; Dieringer \& Schlötterer 2002; see Table 1). Deviation from Hardy-Weinberg equilibrium (HWE) was tested by the Markov chain method (Guo \& Thompson 1992) as implemented in GENEPOP (version 3.4; Raymond \& Rousset 1995). Cfor1415, Cfor1617, Cfor1819, Cfor2627, and Cfor3031 all showed significant deviations from HWE $(P<0.05)$. Possible explanations for these observations include non-random mating in the population as suggested by mitochondrial control region studies (Boon et al. 2001; Ballantyne 2003) and the presence of null alleles. The latter is likely to be the explanation for deviation from HWE in Cfor2627 as 59 individuals were apparently homozygous for the null allele.

Loci isolated were also tested for linkage disequilibrium using GENEPOP (version 3.4; Raymond \& Rousset 1995). Evidence for significant linkage disequilibrium was detected between Cfor0809 and Cfor2829, and between Cfor1415 and Cfor2829 (both with $P=0.00$ ) after Bonferroni correction (Rice 1989). However, we did not find evidence for linkage disequilibrium at these loci in three other New Zealand Cyanoramphus parakeet populations (unpublished data). Therefore, it is unlikely these loci are physically linked on the same chromosomes.

The loci were also tested across a wide range of other parrot and cockatoo species, the results are shown in table 2. We believe that the loci described here, in conjunction with other primers for parrots previously published (for example, Robertson et al. 2000; Sainsbury et al. 2004), will provide useful markers for conservation studies of parrots worldwide. 


\section{Acknowledgements}

We thank the New Zealand Department of Conservation for providing funding and samples for this study. We also appreciate the help from Oliver Berry and Gwilym Haynes (Massey University); Elizabeth MacAvoy and James Sainsbury (Victoria University of Wellington); Hilary Aikman, Colin Miskelly, Christine Reed, Tertia Thurley and Denise Fastier (Department of Conservation) in technical advice or sample collection.

Table 1. Microsatellite loci isolated from Forbes' parakeet: $N=$ number of alleles, $T_{\mathrm{a}}=$ annealing temperature of PCR, $H_{\mathrm{O}}=$ observed heterozygosity, $H_{\mathrm{E}}=$ expected heterozygosity. Loci indicated with asterisks $\left({ }^{*}\right)$ showed significant heterozygote deficiencies (all with $P=0.00$ ). The DNA sequences of microsatellite loci isolated in this study have been deposited in DDBJ under accession numbers AB181800-AB181808.

\begin{tabular}{|c|c|c|c|c|c|c|c|}
\hline Locus & Primer Sequences 5' - 3' & $\begin{array}{l}\text { Repeat Motif as First } \\
\text { Isolated }\end{array}$ & $N$ & $\begin{array}{l}\text { Allele } \\
\text { Size (bp) }\end{array}$ & $\begin{array}{l}T_{a} \\
\left({ }^{\circ} \mathrm{C}\right)\end{array}$ & $H_{0}$ & $H_{\mathrm{E}}$ \\
\hline Cfor0809 & $\begin{array}{l}\text { F: GGATTTGTTCTAAGGGTTGT } \\
\text { R: AAGGTTTTGTGGAGGCTGTG }\end{array}$ & $\begin{array}{l}(\text { GATA })_{4} \text { GATG } \\
(\text { GATA })_{2}(\text { GA })_{2}(\text { GATA })_{3}\end{array}$ & 4 & $183-203$ & 63 & 0.08 & 0.09 \\
\hline Cfor1415 & $\begin{array}{l}\text { F: TTTTTGTTAGCCACTGTT } \\
\text { R: GGGTATACGTTTCTTTTA }\end{array}$ & $(\mathrm{TG})_{16}$ & 7 & $211-227$ & 53 & 0.76 & 0.73 \\
\hline Cfor $1617^{*}$ & $\begin{array}{l}\text { F: GGCACGACCCAGGCAATC } \\
\text { R: CCCGCATCCCCACTCCAG }\end{array}$ & $\begin{array}{l}(\mathrm{CTTT})_{2} \ldots(\mathrm{CTTT})_{2} \mathrm{CCTT} \\
(\mathrm{CTTT})_{5}\end{array}$ & 2 & $217-225$ & 61 & 0.10 & 0.28 \\
\hline Cfor $1819^{\star}$ & $\begin{array}{l}\text { F: AGGGGAGATGAACTGAGG } \\
\text { R: CCCAGGTAAGTGTTTCAA }\end{array}$ & $(\mathrm{CA})_{9}$ & 4 & $176-188$ & 58 & 0.45 & 0.60 \\
\hline Cfor2021 & $\begin{array}{l}\text { F: ACTTCTGCTATCCAAACC } \\
\text { R: TCTGCTTGAGTGTGTCTT }\end{array}$ & $(\mathrm{TG})_{2} \mathrm{G}(\mathrm{TG})_{9}$ & 2 & $233-239$ & 60 & 0.26 & 0.26 \\
\hline Cfor2627 ${ }^{*}$ & $\begin{array}{l}\text { F: GAATCCATCCCACCAACACA } \\
\text { R: AGAAGGCAGTGAAGGGATGT }\end{array}$ & $(T G)_{20}$ & 4 & $160-172$ & 59 & 0.35 & 0.79 \\
\hline Cfor2829 & $\begin{array}{l}\text { F: AATGTTTGCTCCACTTGC } \\
\text { R: CCTGCGGGCTGAATGTGC }\end{array}$ & $\begin{array}{l}(\mathrm{AAAG})_{4} \ldots(\mathrm{AG})_{4} \ldots \\
(\mathrm{AAAG})_{4}\end{array}$ & 3 & $219-231$ & 63 & 0.38 & 0.40 \\
\hline Cfor3031* & $\begin{array}{l}\text { F: TGCATGTGCAAAGAGTCC } \\
\text { R: CATGCTCATACCCTCACTCA }\end{array}$ & $(\mathrm{GT})_{11}$ & 7 & $233-247$ & 57 & 0.41 & 0.65 \\
\hline
\end{tabular}


Table 2. Amplification of Cfor loci in other parrot and cockatoo species. + $=$ amplification of a microsatellite, $-=$ no amplification. Sequences from amplified microsatellites have been deposited in DDBJ under accession numbers listed.

\begin{tabular}{|c|c|c|c|c|c|c|c|c|c|c|c|}
\hline & \multirow[t]{2}{*}{ Species } & \multirow{2}{*}{$\begin{array}{l}\text { DDBJ } \\
\text { Accession } \\
\text { numbers }\end{array}$} & \multicolumn{9}{|c|}{ Loci } \\
\hline & & & 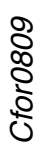 & $\frac{n}{\frac{1}{d}}$ & 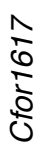 & $\begin{array}{l}\frac{9}{\infty} \\
\frac{1}{0} \\
\frac{5}{0}\end{array}$ & 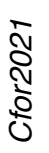 & 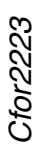 & 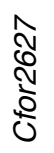 & 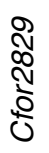 & 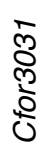 \\
\hline \multirow[t]{19}{*}{ Australasian } & Cyanoramphus novaezelandiae chathamensis & AB182657-65 & + & + & + & + & + & + & + & + & + \\
\hline & Cyanoramphus novaezelandiae novaezelandiae & AB182684-92 & + & + & + & + & + & + & + & + & + \\
\hline & Cyanoramphus auriceps & AB182666-74 & + & + & + & + & + & + & + & + & + \\
\hline & Cyanoramphus malherbi & AB182675-83 & + & + & + & + & + & + & + & + & + \\
\hline & Cyanoramphus hochstetteri & AB183203-11 & + & + & + & + & + & + & + & + & + \\
\hline & Cyanoramphus unicolor & AB181982-90 & + & + & + & + & + & + & + & + & + \\
\hline & Cyanoramphus saisetti & AB185424-32 & + & + & + & + & + & + & + & + & + \\
\hline & Eunymphicus cornutus & AB183212-20 & + & + & + & + & + & + & + & + & + \\
\hline & Eunymphicus uvaeensis & AB183221-29 & + & + & + & + & + & + & + & + & + \\
\hline & Barnardius barnardi & AB185433-39 & + & + & + & + & - & + & + & + & - \\
\hline & Glossopsitta pusilla & AB183241-46 & + & - & + & + & + & - & + & - & + \\
\hline & Micropsitta pusio & AB183230-35 & + & - & + & + & + & - & + & - & + \\
\hline & Platycercus eximius & AB185132-37 & + & + & + & + & - & + & - & - & + \\
\hline & Trichoglossus haematodus & AB183236-40 & + & - & + & - & + & - & + & - & + \\
\hline & Psephotus varius & AB185138-41 & - & + & + & - & - & - & + & - & + \\
\hline & Melopsittacus undulatus & AB185142-43 & - & - & - & + & - & - & + & - & - \\
\hline & Strigops habroptilus & AB182693-94 & - & - & - & + & - & + & - & - & - \\
\hline & Nestor notabilis & AB182695-96 & + & - & + & - & - & - & - & - & - \\
\hline & Nestor meridionalis & AB182697-98 & + & - & + & - & - & - & - & - & - \\
\hline \multirow[t]{4}{*}{ African } & Coracopsis nigra barkyli & AB181960-64 & + & - & - & + & + & - & + & - & + \\
\hline & Poicephalus senegalus & AB181969-75 & + & - & + & + & + & - & + & + & + \\
\hline & Poicephalus meyeri & AB181965-68 & + & - & + & + & - & - & + & - & - \\
\hline & Psittacus erithacus & AB181976-81 & + & - & + & + & + & - & + & - & + \\
\hline \multirow[t]{3}{*}{ Cacatuidae } & Nymphicus hollandicus & AB185416-23 & + & + & + & + & + & + & + & + & - \\
\hline & Eolophus roseicapillus & AB185413-15 & + & - & + & - & - & - & + & - & - \\
\hline & Cacatua haematuropygia & AB185130-31 & + & - & - & - & - & - & + & - & - \\
\hline
\end{tabular}

\section{References}

Armour JAL, Neumann R, Gobert S, Jeffreys AJ (1994) Isolation of human simple repeat loci by hybridization selection. Hum. Mol. Genet., 3, $599-$ 605.

Ballantyne K (2003) A population level analysis of Cyanoramphus forbesi mitochondrial DNA haplogroups. BSc(Hons) Thesis, Victoria University of Wellington, Wellington, New Zealand. 
Berry O, Gleeson DM, Sarre SD (2003) Microsatellite DNA markers for New Zealand skinks. Conservation Genetics, 4, 411 - 414.

Boon WM, Kearvell JC, Daugherty CH, Chambers GK (2001) Molecular systematics and conservation of kakariki (Cyanoramphus spp.). Science for Conservation 176. Department of Conservation, Wellington.

Dieringer D, Schlötterer C (2002) Microsatellite analyser (MSA): a platform independent analysis tool for large microsatellite data sets. Molecular Ecology Notes, 3, 167 - 169.

Guo SW, Thompson EA (1992) Performing the exact test of HardyWeinberg proportions for multiple alleles. Biometrics, 48, 361-372.

Raymond M, Rousset F (1995) GENEPOP (version 1.2): Population genetic software for the exact tests and ecumenicisms. J. Hered., 86, 248 -249 .

Rice WR (1989) Analyzing tables of statistical tests. Evolution, 43, 223 225.

Robertson BC, Minot EO, Lambert DM (2000) Microsatellite primers for the kakapo (Strigops habroptilus) and their utility in other parrots. Conservation Genetics, 1, 93 - 95.

Royle NJ, Hill MC, Jeffreys AJ (1992) Isolation of telomere junction fragments by anchored polymerase chain reaction. Proc. R. Soc. Lond. B, 247, $57-67$. 
Sainsbury JP, MacAvoy ES, Chambers GK (2004) Characterization of microsatellite loci in the Kaka, Nestor meridionalis. Molecular Ecology Notes, 4, $623-625$.

Sambrook J, Fritsch EF, Maniatis T (1989) Molecular Cloning: A Laboratory Manual, 2nd edn. Cold Spring Harbor Laboratory Press, New York. 


\section{Chapter 3: Microsatellite DNA Studies Reveal Extensive Hybridisation between Parakeets on Mangere Island}

\subsection{Introduction}

Hybridisation may bring both advantages and disadvantages to a population. On the positive side, hybridisation can be a source of new genetic variation that enhances adaptation (Lewontin \& Birch 1966), and a stimulus for evolution and diversification (Anderson \& Stebbins 1954; Dowling \& Secor 1997). On the negative side hybridisation may threaten the very existence of a species, especially when genetic introgression is from an abundant species to a rare species (Rhymer \& Simberloff 1996). For example, hybridisation between American black ducks (Anas rubripes) and mallards ( $A$. platyrhynchos) has led to a significant reduction in genetic differentiation and breakdown of species integrity (Mank et al. 2004). In some cases, hybrid progeny are less fit than their parents, but the reverse can also be true (Arnold \& Hodges 1995; Barton 2001). When hybrids are of about equal fitness to one or both parental species, hybrid zones can establish and may remain in equilibrium for long periods of time (Barton \& Hewitt 1985). Although interspecific hybridisation events are common, the processes involved are empirically well understood in only a very few systems (Stone 2000).

The main aims of this chapter are to investigate: 1) the level of hybridisation taking place in the Mangere Island Forbes' parakeet population; 2) methods for classifying parents and hybrids through the use of genetic markers; and 3) the correlation between the genetic status of individual birds and their morphological features. Insights are gained on the genetic structure of the populations through the use of the 
microsatellite markers isolated for Forbes' parakeet. Mutation modes of these loci are also studied.

Two parakeet populations are studied in this chapter: 1) The Mangere Island population, which is a mixed population made up of Forbes' parakeets, Chatham Island Red-crowned parakeets and hybrids; and 2) The South-East Island population, which is largely made up of Chatham Island Red-crowned parakeets. The three different types of markers investigated are microsatellites (MS), mitochondrial DNA control region (MT), and crown plumage morphology (MP).

\subsection{Methods}

\subsubsection{Screening of Parakeets at Cfor loci}

Parakeet DNA was extracted from a total of 285 parakeet blood and feather samples collected between 1999 and 2002 (250 from Mangere Island, 35 from South-East Island). DNA extraction from blood was performed as described in section 2.2.1. To extract DNA from various types of feather samples, the tips of $1-7$ feathers were used as the source of DNA. Higher success of feather DNA extraction is usually obtained from feathers with more skin tissue attached. Extraction was performed using DNeasy Tissue Kit (Qiagen) following manufacturer's protocol.

The DNA samples were genotyped at 8 polymorphic loci (Cfor0809, Cfor1415, Cfor1617, Cfor1819, Cfor2021, Cfor2627, Cfor2829, and Cfor3031). To set up genotyping reactions, $1 \mu \mathrm{M}$ of Fluorescein-12-dUTP (Roche) was added to the PCR reaction set-up (see section 2.2.16), labelling the PCR products with a fluorescent tag. The amplified allelic products were separated on $5 \%$ polyacrylamide gels (Long Ranger Singel 
Pack, BMA) by an ABI Prism 377 sequencer (Applied Biosystems), and analysed by the GeneScan Analysis software (Applied Biosystems).

The DNA sequence identity of each observed allele type was confirmed by cycle sequencing on a Perkin-Elmer model 480 thermocycler with the BigDye Terminator Cycle Sequencing Kit (Applied Biosystems), using double stranded PCR product (section 2.2.16) purified by High Pure PCR Products Purification Kit (Roche) as template. The cycle sequencing reaction was analysed on a 5\% polyacrylamide gel (Long Ranger Singel Pack, BMA) using an ABI Prism 377 sequencer (Applied Biosystems), and analysed by the Sequencing Analysis software (Applied Biosystems).

\subsubsection{Hardy-Weinberg Equilibrium and Linkage Disequilibrium Tests} The Microsatellite Analyser (MSA) software (version M3.15; Dieringer \& Schlötterer 2002) was used to calculate the observed and expected heterozygosity values for all variable loci across the Mangere Island and South-East Island parakeet populations. Allele frequencies at these loci were also calculated using the MSA software, and were compiled with the Appleworks spreadsheet software (version 6; Apple Computer).

Deviation from Hardy-Weinberg equilibrium (HWE) was tested by the Markov chain method (Guo \& Thompson 1992) as implemented in GENEPOP (version 3.4; Raymond \& Rousset 1995). The programme was run for 300 batches with 1000 interations per batch, and dememorization was set at 1000. Linkage disequilibrium between loci was also tested using the GENEPOP software. 


\subsubsection{Models of Microsatellite Evolution}

Loci were evaluated for fit in the infinite allele model (IAM; Kimura \& Crow 1964) versus the one-step mutation model (SMM; Ohta \& Kimura 1973) and the two-phase model (TPM; Di Rienzo et al. 1994) of microsatellite evolution based on observed allele size distributions.

A likelihood test (Nielsen 1997) was performed to assess the goodness-offit to SMM versus TPM models of evolution. The estimator of variance in allele size $\square\left(=4 N_{\mathrm{e}} \mu\right.$; where $N_{\mathrm{e}}$ is the effective population size, and $\mu$ the mutation rate; Valdes et al. 1993), the estimated proportion of multi-step mutations $p$, and the likelihood value $L(\square)$ were estimated using a Markov chain recursion method implemented in the MISAT software (Nielsen 1997). The Markov chain was set for $10^{5}$ runs.

The null hypothesis that the loci evolve via strict SMM was tested for each locus by calculation of the likelihood ratio -2log $\square$, following Nielsen \& Palsbøll (1999), where

$\square=\frac{\max [L(\square, p=0)]}{\max [L(\square, p)]}$

A critical value of this test statistics can be obtained by comparing -2log $\square$ to the $\square^{2}$ distribution with degree of freedom (df) $=1$ (Nielsen 1997). In other words, the null hypothesis can be rejected at $P=0.05$ when $-2 \log \square$ $\geq 3.84\left(\square^{2}\right.$ distribution critical value at $\left.\mathrm{df}=1, P=0.05\right)$.

At present, the software MISAT does not have the capability to calculate likelihood values for loci with more than one repetitive theme. Therefore, the statistics could not be calculated for Cfor2829, which consists of both dinucleotide and tetranucleotide repeat motifs (see Chapter 2, Table 2.1). 
3.2.4 Genetic Differentiation Between Mangere and South-East Islands Populations

Six loci, Cfor0809, Cfor1415, Cfor1617, Cfor2021, Cfor2829, and Cfor3031 were selected for further analyses (see sections 3.3.1 and 3.3.3). Estimator $\square_{S T}$ (Weir \& Cockerham 1984) of $F_{S T}$ (Wright 1951) and the inbreeding coefficient $F_{\text {IS }}$ were calculated using the MSA software. The estimator $\square_{\text {ST }}$ (Rousset 1996) of $R_{\text {ST }}$ (Slatkin 1995) was calculated using the GENEPOP software.

Differentiation between Mangere Island and South-East Island parakeet populations was also assessed by Analysis of Molecular Variance (AMOVA; Excoffier et al. 1992) as implemented in the software GeneticStudio (version 2.01; Dyer \& Sork 2001).

\subsubsection{Testing for Genetic Bottleneck}

In a bottlenecked population, there is a reduction in allelic diversity (allele numbers) and heterozygosity at polymorphic loci. Allelic diversity is reduced faster than heterozygosity in a bottlenecked situation (Cornuet \& Luikart 1996). Therefore, assuming mutation drift-equilibrium, recently bottlenecked populations are expected to show observed heterozygosity $\left(H_{0}\right)$ values larger than those expected from the observed number of alleles in the populations (Cornuet \& Luikart 1996). The Mangere Island and South-East Island parakeet populations were evaluated for evidence of recent genetic bottlenecks using the software Bottleneck (version 1.2.02; Cornuet \& Luikart 1996). This programme tests for significant differences between observed and expected heterozygosities under mutation drift-equilibrium conditions through implementation of three statistical tests for heterozygosity excess, a "sign test", a "standardised differences test", and a "Wilcoxon sign-rank test", each under the mutational models IAM, SMM, and TPM. The statistical power of these 
tests was evaluated by Luikart \& Cornuet (1998) and Luikart et al. (1998). The "sign test" suffered from low statistical power, and the "standardised differences test" requires 20 or more polymorphic loci. The "Wilcoxon sign-rank test" provides relatively high power with as few as four polymorphic loci, and thus is most appropriate for this study. Because most microsatellite loci mutate in a mode between IAM and SMM, the use of both models for the test was recommended (Luikart \& Cornuet 1998). The populations were also tested for recent bottlenecks under the TPM with $5 \%$ multi-step changes. The programme was run for $10^{6}$ replications under the mutation models IAM, SMM, and TPM.

\subsubsection{Bayesian Clustering and Population Assignment}

Assignment tests were performed with the software NewHybrids (version 1.1b3; Anderson \& Thompson 2002). Compared with other available assignment methods, NewHybrids is closely related to that of Rannala \& Mountain (1997), but differs substantially in that NewHybrids treats all individuals in a population simultaneously rather than on an individual basis. NewHybrids is more similar to the Bayesian method, Structure (Pritchard et al. 2000), for analysing structured populations. The method of Pritchard et al. (2000) focuses on populations with unknown underlying structure, whereas when some basic information in the population

structure is available, NewHybrids provides a more detailed analysis using an inheritance model defined by genotype. Assignment tests using fully Bayesian methods (Pritchard et al. 2000) are found to perform better than partial Bayesian exclusion tests (Rannala \& Mountain 1997), provided that representative genotypes of the true population origin are sampled (Manel et al. 2002). 
Accuracy of NewHybrids in assigning an individual to the correct population was tested using a dataset of two simulated populations generated with the software Easypop (version 1.8; Balloux 2001).

To determine the best strategy, a hypothetical population that contained parental species, hybrids and various backcrosses with known genotypes and identities was constructed, and tested with different settings of the NewHybrids software (see Table 3.4).

The contribution of individual loci to the final assignment outcome was assessed by running the programme with one locus removed at a time using the Mangere Island data set.

The NewHybrids assignment test using genotypic data from the Mangere Island and South-East Island populations was run with six loci with a setting of four genotypic classes (2 parental classes, $F_{1}$ and $F_{2}$ hybrids; Table 3.1). The run was repeated for a total of 30 times, each with $10^{6}$ sweeps after a burn in period of $10^{5}$ sweeps. Each run required 3.75 hours on a Macintosh computer with a PowerPC $900 \mathrm{MHz}$ G3 processor.

Table 3.1 Genotypic classes assumed for assignment testing using NewHybrids (Anderson \& Thompson 2002). The symbols $G_{g, 2}, G_{g, 1}$, and $G_{g, 0}$ represent the expected frequencies of loci having 2, 1, or 0 genes originated from species $A$ (Anderson \& Thompson 2002).

\begin{tabular}{cccc}
\hline Genotypic Class & $\mathrm{G}_{\mathrm{a}, 2}(\mathrm{~A}, \mathrm{~A})$ & $\mathrm{G}_{\mathrm{a}, 1}(\mathrm{~A}, \mathrm{~B})$ or $(\mathrm{B}, \mathrm{A})$ & $\mathrm{G}_{\mathrm{a}, \mathrm{0}}(\mathrm{B}, \mathrm{B})$ \\
\hline Parent $\mathrm{A}$ & 1.00 & 0.00 & 0.00 \\
Parent B & 0.00 & 0.00 & 1.00 \\
$\mathrm{~F}_{1}$ Hybrid & 0.00 & 1.00 & 0.00 \\
$\mathrm{~F}_{2}$ Hybrid & 0.25 & 0.50 & 0.25 \\
\hline
\end{tabular}




\subsubsection{Genetic Distances Between Individuals}

A genetic distance measure based on the proportion of shared alleles (Bowcock et al. 1994), which is independent of the models of microsatellite evolution, was used to evaluate the relationship between Forbes' and Chatham Island Red-crowned parakeets through Principal Coordinates Analysis (Gower 1966). A genetic distance matrix was constructed using the MSA software, and was plotted onto two-dimensional space using the software PCO (Anderson 2003).

Because some of the Cfor loci evolve closely to strict SMM (Table 3.3) in the Mangere Island and South-East Island parakeet populations, the pattern of individual genetic differences was also investigated using a second genetic distance measure: $(\square)^{2}$ (Goldstein et al. 1995), which incorporates features of the SMM. The distance measure $(\square \square)^{2}$ is also found to be appropriate for estimating evolutionary divergent times (Takezaki \& Nei 1996) because $(\square)^{2}$ has a linear relationship with time. Genetic distance matrices based on the $(\square)^{2}$ statistic were calculated using the MSA software with 100 bootstrap replicates. The distance matrices were used to construct 100 neighbour-joining trees (Saitou \& Nei 1987 ) by the Neighbor module in the Phylip software package (version 3.61; Felsenstein 1989). A majority-rule consensus of the 100 trees was obtained by using the Consense module in the package, and the resulting consensus tree was plotted using the Drawtree module.

\subsubsection{Correlation Between Genetic and Morphological Variables}

The relationship between microsatellite assignment, mitochondrial haplogroups, and crown plumage variations was explored through Multiple Correspondence Analysis (MCA; Tenenhaus \& Young 1985) using the MCA module of the ADE-4 software (Thioulouse et al. 1997). 
Based on mitochondrial control region studies, Boon et al. (2001) classified Forbes' parakeet into three mtDNA control region sequence haplogroups. Haplogroup 3 represented the pure Forbes' parakeet and haplogroups 1 and 2 represented Chatham Islands Red-crowned parakeet haplogroups present in Forbes' Parakeet morphotypes due to past hybridisations. The Chatham Island Red-crowned parakeets were represented by a separate haplogroup. A PCR-RFLP assay has been developed to distinguish between the three Forbes' parakeet haplogroups and the Chatham Islands Red-crowned parakeet haplogroup (Ballantyne et al. 2004). Haplogroup memebership of samples used in this study was studied by Ballantyne et al. (2004).

The morphology of parakeets was scored by crown plumage (Hilary Aikman, NZ Department of Conservation, pers. comm.) using a five point scale based on Nixon (1982). A clear Forbes' parakeet morphotype was scored as MP1 on the scale and a Chatham Island Red-crowned parakeet morphotype was scored MP5 on the scale. Hybrids were scored on the scale MP2 (fewer red feathers on crown) to MP4 (more red feathers on crown).

\subsection{Results}

3.3.1 Locus Characteristics of Cfor Loci in Mangere and South-East Islands Populations

DNA extracted from samples from the parakeet populations on Mangere Island and South-East Island was screened at the 9 optimised loci. Individual genotype profiles of the 8 polymorphic loci were tabulated (Appendix 3.1), and allele frequencies were calculated (Figure 3.1, Table 3.2). 
Figure 3.1 Allele frequency distributions of $\mathrm{Cfor}$ loci in two populations of parakeets. Black solid bars represent the Mangere Island population (250 individuals), Grey shaded bars represent the South-East Island population (35 individuals), and the numbers above bars represent the number of times an allele was observed.
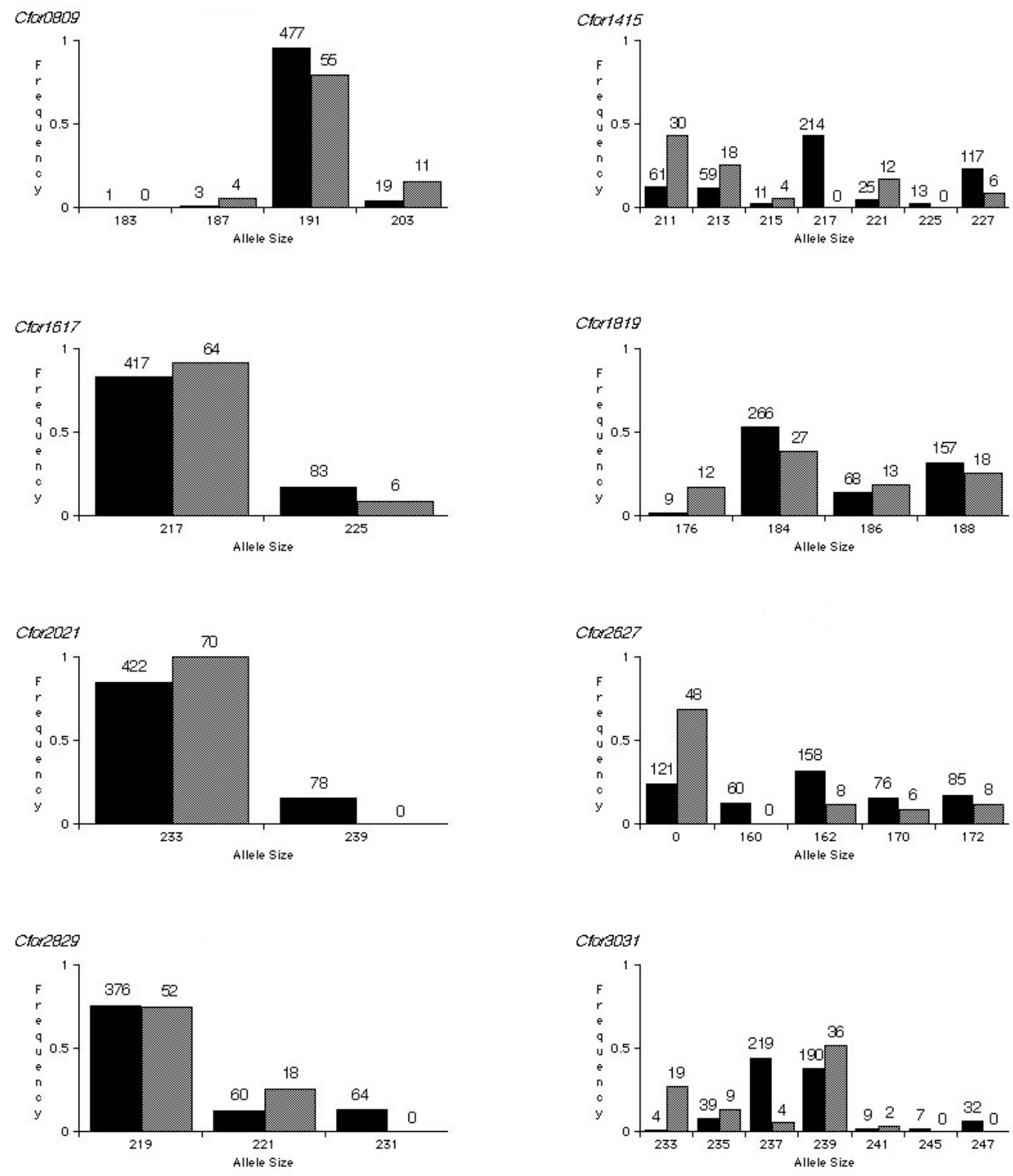

Eight loci (Cfor0809, Cfor1415, Cfor1617, Cfor1819, Cfor2021, Cfor2627, Cfor2829, and Cfor3031) were found to be polymorphic while one locus 
(Cfor2223) was monomorphic (allele size $=217 \mathrm{bp}$ ) across all of the samples tested. Cfor2021 was fixed for the 233 bp allele in the SouthEast Island population.

\subsubsection{Hardy-Weinberg Equilibrium and Linkage Disequilibrium}

Observed and expected heterozygosities were calculated and HardyWeinberg equilibrium (HWE) was tested across all the polymorphic loci (Table 3.2). In the Mangere Island population, Cfor0809, Cfor2021 and Cfor2829 were in HWE while Cfor1415, Cfor1617, Cfor1819, Cfor2627 and Cfor3031 showed significant deviations $(P<0.05)$. In the South-East Island population, all loci except Cfor1819 and Cfor2627 conformed to expectation under HWE. In the Mangere Island population, Cfor1617, Cfor1819, Cfor2627 and Cfor3031 showed significant heterozygote deficiencies ( $P=0.00$ for all 4 loci). In the South-East Island population, only Cfor1819 and Cfor2627 showed significant heterozygote deficiencies $(P=0.00$ for both loci).

Evidence for apparent linkage disequilibrium was found between Cfor0809 and Cfor2829, and between Cfor1415 and Cfor2829 in the Mangere Island population after sequential Bonferroni correction (Rice 1989). However, tests for linkage disequilibrium in other populations suggested the observed linkage disequilibrium in the Mangere Island population may be an artefact caused by the underlying mixed population structure (see section 3.4.3).

It is worth noting that the mixed species nature and overlapping generations in the population samples may affect the reliability of HWE and linkage disequilibrium tests. 


\subsubsection{Size Homoplasy and Null alleles}

Sequencing of 184 bp alleles of Cfor1819 revealed size homoplasy at this locus. Two motifs, $(C A)_{9}$ and $(C A)_{5} \mathrm{C}_{3}(C A)_{2} \mathrm{C}$, (contributing respectively $33 \%$ and $67 \%$ of the 54 sequenced 184 bp alleles) were observed. The $186 \mathrm{bp}$ allele at this locus had a repeat motif of $(\mathrm{CA})_{10}$, and the $188 \mathrm{bp}$ allele had a repeat motif of $(\mathrm{CA})_{4} \mathrm{C}(\mathrm{CA})_{2} \mathrm{C}_{9}$. Size homoplasy at this locus has apparently increased the observed frequency of the $184 \mathrm{bp}$ allele.

Table 3.2 Loci characteristics and Hardy-Weinberg equilibrium. The number of alleles observed is represented by $n ; H_{\mathrm{O}}$ and $H_{\mathrm{E}}$ represent observed and expected heterozygosities respectively. In locus Cfor2627, the frequencies of the null allele, indicated by asterisks $\left({ }^{*}\right)$, represent the observed frequencies in homozygotes.

\begin{tabular}{|c|c|c|c|c|c|c|c|c|}
\hline Locus & Population & $n$ & $\begin{array}{c}\text { Allele } \\
\text { Sizes (bp) }\end{array}$ & $\begin{array}{c}\text { Allele } \\
\text { Frequency }\end{array}$ & $H_{0}$ & $H_{\mathrm{E}}$ & $\begin{array}{c}\text { HWE } \\
(P)\end{array}$ & $\begin{array}{c}\text { HWE } \\
\text { (Std.er.) }\end{array}$ \\
\hline \multirow[t]{7}{*}{ Cfor0809 } & Mangere & 4 & 181 & 0.002 & 0.0840 & 0.0886 & 0.4079 & 0.0080 \\
\hline & & & 187 & 0.006 & & & & \\
\hline & & & 191 & 0.954 & & & & \\
\hline & & & 203 & 0.038 & & & & \\
\hline & South-East & 3 & 187 & 0.057 & 0.3714 & 0.3598 & 1.0000 & 0.0000 \\
\hline & & & 191 & 0.786 & & & & \\
\hline & & & 203 & 0.157 & & & & \\
\hline \multirow[t]{12}{*}{ Cfor1415 } & Mangere & 7 & 211 & 0.122 & 0.7560 & 0.7311 & 0.0000 & 0.0000 \\
\hline & & & 213 & 0.118 & & & & \\
\hline & & & 215 & 0.022 & & & & \\
\hline & & & 217 & 0.428 & & & & \\
\hline & & & 221 & 0.050 & & & & \\
\hline & & & 225 & 0.026 & & & & \\
\hline & & & 227 & 0.234 & & & & \\
\hline & South-East & 5 & 211 & 0.429 & 0.7429 & 0.7205 & 0.5761 & 0.0050 \\
\hline & & & 213 & 0.257 & & & & \\
\hline & & & 215 & 0.057 & & & & \\
\hline & & & 221 & 0.171 & & & & \\
\hline & & & 227 & 0.086 & & & & \\
\hline \multirow[t]{4}{*}{ Cfor 1617} & Mangere & 2 & 217 & 0.834 & 0.1000 & 0.2774 & 0.0000 & 0.0000 \\
\hline & & & 225 & 0.166 & & & & \\
\hline & South-East & 2 & 217 & 0.914 & 0.1714 & 0.1590 & 1.0000 & 0.0000 \\
\hline & & & 225 & 0.086 & & & & \\
\hline
\end{tabular}




\begin{tabular}{|c|c|c|c|c|c|c|c|c|}
\hline \multirow[t]{8}{*}{ Cfor1819 } & Mangere & 4 & 176 & 0.018 & 0.4520 & 0.6008 & 0.0000 & 0.0000 \\
\hline & & & 184 & 0.532 & & & & \\
\hline & & & 186 & 0.136 & & & & \\
\hline & & & 188 & 0.314 & & & & \\
\hline & South-East & 4 & 176 & 0.171 & 0.4000 & 0.7317 & 0.0000 & 0.0000 \\
\hline & & & 184 & 0.386 & & & & \\
\hline & & & 186 & 0.186 & & & & \\
\hline & & & 188 & 0.257 & & & & \\
\hline \multirow[t]{3}{*}{ Cfor2021 } & Mangere & 2 & 233 & 0.844 & 0.2640 & 0.2639 & 1.0000 & 0.0000 \\
\hline & & & 239 & 0.156 & & & & \\
\hline & South-East & 1 & 233 & 1.000 & 0.0000 & 0.0000 & - & - \\
\hline \multirow[t]{9}{*}{ Cfor2627 } & Mangere & 5 & 0 & $0.242^{*}$ & 0.3480 & 0.7923 & 0.0000 & 0.0000 \\
\hline & & & 160 & 0.120 & & & & \\
\hline & & & 162 & 0.316 & & & & \\
\hline & & & 170 & 0.152 & & & & \\
\hline & & & 172 & 0.170 & & & & \\
\hline & South-East & 4 & 0 & $0.686^{*}$ & 0.2286 & 0.7354 & 0.0000 & 0.0000 \\
\hline & & & 162 & 0.114 & & & & \\
\hline & & & 170 & 0.086 & & & & \\
\hline & & & 172 & 0.114 & & & & \\
\hline \multirow[t]{5}{*}{ Cfor2829 } & Mangere & 3 & 219 & 0.752 & 0.3840 & 0.4045 & 0.0568 & 0.0020 \\
\hline & & & 221 & 0.120 & & & & \\
\hline & & & 231 & 0.128 & & & & \\
\hline & South-East & 2 & 219 & 0.743 & 0.4571 & 0.3876 & 0.3939 & 0.0014 \\
\hline & & & 221 & 0.257 & & & & \\
\hline \multirow[t]{12}{*}{ Cfor3031 } & Mangere & 7 & 233 & 0.008 & 0.4120 & 0.6543 & 0.0000 & 0.0000 \\
\hline & & & 235 & 0.078 & & & & \\
\hline & & & 237 & 0.438 & & & & \\
\hline & & & 239 & 0.380 & & & & \\
\hline & & & 241 & 0.018 & & & & \\
\hline & & & 245 & 0.014 & & & & \\
\hline & & & 247 & 0.064 & & & & \\
\hline & South-East & 5 & 233 & 0.271 & 0.5429 & 0.6505 & 0.1569 & 0.0045 \\
\hline & & & 235 & 0.129 & & & & \\
\hline & & & 237 & 0.057 & & & & \\
\hline & & & 239 & 0.514 & & & & \\
\hline & & & 241 & 0.029 & & & & \\
\hline
\end{tabular}

Homozygotes for a null allele at Cfor2627 were observed in both populations. The null allele occurred more frequently in the South-East Island population (allele frequency $=0.686$ ) than in the Mangere population (allele frequency $=0.242$ ). Presence of null alleles generates apparently significant shifts in HWE (Pemberton et al. 1995), creating a bias towards increased proportions of homozygotes. The loci Cfor1819 and Cfor2627 were excluded from further population analyses. 


\subsubsection{Mutation Behaviour of Cfor Loci}

The proportion of multi-step mutations $p$, and the likelihood ratio $-2 \log \square$ (Nielsen \& Palsbøll 1999) was estimated for loci Cfor0809, Cfor1415, Cfor1617, Cfor2021, and Cfor3031 (Table 3.3). Because size homoplasy and the presence of null alleles respectively at loci Cfor1819 and Cfor2627 compromise estimation of $p$, the calculations were not run for these two loci. Locus Cfor2829 was also excluded form the analysis because it is a complex microsatellite locus made up of di- and tetra-nucleotide repeat units. In this case, the present design of the software MISAT will assume a tetranucleotide repeat as jumps of two dinucleotide repeats, thus causing biases towards increase in the number of multi-step mutations.

The proportion of multi-step mutations at maximum likelihood of $\square$, calculated by MISAT using the method described in Nielsen (1997), ranged from 0.000 (in Cfor3031) to 0.475 (in Cfor0809 and Cfor1617). For Cfor0809 and Cfor1415, the SMM was rejected in the Mangere Island population, but the model could not be rejected in the South-East Island population at the statistical confidence level of $P=0.05$. The discrepancies between the two populations may be caused by the mixed population structure on Mangere Island, or the incomplete sampling of alleles due to the small sample size from South-East Island. In locus Cfor1617, the proportion of multi-step mutations $(p)$ at maximum likelihood of $\square$ is 0.475 , but the SMM could not be rejected at this locus because there are only two observed alleles, and the differences between the 217 bp and $225 \mathrm{bp}$ alleles could be accounted for by either two steps of tetranucleotide jumps, or one 8 nucleotide mutation. Analyses revealed that Cfor2021 mutates by TPM and Cfor3031 mutates by SMM. The mutational behaviour of microsatellites will be discussed in more detail in the next chapter. 
Table 3.3 Mutation behaviour of Cfor loci. $p$ indicates the proportion of multi-step mutations at $\max L(\square)$.

\begin{tabular}{ccccc}
\hline Locus & Population & $p$ & $-2 \log \square$ & Mutation Model \\
\hline Cfor0809 & Mangere & 0.475 & 7.50 & TPM \\
& South-East & 0.400 & 1.26 & SMM \\
Cfor1415 & Mangere & 0.025 & 14.68 & TPM \\
& South-East & 0.025 & 0.21 & SMM \\
& & & & \\
Cfor1617 & Mangere & 0.475 & 0.99 & SMM \\
& South-East & 0.475 & 0.29 & SMM \\
& & & 3.84 & TPM \\
Cfor2021 & Mangere & 0.475 & - & - \\
& South-East & - & 0.00 & SMM \\
& & & 0.00 & SMM \\
\hline
\end{tabular}

\subsubsection{Genetic Differentiation Between Populations and Bottlenecks}

$\mathrm{F}_{\mathrm{ST}}$ between the Mangere and South-East Islands parakeet population was $0.1225(P=0.0001)$, and $R_{S T}$ was 0.2014. The higher $R_{S T}$ value suggested that the two populations differed slightly more in distribution of allele size than allele frequency (Slatkin 1995). The variance between the two populations was 0.175 ( $P=0.01$; AMOVA). The inbreeding coefficient $F_{I S}$ was 0.1534 , indicating a moderate level of inbreeding in the populations studied.

Results of the bottleneck tests showed that the one tailed "Wilcoxon signrank test" for heterozygosity excess in the Mangere Island parakeet population was not significant under the IAM $(P=0.22)$, SMM $(P=0.78)$, or TPM $(P=0.58)$ models. In the South-East Island parakeet population, the test was also not significant under the IAM $(P=0.05)$, SMM $(P=0.50)$, or TPM $(P=0.41)$ models. The results suggested the absence of a detectable genetic bottleneck in both populations. 


\subsubsection{Bayesian Assignment of Individuals using Microsatellites}

Testing of the NewHybrids software with an Easypop simulated data set of two populations and 285 individuals showed 284 (99.6\%) of the samples were assigned to the correct population with a posterior probability $\geq 0.95$. The remaining individual assigned to the correct population with $P=0.85$. None of the samples was misassigned. When tested with a hypothetical population consisting of parental types, hybrids and various backcrosses, all parental type individuals were assigned a posterior probability of $\geq 0.95$ to their respective classes (Table 3.4). While all hybrids had posterior probabilities $<0.90$ in the parental classes, some backcrosses could be assigned probabilities between 0.88 to 0.91 to the parental classes. Figure 3.2 shows the effects to the final assignment score of 6 chosen parakeet samples by removal of one locus in the NewHybrids assignment test. The assignment of some individuals remained the same regardless of the removal of any locus. However, the removal of Cfor1617 and Cfor3031 caused a shift in assignment in some individuals. It appears that the assignment methodology relies more heavily on loci that show large differences in genotypes between the two parental types. Increasing the number of loci used in assignments would certainly help in increasing the accuracy and power, but this would be difficult in parrots as it appears difficult to isolate a larger number of microsatellite loci from parrot species (Hughes et al. 1998; Robertson et al. 2000; Russello et al. 2001; Caparroz et al. 2003; Sainsbury et al. 2004).

Parakeets in the Mangere Island and South-East Island populations were scored according to their posterior probabilities in either parental classes (Appendix 3.2; Table 3.5). Birds with $P$ (Forbes') $\geq 0.95$ were given a score of MS1 (Forbes' parakeet; 67 birds, 23.5\%), those with $P($ Redcrowned) $\geq 0.95$ were given a score of MS3 (Red-crowned parakeet; 25 birds, $8.8 \%$ ), all other birds which did not fit either criteria were assigned a score of MS2 (hybrids or unassigned; 193 birds, 67.7\%). At present, the 
programme does not have the ability to distinguish unassigned birds from hybrids. The Mangere Island parakeet population contained birds of all three types (67 Forbes' parakeets; 171 hybrids; 12 Chatham Island Redcrowned parakeets). The South-East Island population was solely made up of Chatham Island Red-crowned parakeets and hybrids (13 Chatham Island Red-crowned parakeets; 22 hybrids).

The assignment results based on multi-locus microsatellite genotypes were compared to data from mitochondrial control region and morphological studies (Appendix 3.2).

Table 3.4 Posterior probabilities of NewHybrids assignment in a hypothetical population of 20 individuals consisting of parents $A$ and $B, F_{1}$ and $F_{2}$ hybrids, $F_{1} \times$ parent $A$ and $F_{1} \times B$ backcrosses, with genotypic classes described in Table 3.1. $P$ refers to the probability of being assigned into a genotypic class.

\begin{tabular}{ccccc}
\hline Genotypic Class & $P(\mathrm{~A})$ & $P(\mathrm{~B})$ & $P\left(\mathrm{~F}_{1}\right)$ & $P\left(\mathrm{~F}_{2}\right)$ \\
\hline Parent A & 0.9970 & 0.0000 & 0.0002 & 0.0028 \\
Parent A & 0.9965 & 0.0000 & 0.0002 & 0.0033 \\
Parent A & 0.9976 & 0.0000 & 0.0001 & 0.0023 \\
Parent B & 0.0000 & 0.9979 & 0.0001 & 0.0020 \\
Parent B & 0.0000 & 0.9988 & 0.0001 & 0.0011 \\
Parent B & 0.0000 & 0.9964 & 0.0002 & 0.0034 \\
$\mathrm{~F}_{1}$ Hybrid & 0.0001 & 0.0147 & 0.9048 & 0.0804 \\
$\mathrm{~F}_{1}$ Hybrid & 0.0047 & 0.0005 & 0.9230 & 0.0718 \\
$\mathrm{~F}_{2}$ Hybrid & 0.0039 & 0.8953 & 0.0041 & 0.0967 \\
$\mathrm{~F}_{2}$ Hybrid & 0.0005 & 0.0004 & 0.8850 & 0.1141 \\
$\mathrm{~F}_{2}$ Hybrid & 0.8005 & 0.0033 & 0.0080 & 0.1882 \\
$\mathrm{~F}_{2}$ Hybrid & 0.0049 & 0.7415 & 0.0913 & 0.1623 \\
$\mathrm{~F}_{2}$ Hybrid & 0.0017 & 0.0000 & 0.7992 & 0.1991 \\
$\mathrm{~F}_{2}$ Hybrid & 0.8595 & 0.0039 & 0.0133 & 0.1233 \\
$\mathrm{~F}_{1} \times$ A Backcross & 0.0386 & 0.0007 & 0.7131 & 0.2476 \\
$\mathrm{~F}_{1} \times$ A Backcross & 0.8950 & 0.0000 & 0.0225 & 0.0825 \\
$\mathrm{~F}_{1} \times$ A Backcross & 0.0172 & 0.3741 & 0.4600 & 0.1487 \\
$\mathrm{~F}_{1} \times$ B Backcross & 0.0000 & 0.8812 & 0.0388 & 0.8000 \\
$\mathrm{~F}_{1} \times$ B Backcross & 0.0003 & 0.0056 & 0.8849 & 0.1092 \\
$\mathrm{~F}_{1} \times$ B Backcross & 0.0017 & 0.9148 & 0.0033 & 0.0802 \\
\hline
\end{tabular}


Figure 3.2 Contribution of individual locus to the final Bayesian assignment probabilities in 6 chosen samples. $P(F B)$ refers to the probability of assignment as a pure Forbes' parakeet.

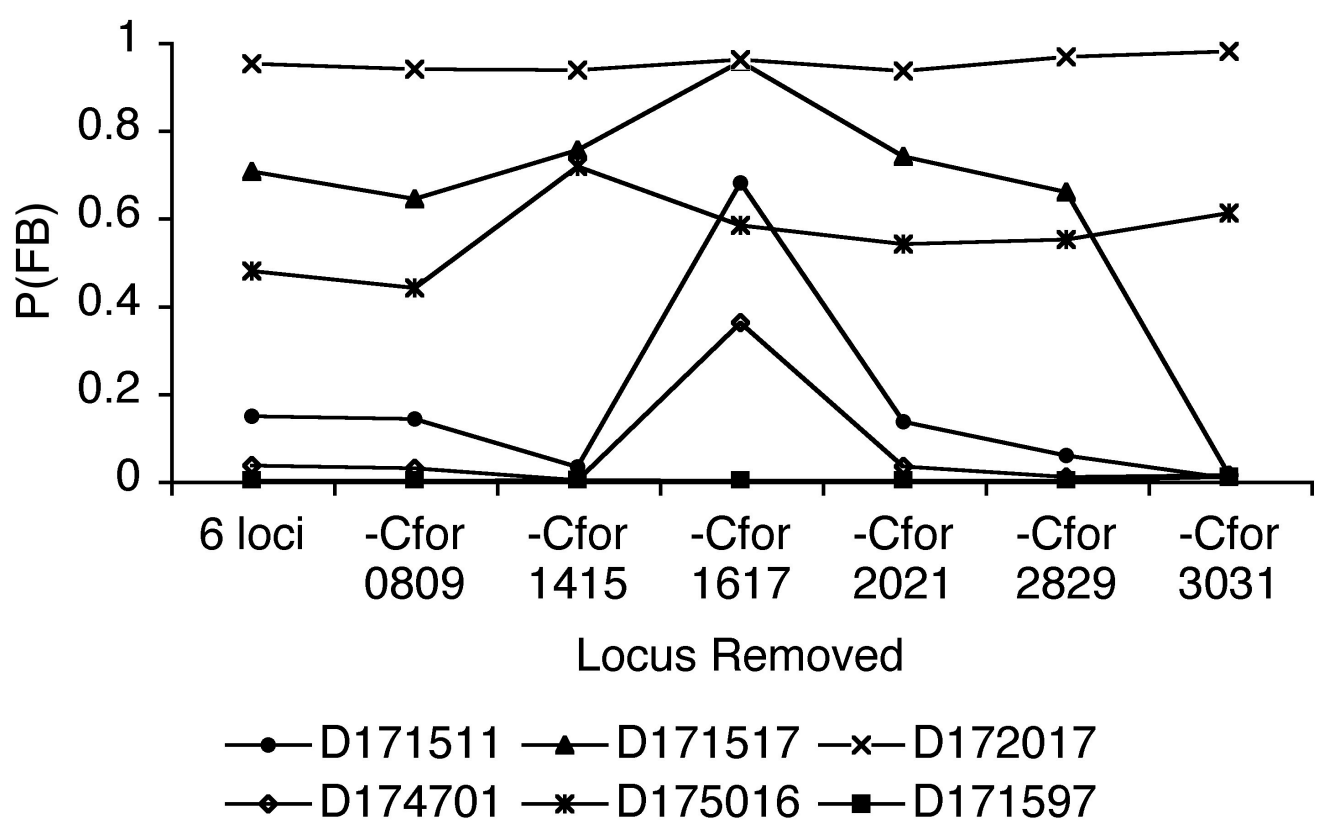

The pure Forbes' parakeets could be defined as birds with microsatellite (NewHybrids) assignment score MS1, mitochondrial haplogroup MT3, and morphological score MP1. Birds with microsatellite assignment score MS3, mitochondrial haplogroup MT4, and morphological score MP5 were classified as Chatham Island Red-crowned parakeets. All other birds were assigned as hybrids.

Among the 285 samples screened with microsatellites in this study, 203 (169 from Mangere Island, and 34 from South-East Island) also had data available on both mitochondrial haplotypes and morphological groups. On Mangere Island, pure Forbes' parakeets made up 30 (17.8\%) of the 169 birds, $2(1.2 \%)$ were pure Chatham Island Red-crowned parakeets and 
137 (81.0\%) were hybrids or unassigned birds. On South-East Island, 12 $(35.3 \%)$ of the 34 birds were pure Chatham Island Red-crowned parakeets, and $22(64.7 \%)$ were hybrids or unassigned birds.

Table 3.5 Classification of parakeets using genotypic and phenotypic markers.

\begin{tabular}{lcl}
\hline Type of Marker & Classes & Description \\
\hline Microsatellites & MS1 & Pure Forbes' parakeet \\
& MS2 & $\begin{array}{l}\text { Hybrids or unassigned } \\
\text { Pure Chatham Island Red-crowned parakeet }\end{array}$ \\
Mitochondrial DNA & MT1 & Hybrid (haplogroup 1) \\
& MT2 & Hybrid (haplogroup 2) \\
& MT3 & Pure Forbes' parakeet \\
& MT4 & Pure Chatham Island Red-crowned parakeet \\
& MP1 & Pure Forbes' parakeet \\
Crown Plumage & MP2 & Hybrids (appearance like Forbes' parakeet) \\
& MP3 & Hybrids \\
& MP4 & Hybrids (appearance like Chatham Island Red-crowned parakeet) \\
& MP5 & Pure Chatham Island Red-crowned parakeet \\
\hline
\end{tabular}

\subsubsection{Genetic Distances Analysis}

Principal Coordinate Analysis of a $203 \times 203$ distance matrix based on the proportion of shared microsatellite alleles allowed graphical comparison between microsatellite assignment and assignment based on both genetic and morphological variables (Figure 3.3). Axis PCO 1 represented $31.5 \%$ of the total variation, while axis PCO 2 represented $21.1 \%$ of the variation. Cumulatively, $52.6 \%$ of the total variability is represented by the two axes. While Chatham Island Red-crowned parakeets cluster as a group to the right of the plot, Forbes' parakeets are more spread out. A large swarm of hybrid or unresolved individuals was scattered mainly towards the Forbes' parakeet side and the centre of the plot. This suggested that a number of birds that were similar to Forbes' parakeet (in terms of microsatellite alleles frequencies) had a hybridisation history detectable by mitochondrial haplotypes or crown plumage. 
Figure 3.3 Principal Coordinate Analysis of genetic distance based on proportion of shared microsatellite alleles. A cumulative $52.6 \%$ of total variation was represented by the two PCO axes. Birds were separated into three categories (Forbes' parakeets, Hybrids, and Red-crowned parakeets) based on assignment using genetic and morphological data.

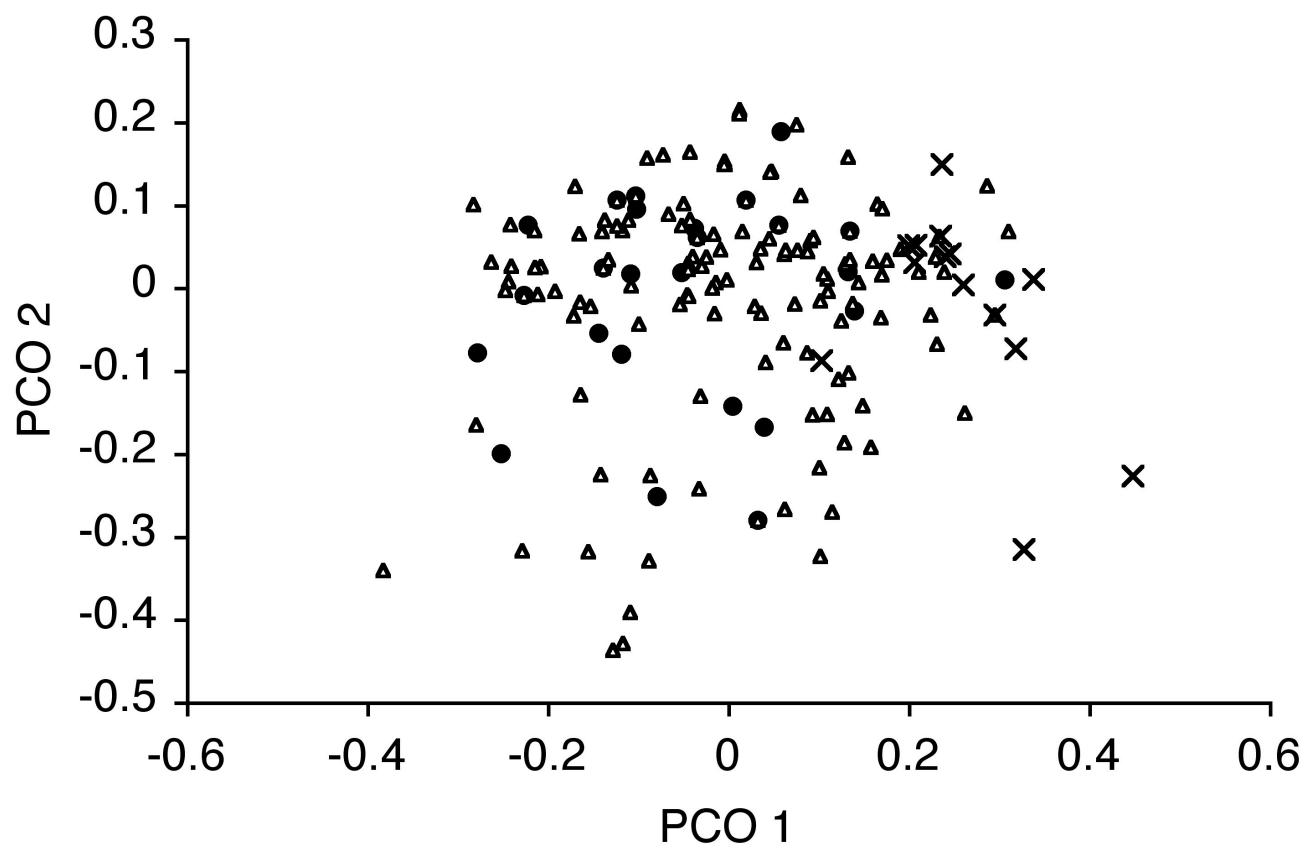

- Forbes' Parakeet $\Delta$ Hybrids $\times$ Red-crowned Parakeet

A neighbour-joining consensus tree constructed from $285 \times 285\left(\square[)^{2}\right.$ matrices of genetic distance between individuals showed that the majority of birds were clustered into a group that originated from about the same point (Figure 3.4). A clear branch was observed which contained mostly Forbes' parakeets (classified using the three available genetic and morphological variables), some unknown Mangere Island parakeets (with mtDNA and / or morphological data missing), and three hybrids or unresolved birds. The pattern of the tree suggested birds which are classified as Forbes' parakeets can be a very variable group genetically, with some individuals very close to Chatham Island Red-crowned 
parakeets and hybrids, while some individuals are more distantly related to all other birds.

Figure 3.4 Neighbour-joining tree built from $(\square \square)^{2}$ genetic distances with 100 bootstraps. F, R, and H represent respectively pure Forbes' parakeet, pure Chatham Island Red-crowned parakeet, and hybrids or unresolved birds; $\mathrm{M}$ and $\mathrm{S}$ respectively represent Mangere Island and South-East Island parakeets with no mitochondrial DNA and / or morphological data available.

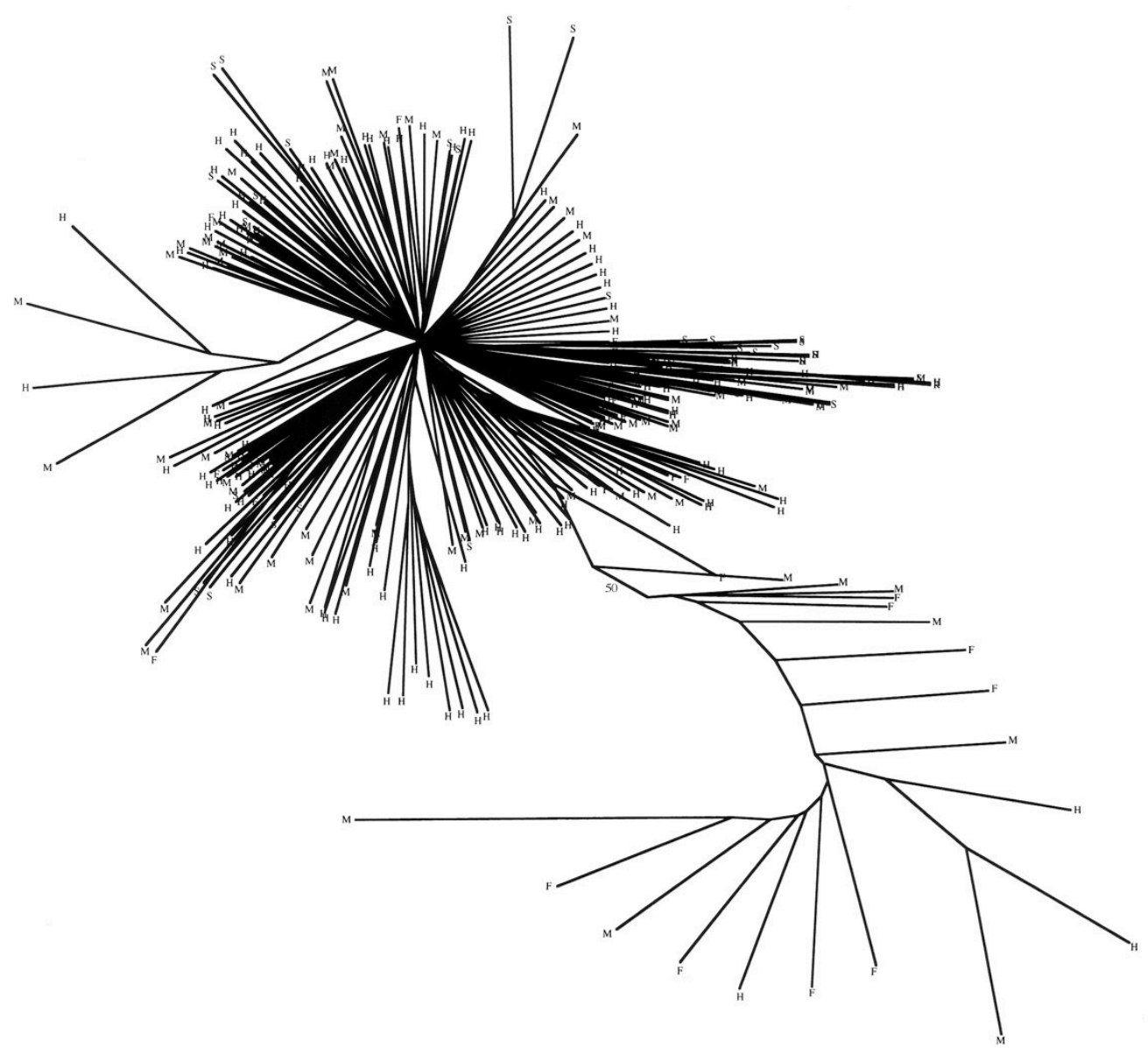

The data also showed discrepancies between Bayesian and distancebased methods for assignment. However, results from both methods 
suggested there had been extensive hybridisation in the Mangere Island parakeet population.

\subsubsection{Relationships Between Genetic and Morphological Variables}

Looking at the 203 samples for which there are data available of all three variables, pairwise comparisons of the variables were made in Table 3.6.

Comparing between microsatellite assignments (MS) and mitochondrial DNA control region haplogroups (MT; Table 3.6a), birds assigned MS1 were largely MT3 individuals. While MS2 birds could have quite variable MT assignments, MS3 birds were mainly MT4 individuals. This indicated that hybridisations that took place in the past have led to extensive genetic mixing between the two species. The existence of MS1 + MT3 individuals suggested that some genetically pure or near-pure Forbes' parakeets still remain in the Mangere Island population. Because the MS2 category consist of individuals which were either hybrids or individuals which were unable to be assigned in the NewHybrid assignment test, it is difficult to precisely determine the relationship between this class of birds and other variables.

Between microsatellite assignment (MS) and crown morphology (MP; Table 3.6b), it is clear that MS1 birds are largely MP1 (with clear Forbes' parakeet crown), and MS3 birds are mostly MP5 (red-crowned). The majority of MS2 birds also have clear Forbes' parakeet crown morphology, indicating the presence of a large number of cryptic hybrids which look like Forbes' parakeets.

Less clear relationships were observed between mitochondrial DNA (MT) and crown morphology (MP; Table 3.6c). MP5 (red-crowned) birds belong to either MT2 or MT4, while most MP1 (Forbes' parakeet crown) birds are 
MT3. Existence of 9 birds with MP1 and MT4 clearly showed hybridisation has taken place between female Chatham Island Red-crowned parakeets and male Forbes' parakeets. The presence of a number of birds with MT3 lineage and MP3 or MP4 crown morphology suggests male Chatham Island Red-crowned parakeets also hybridise with female Forbes' parakeets.

Table 3.6 Relationship between variables analysed by number of individuals in each category (indicated by numbers in brackets). a) microsatellites versus mitochondrial haplotypes; b) microsatellites versus morphology; c) mitochondrial haplotypes versus morphology.

\begin{tabular}{ccccc}
\hline a) & Microsatellites & \multicolumn{4}{c}{ Mitochondrial haplotypes } \\
\cline { 2 - 5 } & MT1 (21) & MT2 (22) & MT3 (112) & MT4 (48) \\
\hline MS1 (43) & 3 & 4 & 32 & 4 \\
MS2 (140) & 16 & 16 & 78 & 30 \\
MS3 (20) & 2 & 2 & 2 & 14 \\
\hline
\end{tabular}

\begin{tabular}{cccccc}
\hline b) & Microsatellites & \multicolumn{5}{c}{ Morphology scores } \\
\cline { 2 - 6 } & MP1 (136) & MP2 (10) & MP3 (11) & MP4 (9) & MP5 (37) \\
\hline MS1 (43) & 38 & 2 & 3 & 0 & 0 \\
MS2 (140) & 97 & 8 & 7 & 6 & 22 \\
MS3 (20) & 1 & 0 & 1 & 3 & 15 \\
\hline
\end{tabular}

\begin{tabular}{cccccc}
\hline c) & Mitochondrial & \multicolumn{5}{c}{ Morphology scores } \\
\cline { 2 - 5 } haplotypes & MP1 (136) & MP2 (10) & MP3 (11) & MP4 (9) & MP5 (37) \\
\hline MT1 (21) & 20 & 0 & 0 & 1 & 0 \\
MT2 (22) & 11 & 2 & 2 & 2 & 5 \\
MT3 (112) & 96 & 8 & 7 & 1 & 0 \\
MT4 (48) & 9 & 0 & 2 & 5 & 32 \\
\hline
\end{tabular}

Comparing crown morphology with the combined genetic data of microsatellites and mitochondrial DNA (Table 3.7), it is clear that the majority of genetic Forbes' parakeets have a clear Forbes' parakeet morphology (MP1). A hybrid, on the other hand, can display variable crown morphology which can be very similar to, or intermediate between, the parent species. 
Correlations among the three variables were also analysed with Multiple Correspondence Analysis (Figure 3.5). The first two axes of MCA represented a cumulative $37.1 \%$ of the variation between the three variables. The $x$-axis sampled $24.1 \%$ of the total variation between the three variables, and the $y$-axis sampled $13.0 \%$. The scatter plot showed correlation between Red-crowned parameters (microsatellites class MS3, mitochondrial haplogroup MT4, morphological scales MP4 and MP5), as well as close associations between Forbes' parakeet genetic characters MS1 and MT3. However, Forbes' parakeet crown plumage MP1 is almost equally distant from MS1 and MS2. The results suggest that crown plumage is a reasonably good indicator of "Red-crownedness", but birds with Forbes' parakeet crown patterns are as likely to be hybrids as to be pure Forbes' parakeets.

Table 3.7 Relationship between genotype and crown morphology. The number of individuals in each category is indicated by numbers in brackets. a) Mangere Island population; b) South-East Island population.

\begin{tabular}{cccccc}
\hline a) & \multicolumn{5}{c}{ Morphology scores } \\
\cline { 2 - 6 } & MP1 (136) & MP2 (10) & MP3 (11) & MP4 (9) & MP5 (3) \\
\hline Forbes' & 30 & 1 & 2 & 0 & 0 \\
$\begin{array}{c}\text { (MS1 + MT3; 33) } \\
\text { Red-crowned }\end{array}$ & 0 & 0 & 0 & 0 & 2 \\
$\begin{array}{c}\text { (MS3 + MT4; 2) } \\
\text { Hybrids }\end{array}$ & 106 & 9 & 9 & 9 & 1 \\
(all others; 134) & & & & & \\
\hline
\end{tabular}

\begin{tabular}{cccccc}
\hline b) Genotype & \multicolumn{5}{c}{ Morphology scores } \\
\cline { 2 - 6 } & MP1 (0) & MP2 (0) & MP3 (0) & MP4 (0) & MP5 (34) \\
\hline Forbes' & 0 & 0 & 0 & 0 & 0 \\
(MS1 + MT3; 0) & 0 & 0 & 0 & 0 & 12 \\
$\begin{array}{c}\text { Red-crowned } \\
\text { (MS3 + MT4; 12) }\end{array} \quad \begin{array}{c}\text { Hybrids } \\
\text { (all others; 22) }\end{array}$ & 0 & 0 & 0 & 0 & 22 \\
\hline
\end{tabular}


Figure 3.5 Multiple Correspondence Analysis of genetic and morphological variables. The ellipses, from the centre, represented 50 , 70,90 , and $99 \%$ of samples. MS, MT and MP abbreviated respectively for microsatellites, mitochondrial control region, and morphology. The number after the marker types corresponded to the classification using that marker (Table 3.5).

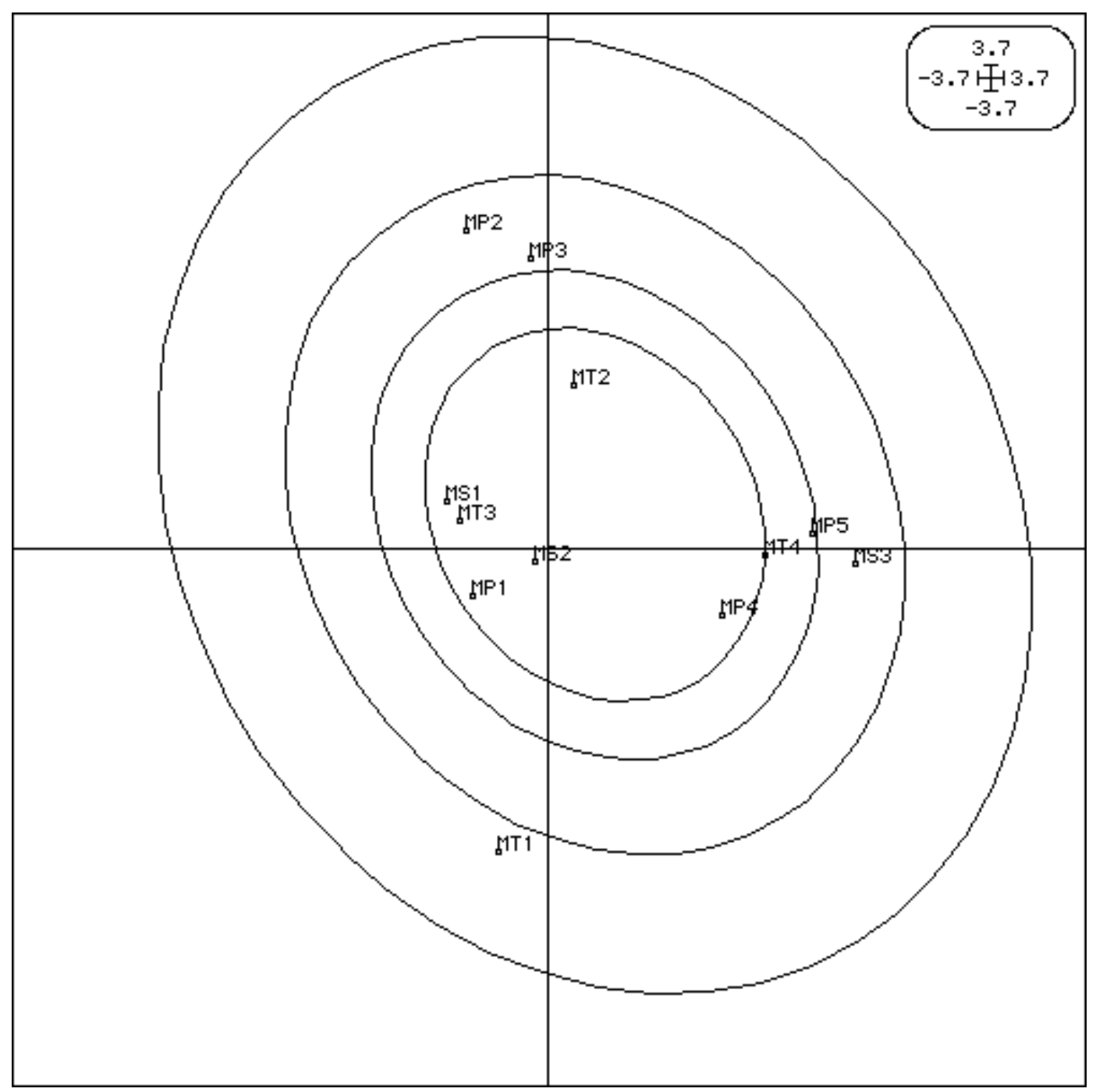

\subsection{Discussion}

\subsubsection{Identification of "Pure" Forbes' Parakeets}

Using microsatellites and mitochondrial DNA genetic markers, a large proportion $(77.9 \%)$ of phenotypic Forbes' parakeets were found to be 
cryptic hybrids. To supplement the previous identification scheme based solely on morphological features, a new system has been developed in this study using nuclear and mitochondrial genetic markers and crown morphology to identify "pure" or near-"pure" Forbes' parakeets. A "pure" Forbes' parakeet needs to satisfy three criteria: 1) being assigned as Forbes' parakeet using microsatellite markers in the NewHybrids assignment (MS1); 2) having mitochondrial control region haplotype 3 (MT3; Boon et al. 2001); and 3) showing a clear Forbes' parakeet crown morphology (MP1; Nixon 1982). Any bird that fails one of these tests is likely to be the progeny of hybridisation between Chatham Island Redcrowned parakeet or other hybrids or backcrosses.

Analyses of microsatellite data with both Bayesian and genetic distance methods have shown extensive interspecific hybridisation in the Mangere Island parakeet population. Calculations of $\mathrm{F}_{\mathrm{ST}}$ and $\mathrm{R}_{\mathrm{ST}}$ showed that there was a clear genetic differentiation in the Mangere and South-East Islands populations, and suggested differences in genetic makeup of these two populations.

$F_{S T}$ and $R_{S T}$ often differ substantially, and there is no clear consensus over their relative accuracy (Balloux \& Lugon-Moulin 2002). Under a strict stepwise mutation model, no statistic was found to be best overall, and the level of differentiation and gene flow determines whether $F_{S T}$ or $R_{S T}$ performed better (Balloux \& Goudet 2002). Although some studies comparing microsatellites with other markers did not detect strong discrepancies in estimating population genetic structure (Barker et al. 1997; Estoup et al. 1998; Lynch et al. 1999; Ross et al. 1999) there were also possibilities of underestimating divergence between populations when highly polymorphic genetic markers, such as microsatellites, were used in the analysis (Nauta \& Weissing 1996; Hedrick 1999; Balloux et al. 2000). Despite the issues raised concerning the accuracy of assessing population 
differentiation using microsatellites, $F_{\mathrm{ST}}$ remains a reasonable basic descriptor of population structure (Neigel 2002; Pearse \& Crandall 2004).

3.4.2 Interspecific Hybridisation in the Mangere Island Parakeet Population

Cyanoramphus is a relatively recently evolved group (Boon et al. 2001), and the possible lack of reproductive isolation between its taxa promotes the possibility of hybridisation (Bigelow 1965; Prager \& Wilson 1975; Grant \& Grant 1992). Little is known about the genetic basis of post-mating isolation mechanisms in birds, such as factors that affect viability and fertility of hybrid embryos (Grant \& Grant 1997). Information about premating barriers, such as morphological and behavioural differences between the two species of parakeets, is also very limited. The abundance of hybrids seen here suggests that pre-mating isolation may be non-existant between the two parakeet species.

The existence of "pure" and near-"pure" Forbes' parakeet types in the population suggests that hybridisation in the past has not driven Forbes' parakeets to complete extinction. Instead, hybridisation may have helped the Mangere Island population survive a severe bottleneck in the past, possibly induced by habitat clearance. However, the presence of a large number of individuals with intermediate genotypes indicated that hybridisation is acting to gradually bring the genetics of the parent species to an intermediate form, and the genetic introgression from Chatham Island Red-crowned parakeets may cause a slow and protracted extinction of Forbes' parakeets. 


\subsubsection{Characteristics of Cfor Loci}

Linkage disequilibrium was detected between Cfor0809 and Cfor2829, and between Cfor1415 and Cfor2829 in the Mangere Island parakeet population. However, linkage disequilibrium was not detected in SouthEast Island samples, mainland Red-crowned parakeets ( $C$. novaezelandiae novaezelandiae) or Yellow-crowned parakeets ( $C$. auriceps; see Chapter 5). Therefore, it is unlikely that these loci are actually physically linked on the same chromosomes. The linkage disequilibrium observed in the Mangere Island samples may be caused by the mixed population structure. It is also worth noting that the power to detect linkage disequilibria is correlated with heterozygosity, and greater heterozygosity generally results in greater power in the estimation (Ott \& Rabinowitz 1997). The relatively low heterozygosities of loci Cfor0809 and Cfor2829 in the Mangere Island population (see Table 3.2) suggest a limited power in the estimation of linkage disequilibria involving these loci.

A large proportion of birds from the South-East Island population were found to be homozygotes for a non-amplifying allele, or null allele, at locus Cfor2627. The occurrence of null alleles may be explained by a large deletion in the locus, or small regions of deletion or nucleotide substitution mutations at the primer annealing sites (Callen et al. 1993). Two sets of primers were designed for Cfor2627. In addition to primers CS126 and CS127 (Table 2.1), primers CS026 (5' AGTTCTTTCCCTGCTGCTAC 3') and CS027 (5' ATGTGCCTGGTGATTTTTGA 3') were designed which were 23 bases and 16 bases towards the 3'-end of CS126 and CS127 respectively (see Chapter 2, Appendix 2.1). In birds which primers CS126 and CS127 failed to amplify the locus Cfor2627, amplifications with primers CS026 and CS027, CS026 and CS127, CS126 and CS027 also failed. All samples which failed to amplify at locus Cfor2627 produced PCR products at all other loci (Appendix 3.1), suggesting that errors in the PCR, such as insufficient starting DNA template, were unlikely. The null 
allele at Cfor2627 was mostly likely to be caused by a large mutation or deletion at the flanking region of the microsatellite, perhaps even deletion of the entire locus. Null alleles could be a tool to investigate the evolutionary constraints on microsatellite loci if alternative primers were available to amplify the allele, and the cause of the non-amplification could be deduced (Lehmann et al. 1996). However, attempts in obtaining sequences from Cfor2627 null alleles have so far been unsuccessful.

Because detection of null alleles in heterozygotes is difficult, loci with null alleles generally show an artefactually higher than expected number of homozygotes. Null alleles can create confusions in population studies, especially in linkage or parentage work (Koorey et al. 1993; Pemberton et al. 1995), thus these loci were not included in further population analyses in this study. A software package, Microchecker, has been developed to estimate the frequency of null alleles and subsequently adjusts allele genotype frequencies of the amplified alleles, permitting their use in some further population analyses (van Oosterhout et al. 2004). However, since this study involved assignment of individuals based on their allelic profiles, such adjustments of allele genotypes may be unsuitable, and the conservative approach of not including the Cfor2627 locus was employed.

Size homoplasy (reviewed in Estoup et al. 2002) refers to microsatellite alleles that are identical in state (i.e. those having identical size), but may not be identical by decent. Homoplasy is a commonly observed phenomenon in molecular evolution, occuring in both allozymes (Coyne et al. 1979) and DNA sequences (Hassanin et al. 1998), and could be widespread at microsatellite loci (for example, van Oppen et al. 2000; Culver et al. 2001; Chambers \& MacAvoy 2004). Size homoplasy in microsatellite data causes reduced observed number of alleles, heterozygosities and gene diversity, and thus could lead to larger than expected numbers of homozygotes in genetic analyses. 


\subsubsection{Accuracy of Assignment Test}

The power and resolution of assignment tests are dependent on the methods used and the number of loci included in the analysis. The relationship between the power to identify different hybrid classes and the number of loci used has been modelled for molecular markers, such as restriction fragment length polymorphisms (RFLP), randomly amplified polymorphic DNA (RAPD), and protein electrophoresis (Boecklen \& Howard 1997). These authors suggested as few as four or five markers should be sufficient to classify individuals into parental, $F_{1}$ hybrids, and simple backcross categories. However, to distinguish more complex classes of backcrosses, upwards of 50 markers would be required (Floate et al. 1994; Boecklen \& Howard 1997). Using 6 loci, the probability of misclassifying a first generation backcross as a parental species was 0.03 , but the probability of misassigning a fifth generation backcross as a parent species could be as high as 0.83 (Boecklen \& Howard 1997). The model also suggested an individual's genotype and allele frequencies would be very similar to the parent species after generations of backcrossing.

Using simulation methods, Cornuet et al. (1999) showed that the mutational process of microsatellites played an important role in determining the efficiency of assignment methods. In a study comparing highly variable microsatellite markers with moderately variable allozymes (Estoup et al. 1998), higher assignment scores were obtained using more variable microsatellite markers.

Bayesian and genetic distance based assignment tests are the most commonly used methods for assigning individuals to populations using microsatellite genotypic data. The accuracy of the two methods varies with genetic differentiation between populations (Cornuet et al. 1999). With 6 loci and at $\mathrm{F}_{\mathrm{ST}}=0.1$, a Bayesian method can result in 70\% (Cornuet et al. 1999) to $97 \%$ (Berry et al. 2004) correct assignment. In comparison, 
genetic distance-based methods using shared allele distance (Bowcock et al. 1994) and $(\square)^{2}$ distance (Goldstein et al. 1995) would give $65 \%$ and $25 \%$ accurate assignment respectively (Cornuet et al. 1999). Discrepancies between Bayesian and distance-based methods could explain the observation that some Forbes' parakeets (assigned by the Bayesian method, mitochondrial control region, and crown plumage) appear in the Chatham Island Red-crowned parakeet cluster in Figures 3.3 and 3.4. On the other hand, existence of a large number of hybrids in the analyses using distance-based methods (Figures 3.3 and 3.4) suggested that a large proportion of MS2 (hybrids or unresolved) category parakeets in the NewHybrids assignment are actual hybrids. A survey by Choisy et al. (2004) of various assignment methods (gene identities, least square regression, private alleles, maximum likelihood, coalescence times, and Monte Carlo Markov chain) showed that, while all methods performed well in populations with recent hybridisation and high differentiation between parental populations, a Monte Carlo Markov chain method (such as NewHybrids) performed better than other methods under more restricted (marginal admixture) proportions and with low differentiation of parental populations, and hence it is more robust.

Another consideration is the nature of the samples collected. The Mangere Island samples came from a mixed population with overlapping generations. There exists a major problem in defining "pure" Forbes' parakeet genotypes, leading to a reduced accuracy of assignment tests.

In summary, through analyses of microsatellite, mitochondrial DNA and morphology data, a new and improved system has been developed to identify Forbes' parakeets, hybrid parakeets and Chatham Island Redcrowned parakeets in the Chatham Islands. Although Forbes' parakeets have hybridised extensively with Chatham Island Red-crowned parakeets, 
the ability to identify existing "pure" or near-"pure" Forbes' parakeets will certainly assist the future conservation of this species.

\subsection{References}

Anderson E, Stebbins GL Jr (1954) Hybridization as an evolutionary stimulus. Evolution, 8, $378-388$.

Anderson EC, Thompson EA (2002) A model-based method for identifying species hybrids using multilocus genetic data. Genetics, 160, $1217-$ 1229.

Anderson MJ (2003) PCO: a FORTRAN computer program for principal coordinate analysis. Department of Statistics, University of Auckland, New Zealand.

Arnold ML, Hodges SA (1995) Are natural hybrids fit or unfit relative to their parents? TREE, 10, 67-71.

Ballantyne KN, Chan C-H, Chambers GK (2004) A PCR-RFLP based method for assigning mitochondrial control region haplogroups in hybridizing Chatham Islands Cyanoramphus parakeets. New Zealand Natural Sciences, 29, 33 - 38.

Balloux F (2001) EASYPOP (version 1.7): a computer program for population genetics simulations. J. Hered., 92, $301-302$.

Balloux F, Goudet J (2002) Statistical properties of population differentiation estimators under stepwise mutation in a finite island model. Molecular Ecology, 11, 771 - 783. 
Balloux F, Lugon-Moulin N (2002) The estimation of population differentiation with microsatellite markers. Molecular Ecology, 11, 155 165.

Balloux F, Brünner H, Lugon-Moulin N, Hausser J, Goudet J (2000) Microsatellites can be misleading: an empirical and simulation study. Evolution, 54, 1414 - 1422.

Barker JSF, Moore SS, Hetzel DJS, Evans D, Tan SG, Byrne K (1997) Genetic diversity of Asian water buffalo (Bubalus bubalus): microsatellite variation and a comparison with protein-coding loci. Animal Genetics, 28, $103-115$.

Barton NH (2001) The role of hybridization in evolution. Molecular Ecology, 10, $551-568$.

Barton NH, Hewitt GM (1985) Analysis of hybrid zones. Ann. Rev. Ecol. Syst., 16, $113-148$.

Berry O, Tocher MD, Sarre SD (2004) Can assignment tests measure dispersal? Molecular Ecology, 13, 551-561.

Bigelow RS (1965) Hybrid zones and reproductive isolation. Evolution, 19, $449-458$.

Boecklen WJ, Howard DJ (1997) Genetic analysis of hybrid zones: number of markers and power of resolution. Ecology, 78, 2611-2616.

Boon WM, Kearvell JC, Daugherty CH, Chambers GK (2001) Molecular systematics and conservation of kakariki (Cyanoramphus spp.): Science for Conservation 176. Department of Conservation, Wellington. 
Bowcock AM, Ruiz-Linares A, Tomfohrde J, Minch E, Kidd JR, CavalliSforza LL (1994) High resolution of human evolutionary trees with polymorphic microsatellites. Nature, $\mathbf{3 6 8}, 455-457$.

Callen DF, Thompson AD, Shen Y, Phillips H, Richards RI, Mulley JC, Sutherland GR (1993) Incidence and origin of 'null' alleles in the (AC) microsatellite markers. Am. J. Hum. Genet., 52, $922-927$.

Caparroz R, Miyaki CY, Baker AJ (2003) Characterization of microsatellite loci in the Blue-and-gold Macaw, Ara ararauna (Psittaciformes: Aves). Molecular Ecology Notes, 3, 441 - 443.

Chambers GK, MacAvoy ES (2004) The mutational dynamics and evolution of DNA microsatellites. In: Dynamical Genetics (eds. Parisi V, De Fonzo V, Aluffi-Pentini F), pp. 133 - 152. Research Signpost, Kerala.

Choisy M, Franck P, Cornuet JM (2004) Estimating admixture proportions with microsatellites: comparison of methods based on simulated data. Molecular Ecology, 13, 955 - 968.

Cornuet JM, Luikart G (1996) Description and power analysis of two tests for detecting recent population bottlenecks from allele frequency data. Genetics, 144, $2001-2014$.

Cornuet JM, Piry S, Luikart G, Estoup A, Solignac M (1999) New methods employing multilocus genotypes to select or exclude populations as origins of individuals. Genetics, 153, $1989-2000$.

Coyne JA, Eanes WF, Lewontin RC (1979) The genetics of electrophoretic variation. Genetics, 92, $353-356$. 
Culver M, Menotti-Raymond MA, O'Brien SJ (2001) Patterns of size homoplasy at 10 microsatellite loci in pumas (Puma concolor). Mol. Biol. Evol., 18, 1151 - 1156.

Di Rienzo A, Peterson AC, Garza JC, Valdes AM, Slatkin M, Freimer NB (1994) Mutational processes of simple-sequence repeat loci in human populations. Proc. Natl. Acad. Sci. USA, 91, $3166-3170$.

Dieringer D, Schlötterer C (2002) Microsatellite analyser (MSA): a platform independent analysis tool for large microsatellite data sets. Molecular Ecology Notes, 3, 167 - 169.

Dowling TE, Secor CL (1997) The role of hybridization and introgression in the diversification of animals. Annu. Rev. Ecol. Syst., 28, 593-619.

Dyer R, Sork VL (2001) Pollen pool heterogeneity in shortleaf pine, Pinus echinata Mill. Molecular Ecology, 10, 859 - 866.

Estoup A, Rousset F, Michalakis Y, Cornuet JM, Adriamanga M, Guyomard R (1998) Comparative analysis of microsatellite and allozyme markers: a case study investigating microgeographic differentiation in brown trout (Salmo trutta). Molecular Ecology, 7, 339 - 353.

Estoup A, Jarne P, Cornuet JM (2002) Homoplasy and mutation model at microsatellite loci and their consequences for population genetics analysis. Molecular Ecology, 11, 1591 - 1604.

Excoffier L, Smouse PE, Quattro JM (1992) Analysis of molecular variance inferred from metric distances among DNA haplotypes: application to human mitochondrial DNA restriction data. Genetics, 131, $479-491$. 
Felsenstein J (1989) PHYLIP - phylogeny inference package (version 3.2). Cladistics, 5, $164-166$.

Floate KD, Whitham TG, Keim P (1994) Morphological versus genetic markers in classifying hybrid plants. Evolution, 48, 929-930.

Goldstein DB, Ruiz Linares A, Cavalli-Sforza LL, Feldman MW (1995) Genetic absolute dating based on microsatellites and the origin of modern humans. Proc. Natl. Acad. Sci. USA, 92, $6723-6727$.

Gower JC (1966) Some distance properties of latent root and vector methods used in multivariate analysis. Biometrika, 53, 325-338.

Grant PR, Grant BR (1992) Hybridization of bird species. Science, 256, $193-197$.

Grant PR, Grant BR (1997) Genetics and the origin of bird species. Proc. Natl. Acad. Sci. USA, 94, $7768-7775$.

Guo SW, Thompson EA (1992) Performing the exact test of HardyWeinberg proportions for multiple alleles. Biometrics, 48, 361-372.

Hassanin A, Lecointre G, Tillier S (1998) The 'evolutionary signal' of homoplasy in protein-coding gene sequences and its consequences for a priori weighting in phylogeny. C. R. Acad. Sci. III., 321, 611-620.

Hedrick PW (1999) Highly variable loci and their interpretation in evolution and conservation. Evolution, 53, 313-318. 
Hughes CR, Melland RR, Beissinger SR (1998) Polymorphic trinucleotide microsatellite loci for a neotropical parrot, the green-rumped parrotlet, Forpus passerinus. Molecular Ecology, 7, 1247 - 1263.

Kimura M, Crow JF (1964) The number of alleles that can be maintained in a finite population. Genetics, 49, $725-738$.

Koorey DJ, Bishop GA, McCaughan GW (1993) Allele non-amplification: a source of confusion in linkage studies employing microsatellite polymorphisms. Human Molecular Genetics, 2, 289 - 291.

Lehmann T, Hawley WA, Collins FH (1996) An evaluation of evolutionary constraints on microsatellite loci using null alleles. Genetics, 144, $1155-$ 1163.

Lewontin RC, Birch LC (1966) Hybridization as a source of variation for adaptation to new environments. Evolution, 20, $345-336$.

Luikart G, Cornuet JM (1998) Empirical evaluation of a test for identifying recently bottlenecked populations from allele frequency data. Conservation Biology, 12, 228 - 237.

Luikart G, Sherwin WB, Steele BM, Allendorf FW (1998) Usefulness of molecular markers for detecting population bottlenecks via monitoring genetic change. Molecular Ecology, 7, 963 - 974.

Lynch M, Pfrender M, Spitze K, Lehman N, Hicks J, Allen D, Latta L, Ottene M, Bogue F, Colbourne J (1999) The quantitative and molecular genetic architecture of a subdivided species. Evolution, 53, $100-110$. 
Manel S, Berthier P, Luikart G (2002) Detecting wildlife poaching: identifying the origin of individuals with Bayesian assignment tests and multilocus genotypes. Conservation Biology, 16, 650 - 659 .

Mank JE, Carlson JE, Brittingham MC (2004) A century of hybridization: Decreasing genetic distance between American black ducks and mallards. Conservation Genetics, 5, 395 - 403.

Nauta MJ, Weissing FJ (1996) Constraints on allele size at microsatellite loci: implications for genetic differentiation. Genetics, 143, 1021 - 1032.

Neigel JE (2002) Is $F_{\text {ST }}$ obsolete? Conservation Genetics, 3, 167 - 173.

Nielsen R (1997) A likelihood approach to population samples of microsatellite alleles. Genetics, 146, 711-716.

Nielsen R, Palsbøll PJ (1999) Single-locus tests of microsatellite evolution: Multi-step mutations and constraints on allele size. Molecular Phylogenetics and Evolution, 11, 477 - 484.

Nixon AJ (1982) Aspects of the Ecology and Morphology of Cyanoramphus Parakeets and Hybrids from Mangere Island, Chatham Islands. MSc thesis, Victoria University of Wellington, Wellington, New Zealand.

Ohta T, Kimura M (1973) A model of mutation appropriate to estimate the number of electrophoretic detectable alleles in a finite population. Genet. Res., 22, $201-204$.

Ott J, Rabinowitz D (1997) The effect of marker heterozygosity on the power to detect linkage disequilibrium. Genetics, 147, 927 - 930. 
Pearse DE, Crandall KA (2004) Beyond $\mathrm{F}_{\mathrm{ST}}$ : analysis of population genetic data for conservation. Conservation Genetics, 5, 585-602.

Pemberton JM, Slate J, Bancroft DR, Barrett JA (1995) Nonamplifying alleles at microsatellite loci: a caution for parentage and population studies. Molecular Ecology, 4, 249-252.

Prager EM, Wilson AC (1975) Slow evolutionary loss of the potential for interspecific hybridization in birds: A manifestation of slow regulatory evolution. Proc. Natl. Acad. Sci. USA, 72, $200-204$.

Pritchard JK, Stephens M, Donnelly P (2000) Inference of population structure using multilocus genotype data. Genetics, 155, 945 - 959.

Rannala B, Mountain JL (1997) Detecting immigration by using multilocus genotypes. Proc. Natl. Acad. Sci. USA, 94, 9197 - 9201.

Raymond M, Rousset F (1995) GENEPOP (version 1.2): Population genetic software for the exact tests and ecumenicisms. J. Hered., 86, 248 -249 .

Rhymer JM, Simberloff D (1996) Extinction by hybridization and introgression. Annu. Rev. Ecol. Syst., 27, 83 - 109.

Rice WR (1989) Analyzing tables of statistical tests. Evolution, 43, 223 225.

Robertson BC, Minot EO, Lambert DM (2000) Microsatellite primers for the kakapo (Strigops habroptilus) and their utility in other parrots. Conservation Genetics, 1, $93-95$. 
Ross KG, Shoemaker DD, Krieger MJB, DeHeer CJ, Keller L (1999) Assessing genetic structure with multiple classes of molecular markers: a case study involving the introduced Fire Ant Solenopsis invicta. Mol. Biol. Evol., 16, $525-543$.

Rousset F (1996) Equilibrium values of measures of population subdivision for stepwise mutation processes. Genetics, 142, 1357 - 1362.

Russello M, Calcagnotto D, DeSalle R, Amato G (2001) Characterization of microsatellite loci in the endangered St. Vincent Parrot, Amazona guildingii. Molecular Ecology Notes, 1, 162 - 164.

Sainsbury JP, MacAvoy ES, Chambers GK (2004) Characterization of microsatellite loci in the Kaka, Nestor meridionalis. Molecular Ecology Notes, 4, $623-625$.

Saitou N, Nei M (1987) The neighbor-joining method: A new method for reconstructing phylogenetic trees. Mol. Bio. Evol., 4, 406 - 425.

Slatkin M (1995) A measure of population subdivision based on microsatellite allele frequencies. Genetics, 139, $457-462$.

Stone G (2000) Phylogeography, hybridization and speciation. TREE, 15, $354-355$.

Takezaki N, Nei M (1996) Genetic distances and reconstruction of phylogenetic trees from microsatellite DNA. Genetics, 144, 389 - 399. 
Tenenhaus M, Young FW (1985) An analysis and synthesis of multiple correspondence analysis, optimal scaling, dual scaling, homogeneity analysis and other methods for quantifying categorical multivariate data. Psychometrika, 50, 91 - 119.

Thioulouse J, Chessel D, Dolédec S, Olivier JM (1997) ADE-4: a multivariate analysis and graphical display software. Statistics and Computing, 7, $75-83$.

Valdes AM, Slatkin M, Freimer NB (1993) Allele frequencies at microsatellite loci: the stepwise mutation model revisited. Genetics, 133, $737-749$.

van Oosterhout C, Hutchinson WF, Wills DPM, Shipley P (2004) MICROCHECKER: software for identifying and correcting genotyping errors in microsatellite data. Molecular Ecology Notes, 4, 535- 538.

van Oppen MJH, Rico C, Turner GF, Hewitt GM (2000) Extensive homoplasy, nonstepwise mutations, and shared ancestral polymorphism at a complex microsatellite locus in Lake Malawi cichlids. Mol. Biol. Evol., $17,489-498$.

Weir BS, Cockerham CC (1984) Estimating F-statistics for the analysis of population structure. Evolution, 38, $1358-1370$.

Wright S (1951) The genetical structure of populations. Ann. Eugenics, $15,323-354$. 


\section{Appendix 3.1 Individual Profiles at Eight Polymorphic Cfor} Microsatellite Loci

Birds were banded with colour bands and / or metal numbered bands. In the case of colour bands the codes are presented in the format:

Left leg band(s) - Right leg band(s)

The colour codes are:

$$
\begin{aligned}
& \text { B-Blue } \\
& \text { Bk-Black } \\
& \text { G-Green } \\
& \text { M- Metal } \\
& \text { O-Orange } \\
& \text { R-Red } \\
& \text { W-White } \\
& \text { Y - Yellow }
\end{aligned}
$$

The allelic genotypes are presented in two-column format for each locus, with one allele size (bp) in each column. 0 indicates a null allele. 


\begin{tabular}{|c|c|c|c|c|c|c|c|c|c|c|c|c|c|c|c|c|c|}
\hline \multirow{3}{*}{$\begin{array}{c}\text { Metal } \\
\text { Band } \\
-\end{array}$} & \multirow{3}{*}{$\begin{array}{c}\text { Colour } \\
\text { Band } \\
\text { BR-G }\end{array}$} & \multicolumn{16}{|c|}{ Microsatellite Loci } \\
\hline & & \multicolumn{2}{|c|}{ Cfor0809 } & \multicolumn{2}{|c|}{ Cfor1415 } & \multicolumn{2}{|c|}{ Cfor1617 } & \multicolumn{2}{|c|}{ Cfor1819 } & \multicolumn{2}{|c|}{ Cfor2021 } & \multicolumn{2}{|c|}{ Cfor2627 } & \multicolumn{2}{|c|}{ Cfor2829 } & \multicolumn{2}{|c|}{ Cfor3031 } \\
\hline & & 191 & 203 & 217 & 217 & 217 & 217 & 184 & 188 & 233 & 233 & 0 & 0 & 219 & 231 & 237 & 237 \\
\hline- & BW-G & 191 & 191 & 225 & 227 & 217 & 217 & 184 & 188 & 233 & 233 & 162 & 172 & 219 & 219 & 245 & 247 \\
\hline- & G-BG & 191 & 191 & 225 & 227 & 217 & 217 & 184 & 188 & 233 & 233 & 170 & 172 & 219 & 219 & 237 & 237 \\
\hline- & G-BO & 191 & 191 & 213 & 227 & 217 & 217 & 184 & 188 & 233 & 239 & 162 & 162 & 219 & 219 & 237 & 237 \\
\hline- & G-BR & 191 & 191 & 217 & 227 & 217 & 217 & 184 & 188 & 233 & 233 & 170 & 172 & 219 & 219 & 237 & 237 \\
\hline- & G-BW & 191 & 191 & 213 & 217 & 217 & 217 & 184 & 188 & 233 & 239 & 170 & 172 & 219 & 231 & 237 & 239 \\
\hline- & G-BY & 191 & 191 & 225 & 227 & 217 & 217 & 184 & 188 & 233 & 233 & 170 & 172 & 219 & 221 & 237 & 237 \\
\hline- & G-GW & 191 & 191 & 213 & 217 & 217 & 217 & 184 & 188 & 233 & 239 & 162 & 162 & 219 & 219 & 237 & 239 \\
\hline- & G-OW & 191 & 191 & 211 & 217 & 217 & 217 & 184 & 184 & 233 & 233 & 170 & 172 & 219 & 231 & 239 & 239 \\
\hline- & GO-W & 191 & 191 & 217 & 227 & 217 & 217 & 184 & 184 & 233 & 233 & 170 & 172 & 219 & 219 & 235 & 237 \\
\hline- & G-RB & 191 & 191 & 225 & 227 & 217 & 217 & 184 & 184 & 233 & 233 & 170 & 172 & 219 & 221 & 237 & 237 \\
\hline- & G-RG & 191 & 191 & 217 & 227 & 217 & 217 & 184 & 188 & 233 & 233 & 170 & 172 & 219 & 221 & 237 & 237 \\
\hline- & G-RO & 191 & 191 & 225 & 227 & 217 & 217 & 184 & 188 & 233 & 233 & 170 & 172 & 219 & 221 & 237 & 237 \\
\hline- & G-RW & 191 & 191 & 211 & 221 & 217 & 217 & 184 & 184 & 233 & 233 & 160 & 160 & 221 & 231 & 239 & 239 \\
\hline- & G-RY & 191 & 191 & 213 & 217 & 217 & 217 & 184 & 184 & 233 & 239 & 170 & 170 & 219 & 219 & 237 & 237 \\
\hline- & G-WB & 191 & 191 & 217 & 221 & 217 & 217 & 184 & 188 & 233 & 239 & 0 & 0 & 219 & 231 & 237 & 237 \\
\hline- & G-WG & 191 & 191 & 217 & 221 & 217 & 217 & 184 & 188 & 233 & 239 & 0 & 0 & 219 & 231 & 237 & 237 \\
\hline- & GW-G & 191 & 191 & 211 & 213 & 217 & 217 & 184 & 188 & 233 & 239 & 160 & 160 & 219 & 221 & 239 & 239 \\
\hline- & G-WO & 191 & 191 & 211 & 217 & 217 & 217 & 184 & 188 & 233 & 239 & 0 & 0 & 219 & 221 & 239 & 239 \\
\hline- & G-WR & 191 & 191 & 217 & 227 & 217 & 217 & 188 & 188 & 233 & 233 & 170 & 172 & 219 & 219 & 235 & 237 \\
\hline- & GW-W & 191 & 191 & 217 & 227 & 217 & 217 & 184 & 188 & 233 & 233 & 162 & 162 & 219 & 219 & 237 & 237 \\
\hline- & G-WY & 191 & 191 & 211 & 217 & 217 & 217 & 184 & 186 & 233 & 233 & 160 & 160 & 219 & 231 & 239 & 239 \\
\hline- & G-YR & 191 & 191 & 211 & 213 & 225 & 225 & 184 & 186 & 233 & 233 & 162 & 172 & 219 & 219 & 237 & 239 \\
\hline- & OW-G & 191 & 191 & 217 & 217 & 217 & 217 & 184 & 184 & 233 & 233 & 170 & 172 & 219 & 231 & 237 & 239 \\
\hline- & OY-G & 191 & 191 & 217 & 217 & 217 & 217 & 186 & 188 & 233 & 239 & 160 & 160 & 219 & 219 & 235 & 237 \\
\hline- & RB-G & 191 & 191 & 211 & 213 & 225 & 225 & 184 & 184 & 233 & 233 & 162 & 162 & 219 & 219 & 237 & 239 \\
\hline- & $R G-G$ & 191 & 191 & 213 & 227 & 217 & 217 & 184 & 188 & 239 & 239 & 162 & 162 & 219 & 219 & 237 & 237 \\
\hline- & RO-G & 191 & 191 & 217 & 227 & 217 & 217 & 186 & 188 & 233 & 233 & 0 & 0 & 219 & 221 & 237 & 237 \\
\hline- & RW-G & 191 & 191 & 217 & 227 & 217 & 217 & 188 & 188 & 233 & 233 & 162 & 172 & 219 & 219 & 237 & 237 \\
\hline- & RW-W & 191 & 191 & 217 & 227 & 217 & 217 & 186 & 186 & 233 & 233 & 162 & 162 & 219 & 219 & 237 & 237 \\
\hline- & $R Y-G$ & 191 & 203 & 211 & 217 & 217 & 225 & 184 & 184 & 233 & 233 & 162 & 162 & 219 & 219 & 237 & 239 \\
\hline
\end{tabular}




\begin{tabular}{|c|c|c|c|c|c|c|c|c|c|c|c|c|c|c|c|c|c|}
\hline- & WB-G & 191 & 191 & 217 & 227 & 217 & 217 & 184 & 184 & 233 & 233 & 162 & 162 & 219 & 219 & 239 & 239 \\
\hline- & WG-G & 191 & 191 & 213 & 217 & 217 & 217 & 184 & 188 & 233 & 233 & 0 & 0 & 219 & 219 & 237 & 239 \\
\hline- & WO-G & 191 & 191 & 225 & 227 & 217 & 217 & 184 & 186 & 233 & 233 & 162 & 172 & 219 & 219 & 245 & 247 \\
\hline- & WR-G & 191 & 191 & 217 & 217 & 217 & 217 & 188 & 188 & 233 & 233 & 162 & 162 & 219 & 219 & 237 & 237 \\
\hline- & W-RW & 191 & 203 & 217 & 217 & 217 & 217 & 176 & 184 & 233 & 233 & 172 & 172 & 219 & 231 & 239 & 239 \\
\hline- & W-WB & 191 & 191 & 217 & 217 & 217 & 217 & 184 & 186 & 233 & 239 & 172 & 172 & 219 & 231 & 237 & 237 \\
\hline- & W-WR & 191 & 203 & 215 & 215 & 217 & 217 & 186 & 188 & 233 & 233 & 170 & 172 & 231 & 231 & 237 & 239 \\
\hline- & WY-G & 191 & 191 & 217 & 227 & 217 & 217 & 184 & 186 & 233 & 233 & 162 & 162 & 219 & 219 & 239 & 239 \\
\hline- & $Y W-G$ & 191 & 203 & 213 & 217 & 217 & 217 & 176 & 184 & 233 & 233 & 170 & 172 & 219 & 231 & 237 & 239 \\
\hline- & $Y-Y G$ & 191 & 203 & 211 & 211 & 217 & 225 & 184 & 184 & 233 & 233 & 0 & 0 & 221 & 221 & 239 & 239 \\
\hline D171508 & GG-M & 191 & 191 & 217 & 227 & 217 & 217 & 184 & 186 & 233 & 233 & 170 & 172 & 219 & 219 & 237 & 237 \\
\hline D171511 & BW-M & 191 & 191 & 213 & 217 & 225 & 225 & 184 & 184 & 233 & 233 & 0 & 0 & 219 & 219 & 237 & 239 \\
\hline D171514 & M-RW & 191 & 191 & 213 & 217 & 217 & 217 & 184 & 188 & 233 & 233 & 0 & 0 & 219 & 219 & 247 & 247 \\
\hline D171515 & $\mathrm{M}-\mathrm{RB}$ & 191 & 191 & 215 & 225 & 217 & 217 & 184 & 188 & 233 & 233 & 162 & 162 & 219 & 219 & 237 & 239 \\
\hline D171516 & $M-R Y$ & 191 & 191 & 217 & 227 & 217 & 217 & 184 & 188 & 233 & 239 & 170 & 172 & 219 & 219 & 235 & 237 \\
\hline D171517 & $M-R G$ & 191 & 191 & 217 & 227 & 225 & 225 & 186 & 186 & 233 & 233 & 162 & 172 & 219 & 219 & 235 & 237 \\
\hline D171518 & M-RO & 191 & 191 & 211 & 217 & 217 & 217 & 184 & 184 & 233 & 239 & 172 & 172 & 219 & 219 & 237 & 237 \\
\hline D171519 & M-WR & 191 & 191 & 213 & 217 & 217 & 225 & 184 & 184 & 233 & 239 & 0 & 0 & 219 & 231 & 237 & 237 \\
\hline D171520 & M-WB & 191 & 191 & 217 & 227 & 217 & 217 & 184 & 184 & 233 & 239 & 162 & 162 & 219 & 231 & 239 & 239 \\
\hline D172001 & M-WY & 191 & 191 & 215 & 217 & 217 & 217 & 184 & 186 & 233 & 233 & 162 & 162 & 219 & 219 & 237 & 239 \\
\hline D172002 & M-WG & 191 & 191 & 225 & 227 & 217 & 217 & 184 & 184 & 233 & 233 & 162 & 162 & 219 & 231 & 247 & 247 \\
\hline D172003 & M-WO & 191 & 191 & 213 & 217 & 217 & 217 & 186 & 188 & 233 & 239 & 0 & 0 & 219 & 231 & 239 & 239 \\
\hline D172005 & M-BW & 191 & 191 & 217 & 227 & 217 & 217 & 186 & 188 & 233 & 239 & 172 & 172 & 219 & 219 & 237 & 239 \\
\hline D172006 & M-BY & 191 & 191 & 213 & 217 & 217 & 225 & 184 & 186 & 233 & 233 & 0 & 0 & 219 & 219 & 237 & 239 \\
\hline D172007 & M-YR & 191 & 191 & 213 & 217 & 225 & 225 & 184 & 186 & 233 & 233 & 162 & 172 & 219 & 221 & 233 & 233 \\
\hline D172008 & $M-Y G$ & 191 & 191 & 211 & 213 & 225 & 225 & 184 & 186 & 233 & 239 & 172 & 172 & 219 & 219 & 237 & 237 \\
\hline D172010 & M-YB & 191 & 191 & 221 & 227 & 217 & 217 & 184 & 184 & 233 & 233 & 160 & 162 & 219 & 219 & 237 & 237 \\
\hline D172011 & M-GR & 191 & 191 & 213 & 217 & 217 & 217 & 186 & 188 & 233 & 239 & 162 & 162 & 219 & 219 & 237 & 237 \\
\hline D172012 & M-GW & 191 & 191 & 213 & 227 & 225 & 225 & 186 & 186 & 233 & 233 & 160 & 172 & 219 & 219 & 241 & 247 \\
\hline D172013 & $M-G B$ & 191 & 191 & 217 & 227 & 217 & 217 & 184 & 188 & 233 & 239 & 170 & 172 & 219 & 219 & 237 & 239 \\
\hline D172015 & M-GO & 191 & 191 & 217 & 217 & 225 & 225 & 184 & 184 & 233 & 239 & 162 & 162 & 219 & 219 & 239 & 239 \\
\hline D172016 & RW-M & 191 & 191 & 213 & 217 & 217 & 217 & 184 & 188 & 233 & 233 & 170 & 172 & 219 & 219 & 235 & 239 \\
\hline D172017 & RB-M & 191 & 191 & 217 & 227 & 217 & 217 & 188 & 188 & 233 & 239 & 0 & 0 & 219 & 231 & 235 & 237 \\
\hline D172018 & RY-M & 191 & 191 & 217 & 227 & 217 & 217 & 184 & 188 & 233 & 239 & 0 & 0 & 219 & 219 & 235 & 235 \\
\hline D172019 & RG-M & 191 & 191 & 217 & 217 & 217 & 217 & 188 & 188 & 233 & 233 & 0 & 0 & 219 & 219 & 235 & 237 \\
\hline
\end{tabular}




\begin{tabular}{|c|c|c|c|c|c|c|c|c|c|c|c|c|c|c|c|c|c|}
\hline D172020 & RO-M & 191 & 191 & 215 & 217 & 217 & 217 & 186 & 188 & 233 & 233 & 170 & 172 & 219 & 219 & 237 & 237 \\
\hline D172021 & WR-M & 191 & 191 & 213 & 217 & 217 & 217 & 184 & 184 & 233 & 239 & 0 & 0 & 219 & 219 & 235 & 237 \\
\hline D172022 & WB-M & 191 & 191 & 213 & 217 & 217 & 217 & 184 & 184 & 233 & 233 & 0 & 0 & 219 & 221 & 237 & 239 \\
\hline D172023 & WY-M & 191 & 191 & 217 & 217 & 217 & 225 & 184 & 188 & 233 & 239 & 160 & 172 & 219 & 219 & 237 & 237 \\
\hline D172024 & WG-M & 191 & 191 & 213 & 217 & 225 & 225 & 184 & 188 & 239 & 239 & 162 & 172 & 219 & 219 & 235 & 237 \\
\hline D172025 & BR-M & 191 & 191 & 217 & 217 & 217 & 217 & 188 & 188 & 233 & 239 & 0 & 0 & 219 & 219 & 235 & 237 \\
\hline D172026 & WO-M & 191 & 191 & 217 & 227 & 217 & 217 & 184 & 188 & 233 & 239 & 170 & 170 & 219 & 221 & 237 & 237 \\
\hline D172027 & BW-M & 191 & 191 & 211 & 213 & 217 & 225 & 184 & 188 & 233 & 239 & 162 & 172 & 219 & 231 & 237 & 237 \\
\hline D172028 & BY-M & 191 & 191 & 213 & 217 & 217 & 217 & 184 & 184 & 233 & 239 & 170 & 170 & 219 & 219 & 235 & 237 \\
\hline D172029 & BG-M & 191 & 191 & 217 & 217 & 217 & 217 & 186 & 186 & 239 & 239 & 170 & 172 & 219 & 219 & 237 & 239 \\
\hline D172030 & BO-M & 191 & 191 & 227 & 227 & 217 & 217 & 184 & 184 & 233 & 233 & 162 & 172 & 219 & 219 & 245 & 247 \\
\hline D172031 & YR-M & 191 & 191 & 221 & 227 & 225 & 225 & 188 & 188 & 233 & 239 & 162 & 162 & 219 & 221 & 237 & 237 \\
\hline D172032 & YW-M & 191 & 191 & 217 & 217 & 217 & 217 & 184 & 184 & 233 & 239 & 170 & 172 & 219 & 219 & 239 & 239 \\
\hline D172033 & YB-M & 191 & 191 & 217 & 217 & 217 & 217 & 184 & 186 & 233 & 239 & 170 & 172 & 219 & 219 & 237 & 239 \\
\hline D172034 & YG-M & 191 & 191 & 217 & 217 & 217 & 217 & 186 & 188 & 233 & 233 & 0 & 0 & 219 & 221 & 239 & 239 \\
\hline D172035 & YO-M & 191 & 191 & 217 & 217 & 217 & 217 & 184 & 184 & 233 & 233 & 0 & 0 & 219 & 231 & 237 & 239 \\
\hline D172036 & GR-M & 191 & 191 & 213 & 227 & 217 & 217 & 188 & 188 & 233 & 233 & 160 & 160 & 219 & 219 & 245 & 247 \\
\hline D172037 & GW-M & 191 & 191 & 217 & 227 & 217 & 217 & 186 & 188 & 233 & 233 & 162 & 162 & 219 & 231 & 237 & 239 \\
\hline D172038 & GB-M & 191 & 191 & 221 & 227 & 217 & 217 & 184 & 188 & 233 & 233 & 160 & 162 & 219 & 231 & 239 & 239 \\
\hline D172040 & M-BO & 191 & 191 & 221 & 227 & 217 & 217 & 184 & 186 & 233 & 233 & 162 & 162 & 219 & 219 & 247 & 247 \\
\hline D172042 & $M-Y O$ & 191 & 191 & 217 & 227 & 217 & 217 & 188 & 188 & 233 & 233 & 162 & 162 & 219 & 219 & 237 & 237 \\
\hline D172043 & GO-M & 191 & 191 & 217 & 227 & 217 & 217 & 188 & 188 & 233 & 233 & 170 & 170 & 219 & 219 & 237 & 239 \\
\hline D172044 & M-OO & 191 & 191 & 213 & 217 & 217 & 217 & 184 & 188 & 233 & 239 & 162 & 162 & 219 & 219 & 235 & 239 \\
\hline D172046 & M-BB & 191 & 191 & 213 & 227 & 217 & 217 & 184 & 184 & 239 & 239 & 0 & 0 & 219 & 219 & 237 & 237 \\
\hline D172047 & M- & 191 & 191 & 213 & 227 & 217 & 225 & 184 & 188 & 233 & 233 & 170 & 170 & 219 & 219 & 245 & 247 \\
\hline D172048 & OW-M & 191 & 191 & 221 & 227 & 225 & 225 & 184 & 184 & 233 & 233 & 160 & 160 & 219 & 219 & 239 & 239 \\
\hline D172049 & OR-M & 191 & 191 & 217 & 227 & 225 & 225 & 184 & 188 & 233 & 233 & 170 & 172 & 219 & 219 & 235 & 237 \\
\hline D172050 & OY-M & 191 & 191 & 217 & 227 & 217 & 217 & 186 & 188 & 233 & 233 & 170 & 170 & 219 & 219 & 237 & 237 \\
\hline D172051 & OG-M & 191 & 191 & 211 & 221 & 217 & 225 & 184 & 184 & 233 & 233 & 160 & 162 & 219 & 219 & 239 & 239 \\
\hline D172052 & OB-M & 191 & 191 & 211 & 217 & 217 & 217 & 184 & 188 & 233 & 233 & 160 & 160 & 219 & 219 & 235 & 237 \\
\hline D172053 & M-OW & 187 & 191 & 217 & 217 & 225 & 225 & 184 & 188 & 233 & 233 & 162 & 162 & 219 & 221 & 237 & 239 \\
\hline D172054 & M-OR & 191 & 191 & 211 & 227 & 217 & 217 & 184 & 184 & 233 & 239 & 0 & 0 & 219 & 219 & 245 & 247 \\
\hline D172055 & $\mathrm{M}-\mathrm{OY}$ & 191 & 191 & 213 & 217 & 217 & 217 & 184 & 184 & 233 & 239 & 0 & 0 & 219 & 219 & 235 & 237 \\
\hline D172056 & M-OG & 191 & 191 & 211 & 217 & 217 & 217 & 184 & 188 & 233 & 233 & 162 & 162 & 219 & 219 & 235 & 237 \\
\hline D172057 & $\mathrm{M}-\mathrm{OB}$ & 191 & 191 & 211 & 217 & 217 & 217 & 184 & 184 & 233 & 233 & 162 & 162 & 219 & 219 & 237 & 237 \\
\hline
\end{tabular}




\begin{tabular}{|c|c|c|c|c|c|c|c|c|c|c|c|c|c|c|c|c|c|}
\hline D172058 & M-YY & 191 & 191 & 211 & 213 & 217 & 225 & 188 & 188 & 233 & 233 & 160 & 160 & 219 & 219 & 239 & 239 \\
\hline D172059 & M-GG & 191 & 191 & 215 & 217 & 217 & 217 & 186 & 188 & 233 & 233 & 0 & 170 & 219 & 221 & 235 & 237 \\
\hline D172061 & M-WW & 191 & 191 & 213 & 217 & 217 & 217 & 184 & 184 & 233 & 233 & 0 & 170 & 219 & 231 & 237 & 239 \\
\hline D174701 & R-GO & 191 & 191 & 217 & 227 & 225 & 225 & 184 & 184 & 233 & 233 & 160 & 162 & 219 & 219 & 239 & 239 \\
\hline D174702 & R-RW & 191 & 191 & 217 & 227 & 217 & 217 & 184 & 184 & 233 & 233 & 160 & 160 & 219 & 219 & 239 & 239 \\
\hline D174703 & R-BY & 191 & 191 & 217 & 227 & 217 & 217 & 184 & 188 & 233 & 239 & 162 & 162 & 219 & 219 & 237 & 239 \\
\hline D174704 & R-RB & 191 & 191 & 217 & 217 & 217 & 225 & 184 & 184 & 233 & 233 & 0 & 0 & 219 & 219 & 237 & 239 \\
\hline D174705 & $\mathrm{R}-\mathrm{OR}$ & 191 & 203 & 213 & 217 & 217 & 217 & 176 & 184 & 233 & 233 & 170 & 172 & 219 & 219 & 237 & 239 \\
\hline D174706 & R-OY & 203 & 203 & 217 & 217 & 217 & 225 & 176 & 184 & 233 & 233 & 0 & 0 & 219 & 219 & 237 & 239 \\
\hline D174707 & R-GW & 191 & 191 & 217 & 217 & 225 & 225 & 184 & 184 & 233 & 233 & 170 & 172 & 219 & 231 & 239 & 241 \\
\hline D174708 & $\mathrm{R}-\mathrm{RY}$ & 191 & 191 & 211 & 227 & 217 & 217 & 188 & 188 & 233 & 233 & 0 & 0 & 219 & 221 & 237 & 239 \\
\hline D174709 & R-BO & 191 & 191 & 217 & 227 & 217 & 217 & 184 & 184 & 233 & 233 & 0 & 0 & 219 & 219 & 235 & 235 \\
\hline D174710 & R-OG & 191 & 191 & 211 & 217 & 217 & 217 & 188 & 188 & 233 & 239 & 0 & 0 & 219 & 221 & 237 & 237 \\
\hline D174711 & R-GY & 191 & 191 & 217 & 227 & 217 & 217 & 184 & 188 & 233 & 239 & 170 & 170 & 219 & 219 & 237 & 239 \\
\hline D174712 & $R-R G$ & 191 & 191 & 221 & 227 & 217 & 217 & 184 & 184 & 233 & 233 & 170 & 170 & 219 & 219 & 237 & 239 \\
\hline D174713 & R-WO & 191 & 191 & 221 & 227 & 225 & 225 & 184 & 184 & 233 & 233 & 170 & 172 & 219 & 219 & 237 & 239 \\
\hline D174714 & $\mathrm{R}-\mathrm{RO}$ & 191 & 191 & 217 & 217 & 217 & 217 & 184 & 188 & 233 & 233 & 170 & 170 & 219 & 219 & 235 & 237 \\
\hline D174715 & R-YB & 191 & 191 & 221 & 227 & 217 & 217 & 184 & 184 & 233 & 233 & 160 & 162 & 219 & 219 & 237 & 239 \\
\hline D174716 & R-WY & 191 & 191 & 213 & 227 & 217 & 217 & 184 & 188 & 233 & 233 & 0 & 0 & 219 & 219 & 235 & 235 \\
\hline D174717 & $R-Y R$ & 191 & 191 & 217 & 227 & 217 & 217 & 184 & 188 & 233 & 233 & 0 & 0 & 219 & 219 & 235 & 237 \\
\hline D174718 & $R-G B$ & 191 & 191 & 217 & 227 & 217 & 217 & 186 & 188 & 233 & 239 & 160 & 160 & 219 & 219 & 237 & 237 \\
\hline D174719 & $\mathrm{R}-\mathrm{OB}$ & 191 & 191 & 217 & 227 & 217 & 217 & 184 & 188 & 233 & 233 & 0 & 0 & 219 & 219 & 235 & 237 \\
\hline D174774 & $R-Y G$ & 191 & 191 & 211 & 217 & 217 & 217 & 184 & 184 & 233 & 233 & 0 & 0 & 219 & 231 & 237 & 239 \\
\hline D175001 & $B Y-G$ & 191 & 191 & 217 & 227 & 217 & 217 & 188 & 188 & 233 & 233 & 160 & 160 & 219 & 231 & 235 & 235 \\
\hline D175002 & G-YW & 191 & 191 & 213 & 217 & 217 & 217 & 184 & 184 & 233 & 239 & 160 & 162 & 221 & 231 & 235 & 237 \\
\hline D175003 & G-YB & 191 & 191 & 217 & 217 & 217 & 217 & 184 & 188 & 233 & 233 & 162 & 172 & 219 & 219 & 237 & 247 \\
\hline D175004 & YB-G & 191 & 191 & 213 & 217 & 217 & 217 & 184 & 184 & 233 & 239 & 160 & 162 & 219 & 219 & 237 & 237 \\
\hline D175005 & G-YO & 191 & 191 & 211 & 227 & 217 & 217 & 184 & 188 & 233 & 233 & 0 & 0 & 219 & 219 & 237 & 239 \\
\hline D175006 & $B G-G$ & 191 & 191 & 217 & 227 & 217 & 217 & 184 & 188 & 233 & 233 & 160 & 162 & 219 & 219 & 237 & 239 \\
\hline D175007 & G-YG & 191 & 191 & 213 & 217 & 225 & 225 & 186 & 188 & 233 & 239 & 0 & 0 & 221 & 231 & 237 & 239 \\
\hline D175009 & YG-G & 191 & 191 & 217 & 217 & 217 & 217 & 188 & 188 & 233 & 233 & 0 & 0 & 219 & 219 & 235 & 237 \\
\hline D175010 & $B O-G$ & 191 & 191 & 217 & 221 & 217 & 217 & 184 & 184 & 233 & 233 & 162 & 162 & 219 & 219 & 239 & 239 \\
\hline D175013 & GR-G & 191 & 191 & 213 & 227 & 217 & 217 & 186 & 186 & 233 & 233 & 162 & 162 & 219 & 219 & 245 & 247 \\
\hline D175014 & G-GY & 191 & 191 & 211 & 211 & 225 & 225 & 188 & 188 & 233 & 233 & 162 & 162 & 219 & 221 & 239 & 239 \\
\hline D175015 & G-GO & 191 & 191 & 217 & 227 & 217 & 217 & 184 & 188 & 233 & 233 & 162 & 162 & 219 & 221 & 241 & 241 \\
\hline
\end{tabular}




\begin{tabular}{|c|c|c|c|c|c|c|c|c|c|c|c|c|c|c|c|c|c|}
\hline D175016 & G-OR & 191 & 191 & 211 & 217 & 217 & 217 & 188 & 188 & 233 & 233 & 162 & 172 & 219 & 231 & 237 & 237 \\
\hline D175017 & G-OB & 191 & 191 & 215 & 227 & 217 & 225 & 184 & 184 & 233 & 233 & 162 & 162 & 219 & 221 & 239 & 239 \\
\hline D175018 & GO-G & 191 & 191 & 217 & 227 & 217 & 217 & 188 & 188 & 233 & 233 & 0 & 0 & 219 & 219 & 235 & 235 \\
\hline D175019 & GB-G & 191 & 191 & 211 & 213 & 217 & 225 & 186 & 186 & 233 & 233 & 162 & 162 & 219 & 219 & 235 & 237 \\
\hline D175020 & GY-G & 191 & 191 & 227 & 227 & 225 & 225 & 184 & 188 & 233 & 233 & 0 & 0 & 219 & 221 & 247 & 247 \\
\hline D175021 & G-OG & 191 & 191 & 217 & 227 & 217 & 217 & 188 & 188 & 233 & 233 & 170 & 172 & 219 & 219 & 237 & 239 \\
\hline D175022 & G-OY & 191 & 191 & 211 & 211 & 217 & 217 & 186 & 186 & 233 & 233 & 0 & 0 & 219 & 221 & 239 & 239 \\
\hline D175023 & OR-G & 191 & 191 & 217 & 227 & 217 & 217 & 184 & 184 & 233 & 233 & 170 & 172 & 219 & 221 & 239 & 239 \\
\hline D175101 & RW-B & 191 & 191 & 215 & 217 & 217 & 217 & 184 & 188 & 233 & 233 & 160 & 172 & 219 & 231 & 239 & 239 \\
\hline D175102 & RB-B & 191 & 191 & 211 & 217 & 217 & 225 & 184 & 188 & 233 & 233 & 170 & 172 & 219 & 231 & 239 & 239 \\
\hline D175103 & $R Y-B$ & 191 & 191 & 225 & 227 & 217 & 217 & 184 & 184 & 233 & 233 & 162 & 172 & 219 & 219 & 247 & 247 \\
\hline D175104 & $R G-B$ & 191 & 191 & 217 & 227 & 217 & 217 & 186 & 188 & 233 & 233 & 170 & 170 & 219 & 219 & 247 & 247 \\
\hline D175105 & B-RW & 191 & 203 & 213 & 217 & 225 & 225 & 176 & 188 & 233 & 239 & 162 & 172 & 219 & 231 & 237 & 239 \\
\hline D175106 & B-RB & 191 & 191 & 213 & 221 & 217 & 217 & 184 & 184 & 233 & 239 & 162 & 162 & 219 & 231 & 239 & 239 \\
\hline D175107 & B-RY & 191 & 191 & 217 & 227 & 225 & 225 & 184 & 188 & 233 & 233 & 160 & 162 & 219 & 231 & 239 & 239 \\
\hline D175108 & B-RG & 191 & 191 & 211 & 217 & 225 & 225 & 184 & 186 & 233 & 233 & 0 & 0 & 219 & 221 & 237 & 237 \\
\hline D175109 & B-RO & 191 & 203 & 211 & 211 & 225 & 225 & 176 & 188 & 233 & 239 & 170 & 172 & 219 & 231 & 237 & 237 \\
\hline D175110 & B-WR & 191 & 191 & 217 & 227 & 225 & 225 & 184 & 184 & 233 & 233 & 162 & 172 & 219 & 219 & 237 & 237 \\
\hline D175111 & B-WB & 191 & 191 & 217 & 217 & 217 & 217 & 186 & 188 & 233 & 233 & 160 & 162 & 219 & 219 & 237 & 237 \\
\hline D175112 & RO-B & 191 & 191 & 213 & 217 & 217 & 217 & 184 & 186 & 233 & 239 & 162 & 172 & 219 & 219 & 237 & 237 \\
\hline D175113 & B-WY & 191 & 191 & 217 & 217 & 217 & 217 & 186 & 186 & 233 & 233 & 162 & 162 & 219 & 219 & 237 & 239 \\
\hline D175114 & WR-B & 191 & 191 & 217 & 227 & 217 & 217 & 184 & 184 & 233 & 239 & 162 & 162 & 219 & 219 & 247 & 247 \\
\hline D175115 & WB-B & 191 & 191 & 215 & 217 & 217 & 217 & 176 & 176 & 233 & 233 & 170 & 172 & 231 & 231 & 239 & 239 \\
\hline D175116 & $B-W G$ & 191 & 191 & 213 & 217 & 225 & 225 & 184 & 184 & 233 & 233 & 162 & 162 & 219 & 231 & 239 & 239 \\
\hline D175117 & WY-B & 191 & 191 & 217 & 217 & 217 & 217 & 184 & 184 & 233 & 239 & 162 & 162 & 219 & 219 & 237 & 239 \\
\hline D175118 & BW-B & 191 & 191 & 213 & 217 & 217 & 217 & 184 & 184 & 233 & 233 & 170 & 172 & 219 & 221 & 237 & 247 \\
\hline D175119 & B-WO & 191 & 191 & 211 & 217 & 225 & 225 & 184 & 188 & 233 & 233 & 162 & 172 & 219 & 219 & 239 & 239 \\
\hline D175120 & B-BR & 191 & 191 & 217 & 227 & 217 & 217 & 188 & 188 & 233 & 233 & 160 & 160 & 219 & 231 & 239 & 239 \\
\hline D175121 & B-BW & 183 & 191 & 211 & 217 & 217 & 217 & 186 & 188 & 233 & 233 & 170 & 172 & 219 & 231 & 237 & 237 \\
\hline D175122 & B-BY & 191 & 191 & 211 & 217 & 217 & 217 & 176 & 188 & 233 & 233 & 160 & 172 & 219 & 231 & 239 & 241 \\
\hline D175123 & WG-B & 191 & 191 & 217 & 227 & 217 & 217 & 184 & 184 & 233 & 239 & 170 & 172 & 219 & 219 & 239 & 239 \\
\hline D175124 & B-BG & 191 & 191 & 213 & 227 & 217 & 217 & 184 & 186 & 233 & 233 & 0 & 172 & 219 & 231 & 237 & 237 \\
\hline D175125 & B-BO & 191 & 191 & 213 & 227 & 217 & 217 & 186 & 188 & 239 & 239 & 162 & 162 & 219 & 231 & 235 & 235 \\
\hline D175126 & WO-B & 191 & 191 & 211 & 227 & 217 & 217 & 184 & 188 & 233 & 233 & 162 & 172 & 219 & 221 & 239 & 239 \\
\hline D175127 & BR-B & 191 & 191 & 217 & 227 & 217 & 217 & 184 & 184 & 233 & 233 & 172 & 172 & 221 & 221 & 239 & 239 \\
\hline
\end{tabular}




\begin{tabular}{|c|c|c|c|c|c|c|c|c|c|c|c|c|c|c|c|c|c|}
\hline D175128 & B-YR & 191 & 191 & 217 & 217 & 217 & 217 & 188 & 188 & 233 & 239 & 162 & 162 & 219 & 219 & 237 & 237 \\
\hline D175129 & BY-B & 191 & 191 & 213 & 217 & 217 & 225 & 188 & 188 & 233 & 239 & 162 & 162 & 219 & 219 & 237 & 237 \\
\hline D175130 & $B-Y W$ & 191 & 191 & 217 & 227 & 217 & 217 & 184 & 188 & 233 & 233 & 160 & 160 & 219 & 231 & 237 & 237 \\
\hline D175131 & B-YB & 191 & 191 & 217 & 217 & 217 & 217 & 186 & 188 & 233 & 239 & 0 & 0 & 219 & 219 & 233 & 237 \\
\hline D175132 & BG-B & 191 & 191 & 227 & 227 & 217 & 217 & 184 & 188 & 233 & 233 & 162 & 162 & 219 & 231 & 247 & 247 \\
\hline D175133 & $B-Y G$ & 191 & 191 & 217 & 221 & 217 & 217 & 184 & 184 & 233 & 239 & 160 & 160 & 231 & 231 & 239 & 241 \\
\hline D175134 & BO-B & 191 & 191 & 211 & 213 & 217 & 225 & 186 & 188 & 233 & 233 & 162 & 162 & 219 & 221 & 237 & 239 \\
\hline D175135 & YR-B & 191 & 191 & 213 & 217 & 217 & 217 & 184 & 188 & 233 & 239 & 170 & 172 & 219 & 219 & 237 & 237 \\
\hline D175136 & YW-B & 191 & 191 & 217 & 227 & 217 & 217 & 186 & 188 & 233 & 239 & 0 & 0 & 219 & 219 & 237 & 237 \\
\hline D175139 & B-GR & 191 & 191 & 217 & 217 & 217 & 217 & 184 & 188 & 233 & 239 & 162 & 162 & 219 & 219 & 237 & 239 \\
\hline D175140 & B-GW & 191 & 191 & 211 & 215 & 217 & 217 & 184 & 184 & 233 & 233 & 162 & 162 & 219 & 221 & 239 & 239 \\
\hline D175141 & YG-B & 191 & 191 & 225 & 227 & 217 & 225 & 184 & 184 & 233 & 233 & 162 & 172 & 219 & 219 & 239 & 239 \\
\hline D175142 & B-GB & 191 & 191 & 213 & 217 & 217 & 217 & 184 & 184 & 233 & 233 & 172 & 172 & 219 & 231 & 237 & 237 \\
\hline D175143 & $B-G Y$ & 191 & 191 & 211 & 211 & 217 & 217 & 188 & 188 & 233 & 233 & 162 & 162 & 219 & 219 & 239 & 239 \\
\hline D175144 & YO-B & 191 & 191 & 211 & 225 & 217 & 225 & 184 & 184 & 233 & 233 & 162 & 162 & 219 & 221 & 237 & 239 \\
\hline D175145 & B-GO & 191 & 191 & 211 & 211 & 217 & 217 & 186 & 186 & 233 & 233 & 0 & 0 & 219 & 221 & 233 & 239 \\
\hline D175146 & B-BkW & 191 & 191 & 217 & 217 & 225 & 225 & 188 & 188 & 233 & 233 & 162 & 172 & 219 & 219 & 237 & 239 \\
\hline D175173 & GR-B & 187 & 191 & 211 & 213 & 217 & 217 & 184 & 184 & 233 & 233 & 0 & 0 & 219 & 221 & 239 & 239 \\
\hline D175174 & GG-B & 191 & 191 & 217 & 221 & 217 & 217 & 184 & 184 & 233 & 233 & 160 & 160 & 219 & 221 & 239 & 239 \\
\hline D175175 & GW-B & 191 & 191 & 225 & 227 & 217 & 217 & 188 & 188 & 233 & 233 & 170 & 172 & 219 & 219 & 237 & 237 \\
\hline D175176 & GY-B & 191 & 191 & 211 & 217 & 217 & 225 & 186 & 188 & 233 & 233 & 170 & 172 & 219 & 219 & 239 & 239 \\
\hline D175177 & OO-B & 191 & 203 & 217 & 217 & 217 & 217 & 186 & 188 & 233 & 233 & 0 & 0 & 219 & 221 & 237 & 237 \\
\hline D175178 & YY-B & 191 & 191 & 217 & 217 & 217 & 217 & 184 & 184 & 233 & 233 & 0 & 0 & 219 & 219 & 237 & 239 \\
\hline D175179 & RR-B & 191 & 191 & 217 & 227 & 217 & 217 & 184 & 184 & 233 & 233 & 170 & 172 & 219 & 219 & 235 & 237 \\
\hline D175180 & B-OR & 191 & 191 & 217 & 227 & 217 & 217 & 188 & 188 & 233 & 233 & 0 & 0 & 219 & 219 & 239 & 239 \\
\hline D175181 & B- & 191 & 191 & 227 & 227 & 217 & 217 & 184 & 188 & 233 & 233 & 162 & 162 & 219 & 219 & 247 & 247 \\
\hline D175182 & B-OW & 191 & 191 & 221 & 221 & 217 & 217 & 188 & 188 & 233 & 233 & 162 & 172 & 219 & 231 & 239 & 239 \\
\hline D175183 & $\mathrm{B}-\mathrm{OB}$ & 191 & 191 & 211 & 225 & 217 & 217 & 184 & 184 & 233 & 233 & 162 & 162 & 219 & 219 & 237 & 237 \\
\hline D175184 & B-OG & 191 & 191 & 217 & 217 & 225 & 225 & 188 & 188 & 233 & 239 & 0 & 0 & 219 & 219 & 239 & 241 \\
\hline D175186 & OR-B & 191 & 191 & 227 & 227 & 217 & 225 & 184 & 188 & 233 & 233 & 160 & 162 & 219 & 219 & 237 & 237 \\
\hline D175187 & GO-B & 191 & 191 & 217 & 217 & 217 & 217 & 184 & 184 & 233 & 233 & 0 & 0 & 219 & 219 & 237 & 237 \\
\hline D175190 & OY-B & 191 & 191 & 217 & 227 & 217 & 217 & 184 & 184 & 233 & 233 & 170 & 172 & 219 & 219 & 237 & 237 \\
\hline D175191 & OY-B & 191 & 191 & 213 & 217 & 217 & 217 & 184 & 184 & 233 & 239 & 0 & 0 & 221 & 221 & 237 & 241 \\
\hline D175192 & OG-B & 191 & 191 & 217 & 227 & 217 & 217 & 184 & 188 & 233 & 233 & 170 & 170 & 219 & 219 & 237 & 239 \\
\hline D175193 & WW-B & 191 & 191 & 217 & 227 & 217 & 225 & 188 & 188 & 233 & 239 & 160 & 162 & 219 & 219 & 237 & 237 \\
\hline
\end{tabular}




\begin{tabular}{|c|c|c|c|c|c|c|c|c|c|c|c|c|c|c|c|c|c|}
\hline D175194 & BkR-B & 191 & 191 & 221 & 227 & 217 & 217 & 184 & 188 & 233 & 239 & 160 & 162 & 219 & 231 & 239 & 239 \\
\hline D175197 & B-BkR & 191 & 191 & 217 & 227 & 217 & 217 & 184 & 184 & 233 & 233 & 162 & 162 & 219 & 221 & 237 & 237 \\
\hline D175198 & $\mathrm{B}-\mathrm{BkO}$ & 191 & 191 & 211 & 213 & 217 & 217 & 184 & 184 & 233 & 233 & 162 & 162 & 219 & 221 & 239 & 239 \\
\hline D175199 & B-BkG & 191 & 203 & 211 & 213 & 217 & 217 & 184 & 184 & 233 & 233 & 0 & 0 & 219 & 221 & 237 & 239 \\
\hline D175200 & B-BkY & 191 & 191 & 213 & 217 & 217 & 217 & 184 & 184 & 233 & 233 & 162 & 162 & 219 & 219 & 237 & 239 \\
\hline D175201 & - & 191 & 191 & 213 & 227 & 217 & 217 & 186 & 186 & 233 & 233 & 160 & 160 & 221 & 231 & 239 & 239 \\
\hline D175202 & - & 191 & 191 & 217 & 227 & 217 & 217 & 184 & 188 & 233 & 239 & 162 & 162 & 219 & 219 & 239 & 239 \\
\hline D175203 & - & 191 & 191 & 217 & 217 & 217 & 217 & 184 & 184 & 233 & 233 & 162 & 162 & 219 & 221 & 237 & 237 \\
\hline D175204 & - & 191 & 191 & 217 & 227 & 217 & 217 & 184 & 184 & 233 & 233 & 0 & 0 & 231 & 231 & 239 & 239 \\
\hline D175205 & - & 191 & 191 & 217 & 227 & 217 & 217 & 184 & 188 & 239 & 239 & 162 & 172 & 219 & 219 & 237 & 237 \\
\hline D175206 & - & 191 & 191 & 217 & 227 & 217 & 217 & 184 & 188 & 233 & 233 & 162 & 172 & 219 & 219 & 239 & 239 \\
\hline D175207 & - & 191 & 191 & 217 & 217 & 217 & 217 & 184 & 186 & 233 & 233 & 160 & 160 & 219 & 219 & 237 & 237 \\
\hline D175208 & - & 191 & 191 & 217 & 227 & 217 & 217 & 184 & 188 & 233 & 233 & 170 & 170 & 219 & 221 & 239 & 239 \\
\hline D175209 & - & 191 & 191 & 213 & 217 & 217 & 217 & 184 & 186 & 233 & 239 & 162 & 162 & 219 & 219 & 239 & 241 \\
\hline D175210 & - & 191 & 191 & 217 & 217 & 217 & 217 & 184 & 184 & 233 & 233 & 162 & 162 & 219 & 219 & 237 & 239 \\
\hline D175211 & - & 191 & 191 & 217 & 227 & 217 & 217 & 184 & 184 & 233 & 239 & 162 & 172 & 219 & 219 & 237 & 237 \\
\hline D175212 & - & 191 & 191 & 217 & 217 & 217 & 217 & 184 & 188 & 233 & 233 & 170 & 170 & 219 & 231 & 237 & 239 \\
\hline D175213 & - & 191 & 191 & 213 & 217 & 217 & 217 & 184 & 184 & 233 & 239 & 0 & 0 & 219 & 219 & 235 & 237 \\
\hline D175214 & - & 191 & 191 & 217 & 217 & 217 & 217 & 184 & 184 & 233 & 233 & 0 & 0 & 219 & 219 & 237 & 237 \\
\hline D175215 & - & 191 & 191 & 217 & 227 & 217 & 217 & 188 & 188 & 233 & 233 & 170 & 170 & 219 & 219 & 239 & 239 \\
\hline D175216 & - & 191 & 191 & 221 & 227 & 217 & 217 & 184 & 184 & 233 & 233 & 160 & 160 & 219 & 231 & 247 & 247 \\
\hline D175218 & - & 191 & 191 & 217 & 217 & 217 & 217 & 184 & 188 & 233 & 233 & 0 & 0 & 219 & 231 & 237 & 239 \\
\hline D175219 & - & 191 & 191 & 217 & 227 & 217 & 225 & 186 & 186 & 233 & 233 & 170 & 170 & 219 & 219 & 239 & 239 \\
\hline D175223 & - & 191 & 191 & 227 & 227 & 217 & 217 & 184 & 184 & 233 & 233 & 170 & 170 & 219 & 221 & 237 & 237 \\
\hline D175225 & - & 191 & 191 & 217 & 227 & 217 & 217 & 186 & 186 & 233 & 233 & 0 & 0 & 219 & 221 & 239 & 239 \\
\hline D175226 & - & 191 & 191 & 213 & 217 & 217 & 217 & 184 & 184 & 233 & 233 & 170 & 172 & 219 & 219 & 237 & 237 \\
\hline D175227 & - & 191 & 191 & 221 & 227 & 217 & 217 & 184 & 184 & 233 & 239 & 162 & 162 & 219 & 231 & 239 & 239 \\
\hline D175228 & - & 191 & 191 & 217 & 217 & 217 & 217 & 184 & 184 & 233 & 239 & 170 & 172 & 219 & 231 & 237 & 237 \\
\hline D175230 & - & 191 & 191 & 211 & 227 & 217 & 225 & 184 & 188 & 233 & 233 & 170 & 172 & 219 & 231 & 239 & 239 \\
\hline D175231 & - & 191 & 191 & 211 & 211 & 217 & 217 & 184 & 184 & 233 & 233 & 160 & 160 & 219 & 231 & 239 & 239 \\
\hline D175232 & - & 191 & 191 & 217 & 221 & 217 & 217 & 186 & 186 & 233 & 233 & 0 & 0 & 219 & 221 & 239 & 239 \\
\hline D175234 & - & 191 & 191 & 211 & 217 & 217 & 217 & 184 & 186 & 233 & 239 & 160 & 160 & 219 & 231 & 239 & 239 \\
\hline D175237 & - & 191 & 191 & 211 & 227 & 217 & 217 & 184 & 188 & 233 & 233 & 160 & 160 & 219 & 231 & 239 & 239 \\
\hline D175243 & - & 191 & 191 & 221 & 227 & 217 & 217 & 188 & 188 & 233 & 233 & 160 & 162 & 219 & 231 & 237 & 239 \\
\hline D175248 & - & 191 & 191 & 221 & 221 & 217 & 217 & 188 & 188 & 233 & 233 & 162 & 172 & 219 & 231 & 239 & 239 \\
\hline
\end{tabular}




\begin{tabular}{|c|c|c|c|c|c|c|c|c|c|c|c|c|c|c|c|c|c|}
\hline D175250 & - & 191 & 203 & 217 & 217 & 217 & 217 & 184 & 184 & 233 & 233 & 162 & 162 & 219 & 219 & 237 & 239 \\
\hline D175255 & - & 191 & 191 & 227 & 227 & 217 & 217 & 184 & 184 & 233 & 233 & 170 & 172 & 219 & 219 & 247 & 247 \\
\hline D175267 & - & 191 & 203 & 217 & 227 & 217 & 217 & 184 & 184 & 233 & 233 & 162 & 162 & 219 & 219 & 237 & 239 \\
\hline D175271 & - & 191 & 191 & 217 & 217 & 217 & 217 & 186 & 186 & 233 & 233 & 162 & 162 & 219 & 219 & 235 & 237 \\
\hline D175272 & Y-GR & 187 & 191 & 211 & 215 & 217 & 217 & 184 & 184 & 233 & 233 & 0 & 0 & 221 & 221 & 237 & 239 \\
\hline D175273 & Y-OR & 191 & 203 & 211 & 217 & 225 & 225 & 184 & 184 & 233 & 233 & 0 & 0 & 221 & 221 & 237 & 239 \\
\hline D175275 & YB-Y & 191 & 203 & 211 & 211 & 217 & 225 & 188 & 188 & 233 & 233 & 0 & 0 & 221 & 221 & 237 & 239 \\
\hline D175276 & YO-Y & 191 & 203 & 211 & 217 & 217 & 225 & 184 & 184 & 233 & 233 & 162 & 162 & 221 & 221 & 237 & 239 \\
\hline D175278 & YW-Y & 191 & 203 & 211 & 211 & 217 & 217 & 184 & 184 & 233 & 233 & 162 & 162 & 221 & 221 & 239 & 239 \\
\hline
\end{tabular}

South-East Island Population:

\begin{tabular}{|c|c|c|c|c|c|c|c|c|c|c|c|c|c|c|c|c|c|}
\hline \multirow{3}{*}{$\begin{array}{l}\text { Metal } \\
\text { Band } \\
-\end{array}$} & \multirow{3}{*}{$\begin{array}{c}\text { Colour } \\
\text { Band } \\
\text { YY-M }\end{array}$} & \multicolumn{16}{|c|}{ Microsatellite Loci } \\
\hline & & \multicolumn{2}{|c|}{ Cfor0809 } & \multicolumn{2}{|c|}{ Cfor1415 } & \multicolumn{2}{|c|}{ Cfor1617 } & \multicolumn{2}{|c|}{ Cfor1819 } & \multicolumn{2}{|c|}{ Cfor2021 } & \multicolumn{2}{|c|}{ Cfor2627 } & \multicolumn{2}{|c|}{ Cfor2829 } & \multicolumn{2}{|c|}{ Cfor3031 } \\
\hline & & 191 & 191 & 211 & 213 & 217 & 225 & 188 & 188 & 233 & 233 & 162 & 162 & 219 & 221 & 235 & 239 \\
\hline D171523 & - & 191 & 191 & 211 & 215 & 217 & 225 & 184 & 186 & 233 & 233 & 170 & 172 & 219 & 221 & 233 & 239 \\
\hline D171524 & - & 191 & 191 & 211 & 227 & 217 & 217 & 188 & 188 & 233 & 233 & 0 & 0 & 219 & 219 & 235 & 241 \\
\hline D171525 & - & 191 & 191 & 211 & 213 & 217 & 217 & 186 & 186 & 233 & 233 & 0 & 0 & 219 & 219 & 239 & 239 \\
\hline D171526 & - & 191 & 191 & 211 & 213 & 217 & 217 & 184 & 186 & 233 & 233 & 0 & 0 & 221 & 221 & 233 & 233 \\
\hline D171527 & - & 191 & 203 & 211 & 221 & 217 & 217 & 184 & 186 & 233 & 233 & 170 & 172 & 219 & 219 & 233 & 239 \\
\hline D171528 & - & 191 & 203 & 211 & 227 & 217 & 217 & 184 & 184 & 233 & 233 & 0 & 0 & 219 & 221 & 239 & 239 \\
\hline D171531 & - & 187 & 191 & 211 & 213 & 217 & 217 & 184 & 188 & 233 & 233 & 0 & 0 & 219 & 221 & 239 & 239 \\
\hline D171532 & - & 191 & 191 & 211 & 213 & 217 & 217 & 184 & 184 & 233 & 233 & 162 & 172 & 219 & 219 & 233 & 239 \\
\hline D171533 & - & 191 & 191 & 211 & 221 & 217 & 217 & 176 & 176 & 233 & 233 & 0 & 0 & 219 & 221 & 233 & 239 \\
\hline D171534 & - & 191 & 191 & 211 & 213 & 217 & 217 & 176 & 188 & 233 & 233 & 162 & 162 & 219 & 219 & 235 & 235 \\
\hline D171535 & - & 187 & 191 & 213 & 221 & 217 & 217 & 184 & 186 & 233 & 233 & 0 & 0 & 219 & 221 & 233 & 239 \\
\hline D171536 & - & 191 & 203 & 211 & 211 & 217 & 217 & 176 & 176 & 233 & 233 & 0 & 0 & 219 & 219 & 233 & 239 \\
\hline D171537 & - & 191 & 191 & 211 & 211 & 217 & 217 & 184 & 188 & 233 & 233 & 170 & 172 & 219 & 221 & 235 & 239 \\
\hline D171538 & - & 191 & 191 & 215 & 221 & 217 & 217 & 184 & 186 & 233 & 233 & 0 & 0 & 219 & 221 & 233 & 237 \\
\hline D171539 & - & 191 & 191 & 211 & 213 & 217 & 217 & 176 & 176 & 233 & 233 & 0 & 0 & 219 & 219 & 233 & 239 \\
\hline D171540 & - & 191 & 191 & 211 & 213 & 217 & 225 & 184 & 184 & 233 & 233 & 0 & 0 & 219 & 221 & 233 & 237 \\
\hline D171541 & - & 191 & 203 & 211 & 227 & 217 & 217 & 188 & 188 & 233 & 233 & 170 & 172 & 219 & 219 & 233 & 233 \\
\hline
\end{tabular}




\begin{tabular}{|c|c|c|c|c|c|c|c|c|c|c|c|c|c|c|c|c|c|}
\hline D171542 & - & 191 & 191 & 213 & 213 & 217 & 217 & 176 & 188 & 233 & 233 & 0 & 0 & 219 & 219 & 239 & 239 \\
\hline D171583 & - & 191 & 203 & 211 & 211 & 217 & 217 & 184 & 184 & 233 & 233 & 0 & 0 & 219 & 219 & 235 & 239 \\
\hline D171584 & - & 191 & 191 & 211 & 213 & 217 & 217 & 184 & 186 & 233 & 233 & 0 & 0 & 219 & 219 & 233 & 239 \\
\hline D171585 & - & 187 & 191 & 213 & 215 & 217 & 217 & 176 & 186 & 233 & 233 & 0 & 0 & 219 & 219 & 237 & 239 \\
\hline D171586 & - & 191 & 191 & 221 & 221 & 217 & 217 & 184 & 186 & 233 & 233 & 0 & 0 & 219 & 221 & 239 & 239 \\
\hline D171587 & - & 191 & 203 & 221 & 227 & 217 & 225 & 186 & 186 & 233 & 233 & 0 & 0 & 219 & 221 & 239 & 239 \\
\hline D171588 & - & 187 & 191 & 211 & 211 & 217 & 217 & 184 & 184 & 233 & 233 & 0 & 0 & 219 & 221 & 239 & 239 \\
\hline D171589 & - & 191 & 191 & 211 & 211 & 217 & 217 & 184 & 184 & 233 & 233 & 162 & 162 & 219 & 219 & 239 & 241 \\
\hline D171590 & - & 191 & 191 & 211 & 213 & 217 & 217 & 188 & 188 & 233 & 233 & 0 & 0 & 219 & 221 & 235 & 235 \\
\hline D171591 & - & 191 & 203 & 211 & 213 & 217 & 217 & 184 & 184 & 233 & 233 & 0 & 0 & 219 & 219 & 237 & 239 \\
\hline D171592 & - & 191 & 203 & 221 & 227 & 217 & 217 & 184 & 184 & 233 & 233 & 170 & 172 & 219 & 221 & 239 & 239 \\
\hline D171593 & - & 191 & 203 & 221 & 221 & 217 & 217 & 176 & 176 & 233 & 233 & 0 & 0 & 219 & 221 & 233 & 233 \\
\hline D171594 & - & 191 & 191 & 213 & 221 & 217 & 217 & 184 & 186 & 233 & 233 & 162 & 172 & 219 & 219 & 233 & 239 \\
\hline D171595 & - & 191 & 191 & 213 & 221 & 217 & 217 & 188 & 188 & 233 & 233 & 0 & 0 & 219 & 219 & 235 & 239 \\
\hline D171596 & - & 203 & 203 & 211 & 211 & 217 & 225 & 188 & 188 & 233 & 233 & 170 & 172 & 219 & 221 & 239 & 239 \\
\hline D171597 & - & 191 & 191 & 211 & 215 & 217 & 225 & 176 & 184 & 233 & 233 & 0 & 0 & 219 & 219 & 233 & 233 \\
\hline D171598 & - & 191 & 191 & 213 & 227 & 217 & 217 & 188 & 188 & 233 & 233 & 0 & 0 & 219 & 219 & 239 & 239 \\
\hline
\end{tabular}




\section{Appendix 3.2 Assignment of Mangere and South-East Islands Parakeets Using Microsatellites, Mitochondrial DNA, and Morphological Markers.}

Birds were assigned using microsatellite allele frequencies, mitochondrial control region haplotype, and crown plumage variation. $P(\mathrm{FB}), P(\mathrm{RC})$, $P\left(\mathrm{~F}_{1}\right)$, and $P\left(\mathrm{~F}_{2}\right)$ refer to the posterior probabilities of being a Forbes' parakeet, Chatham Island Red-crowned parakeet, $F_{1}$ hybrid, and $F_{2}$ hybrid respectively in the Bayesian assignment test. In the overall assignment, F, H, R and ? stand for Forbes' parakeet, Hybrids, Chatham Island Redcrowned parakeet, and assignment not made due to insufficient data respectively. $\mathrm{H}^{*}$ denotes morphological Forbes' parakeets with Forbes' parakeet microsatellite assignment, but have an ancient hybridisation event detected only by mitochondrial DNA.

Mangere Island Population:

\begin{tabular}{|c|c|c|c|c|c|c|c|c|c|}
\hline \multirow{2}{*}{$\begin{array}{l}\text { Metal } \\
\text { Band }\end{array}$} & \multirow{2}{*}{$\begin{array}{l}\text { Colour } \\
\text { Band }\end{array}$} & \multicolumn{5}{|c|}{ Microsatellites } & \multirow{2}{*}{$\begin{array}{l}\text { mtDNA } \\
\text { Assign }\end{array}$} & \multirow{2}{*}{$\begin{array}{l}\text { Morph. } \\
\text { Assign }\end{array}$} & \multirow{2}{*}{$\begin{array}{c}\text { Overall } \\
\text { Assignment }\end{array}$} \\
\hline & & $P(\mathrm{FB})$ & $P(\mathrm{RC})$ & $P\left(\mathrm{~F}_{1}\right)$ & $P\left(\mathrm{~F}_{2}\right)$ & Assign & & & \\
\hline & BR-G & 0.5752 & 0.1693 & 0.0141 & 0.2414 & MS2 & - & MP3 & $?$ \\
\hline & $B W-G$ & 0.9841 & 0.0000 & 0.0001 & 0.0158 & MS1 & MT3 & MP1 & $\mathrm{F}$ \\
\hline & G-BG & 0.9705 & 0.0060 & 0.0008 & 0.0227 & MS1 & MT4 & MP1 & $\mathrm{H}^{*}$ \\
\hline & G-BO & 0.9663 & 0.0081 & 0.0013 & 0.0243 & MS1 & MT3 & MP1 & $\mathrm{F}$ \\
\hline & G-BR & 0.9588 & 0.0103 & 0.0013 & 0.0296 & MS1 & MT3 & MP1 & $\mathrm{F}$ \\
\hline & G-BW & 0.7247 & 0.1101 & 0.0171 & 0.1481 & MS2 & MT1 & MP1 & $\mathrm{H}$ \\
\hline & G-BY & 0.9018 & 0.0140 & 0.0029 & 0.0813 & MS2 & МT3 & MP1 & $\mathrm{H}$ \\
\hline & G-GW & 0.8286 & 0.0540 & 0.0113 & 0.1061 & MS2 & MT2 & MP1 & $\mathrm{H}$ \\
\hline & G-OW & 0.0235 & 0.8580 & 0.0054 & 0.1131 & MS2 & - & - & $?$ \\
\hline & GO-W & 0.9649 & 0.0078 & 0.0010 & 0.0264 & MS1 & - & MP1 & $?$ \\
\hline & G-RB & 0.9018 & 0.0140 & 0.0029 & 0.0813 & MS2 & MT3 & MP1 & $\mathrm{H}$ \\
\hline & G-RG & 0.8590 & 0.0359 & 0.0046 & 0.1006 & MS2 & MT3 & MP1 & $\mathrm{H}$ \\
\hline & G-RO & 0.9018 & 0.0140 & 0.0029 & 0.0813 & MS2 & МT3 & MP1 & $\mathrm{H}$ \\
\hline & G-RW & 0.0058 & 0.9687 & 0.0004 & 0.0251 & MS3 & MT1 & MP1 & $\mathrm{H}$ \\
\hline & G-RY & 0.9647 & 0.0088 & 0.0014 & 0.0251 & MS1 & MT3 & MP1 & $F$ \\
\hline & G-WB & 0.8129 & 0.0460 & 0.0087 & 0.1324 & MS2 & MT3 & MP1 & $\mathrm{H}$ \\
\hline & G-WG & 0.8129 & 0.0460 & 0.0087 & 0.1324 & MS2 & MT3 & MP1 & $\mathrm{H}$ \\
\hline & GW-G & 0.0192 & 0.8163 & 0.0064 & 0.1582 & MS2 & MT3 & MP1 & $\mathrm{H}$ \\
\hline & G-WO & 0.0316 & 0.7513 & 0.0112 & 0.2059 & MS2 & MT3 & MP1 & $\mathrm{H}$ \\
\hline & G-WR & 0.9649 & 0.0078 & 0.0010 & 0.0264 & MS1 & - & MP1 & $?$ \\
\hline & GW-W & 0.9588 & 0.0103 & 0.0013 & 0.0296 & MS1 & MT3 & MP1 & $\mathrm{F}$ \\
\hline
\end{tabular}




\begin{tabular}{|c|c|c|c|c|c|c|c|c|c|}
\hline & G-WY & 0.0235 & 0.8580 & 0.0054 & 0.1131 & MS2 & MT1 & MP1 & $\mathrm{H}$ \\
\hline & G-YR & 0.0319 & 0.8126 & 0.0098 & 0.1457 & MS2 & MT3 & MP1 & $\mathrm{H}$ \\
\hline & OW-G & 0.6494 & 0.1747 & 0.0154 & 0.1606 & MS2 & MT4 & MP1 & $\mathrm{H}$ \\
\hline & OY-G & 0.9773 & 0.0063 & 0.0007 & 0.0158 & MS1 & MT3 & MP1 & $F$ \\
\hline & RB-G & 0.0319 & 0.8126 & 0.0098 & 0.1457 & MS2 & MT2 & MP1 & $\mathrm{H}$ \\
\hline & $R G-G$ & 0.9790 & 0.0063 & 0.0006 & 0.0141 & MS1 & MT3 & MP1 & $\mathrm{F}$ \\
\hline & RO-G & 0.8590 & 0.0359 & 0.0046 & 0.1006 & MS2 & MT3 & MP1 & $\mathrm{H}$ \\
\hline & RW-G & 0.9588 & 0.0103 & 0.0013 & 0.0296 & MS1 & - & - & $?$ \\
\hline & RW-W & 0.9588 & 0.0103 & 0.0013 & 0.0296 & MS1 & MT2 & MP1 & $\mathrm{H}^{*}$ \\
\hline & $R Y-G$ & 0.0199 & 0.7732 & 0.0218 & 0.1851 & MS2 & MT2 & MP1 & $\mathrm{H}$ \\
\hline & WB-G & 0.3381 & 0.4470 & 0.0072 & 0.2077 & MS2 & MT1 & MP1 & $\mathrm{H}$ \\
\hline & WG-G & 0.6858 & 0.1518 & 0.0145 & 0.1479 & MS2 & MT4 & MP1 & $\mathrm{H}$ \\
\hline & WO-G & 0.9841 & 0.0000 & 0.0001 & 0.0158 & MS1 & MT3 & MP1 & $\mathrm{F}$ \\
\hline & WR-G & 0.9563 & 0.0116 & 0.0014 & 0.0306 & MS1 & MT3 & MP1 & $F$ \\
\hline & W-RW & 0.0302 & 0.8162 & 0.0052 & 0.1484 & MS2 & MT3 & MP1 & $\mathrm{H}$ \\
\hline & W-WB & 0.9590 & 0.0099 & 0.0016 & 0.0295 & MS1 & MT3 & MP1 & $F$ \\
\hline & W-WR & 0.0077 & 0.9179 & 0.0023 & 0.0721 & MS2 & - & MP1 & $?$ \\
\hline & $W Y-G$ & 0.3381 & 0.4470 & 0.0072 & 0.2077 & MS2 & MT1 & - & $?$ \\
\hline & YW-G & 0.1174 & 0.6166 & 0.0251 & 0.2409 & MS2 & MT1 & - & $?$ \\
\hline & $Y-Y G$ & 0.0055 & 0.9892 & 0.0001 & 0.0052 & MS3 & MT4 & - & $?$ \\
\hline D171508 & GG-M & 0.9588 & 0.0103 & 0.0013 & 0.0296 & MS1 & MT2 & MP2 & $\mathrm{H}$ \\
\hline D171511 & BW-M & 0.2206 & 0.5455 & 0.0151 & 0.2187 & MS2 & MT1 & MP1 & $\mathrm{H}$ \\
\hline D171514 & M-RW & 0.9702 & 0.0001 & 0.0001 & 0.0296 & MS1 & MT3 & MP1 & $\mathrm{F}$ \\
\hline D171515 & $M-R B$ & 0.4117 & 0.1852 & 0.0570 & 0.3461 & MS2 & MT2 & MP2 & $\mathrm{H}$ \\
\hline D171516 & M-RY & 0.9781 & 0.0061 & 0.0006 & 0.0152 & MS1 & MT2 & MP1 & $\mathrm{H}^{*}$ \\
\hline D171517 & M-RG & 0.8062 & 0.0409 & 0.0032 & 0.1497 & MS2 & MT3 & MP1 & $\mathrm{H}$ \\
\hline D171518 & M-RO & 0.8463 & 0.0285 & 0.0069 & 0.1183 & MS2 & MT4 & MP1 & $\mathrm{H}$ \\
\hline D171519 & M-WR & 0.8591 & 0.0376 & 0.0055 & 0.0978 & MS2 & MT1 & MP1 & $\mathrm{H}$ \\
\hline D171520 & M-WB & 0.4090 & 0.3450 & 0.0097 & 0.2363 & MS2 & MT3 & MP1 & $\mathrm{H}$ \\
\hline D172001 & M-WY & 0.2668 & 0.4303 & 0.0313 & 0.2717 & MS2 & MT3 & MP1 & $\mathrm{H}$ \\
\hline D172002 & M-WG & 0.9744 & 0.0000 & 0.0001 & 0.0255 & MS1 & - & MP1 & $?$ \\
\hline D172003 & M-WO & 0.2738 & 0.4898 & 0.0102 & 0.2262 & MS2 & - & MP1 & $?$ \\
\hline D172005 & M-BW & 0.8871 & 0.0267 & 0.0074 & 0.0788 & MS2 & MT1 & MP1 & $\mathrm{H}$ \\
\hline D172006 & M-BY & 0.4294 & 0.3379 & 0.0209 & 0.2118 & MS2 & - & MP1 & $?$ \\
\hline D172007 & M-YR & 0.0049 & 0.9517 & 0.0001 & 0.0432 & MS3 & MT3 & MP3 & $\mathrm{H}$ \\
\hline D172008 & $M-Y G$ & 0.3955 & 0.2768 & 0.0114 & 0.3163 & MS2 & MT3 & MP1 & $\mathrm{H}$ \\
\hline D172010 & $M-Y B$ & 0.8053 & 0.0544 & 0.0075 & 0.1327 & MS2 & MT3 & MP1 & $\mathrm{H}$ \\
\hline D172011 & M-GR & 0.9647 & 0.0088 & 0.0014 & 0.0251 & MS1 & MT3 & MP1 & $F$ \\
\hline D172012 & M-GW & 0.4620 & 0.0567 & 0.0524 & 0.4289 & MS2 & - & MP1 & $?$ \\
\hline D172013 & M-GB & 0.8871 & 0.0267 & 0.0074 & 0.0788 & MS2 & MT1 & MP1 & $\mathrm{H}$ \\
\hline D172015 & M-GO & 0.1515 & 0.5966 & 0.0067 & 0.2452 & MS2 & MT3 & MP1 & $\mathrm{H}$ \\
\hline D172016 & RW-M & 0.7565 & 0.0822 & 0.0158 & 0.1456 & MS2 & MT4 & MP3 & $\mathrm{H}$ \\
\hline D172017 & RB-M & 0.9666 & 0.0070 & 0.0011 & 0.0253 & MS1 & - & MP1 & $?$ \\
\hline D172018 & $R Y-M$ & 0.9801 & 0.0059 & 0.0004 & 0.0136 & MS1 & - & MP1 & $?$ \\
\hline D172019 & RG-M & 0.9633 & 0.0084 & 0.0011 & 0.0273 & MS1 & - & MP1 & $?$ \\
\hline D172020 & RO-M & 0.5941 & 0.1348 & 0.0163 & 0.2548 & MS2 & MT3 & MP2 & $\mathrm{H}$ \\
\hline D172021 & WR-M & 0.9695 & 0.0071 & 0.0010 & 0.0224 & MS1 & MT4 & MP1 & $\mathrm{H}^{*}$ \\
\hline D172022 & WB-M & 0.3264 & 0.4178 & 0.0247 & 0.2312 & MS2 & MT3 & MP1 & $\mathrm{F}$ \\
\hline D172023 & WY-M & 0.9379 & 0.0123 & 0.0022 & 0.0475 & MS2 & - & MP1 & $?$ \\
\hline D172024 & WG-M & 0.8920 & 0.0147 & 0.0016 & 0.0918 & MS2 & MT3 & MP1 & $\mathrm{H}$ \\
\hline D172025 & BR-M & 0.9773 & 0.0063 & 0.0007 & 0.0158 & MS1 & - & MP1 & $?$ \\
\hline
\end{tabular}




\begin{tabular}{|c|c|c|c|c|c|c|c|c|c|}
\hline D172026 & WO-M & 0.9195 & 0.0141 & 0.0031 & 0.0633 & MS2 & MT3 & MP1 & $\mathrm{H}$ \\
\hline D172027 & BW-M & 0.4706 & 0.2265 & 0.0160 & 0.2870 & MS2 & MT3 & MP1 & $\mathrm{H}$ \\
\hline D172028 & BY-M & 0.9695 & 0.0071 & 0.0010 & 0.0224 & MS1 & MT1 & MP1 & $\mathrm{H}^{*}$ \\
\hline D172029 & BG-M & 0.9315 & 0.0142 & 0.0035 & 0.0508 & MS2 & MT3 & MP1 & $\mathrm{H}$ \\
\hline D172030 & BO-M & 0.9797 & 0.0000 & 0.0001 & 0.0202 & MS1 & - & MP1 & ? \\
\hline D172031 & YR-M & 0.2990 & 0.3306 & 0.0197 & 0.3508 & MS2 & - & MP1 & ? \\
\hline D172032 & YW-M & 0.5370 & 0.2435 & 0.0081 & 0.2113 & MS2 & MT3 & MP1 & $\mathrm{H}$ \\
\hline D172033 & YB-M & 0.8792 & 0.0318 & 0.0079 & 0.0811 & MS2 & - & MP1 & ? \\
\hline D172034 & YG-M & 0.0891 & 0.7246 & 0.0067 & 0.1797 & MS2 & MT1 & MP1 & $\mathrm{H}$ \\
\hline D172035 & YO-M & 0.6494 & 0.1747 & 0.0154 & 0.1606 & MS2 & MT3 & MP1 & $\mathrm{H}$ \\
\hline D172036 & GR-M & 0.9704 & 0.0000 & 0.0002 & 0.0294 & MS1 & & MP1 & $?$ \\
\hline D172037 & GW-M & 0.6723 & 0.1526 & 0.0151 & 0.1600 & MS2 & MT3 & MP1 & $\mathrm{H}$ \\
\hline D172038 & GB-M & 0.0395 & 0.8307 & 0.0062 & 0.1235 & MS2 & MT3 & MP3 & $\mathrm{H}$ \\
\hline D172040 & M-BO & 0.8935 & 0.0005 & 0.0003 & 0.1058 & MS2 & - & MP1 & ? \\
\hline D172042 & M-YO & 0.9588 & 0.0103 & 0.0013 & 0.0296 & MS1 & MT3 & MP1 & $\mathrm{F}$ \\
\hline D172043 & GO-M & 0.7942 & 0.0764 & 0.0103 & 0.1191 & MS2 & MT2 & MP1 & $\mathrm{H}$ \\
\hline D172044 & M-OO & 0.8602 & 0.0299 & 0.0115 & 0.0984 & MS2 & - & - & $?$ \\
\hline D172046 & M-BB & 0.9790 & 0.0063 & 0.0006 & 0.0141 & MS1 & - & - & $?$ \\
\hline D172047 & M- & 0.9246 & 0.0002 & 0.0004 & 0.0748 & MS2 & - & - & $?$ \\
\hline D172048 & OW-M & 0.0131 & 0.9095 & 0.0028 & 0.0745 & MS2 & - & - & $?$ \\
\hline D172049 & OR-M & 0.8062 & 0.0409 & 0.0032 & 0.1497 & MS2 & MT3 & - & ? \\
\hline D172050 & OY-M & 0.9588 & 0.0103 & 0.0013 & 0.0296 & MS1 & - & - & ? \\
\hline D172051 & OG-M & 0.0068 & 0.9486 & 0.0008 & 0.0438 & MS2 & - & - & $?$ \\
\hline D172052 & OB-M & 0.7883 & 0.0433 & 0.0076 & 0.1608 & MS2 & MT1 & - & $?$ \\
\hline D172053 & M-OW & 0.0088 & 0.8198 & 0.0110 & 0.1604 & MS2 & - & MP5 & $?$ \\
\hline D172054 & M-OR & 0.9110 & 0.0001 & 0.0006 & 0.0884 & MS2 & - & - & $?$ \\
\hline D172055 & M-OY & 0.9695 & 0.0071 & 0.0010 & 0.0224 & MS1 & - & - & ? \\
\hline D172056 & $\mathrm{M}-\mathrm{OG}$ & 0.7883 & 0.0433 & 0.0076 & 0.1608 & MS2 & MT2 & - & $?$ \\
\hline D172057 & M-OB & 0.7429 & 0.0795 & 0.0094 & 0.1682 & MS2 & - & MP1 & $?$ \\
\hline D172058 & $M-Y Y$ & 0.0112 & 0.9180 & 0.0026 & 0.0681 & MS2 & - & MP5 & $?$ \\
\hline D172059 & $M-G G$ & 0.4389 & 0.1830 & 0.0227 & 0.3554 & MS2 & MT3 & MP3 & $\mathrm{H}$ \\
\hline D172061 & M-WW & 0.5283 & 0.2723 & 0.0189 & 0.1804 & MS2 & MT3 & MP1 & $\mathrm{H}$ \\
\hline D174701 & R-GO & 0.0630 & 0.7814 & 0.0039 & 0.1517 & MS2 & MT3 & - & $?$ \\
\hline D174702 & R-RW & 0.3381 & 0.4470 & 0.0072 & 0.2077 & MS2 & - & - & $?$ \\
\hline D174703 & R-BY & 0.8871 & 0.0267 & 0.0074 & 0.0788 & MS2 & - & - & ? \\
\hline D174704 & R-RB & 0.5546 & 0.2268 & 0.0178 & 0.2009 & MS2 & - & - & $?$ \\
\hline D174705 & R-OR & 0.2005 & 0.5023 & 0.0277 & 0.2695 & MS2 & - & - & $?$ \\
\hline D174706 & R-OY & 0.0333 & 0.7325 & 0.0058 & 0.2284 & MS2 & - & - & $?$ \\
\hline D174707 & R-GW & 0.0694 & 0.8102 & 0.0044 & 0.1160 & MS2 & 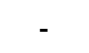 & - & $?$ \\
\hline D174708 & R-RY & 0.0915 & 0.6325 & 0.0324 & 0.2436 & MS2 & - & - & $?$ \\
\hline D174709 & R-BO & 0.9685 & 0.0072 & 0.0006 & 0.0236 & MS1 & - & - & $?$ \\
\hline D174710 & $\mathrm{R}-\mathrm{OG}$ & 0.6140 & 0.1090 & 0.0184 & 0.2586 & MS2 & - & - & $?$ \\
\hline D174711 & R-GY & 0.8871 & 0.0267 & 0.0074 & 0.0788 & MS2 & MT3 & MP1 & $\mathrm{H}$ \\
\hline D174712 & $\mathrm{R}-\mathrm{RG}$ & 0.3959 & 0.3347 & 0.0285 & 0.2409 & MS2 & MT3 & MP1 & $\mathrm{H}$ \\
\hline D174713 & R-WO & 0.0851 & 0.6911 & 0.0180 & 0.2058 & MS2 & MT1 & MP1 & $\mathrm{H}$ \\
\hline D174714 & $\mathrm{R}-\mathrm{RO}$ & 0.9633 & 0.0084 & 0.0011 & 0.0273 & MS1 & MT3 & MP1 & $\mathrm{F}$ \\
\hline D174715 & $R-Y B$ & 0.3959 & 0.3347 & 0.0285 & 0.2409 & MS2 & MT2 & MP1 & $\mathrm{H}$ \\
\hline D174716 & R-WY & 0.9562 & 0.0093 & 0.0010 & 0.0334 & MS1 & - & - & ? \\
\hline D174717 & $R-Y R$ & 0.9649 & 0.0078 & 0.0010 & 0.0264 & MS1 & МТ3 & MP1 & $\mathrm{F}$ \\
\hline D174718 & R-GB & 0.9753 & 0.0068 & 0.0008 & 0.0171 & MS1 & MT3 & MP1 & $\mathrm{F}$ \\
\hline D174719 & R-OB & 0.9649 & 0.0078 & 0.0010 & 0.0264 & MS1 & MT1 & MP1 & $\mathrm{H}$ \\
\hline
\end{tabular}




\begin{tabular}{|c|c|c|c|c|c|c|c|c|c|}
\hline D174774 & $R-Y G$ & 0.1731 & 0.5534 & 0.0293 & 0.2442 & MS2 & MT3 & MP1 & $\mathrm{H}$ \\
\hline D175001 & BY-G & 0.9505 & 0.0098 & 0.0011 & 0.0386 & MS1 & MT3 & - & ? \\
\hline D175002 & G-YW & 0.8457 & 0.0296 & 0.0044 & 0.1204 & MS2 & MT2 & MP1 & $\mathrm{H}$ \\
\hline D175003 & G-YB & 0.9732 & 0.0005 & 0.0008 & 0.0255 & MS1 & MT3 & MP1 & $\mathrm{F}$ \\
\hline D175004 & YB-G & 0.9647 & 0.0088 & 0.0014 & 0.0251 & MS1 & MT3 & MP3 & $\mathrm{H}$ \\
\hline D175005 & G-YO & 0.3139 & 0.3872 & 0.0323 & 0.2666 & MS2 & MT3 & MP1 & $\mathrm{H}$ \\
\hline D175006 & BG-G & 0.7942 & 0.0764 & 0.0103 & 0.1191 & MS2 & MT3 & MP1 & $\mathrm{H}$ \\
\hline D175007 & G-YG & 0.0916 & 0.6470 & 0.0153 & 0.2461 & MS2 & MT3 & MP1 & $\mathrm{H}$ \\
\hline D175009 & YG-G & 0.9633 & 0.0084 & 0.0011 & 0.0273 & MS1 & MT3 & MP2 & $\mathrm{H}$ \\
\hline D175010 & BO-G & 0.0656 & 0.7731 & 0.0070 & 0.1543 & MS2 & MT3 & MP1 & $\mathrm{H}$ \\
\hline D175013 & GR-G & 0.9704 & 0.0000 & 0.0002 & 0.0294 & MS1 & MT3 & MP1 & $\mathrm{F}$ \\
\hline D175014 & G-GY & 0.0055 & 0.9821 & 0.0002 & 0.0122 & MS3 & MT4 & MP5 & $\mathrm{R}$ \\
\hline D175015 & G-GO & 0.2399 & 0.5949 & 0.0049 & 0.1603 & MS2 & MT3 & MP2 & $\mathrm{H}$ \\
\hline D175016 & G-OR & 0.6191 & 0.1534 & 0.0135 & 0.2140 & MS2 & MT1 & MP1 & $\mathrm{H}$ \\
\hline D175017 & G-OB & 0.0081 & 0.9271 & 0.0037 & 0.0611 & MS2 & MT4 & MP4 & $\mathrm{H}$ \\
\hline D175018 & GO-G & 0.9685 & 0.0072 & 0.0006 & 0.0236 & MS1 & - & MP1 & $?$ \\
\hline D175019 & GB-G & 0.5137 & 0.1787 & 0.0119 & 0.2956 & MS2 & MT2 & MP5 & $\mathrm{H}$ \\
\hline D175020 & GY-G & 0.7181 & 0.0034 & 0.0005 & 0.2780 & MS2 & MT4 & MP1 & $\mathrm{H}$ \\
\hline D175021 & G-OG & 0.7942 & 0.0764 & 0.0103 & 0.1191 & MS2 & MT3 & MP1 & $\mathrm{H}$ \\
\hline D175022 & G-OY & 0.0060 & 0.9581 & 0.0006 & 0.0353 & MS3 & MT4 & MP5 & $\mathrm{R}$ \\
\hline D175023 & OR-G & 0.0981 & 0.7065 & 0.0072 & 0.1882 & MS2 & MT1 & MP1 & $\mathrm{H}$ \\
\hline D175101 & RW-B & 0.0262 & 0.8550 & 0.0055 & 0.1133 & MS2 & MT3 & MP2 & $\mathrm{H}$ \\
\hline D175102 & RB-B & 0.0109 & 0.9118 & 0.0038 & 0.0735 & MS2 & MT2 & MP1 & $\mathrm{H}$ \\
\hline D175103 & $R Y-B$ & 0.9845 & 0.0000 & 0.0000 & 0.0154 & MS1 & МТ3 & MP1 & $\mathrm{F}$ \\
\hline D175104 & RG-B & 0.9797 & 0.0001 & 0.0000 & 0.0202 & MS1 & MT3 & MP1 & $\mathrm{F}$ \\
\hline D175105 & B-RW & 0.0549 & 0.6652 & 0.0213 & 0.2585 & MS2 & MT3 & MP1 & $\mathrm{H}$ \\
\hline D175106 & B-RB & 0.0612 & 0.7482 & 0.0072 & 0.1833 & MS2 & MT3 & MP1 & $\mathrm{H}$ \\
\hline D175107 & $\mathrm{B}-\mathrm{RY}$ & 0.0342 & 0.8477 & 0.0031 & 0.1150 & MS2 & MT3 & MP3 & $\mathrm{H}$ \\
\hline D175108 & $B-R G$ & 0.1053 & 0.6002 & 0.0138 & 0.2807 & MS2 & MT3 & MP1 & $\mathrm{H}$ \\
\hline D175109 & B-RO & 0.0165 & 0.7146 & 0.0044 & 0.2645 & MS2 & МT3 & MP1 & $\mathrm{H}$ \\
\hline D175110 & B-WR & 0.7634 & 0.0774 & 0.0040 & 0.1552 & MS2 & - & MP3 & $?$ \\
\hline D175111 & B-WB & 0.9563 & 0.0116 & 0.0014 & 0.0306 & MS1 & MT3 & MP1 & $\mathrm{F}$ \\
\hline D175112 & RO-B & 0.9647 & 0.0088 & 0.0014 & 0.0251 & MS1 & - & MP1 & $?$ \\
\hline D175113 & B-WY & 0.7783 & 0.0898 & 0.0108 & 0.1212 & MS2 & MT3 & MP1 & $\mathrm{H}$ \\
\hline D175114 & WR-B & 0.9883 & 0.0000 & 0.0000 & 0.0116 & MS1 & MT3 & MP1 & $\mathrm{F}$ \\
\hline D175115 & WB-B & 0.0161 & 0.8979 & 0.0034 & 0.0825 & MS2 & MT3 & MP1 & $\mathrm{H}$ \\
\hline D175116 & B-WG & 0.0182 & 0.9058 & 0.0023 & 0.0738 & MS2 & MT3 & MP1 & $\mathrm{H}$ \\
\hline D175117 & WY-B & 0.8792 & 0.0318 & 0.0079 & 0.0811 & MS2 & MT3 & MP1 & $\mathrm{H}$ \\
\hline D175118 & BW-B & 0.8733 & 0.0026 & 0.0042 & 0.1199 & MS2 & MT3 & MP1 & $\mathrm{H}$ \\
\hline D175119 & B-WO & 0.0096 & 0.9212 & 0.0024 & 0.0668 & MS2 & MT3 & MP1 & $\mathrm{H}$ \\
\hline D175120 & B-BR & 0.2063 & 0.5930 & 0.0071 & 0.1936 & MS2 & MT3 & MP1 & $\mathrm{H}$ \\
\hline D175121 & B-BW & 0.5908 & 0.1732 & 0.0142 & 0.2218 & MS2 & MT3 & MP1 & $\mathrm{H}$ \\
\hline D175122 & B-BY & 0.0517 & 0.8150 & 0.0087 & 0.1246 & MS2 & MT3 & MP1 & $\mathrm{H}$ \\
\hline D175123 & WG-B & 0.5610 & 0.2184 & 0.0081 & 0.2126 & MS2 & MT3 & MP1 & $\mathrm{H}$ \\
\hline D175124 & $B-B G$ & 0.9010 & 0.0301 & 0.0035 & 0.0654 & MS2 & MT3 & MP2 & $\mathrm{H}$ \\
\hline D175125 & B-BO & 0.9745 & 0.0062 & 0.0005 & 0.0187 & MS1 & MT3 & MP3 & $\mathrm{H}$ \\
\hline D175126 & WO-B & 0.0131 & 0.8850 & 0.0053 & 0.0965 & MS2 & MT3 & MP1 & $\mathrm{H}$ \\
\hline D175127 & BR-B & 0.0252 & 0.8475 & 0.0024 & 0.1249 & MS2 & MT3 & MP2 & $\mathrm{H}$ \\
\hline D175128 & B-YR & 0.9741 & 0.0072 & 0.0009 & 0.0178 & MS1 & МT3 & MP1 & $\mathrm{F}$ \\
\hline D175129 & BY-B & 0.9130 & 0.0189 & 0.0033 & 0.0648 & MS2 & MT3 & MP1 & $\mathrm{H}$ \\
\hline D175130 & B-YW & 0.9321 & 0.0178 & 0.0023 & 0.0478 & MS2 & MT1 & MP1 & $\mathrm{H}$ \\
\hline
\end{tabular}




\begin{tabular}{|c|c|c|c|c|c|c|c|c|c|}
\hline D175131 & B-YB & 0.2387 & 0.2483 & 0.0622 & 0.4508 & MS2 & MT4 & MP1 & $\mathrm{H}$ \\
\hline D175132 & BG-B & 0.9674 & 0.0001 & 0.0001 & 0.0325 & MS1 & MT1 & MP1 & $\mathrm{H}^{*}$ \\
\hline D175133 & B-YG & 0.0992 & 0.7027 & 0.0105 & 0.1876 & MS2 & MT2 & MP1 & $\mathrm{H}$ \\
\hline D175134 & BO-B & 0.0189 & 0.8378 & 0.0132 & 0.1301 & MS2 & MT4 & MP4 & $\mathrm{H}$ \\
\hline D175135 & YR-B & 0.9647 & 0.0088 & 0.0014 & 0.0251 & MS1 & MT3 & MP1 & $\mathrm{F}$ \\
\hline D175136 & YW-B & 0.9753 & 0.0068 & 0.0008 & 0.0171 & MS1 & - & MP1 & ? \\
\hline D175139 & B-GR & 0.8792 & 0.0318 & 0.0079 & 0.0811 & MS2 & MT3 & MP1 & $\mathrm{H}$ \\
\hline D175140 & B-GW & 0.0060 & 0.9579 & 0.0006 & 0.0355 & MS3 & - & MP4 & ? \\
\hline D175141 & YG-B & 0.3631 & 0.2892 & 0.0113 & 0.3364 & MS2 & MT3 & MP1 & $\mathrm{H}$ \\
\hline D175142 & B-GB & 0.8939 & 0.0352 & 0.0037 & 0.0672 & MS2 & MT1 & MP1 & $\mathrm{H}$ \\
\hline D175143 & B-GY & 0.0086 & 0.9223 & 0.0010 & 0.0680 & MS2 & MT4 & MP4 & $\mathrm{H}$ \\
\hline D175144 & YO-B & 0.1287 & 0.3877 & 0.0830 & 0.4005 & MS2 & MT4 & MP4 & $\mathrm{H}$ \\
\hline D175145 & B-GO & 0.0054 & 0.9641 & 0.0003 & 0.0302 & MS3 & MT2 & MP4 & $\mathrm{H}$ \\
\hline D175146 & B-BkW & 0.3222 & 0.4241 & 0.0146 & 0.2391 & MS2 & MT3 & MP1 & $\mathrm{H}$ \\
\hline D175173 & GR-B & 0.0055 & 0.9629 & 0.0013 & 0.0303 & MS3 & MT3 & MP4 & $\mathrm{H}$ \\
\hline D175174 & GG-B & 0.0162 & 0.8840 & 0.0047 & 0.0950 & MS2 & MT3 & MP1 & $\mathrm{H}$ \\
\hline D175175 & GW-B & 0.9705 & 0.0060 & 0.0008 & 0.0227 & MS1 & MT4 & MP1 & $\mathrm{H}^{*}$ \\
\hline D175176 & GY-B & 0.0173 & 0.8742 & 0.0050 & 0.1034 & MS2 & MT3 & MP1 & $\mathrm{H}$ \\
\hline D175177 & OО-B & 0.4073 & 0.2585 & 0.0187 & 0.3155 & MS2 & MT1 & MP1 & $\mathrm{H}$ \\
\hline D175178 & YY-B & 0.7783 & 0.0898 & 0.0108 & 0.1212 & MS2 & MT3 & MP1 & $\mathrm{H}$ \\
\hline D175179 & RR-B & 0.9649 & 0.0078 & 0.0010 & 0.0264 & MS1 & MT4 & MP1 & $\mathrm{H}^{*}$ \\
\hline D175180 & B-OR & 0.3381 & 0.4470 & 0.0072 & 0.2077 & MS2 & MT3 & MP1 & $\mathrm{H}$ \\
\hline D175181 & B- & 0.9802 & 0.0001 & 0.0000 & 0.0197 & MS1 & MT3 & MP1 & $\mathrm{F}$ \\
\hline D175182 & B-OW & 0.0099 & 0.9367 & 0.0011 & 0.0522 & MS2 & МТ3 & MP1 & $\mathrm{H}$ \\
\hline D175183 & B-OB & 0.8162 & 0.0288 & 0.0101 & 0.1449 & MS2 & MT2 & MP1 & $\mathrm{H}$ \\
\hline D175184 & B-OG & 0.1982 & 0.5586 & 0.0071 & 0.2360 & MS2 & MT3 & MP1 & $\mathrm{H}$ \\
\hline D175186 & OR-B & 0.9026 & 0.0220 & 0.0028 & 0.0726 & MS2 & MT3 & MP1 & $\mathrm{H}$ \\
\hline D175187 & GO-B & 0.9563 & 0.0116 & 0.0014 & 0.0306 & MS1 & MT3 & MP1 & $\mathrm{F}$ \\
\hline D175190 & OY-B & 0.9588 & 0.0103 & 0.0013 & 0.0296 & MS1 & MT3 & MP1 & $\mathrm{F}$ \\
\hline D175191 & OY-B & 0.2697 & 0.4204 & 0.0171 & 0.2928 & MS2 & MT2 & MP3 & $\mathrm{H}$ \\
\hline D175192 & OG-B & 0.7942 & 0.0764 & 0.0103 & 0.1191 & MS2 & MT1 & MP1 & $\mathrm{H}$ \\
\hline D175193 & WW-B & 0.9413 & 0.0108 & 0.0020 & 0.0459 & MS2 & MT1 & MP1 & $\mathrm{H}$ \\
\hline D175194 & BkR-B & 0.1127 & 0.6411 & 0.0127 & 0.2335 & MS2 & MT3 & MP1 & $\mathrm{H}$ \\
\hline D175197 & B-BkR & 0.8590 & 0.0359 & 0.0046 & 0.1006 & MS2 & MT3 & MP1 & $\mathrm{H}$ \\
\hline D175198 & B-BkO & 0.0086 & 0.9302 & 0.0024 & 0.0588 & MS2 & MT4 & MP4 & $\mathrm{H}$ \\
\hline D175199 & B-BkG & 0.0096 & 0.8590 & 0.0116 & 0.1199 & MS2 & MT2 & MP4 & $\mathrm{H}$ \\
\hline D175200 & B-BkY & 0.6858 & 0.1518 & 0.0145 & 0.1479 & MS2 & MT3 & MP1 & $\mathrm{H}$ \\
\hline D175201 & & 0.0290 & 0.8622 & 0.0034 & 0.1054 & MS2 & MT3 & - & $?$ \\
\hline D175202 & & 0.5610 & 0.2184 & 0.0081 & 0.2126 & MS2 & MT3 & - & ? \\
\hline D175203 & & 0.8496 & 0.0425 & 0.0049 & 0.1030 & MS2 & MT3 & - & ? \\
\hline D175204 & & 0.1223 & 0.7090 & 0.0050 & 0.1637 & MS2 & MT3 & - & ? \\
\hline D175205 & & 0.9839 & 0.0059 & 0.0004 & 0.0099 & MS1 & MT3 & - & $?$ \\
\hline D175206 & & 0.3381 & 0.4470 & 0.0072 & 0.2077 & MS2 & MT1 & - & $?$ \\
\hline D175207 & & 0.9563 & 0.0116 & 0.0014 & 0.0306 & MS1 & MT3 & MP1 & $\mathrm{F}$ \\
\hline D175208 & & 0.0981 & 0.7065 & 0.0072 & 0.1882 & MS2 & MT3 & MP2 & $\mathrm{H}$ \\
\hline D175209 & & 0.3786 & 0.3669 & 0.0095 & 0.2450 & MS2 & MT3 & MP1 & $\mathrm{H}$ \\
\hline D175210 & & 0.7783 & 0.0898 & 0.0108 & 0.1212 & MS2 & MT3 & MP1 & $\mathrm{H}$ \\
\hline D175211 & & 0.9753 & 0.0068 & 0.0008 & 0.0171 & MS1 & MT2 & MP3 & $\mathrm{H}$ \\
\hline D175212 & & 0.6494 & 0.1747 & 0.0154 & 0.1606 & MS2 & МT3 & - & $?$ \\
\hline D175213 & & 0.9695 & 0.0071 & 0.0010 & 0.0224 & MS1 & MT3 & - & ? \\
\hline D175214 & & 0.9563 & 0.0116 & 0.0014 & 0.0306 & MS1 & MT3 & MP1 & $\mathrm{F}$ \\
\hline
\end{tabular}




\begin{tabular}{|c|c|c|c|c|c|c|c|c|c|}
\hline D175215 & & 0.3381 & 0.4470 & 0.0072 & 0.2077 & MS2 & MT4 & MP3 & $\mathrm{H}$ \\
\hline D175216 & & 0.8479 & 0.0011 & 0.0005 & 0.1505 & MS2 & MT3 & MP3 & $\mathrm{H}$ \\
\hline D175218 & & 0.6494 & 0.1747 & 0.0154 & 0.1606 & MS2 & MT3 & - & $?$ \\
\hline D175219 & & 0.1496 & 0.6475 & 0.0071 & 0.1959 & MS2 & MT3 & - & ? \\
\hline D175223 & & 0.8652 & 0.0322 & 0.0043 & 0.0983 & MS2 & MT3 & MP1 & $\mathrm{H}$ \\
\hline D175225 & & 0.0981 & 0.7065 & 0.0072 & 0.1882 & MS2 & МT3 & - & $?$ \\
\hline D175226 & & 0.9376 & 0.0176 & 0.0021 & 0.0427 & MS2 & MT3 & MP2 & $\mathrm{H}$ \\
\hline D175227 & & 0.1127 & 0.6411 & 0.0127 & 0.2335 & MS2 & MT3 & - & $?$ \\
\hline D175228 & & 0.9590 & 0.0099 & 0.0016 & 0.0295 & MS1 & МT3 & - & $?$ \\
\hline D175230 & & 0.0116 & 0.9059 & 0.0043 & 0.0781 & MS2 & MT3 & - & $?$ \\
\hline D175231 & & 0.0068 & 0.9459 & 0.0007 & 0.0466 & MS2 & MT1 & - & $?$ \\
\hline D175232 & & 0.0162 & 0.8840 & 0.0047 & 0.0950 & MS2 & MT3 & - & $?$ \\
\hline D175234 & & 0.0696 & 0.6907 & 0.0119 & 0.2278 & MS2 & MT3 & MP1 & $\mathrm{H}$ \\
\hline D175237 & & 0.0260 & 0.8479 & 0.0062 & 0.1198 & MS2 & MT3 & - & ? \\
\hline D175243 & & 0.2571 & 0.4761 & 0.0296 & 0.2372 & MS2 & MT3 & - & $?$ \\
\hline D175248 & & 0.0099 & 0.9367 & 0.0011 & 0.0522 & MS2 & MT3 & - & $?$ \\
\hline D175250 & & 0.2918 & 0.3923 & 0.0275 & 0.2884 & MS2 & MT3 & - & $?$ \\
\hline D175255 & & 0.9802 & 0.0001 & 0.0000 & 0.0197 & MS1 & MT4 & - & $?$ \\
\hline D175267 & & 0.3101 & 0.3664 & 0.0283 & 0.2952 & MS2 & MT4 & - & $?$ \\
\hline D175271 & & 0.9633 & 0.0084 & 0.0011 & 0.0273 & MS1 & MT3 & - & $?$ \\
\hline D175272 & Y-GR & 0.0053 & 0.9535 & 0.0009 & 0.0404 & MS3 & MT1 & MP4 & $\mathrm{H}$ \\
\hline D175273 & Y-OR & 0.0056 & 0.9503 & 0.0021 & 0.0420 & MS3 & МT3 & - & $?$ \\
\hline D175275 & YB-Y & 0.0055 & 0.9687 & 0.0006 & 0.0252 & MS3 & MT3 & - & ? \\
\hline D175276 & YO-Y & 0.0059 & 0.9231 & 0.0044 & 0.0666 & MS2 & MT4 & - & $?$ \\
\hline D175278 & $Y W-Y$ & 0.0055 & 0.9853 & 0.0001 & 0.0091 & MS3 & - & - & $?$ \\
\hline
\end{tabular}


South-East Island Population:

\begin{tabular}{|c|c|c|c|c|c|c|c|c|c|}
\hline \multirow{2}{*}{$\begin{array}{l}\text { Metal } \\
\text { Band }\end{array}$} & \multirow{2}{*}{$\begin{array}{l}\text { Colour } \\
\text { Band }\end{array}$} & \multicolumn{5}{|c|}{ Microsatellites } & \multirow{2}{*}{$\begin{array}{l}\text { mtDNA } \\
\text { Assign }\end{array}$} & \multirow{2}{*}{$\begin{array}{l}\text { Morph. } \\
\text { Assign }\end{array}$} & \multirow{2}{*}{$\begin{array}{c}\text { Overall } \\
\text { Assignment }\end{array}$} \\
\hline & & $P(\mathrm{FB})$ & $P(\mathrm{RC})$ & $P\left(\mathrm{~F}_{1}\right)$ & $P\left(\mathrm{~F}_{2}\right)$ & Assign & & & \\
\hline & YY-M & 0.0405 & 0.6491 & 0.0312 & 0.2793 & MS2 & - & - & $?$ \\
\hline D171523 & & 0.0054 & 0.9766 & 0.0002 & 0.0178 & MS3 & MT2 & MP5 & $\mathrm{H}$ \\
\hline D171524 & & 0.3825 & 0.2422 & 0.0445 & 0.3308 & MS2 & MT4 & MP5 & $\mathrm{H}$ \\
\hline D171525 & & 0.0247 & 0.8649 & 0.0038 & 0.1066 & MS2 & MT4 & MP5 & $\mathrm{H}$ \\
\hline D171526 & & 0.0050 & 0.9728 & 0.0001 & 0.0222 & MS3 & MT4 & MP5 & $\mathrm{R}$ \\
\hline D171527 & & 0.0054 & 0.9606 & 0.0004 & 0.0336 & MS3 & MT4 & MP5 & $\mathrm{R}$ \\
\hline D171528 & & 0.0061 & 0.9360 & 0.0031 & 0.0548 & MS2 & MT4 & MP5 & $\mathrm{H}$ \\
\hline D171531 & & 0.0055 & 0.9629 & 0.0013 & 0.0303 & MS3 & MT4 & MP5 & $\mathrm{R}$ \\
\hline D171532 & & 0.0062 & 0.8967 & 0.0022 & 0.0949 & MS2 & MT2 & MP5 & $\mathrm{H}$ \\
\hline D171533 & & 0.0054 & 0.9622 & 0.0004 & 0.0320 & MS3 & MT4 & MP5 & $\mathrm{R}$ \\
\hline D171534 & & 0.7507 & 0.0590 & 0.0048 & 0.1855 & MS2 & MT2 & MP5 & $\mathrm{H}$ \\
\hline D171535 & & 0.0051 & 0.9667 & 0.0008 & 0.0274 & MS3 & MT4 & MP5 & $\mathrm{R}$ \\
\hline D171536 & & 0.0054 & 0.9626 & 0.0003 & 0.0317 & MS3 & MT4 & MP5 & $\mathrm{R}$ \\
\hline D171537 & & 0.0272 & 0.6694 & 0.0140 & 0.2894 & MS2 & MT4 & MP5 & $\mathrm{H}$ \\
\hline D171538 & & 0.0051 & 0.8658 & 0.0066 & 0.1225 & MS2 & MT4 & MP5 & $\mathrm{H}$ \\
\hline D171539 & & 0.0062 & 0.8967 & 0.0022 & 0.0949 & MS2 & MT4 & MP5 & $\mathrm{H}$ \\
\hline D171540 & & 0.0057 & 0.8647 & 0.0131 & 0.1164 & MS2 & MT4 & MP5 & $\mathrm{H}$ \\
\hline D171541 & & 0.0051 & 0.9174 & 0.0004 & 0.0771 & MS2 & MT4 & MP5 & $\mathrm{H}$ \\
\hline D171542 & & 0.1240 & 0.7257 & 0.0054 & 0.1448 & MS2 & MT4 & MP5 & $\mathrm{H}$ \\
\hline D171583 & & 0.0169 & 0.6735 & 0.0135 & 0.2960 & MS2 & MT4 & MP5 & $\mathrm{H}$ \\
\hline D171584 & & 0.0062 & 0.8967 & 0.0022 & 0.0949 & MS2 & MT4 & MP5 & $\mathrm{H}$ \\
\hline D171585 & & 0.0134 & 0.7810 & 0.0170 & 0.1886 & MS2 & MT4 & MP5 & $\mathrm{H}$ \\
\hline D171586 & & 0.0070 & 0.9523 & 0.0009 & 0.0398 & MS3 & MT4 & MP5 & $\mathrm{R}$ \\
\hline D171587 & & 0.0058 & 0.9571 & 0.0021 & 0.0350 & MS3 & MT4 & MP5 & $\mathrm{R}$ \\
\hline D171588 & & 0.0054 & 0.9766 & 0.0003 & 0.0177 & MS3 & MT4 & MP5 & $\mathrm{R}$ \\
\hline D171589 & & 0.0182 & 0.8922 & 0.0023 & 0.0873 & MS2 & MT4 & MP5 & $\mathrm{H}$ \\
\hline D171590 & & 0.4878 & 0.1703 & 0.0102 & 0.3317 & MS2 & MT4 & MP5 & $\mathrm{H}$ \\
\hline D171591 & & 0.0288 & 0.7626 & 0.0171 & 0.1915 & MS2 & MT2 & MP5 & $\mathrm{H}$ \\
\hline D171592 & & 0.0066 & 0.9323 & 0.0032 & 0.0579 & MS2 & MT4 & MP5 & $\mathrm{H}$ \\
\hline D171593 & & 0.0053 & 0.9794 & 0.0000 & 0.0152 & MS3 & MT4 & MP5 & $\mathrm{R}$ \\
\hline D171594 & & 0.0069 & 0.8911 & 0.0023 & 0.0996 & MS2 & MT4 & MP5 & $\mathrm{H}$ \\
\hline D171595 & & 0.3706 & 0.3132 & 0.0294 & 0.2867 & MS2 & MT4 & MP5 & $\mathrm{H}$ \\
\hline D171596 & & 0.0055 & 0.9890 & 0.0000 & 0.0055 & MS3 & MT4 & MP5 & $\mathrm{R}$ \\
\hline D171597 & & 0.0049 & 0.9645 & 0.0001 & 0.0305 & MS3 & MT4 & MP5 & $\mathrm{R}$ \\
\hline D171598 & & 0.2228 & 0.5827 & 0.0075 & 0.1871 & MS2 & MT4 & MP5 & $\mathrm{H}$ \\
\hline
\end{tabular}




\section{Appendix 3.3 Genetic Analysis of Interspecific Hybridisation in the World's Only Forbes' Parakeet (Cyanoramphus forbesi) Natural Population}

Manuscript submitted to Conservation Genetics, in press.

Chi-hang Chan ${ }^{1}$, Kaye N. Ballantyne ${ }^{1}$, Hilary Aikman², Denise Fastier ${ }^{3}$, Charles H. Daugherty ${ }^{1}$, and Geoffrey K. Chambers ${ }^{1}$

${ }^{1}$ Institute for Molecular Systematics, School of Biological Sciences, Victoria University of Wellington, PO Box 600, Wellington, New Zealand.

${ }^{2}$ Wellington Conservancy, Department of Conservation, PO Box 5086, Wellington, New Zealand.

${ }^{3}$ Chatham Islands Area Office, Department of Conservation, PO Box 114, Chatham Islands, New Zealand.

Keywords: Cyanoramphus forbesi, hybridisation, microsatellite, mitochondrial DNA, crown plumage morphology

\section{Abstract}

Genetic introgression from Chatham Island Red-crowned parakeet (Cyanoramphus novaezelandiae chathamensis) is a long-standing problem in the conservation of the rare Forbes' parakeet ( $C$. forbesi) on Mangere Island, New Zealand. Microsatellite genotypes, mitochondrial DNA sequences, and morphological markers have been applied to study the situation. An extensive history of hybridisation was detected in the single remaining Forbes' parakeet population, where no less than $81 \%$ of all birds screened are considered hybrids. Genetic markers showed that a large proportion of birds identified as Forbes' parakeets by crown plumage are cryptic hybrids. Only a small proportion of birds with Forbes' parakeet morphotype were found to be genetically distinct from Chatham Island 
Red-crowned parakeets using microsatellite and mitochondrial DNA assignment tests, but these still represent an Evolutionarily Significant Unit (ESU) for conservation.

\section{Introduction}

Forbes' parakeet (Cyanoramphus forbesi) is a highly threatened parrot species found on Mangere Island and the adjacent Little Mangere Island in the Chatham Islands group of New Zealand (Figure 1). Increased urgent attention towards its conservation was prompted after an allozyme electrophoresis study (Triggs \& Daugherty 1996) suggested elevation of Forbes' parakeet from a subspecies of Yellow-crowned parakeet $(C$. auriceps forbesi) to its present full species status. Further studies using mitochondrial control region DNA sequences vindicated this view and convincingly placed Forbes' parakeet phylogenetically basal to all other New Zealand Cyanoramphus parakeets (Boon et al. 2000). Forbes' parakeet is classified by the IUCN as an endangered species.

The Chatham Island Red-crowned parakeet (C. novaezelandiae chathamensis) has not been ranked into IUCN threat categories as a subspecies, but the New Zealand Red-crowned parakeet ( $C$. novaezelandiae), in general, is ranked as vulnerable. The Chatham Island Red-crowned parakeet can be found on the main Chatham Island, Pitt Island, Rangatira (also known as South-East Island), but also visits and breeds on Mangere and Little Mangere Islands (Figure 1). Morphogically, Forbes' parakeets are distinguished from Chatham Island Red-crowned parakeets by a yellow crown with red frontal band that does not extend beyond the eyes. They differ from mainland Yellow-crowned parakeets (C. auriceps) by having yellowish cheeks and are generally larger in size. In contrast, Chatham Island Red-crowned parakeets, a subspecies of New Zealand Red-crowned parakeets, are very similar to the mainland 
subspecies (C. n. novaezelandiae), in having only red crown plumage. Hybrids between Forbes' and Chatham Island Red-crowned parakeets can show a range of crown colourations intermediate between the two parent species (Nixon 1982). Forbes' parakeets seem to prefer native forest habitats to open vegetation, while Chatham Island Red-crowned parakeets are more commonly seen on scattered patches of grass (Taylor 1975). Forest clearance for farming on Mangere Island is believed to have promoted interspecific hybridisation between the two taxa in the past (Taylor 1975).

Examination of mitochondrial control region DNA sequences showed four distinct haplotypes from Mangere Island parakeets, and suggested past hybridisations with Chatham Island Red-crowned parakeets may have modified the Forbes' parakeet gene pool (Boon et al. 2001). Haplogroups 1 and 2 (denoted by MT1 and MT2 hereafter) sit respectively within, and basal to, a Red-crowned parakeet clade, and were suggested to represent lineages derived from Red-crowned parakeets hybridising with Forbes' parakeets in the past. Haplogroup 3 (MT3) is basal to all other New Zealand parakeets, and is thought to be the true ancestral Forbes' parakeet haplotype. Birds with the Chatham Island Red-crowned parakeet haplotype (MT4) are also found on Mangere Island.

Interspecific hybridisation can potentially assimilate and displace native genotypes (Huxel 1999), or threaten the existence of rare species (Rhymer \& Simberloff 1996; Wolf et al. 2001). In the case of Forbes' parakeet, where introgression is from the generally more abundant Chatham Island Red-crowned parakeet, there is a high potential risk of complete extinction of the rare ancestral Forbes' parakeet genotypes. Conversely, hybridisation can also be a valuable source of genetic diversity capable of simulating the diversification of populations (Anderson \& Stebbins 1954; Dowling \& Secor 1997), and leading to rapid adaptive 
evolution (Lewontin \& Birch 1966). Through the use of molecular markers, studies in hybrid zones have greatly enhanced opportunities in understanding hybridisation patterns and the role of hybridisation in evolution (reviewed in Barton 2001).

Aimed at identifying 'populations possessing genetic attributes significant for present and future generations of the species in question', the Evolutionarily Significant Unit (ESU) concept was first proposed by Ryder (1986) in order to provide a rational basis for setting priorities in conservation that reflects the underlying genetic diversity. Various different criteria have been suggested to define ESUs (reviewed in Fraser \& Bernatchez 2001). For example, Moritz (1994) defined ESUs as 'reciprocally monophyletic for mtDNA alleles and show significant divergence of allele frequencies at nuclear loci', whereas Crandall et al. (2000) recommended ecological data and genetic variation of adaptive significance be taken into account in establishing ESUs.

To further understand the role that hybridisation plays in Forbes' parakeet and to help guide future management strategies, we first need to accurately identify hybrids and parental types. A scoring scheme based on crown morphology has been developed to identify Forbes' parakeets and their hybrids (Nixon 1982; Greene 2000). However, the correlation between crown plumage patterns and their underlying genetics had not yet been tested. Identification of "pure" Forbes' parakeets in the Mangere Island population is difficult, as it is not easy to find reliable diagnostic markers that are capable of performing this task. This matter is further complicated by the possibility that biological samples obtained in the field may be from birds nearest to the original Forbes' parakeets rather than "pure" Forbes' parakeets. We have previously isolated microsatellite loci from Forbes' parakeet (Chan et al. 2005), and along with mitochondrial control region markers (Boon et al. 2001), it is now possible to investigate 
the relationship between morphology and genetics in Forbes' parakeet, and to examine the extent of hybridisation at the molecular level.

\section{Materials and Methods}

Sample Collection, Morphological Identification, and DNA Extraction

A total of 250 blood and feather samples were collected from the mixed parakeet population on Mangere Island, and a further 35 Chatham Island Red-crowned parakeet blood samples were collected from Rangatira. Most birds were caught in mist-nets. Three breast feathers were taken from all birds caught and were kept in labelled paper envelopes before being sent off the islands. Blood samples were also taken from the wing when liquid nitrogen was available for their storage.

Parakeets were assigned to morphological categories based on crown plumage. A simple five-category scoring scheme (developed by Greene 2000, adapted from Nixon 1982) was used to enable easy field application. MP1 is a bird with Forbes' parakeet morphology: a pure yellow crown and a red frontal band that does not extend to the eye. MP5 has Chatham Island Red-crowned parakeet morphology, with no yellow in the crown. MP2-MP4 cover the plumage variations found between these two. Categories were assigned using a combination of direct field observation and photographic records of the parakeets. A number of parakeets had feather samples collected but could not be assigned morphological categories because they were chicks when sampled and their plumage was not yet fully developed.

DNA was extracted from $3 \mu$ l aliquots of blood samples using a phenol / chloroform method (Sambrook et al. 1989), or from feather tips with DNeasy Tissue Kit (Qiagen). 
Screening of Mitochondrial Control Region Haplotypes

A convenient PCR-RFLP screening system has been designed to score the samples for mitochondrial control region DNA haplotypes (Ballantyne et al. 2004). Briefly, the mitochondrial control region was PCR amplified using primers designed by Boon et al. (2001), and the final 1.6kb amplified products were digested with various combinations of restriction enzymes, Clal, Haelll, HindlII, and Rcal (Roche). Agarose gel electrophoresis was then used to analyse the digest fragments and produce characteristic patterns that could be used to assign individuals to membership of haplogroup. The reliability of this scoring method was confirmed by DNA sequencing of PCR products from randomly selected samples. DNA sequencing was performed on an $A B I$ Prism 377 sequencer (Applied Biosystems).

\section{Microsatellite Genotyping}

Six loci, Cfor0809, Cfor1415, Cfor1617, Cfor2021, Cfor2829, and Cfor3031 were selected for this population study. Two other previously isolated polymorphic loci were not used. These were Cfor1819, which showed size homoplasy at the 184bp allele by DNA sequencing, and Cfor2627, where some individuals are homozygous for null alleles (Chan et al. 2005).

PCR amplifications were carried out in 1x PCR buffer (Qiagen), 2mM $\mathrm{MgCl}_{2}, 50 \mathrm{mM} \mathrm{KCl}, 0.1 \mathrm{mM}$ dNTPs, $1 \mu \mathrm{M}$ fluorescein-12-dUTP (Roche), $0.4 \mu \mathrm{M}$ of each primer ( $0.8 \mu \mathrm{M}$ for Cfor2021), and $1 \mathrm{U}$ Taq DNA polymerase (Qiagen). The reactions were run on a Perkin Elmer 480 thermal cycler under conditions described in Chan et al. (2005). The products were analysed using an ABI Prism 377 sequencer and GeneScan Analysis 3.7 software (Applied Biosystems). 
Evaluation of the Stepwise Mutation Model in Forbes' Parakeet Microsatellite Loci

A likelihood test was performed using the software MISAT (Nielsen 1997) to assess the goodness-of-fit of the stepwise mutation model (SMM; Ohta \& Kimura 1973) to the allele frequency spectra of the loci used in this study. The estimator of variance in allele size $\square$ (Valdes et al. 1993), the estimated proportion of multi-step mutations $p$, and the likelihood value $L(\square)$ were estimated using a Markov chain recursion method set for $10^{5}$ runs. The null hypothesis that a locus evolves via SMM was tested by calculation of the likelihood ratio $-2 \log \square$, following Nielsen \& Palsbøll (1999), where $\square=\max [L(\square, p=0)] / \max [L(\square, p)]$. At present, the design of this software does not cater for loci with more than one repetitive theme. Here, the statistics for the locus Cfor2829, which contains both dinucleotide and tetranucleotide repeats (Chan et al. 2005) were not calculated.

Genetic Differentiation Between Mangere Island and Rangatira Populations at Microsatellite Loci

The estimator of $F_{\text {ST }}$ (Weir \& Cockerham 1984), and the inbreeding coefficient $F_{\text {IS }}$ were calculated using the Microsatellite Analyser software (version M3.15; Dieringer \& Schlötterer 2002). The alternate statistic $R_{S T}$ (Slatkin 1995), which is analogous to $F_{S T}$ but also allows for allele size differences under the SMM (Ohta \& Kimura 1973), was estimated by the GENEPOP software (version 3.4; Raymond \& Rousset 1995). Differentiation between the Mangere Island and Rangatira populations was also assessed by Analysis of Molecular Variance (AMOVA; Excoffier et al. 1992) as implemented in the software GeneticStudio (version 2.01; Dyer \& Sork 2001). 
Testing for Genetic Bottleneck Effects in the Parakeet Populations In a bottlenecked population, reduction in allelic diversity (allele numbers) and heterozygosity can be observed, and allelic diversity is reduced faster than heterozygosity. Therefore, recently bottlenecked populations are expected to show heterozygosity values larger than those expected from the observed number of alleles in the population (Cornuet \& Luikart 1996). The possibility of recent bottlenecks in the Mangere Island and Rangatira parakeet populations was tested with microsatellite loci using the software Bottleneck (version 1.2.02; Cornuet \& Luikart 1996). Three tests for heterozygosity excess, each one under the infinite allele model (IAM; Kimura \& Crow 1964), stepwise mutation model (SMM; Ohta \& Kimura 1973), and the two-phase mutation model (TPM; Di Rienzo et al. 1994) are implemented by Bottleneck. All bottleneck tests were run for $10^{6}$ replications, and the TPM tests were run assuming 95\% single-step mutations and $5 \%$ multi-step mutations.

\section{Bayesian Clustering and Population Assignment}

Assignment tests were performed with the software NewHybrids (version 1.1b3; Anderson \& Thompson 2002) using the microsatellite dataset. NewHybrids is similar to the Bayesian method of Pritchard et al. (2000), but given some basic information about the population structure, NewHybrids provides a more detailed picture using an inheritance model defined by genotype. The accuracy of the software in assigning an individual to the correct population was tested with a simulated genotypic dataset of two populations containing 285 individuals using the Easypop software (version 1.8; Balloux 2001). The results (not included) showed that 284 individuals were assigned to their correct population with a posterior probability $\geq 0.95$. To determine the best strategy for the assignment runs, a test run was performed with a simple hypothetical hybridising population consisting of parental species, $F_{1}$ and $F_{2}$ hybrids, 
and various first generation backcrosses. The test was performed using genotypic class and allele frequency assumptions described in Anderson \& Thompson (2002) for the two parental classes, $F_{1}$ and $F_{2}$ hybrids. Under these settings, the assignment results showed that all parental individuals were assigned with a posterior probability $\geq 0.95$ to their respective species, but hybrids and backcrosses showed variable success with respect to assignment scores, e.g. some backcross genotypes had posterior probabilities as high as 0.91 for assignment to a parent species. The parakeet microsatellite genotypic dataset was run for $10^{6}$ sweeps after a burn-in period of $10^{5}$ sweeps. The run was repeated 30 times and each run required 3.75 hours on a Macintosh computer with a PowerPC G3 900Mhz processor.

\section{Ordination and Clustering of Individual Microsatellite Genotypes}

Genetic distances between individuals, including the proportion of shared alleles (Bowcock et al. 1994) and deltamu $(\square \mu)^{2}$ (Goldstein et al. 1995) distances were estimated with the Microsatellite Analyser software (version M3.15; Dieringer \& Schlötterer 2002). The proportion of shared alleles distance matrix was analysed through Principal Coordinates Analysis implemented in the software PCO (Anderson 2003). Neighborjoining trees (Saitou \& Nei 1987) were constructed from 100 bootstrap replica $(\square \mu)^{2}$ matrices with the Neighbor module, in the Phylip software package (version 3.61; Felsenstein 1989).

\section{Correlation Between Genetic and Morphological Characters}

The relationship between microsatellite assignments, mitochondrial control region DNA haplogroups, and crown plumage variations was analysed by Multiple Correspondence Analysis using the MCA module of the ADE-4 software package (Thioulouse et al. 1997). This analysis was performed 
with 169 Mangere Island and the 34 Rangatira parakeet samples from which all three types of data (morphological, microsatellite and mitochondrial DNA) were collected.

\section{Results}

Morphological and Mitochondrial DNA Control Region Haplotype Scorings Crown plumage morphotype data were collected for 169 Mangere Island parakeets and 34 Rangatira parakeets (full dataset can be obtained from authors). In the mixed population on Mangere Island, 136 (80\% of total) of the 169 birds showed Forbes' parakeet crown morphology (MP1), 3 (2\% of total) showed Chatham Island Red-crowned parakeet crowns (MP5), and 30 (18\% of total) showed intermediate hybrid crown morphotypes (10 MP2, $11 \mathrm{MP3}$, and $9 \mathrm{MP4}$ ). On Rangatira, all 34 parakeets scored have typical Chatham Island Red-crowned parakeet morphology (MP5). Thus the preliminary morphological survey showed that the population on Mangere Island is predominantly made up of Forbes' parakeets, while all Rangatira parakeets are Chatham Island Red-crowned parakeets, in line with general expectations.

Screening of 203 of the Mangere Island parakeets and 34 of the Rangatira parakeets for their mitochondrial DNA inheritance patterns showed that, on Mangere Island, 136 (67\% of total) belong to the Forbes' parakeet MT3 maternal lineage, 22 ( $11 \%$ of total) birds are maternally linked to Chatham Island Red-crowned parakeets (MT4), and respectively 26 (13\% of total) and 19 (9\% of total) parakeets have the MT1 and MT2 maternal lineages. This showed at least some of the Forbes' parakeet morphotypes (MP1) must have Forbes' parakeet mitochondrial DNA control region haplotype MT3, supporting the observation by Boon et al. (2001). The data also suggested the presence of cryptic hybrids on Mangere Island that resemble Forbes' parakeet very closely morphologically. In the Rangatira 
population, the majority $(30 ; 88 \%$ of total) of birds have Chatham Island Red-crowned parakeets MT4 maternal haplotype. A further 4 individuals (12\% of total) with the MT2 haplotype are also present.

Mutation Pattern at Microsatellite Loci in Forbes' Parakeet

Allele frequency distributions varied across the microsatellite loci screened. For each of the loci Cfor0809, Cfor1617, Cfor2021, and Cfor2829, the recorded patterns are fairly similar between the two populations, but for Cfor1415 and Cfor3031, some differences between the populations are apparent (Figure 2). Using the method described in Nielsen (1997), all five of the loci tested conformed to SMM expectations in the Rangatira population. However, in the Mangere Island population, only Cfor 1617 and Cfor3031 conformed to strict SMM predictions, and the TPM is a better descriptor for Cfor0809, Cfor1415, and Cfor2021 (Table 1). It is worth noting that stochasticity and sampling effects to some unknown extent may possibly account for some of the differences, and for loci Cfor1617 and Cfor2021, distinguishing between the mutation models is difficult since there are only two observed alleles at each locus.

Sequencing of alleles from these six loci showed that the structure of the repeat motifs are identical between the two populations studied, and that size homoplasy was not detected.

Genetic Differentiation Between Populations and Estimation of Bottleneck Effects

Microsatellite variability was estimated between the Mangere Island and Rangatira parakeet populations at $\mathrm{F}_{\mathrm{ST}}=0.12$ and $\mathrm{R}_{\mathrm{ST}}=0.20$. The higher $R_{S T}$ value suggested the two populations differed more in terms of allele sizes than allele frequencies. Significant differences between the two 
populations was also suggested by AMOVA $(0.18, P=0.01)$. A moderate level of inbreeding in the populations was apparent as suggested by an inbreeding coefficient $F_{I S}$ of 0.15 .

Bottleneck testing using a one tailed Wilcoxon sign-rank test for heterozygosity excess in the Mangere Island population suggested against a significant bottleneck under the IAM $(P=0.22)$, SMM $(P=0.78)$, and TPM $(P=0.58)$. In the Rangatira population, tests for bottleneck were insignificant under either the IAM $(P=0.05)$, or SMM $(P=0.50)$, or TPM $(P=0.41)$.

\section{Bayesian Assignment of Individuals Using Microsatellite Genotypes}

Based on the posterior probabilities in the parental classes $P$ (Forbes') and $P$ (Red-crowned), parakeets from the Mangere Island and Rangatira were scored into three classes. Birds with $P$ (Forbes') $\geq 0.95$ were scored MS1 (Forbes' parakeet), those with $P($ Red-crowned) $\geq 0.95$ were assigned as MS3 (Chatham Island Red-crowned parakeet), and all other birds which did not fit into either of these two classes were scored MS2 (hybrids or unable to assigned). Under this classification, the sampled population on Mangere Island was made up of 67 Forbes' parakeets (27\% of total), 171 hybrids or unassigned (68\% of total), and 12 Chatham Island Redcrowned parakeets ( $5 \%$ of total). On Rangatira, the sampled population was made up of 13 Chatham Island Red-crowned parakeets (37\% of total) and 22 hybrids or unassigned individuals (63\% of total).

A "pure" Forbes' parakeet, therefore, is required to pass three tests. It must be classified MS1 by microsatellites, MT3 by mitochondrial DNA haplotypes, and MP1 by morphology. A "pure" Chatham Island Redcrowned parakeet would have an MS3 microsatellite assignment, mitochondrial DNA haplogroup MT4, and MP5 class morphology. Birds 
which do not match either or the other of these two strict criteria were put in a hybrids category, which also include birds unable to be assigned in the microsatellite assignment test. Applying this classification to the 169 Mangere Island and 34 Rangatira samples which have available microsatellite, mitochondrial DNA and morphological data, the sampled Mangere Island population appears to be made up of $30(18 \%)$ of Forbes' parakeets, $137(81 \%)$ of hybrids, and $2(1 \%)$ of Chatham Island Redcrowned parakeets. On Rangatira, the samples consist of 12 (35\%) Chatham Island Red-crowned parakeets and 22 (65\%) hybrids.

\section{Microsatellite Genetic Distances Between Individuals}

A cumulative $52.6 \%$ of the total variability was represented by the two PCO axes in a Principal Coordinate Analysis of a distance matrix calculated using the Bowcock et al. (1994) distance based on proportion of shared alleles (Figure 3). This genetic distance data was compared to the assignment method described in the previous section, using mitochondrial DNA, morphological, and Bayesian analysis of microsatellite data. The Chatham Island Red-crowned parakeets assigned using the three criteria appeared to cluster fairly closely as a group towards the right hand side in the PCO plot (indicated by triangles), while Forbes' parakeets assigned by the three criteria (indicated by circles) are spread out more and lie towards the left in Figure 3. A large cloud of hybrids or unassigned birds are scattered widely in the centre of the plot but also lie more towards the Forbes' parakeet cluster.

Neighbor-joining trees constructed using $(\square \mu)^{2}$ distances (Figure 4) seem to be of little value in identifying hybrids in the populations. The performance of the test was even worse when other genetic distance measures were used (data not shown). Bootstrap support values tend to be quite low, the highest being only $50 \%$. The tree shows that the majority 
of birds, regardless of their assigned identities, formed a large unresolved cluster. However, one clear extended branch is apparent and is largely made up of Mangere Island parakeets. Among the individuals found along this branch, eight were assigned as "pure" Forbes' parakeets and three were assigned as hybrids by the three criteria test.

\section{Relationships Between Genetic and Morphological Variables}

Association between parameters for "Red-crownedness" (microsatellite class MS3, mitochondrial haplogroup MT4, and morphological scales MP5) is clearly shown in the MCA plot of the variables (Figure 5). There seemed to be a somewhat weaker correlation between Forbes' parakeet parameters (MS1, MT3, and MP1), which are represented in less than $50 \%$ of the screened samples. Other "hybrid" factors (MS2, MT1, MT2, MP2-4) appeared as random features, except that MP4 was closer to the Red-crowned parameters and MP2 fell close to MP3. The plot can be interpreted to suggest that Forbes' parakeet phenotype and genotypes are not as clearly defined as the Chatham Island Red-crowned parakeet.

A more detailed analysis of the correlations was made by pairwise comparison of the three scoring variables in the Mangere Island population (Table 2). Comparing mitochondrial haplotypes with morphology, a total of 40 cryptic hybrids could be identified, that is, those which showed Forbes' parakeet morphotype, but have Red-crowned related mitochondrial haplotypes (Table 2a). The presence of these birds shows that individuals which look like Forbes' parakeets can have a hybridisation history undetectable by plumage phenotype. The microsatellite data also confirm that morphological Forbes' parakeets are actually made up of both "pure" Forbes' parakeets and hybrids (Table 2b). Most birds (74\%) that were assigned by microsatellites as Forbes' parakeets (MS1) were birds that have a Forbes' parakeet mitochondrial 
lineage (MT3; Table 2c), indicating a fairly high level of agreement between the two genetic tests.

\section{Discussion}

The Present Status of the Forbes' Parakeet Population

The results obtained in this study clearly show that Forbes' parakeets have already hybridised fairly extensively with Chatham Island Redcrowned parakeets. Despite this historical record of interspecific hybridisation written in the genes of their descendants, there is still a group of "pure" Forbes' parakeets that remains entirely genetically distinct from Chatham Island Red-crowned parakeets. These parakeets may not be genuine versions of the original Forbes' parakeet types that once inhabited Mangere Island before habitat modification and large-scale hybridisation. Nonetheless, they are likely to represent the nearest "pure" Forbes' parakeet types that still exist anywhere at present.

The original Forbes' parakeet population is believed to have experienced a reduction in population size when Mangere Island was cleared for farming (Taylor 1975). A lack of documentation regarding the parakeet population size before or after forest clearance on Mangere Island makes it quite difficult to determine whether the population is likely to have experienced a genetic bottleneck. Our microsatellite evidence does not support a significant recent genetic bottleneck in the Mangere Island population, but the low numbers of individuals observed by Taylor (1975) suggest there was a demographic bottleneck of uncertain duration in the history of this population.

Hybridisation can introduce adaptive genetic variability into a population (Seehausen 2004), and may even contribute positively to the evolution of a species (see Barton 2001). Further hybridisation in the Mangere Island 
parakeet population, however, would only result in more complete mixing of the gene pool between the two species. The low numbers of "pure" or near-"pure" Forbes' parakeets also suggest that hybridisation has been slowly displacing the Forbes' parakeet parental genotypes, and may constitute a threat to the long-term survival of the integrity of the species, not withstanding the hypothetical benefits.

In any recently derived group of parrots such as the Cyanoramphus parakeets (Boon et al. 2001), a potential to hybridise persists due to the relatively slow development of postzygotic isolating mechanisms (Bigelow 1965; Prager \& Wilson 1975; Grant \& Grant 1992). Despite field observations showed Mangere Island parakeets preferentially mate with morphologically similar parakeets (unpublished data), knowledge about pre-mating barriers between these two species of parakeets is still very limited. The abundance of hybrids on Mangere Island suggests there may be very little pre-mating isolation between Forbes' parakeets, Chatham Island Red-crowned parakeets and their hybrids under the ecological conditions now present.

A major obstacle for the conservation of Forbes' parakeets is arriving at a correct and practical definition of the "pure" Forbes' parakeet. The previous system based solely on morphology suffers from a serious failing in its ability to identify cryptic hybrids. Resolution based on molecular genetics alone is also limited due to failure to resolve some hybrid individuals in the microsatellite assignment test. Also, our PCO plot of genetic distances (Figure 3 ) indicated that the birds classified as Forbes' parakeet can have very variable microsatellite genotypes which some hybrids or unresolved samples shared, and it suggested a number of birds having similar microsatellite genotypes as Forbes' parakeets had a hybridisation history only detectable by mitochondrial haplotypes or crown plumage. Therefore, the three criteria identification system based on both 
genetic and morphological factors is suggested as the best available present solution.

All the birds that we classified as "pure" Forbes' parakeets undoubtedly form an ESU. These birds are important regardless of whether or not they represent the original Forbes' parakeet types. Their significance derives from the fact that they all have the MT3 mitochondrial haplogroup that is phylogenetically basal to all other New Zealand Cyanoramphus species (Boon et al. 2001), they still show significant divergence from Chatham Island Red-crowned parakeets with respect to allele frequencies at nuclear microsatellite loci, and they are morphologically unique.

Number of Loci and Power of Assignment Using Microsatellite Genotypes The resolution and power of assignment tests are dependent on the number of loci included in the analysis and the methods used. Earlier studies using restriction fragment length polymorphisms (RFLP), randomly amplified polymorphic DNA (RAPD), and protein electrophoresis have suggested that four or five markers would be sufficient to classify parental, $F_{1}$ hybrids and simple backcrosses, but that these may not be able to distinguish more complex backcrosses (Boecklen \& Howard 1997). Removal of loci Cfor1415, Cfor1617, and Cfor3031 in our assignment test changed the outcome more than removal of other loci (data not shown), suggesting that more robust assignments might be achieved by using more informative loci. This very desirable objective is limited in parrots by the technical difficulties inherent in isolating a large number of microsatellite loci from the taxa (Hughes et al. 1998; Robertson et al. 2000; Russello et al. 2001; Caparroz et al. 2003; Sainsbury et al. 2004). This may due to a generally low abundance of microsatellites in birds (Primmer et al. 1997). 


\section{General Outlook for the Conservation of Forbes' Parakeet}

Our results have shown that reasonable numbers of Forbes' parakeets that are both morphologically and genetically distinct from Chatham Island Red-crowned parakeets still exist in the Mangere Island population. Although these individual parakeets do have a greater or lesser history of genetic introgression, and none may represent the original Forbes' parakeets present before the modification of the habitat, they are distinct, and hence deserve special conservation attention. Acceptance of some genetic introgression and hybridisation as part of the natural history of Forbes' parakeet does not reduce the survival chances of the species as a whole or diminish its importance.

Hybrids now present on the island were likely to have arisen in part by natural process and in part from anthropogenic causes, since the two species probably co-existed (and hybridised) before human arrival on Mangere Island. Subsequent human activities have certainly promoted interspecific hybridisation. Natural hybrids themselves may deserve some form of special protection (Allendorf et al. 2001) to preserve genetic diversity, but in this case, they should only be protected if this can be achieved without threatening the "pure" or near-"pure" Forbes' parakeets via further backcross hybridisation. The ongoing survival of Forbes' parakeets will depend on careful monitoring and genetic control of the population.

\section{Acknowledgements}

We thank the New Zealand Department of Conservation and Victoria University of Wellington for funding this research. We also thank Tertia Thurley and other field workers for sample collection, James Sainsbury, Elizabeth MacAvoy, Rod Hitchmough, and Colin Miskelly for technical 
assistance, and two anonymous reviewers for their comments on this manuscript.

Figure 1. Map of the Chatham Islands group of New Zealand, showing Mangere Island and Rangatira where field samples were collected.
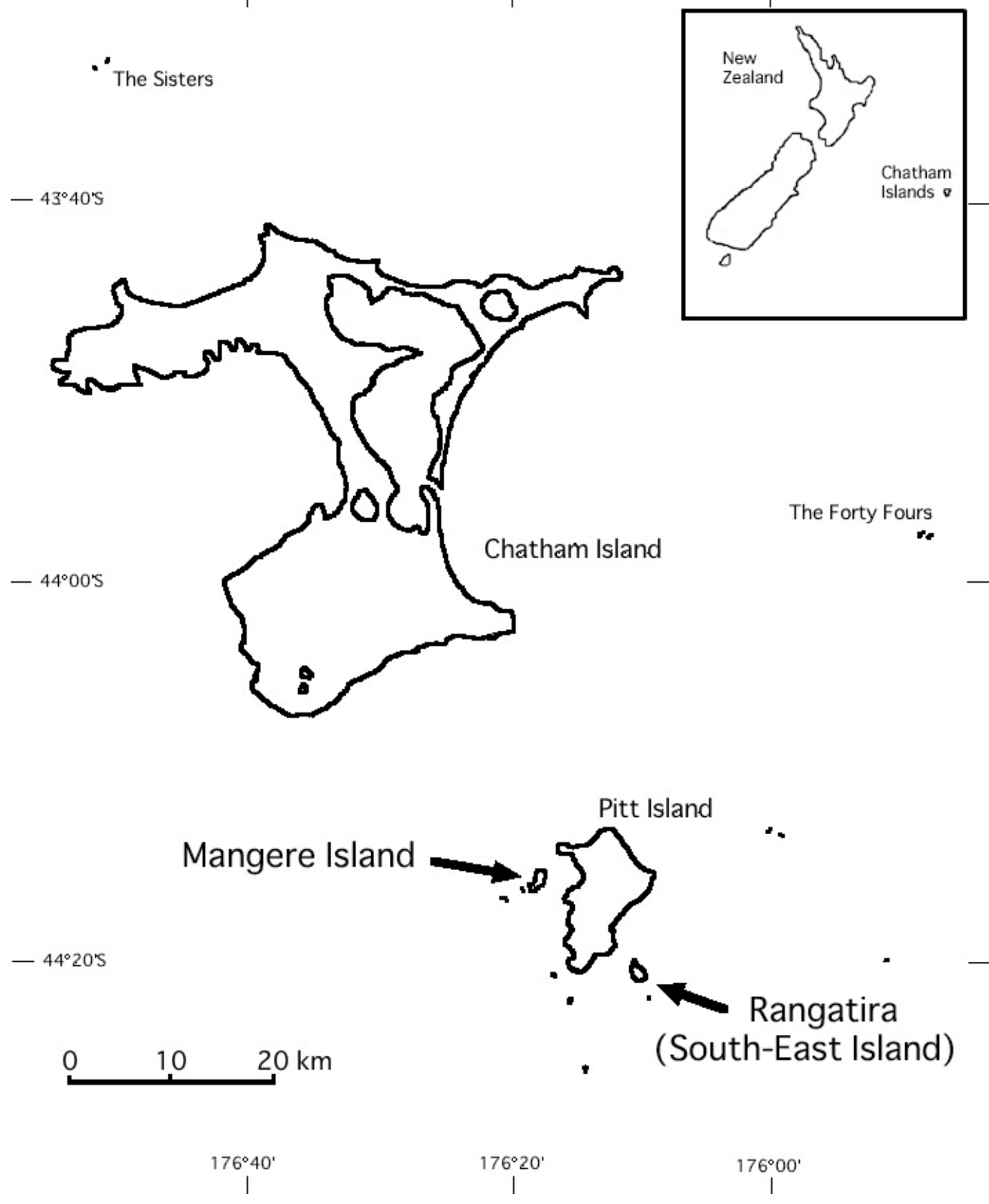
Figure 2. Allele frequency distributions of the six microsatellite loci in two populations of parakeets. The Mangere Island parakeets and Rangatira parakeets are respectively represented by black and grey bars. The $x$-axis in each plot shows the allele sizes, and the $y$-axis shows the allele frequencies.
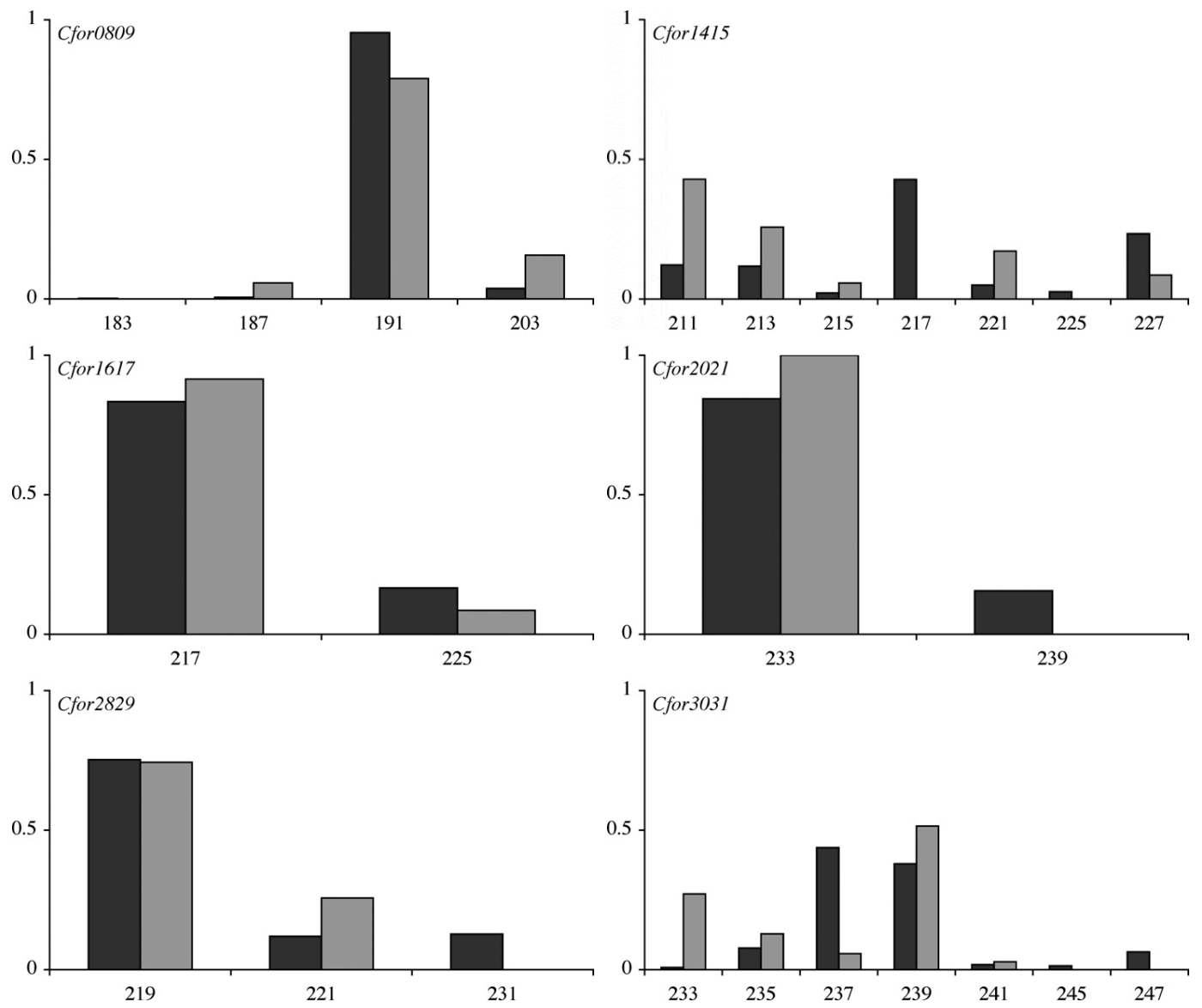
Figure 3. Principal Coordinate Analysis of distance matrix constructed using proportion of shared microsatellite alleles distances (Bowcock et al. 1994). PCO axis 1 and 2 respectively represent $31.5 \%$ and $21.1 \%$ of the total variability. Birds were assigned as Forbes' parakeet, hybrid, or Chatham Island Red-crowned parakeet using mitochondrial DNA control region, morphological data, and microsatellites data by Bayesian method. The symbol $\square$ represents Forbes' parakeets, $\square$ represents hybrids, and $\square$ represents Chatham Island Red-crowned parakeets classified using the three criteria test.

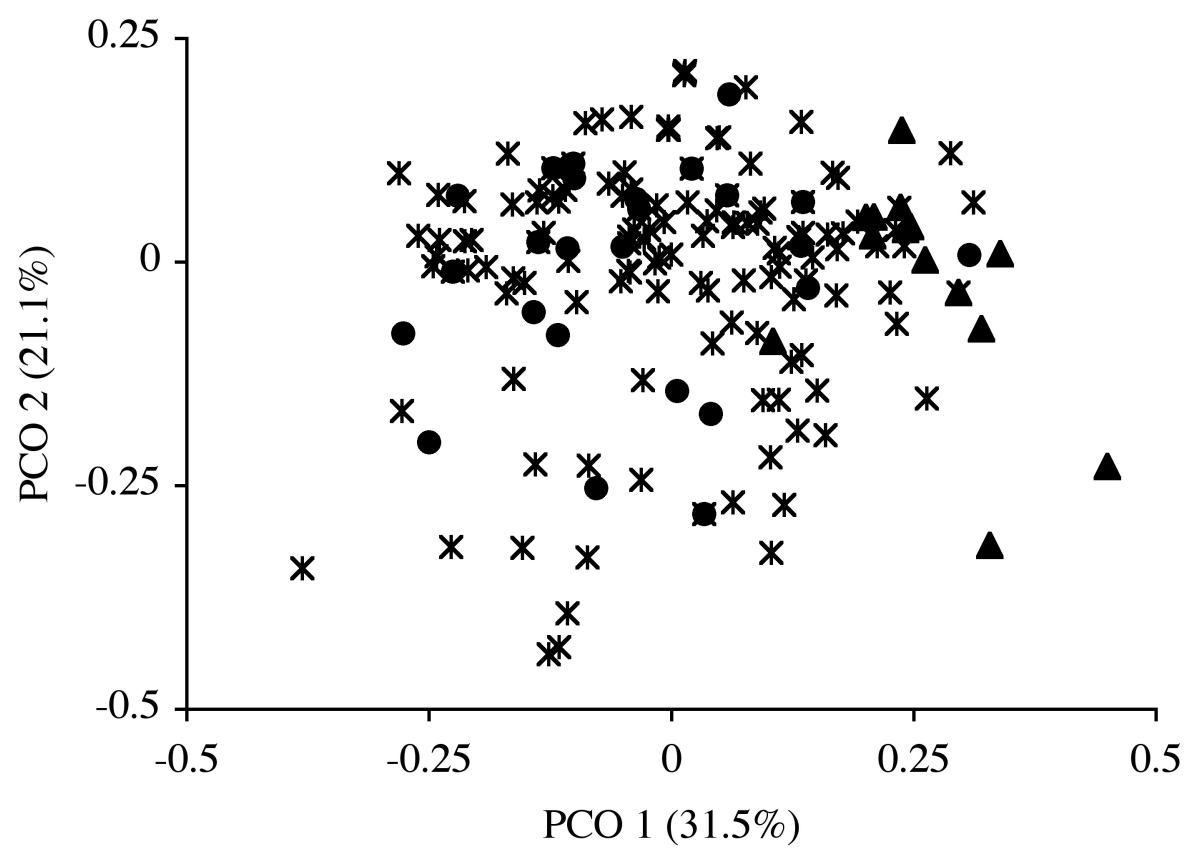


Figure 4. Neighbor-joining tree built from $(\square \mu)^{2}$ genetic distances with 100 bootstrap pseudo replicates. Forbes' parakeets, hybrids, and Chatham Island Red-crowned parakeets were represented by letters $F, H$, and $\mathrm{R}$ respectively. Parakeets with no available mitochondrial DNA and/or morphological data were labelled M (Mangere Island) or S (Rangatira) dependent on the site of sample collection.

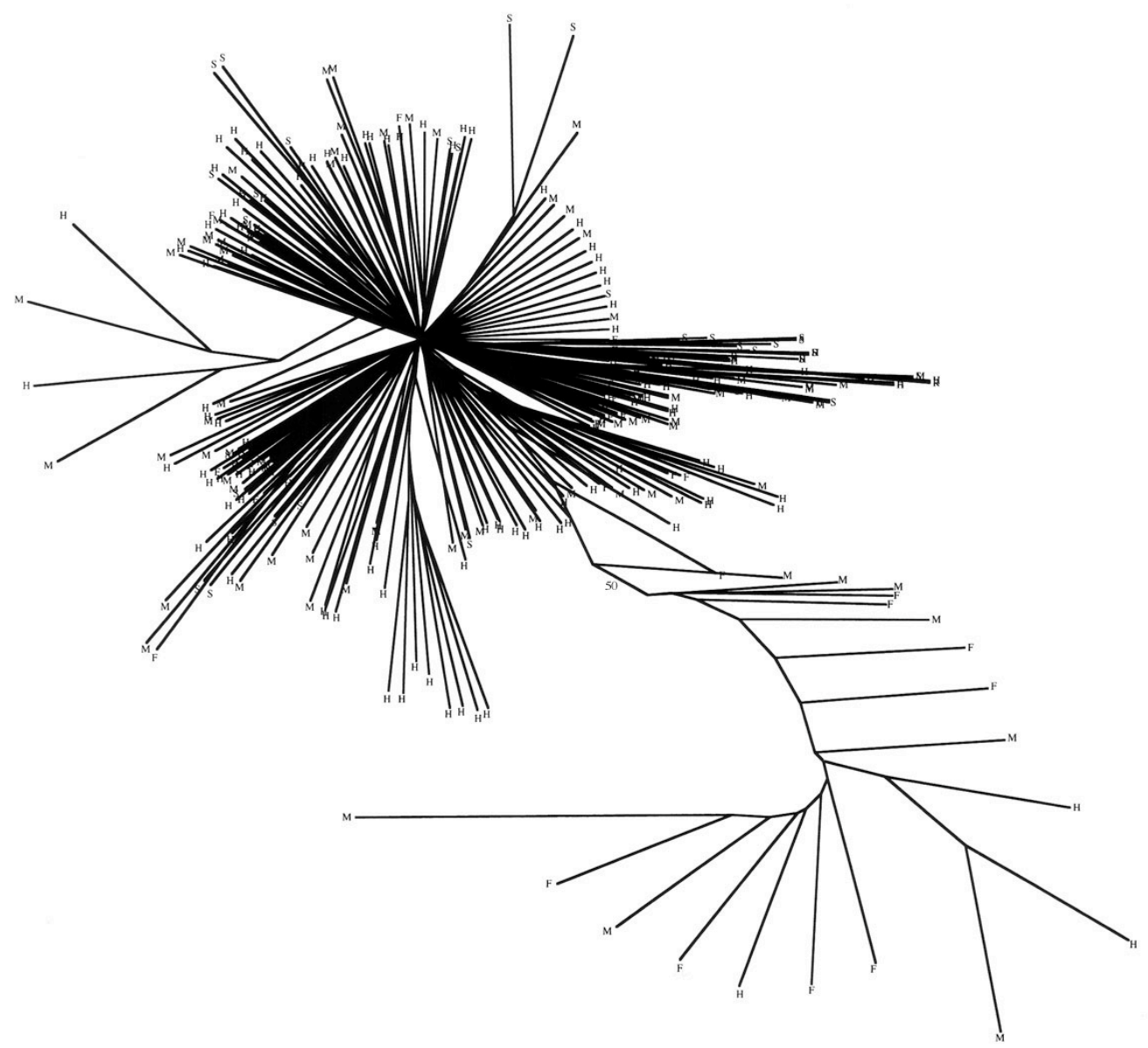


Figure 5. Relationships between genetic and morphological variables analysed by Multiple Correspondence Analysis. Ellipses from centre show correlations fit 50,90 , and $99 \%$ of samples. The $x$ - and $y$-axes respectively represent $24.1 \%$ and $13.0 \%$ of the total variation between the variables. Forbes' parakeet characters are symbolised by $\square$, hybrid characters are symbolised by $\mathrm{u}$, and Chatham Island Red-crowned parakeet characters are symbolised by .

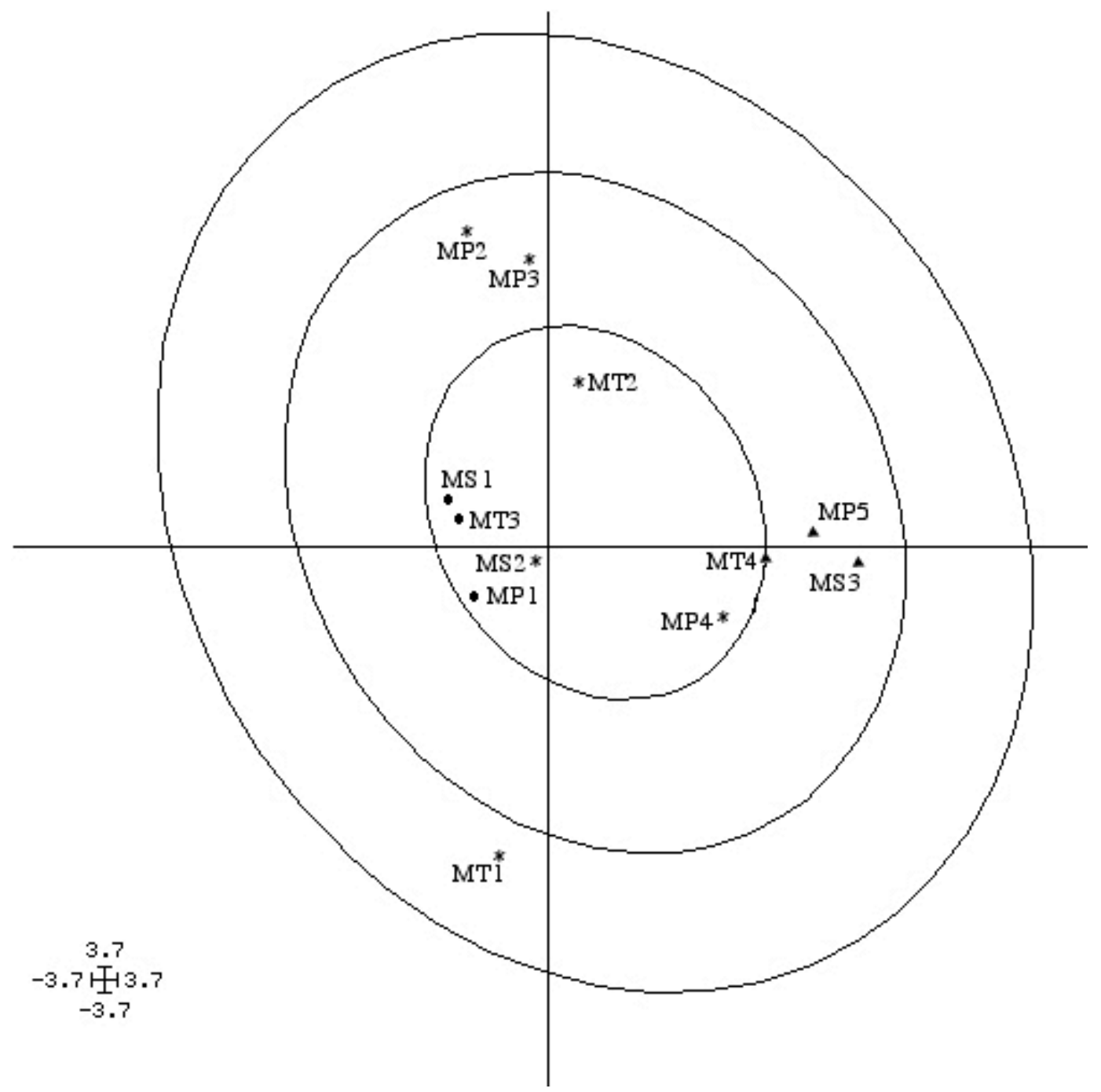


Table 1. Mutation behaviour of Cfor loci. $p$ indicates the proportion of multi-step mutations at $\max L(\square)$.

\begin{tabular}{ccccc}
\hline Locus & Population & $p$ & $-2 \log \square$ & Mutation Model \\
\hline Cfor0809 & Mangere & 0.475 & 7.50 & TPM \\
& Rangatira & 0.400 & 1.26 & SMM \\
& & & & TPM \\
Cfor1415 & Mangere & 0.025 & 14.68 & SMM \\
& Rangatira & 0.025 & 0.21 & SMM \\
& Mangere & 0.475 & 0.99 & SMM \\
Cfor1617 & Rangatira & 0.475 & 0.29 & TPM \\
& & & & - \\
Cfor3031 & Mangere & 0.475 & 3.84 & SMM \\
& Rangatira & - & - & SMM \\
\hline
\end{tabular}

Table 2. Relationship between variables among 169 Mangere Island samples. a) mitochondrial haplotypes versus morphology; b) microsatellites versus morphology; c) microsatellites versus mitochondrial haplotypes. Number of individuals in each category is in brackets.

\begin{tabular}{cccccc}
\hline a) & Mitochondrial & \multicolumn{5}{c}{ Morphology scores } \\
\cline { 2 - 5 } haplotypes & MP1 (136) & MP2 (10) & MP3 (11) & MP4 (9) & MP5 (3) \\
\hline MT1 (21) & 20 & 0 & 0 & 1 & 0 \\
MT2 (18) & 11 & 2 & 2 & 2 & 1 \\
MT3 (112) & 96 & 8 & 7 & 1 & 0 \\
MT4 (18) & 9 & 0 & 2 & 5 & 2 \\
\hline
\end{tabular}

\begin{tabular}{cccccc}
\hline b) Microsatellites & \multicolumn{5}{c}{ Morphology scores } \\
\cline { 2 - 5 } & MP1 (136) & MP2 (10) & MP3 (11) & MP4 (9) & MP5 (3) \\
\hline MS1 (43) & 38 & 2 & 3 & 0 & 0 \\
MS2 (119) & 97 & 8 & 7 & 6 & 1 \\
MS3 (7) & 1 & 0 & 1 & 3 & 2 \\
\hline
\end{tabular}

\begin{tabular}{ccccc}
\hline c) & Microsatellites & \multicolumn{4}{c}{ Mitochondrial haplotypes } \\
\cline { 2 - 5 } & MT1 (21) & MT2 (18) & MT3 (112) & MT4 (18) \\
\hline MS1 (43) & 3 & 4 & 32 & 4 \\
MS2 (119) & 16 & 13 & 78 & 12 \\
MS3 (7) & 2 & 1 & 2 & 2 \\
\hline
\end{tabular}




\section{References}

Allendorf FW, Leary RF, Spruell P, Wenburg JK (2001) The problems with hybrids: Setting conservation guidelines. TREE, 16, 613-622.

Anderson E, Stebbins GL Jr (1954) Hybridization as an evolutionary stimulus. Evolution, 8, $377-388$.

Anderson EC, Thompson EA (2002) A model-based method for identifying species hybrids using multilocus genetic data. Genetics, 160, $1217-$ 1229.

Anderson MJ (2003) PCO: a FORTRAN computer program for principal coordinate analysis. Department of Statistics, University of Auckland, New Zealand.

Ballantyne KN, Chan C-H, Chambers GK (2004) A PCR-RFLP based method for assigning mitochondrial control region haplogroups in hybridizing Chatham Islands Cyanoramphus parakeets. New Zealand Natural Sciences, 29, 33 - 38.

Balloux F (2001) EASYPOP (version 1.7): a computer program for population genetics simulations. J. Hered., 92, $301-302$.

Barton NH (2001) The role of hybridization in evolution. Molecular Ecology, 10, $551-568$.

Bigelow RS (1965) Hybrid zones and reproductive isolation. Evolution, 19, $449-458$.

Boecklen WJ, Howard DJ (1997) Genetic analysis of hybrid zones: Number of markers and power of resolution. Ecology, 78, 2611-2616. 
Boon WM, Kearvell JC, Daugherty CH, Chambers GK (2000) Molecular systematics of New Zealand Cyanoramphus parakeets: Conservation of Orange-fronted and Forbes' parakeets. Bird Conservation International, $10,211-239$.

Boon WM, Kearvell JC, Daugherty CH, Chambers GK (2001) Molecular systematics and conservation of kakariki (Cyanoramphus spp.): Science for Conservation 176. Department of Conservation, Wellington.

Bowcock AM, Ruiz-Linares A, Tomfohrde J, Minch E, Kidd JR, CavalliSforza LL (1994) High resolution of human evolutionary trees with polymorphic microsatellites. Nature, 368, $455-457$.

Caparroz R, Miyaki CY, Baker AJ (2003) Characterization of microsatellite loci in the Blue-and-gold Macaw, Ara ararauna (Psittaciformes: Aves). Molecular Ecology Notes, 3, 441 - 443.

Chan C-H, Ballantyne KN, Lambert DM, Chambers GK (2005) Characterization of variable microsatellite loci in Forbes' parakeet (Cyanoramphus forbesi) and their use in other parrots. Conservation Genetics, 6, in press.

Cornuet JM, Luikart G (1996) Description and power analysis of two tests for detecting recent population bottlenecks from allele frequency data. Genetics, 144, $2001-2014$.

Crandall KA, Bininda-Emonds ORP, Mace GM, Wayne RK (2000) Considering evolutionary processes in conservation biology. TREE, 15, $290-295$. 
Di Rienzo A, Peterson AC, Garza JC, Valdes AM, Slatkin M, Freimer NB (1994) Mutational processes of simple-sequence repeat loci in human populations. Proc. Natl. Acad. Sci. USA, 91, $3166-3170$.

Dieringer D, Schlötterer C (2002) Microsatellite analyser (MSA): a platform independent analysis tool for large microsatellite data sets. Molecular Ecology Notes, 3, 167 - 169.

Dowling TE, Secor CL (1997) The role of hybridization and introgression in the diversification of animals. Annu. Rev. Ecol. Syst., 28, 593-619.

Dyer R, Sork VL (2001) Pollen pool heterogeneity in shortleaf pine, Pinus echinata Mill. Molecular Ecology, 10, 859 - 866.

Excoffier L, Smouse PE, Quattro JM (1992) Analysis of molecular variance inferred from metric distances among DNA haplotypes: application to human mitochondrial DNA restriction data. Genetics, 131, 479-491.

Felsenstein J (1989) PHYLIP - phylogeny inference package (version 3.2). Cladistics, 5, $164-166$.

Fraser DJ, Bernatchez L (2001) Adaptive evolutionary conservation: towards a unified concept for defining conservation units. Molecular Ecology, 10, $2741-2752$.

Goldstein DB, Ruiz Linares A, Cavalli-Sforza LL, Feldman MW (1995) Genetic absolute dating based on microsatellites and the origin of modern humans. Proc. Natl. Acad. Sci. USA, 92, 6723-6727.

Grant PR, Grant BR (1992) Hybridization of bird species. Science, 256, $193-197$. 
Greene TC (2000) Forbes' parakeet (Cyanoramphus forbesi) population on Mangere Island, Chatham Islands: Conservation Advisory Science Notes 319. Department of Conservation, Wellington.

Hughes CR, Melland RR, Beissinger SR (1998) Polymorphic trinucleotide microsatellite loci for a neotropical parrot, the green-rumped parrotlet, Forpus passerinus. Molecular Ecology, 7, 1247 - 1263.

Huxel GR (1999) Rapid displacement of native species by invasive species: Effects of hybridization. Biological Conservation, 89, 143-152.

Kimura M, Crow JF (1964) The number of alleles that can be maintained in a finite population. Genetics, 49, $725-738$.

Lewontin RC, Birch LC (1966) Hybridization as a source of variation for adaptation to new environments. Evolution, 20, 315-336.

Moritz C (1994) Defining 'Evolutionarily Significant Units' for conservation. TREE, 9, $373-375$.

Nielsen R (1997) A likelihood approach to population samples of microsatellite alleles. Genetics, 146, 711-716.

Nielsen R, Palsbøll PJ (1999) Single-locus tests of microsatellite evolution: Multi-step mutations and constraints on allele size. Molecular Phylogenetics and Evolution, 11, 477 - 484.

Nixon AJ (1982) Aspects of the ecology and morphology of Cyanoramphus parakeets and hybrids from Mangere Island, Chatham Islands. MSc thesis, Victoria University of Wellington, Wellington, New Zealand. 
Ohta T, Kimura M (1973) A model of mutation appropriate to estimate the number of electrophoretic detectable alleles in a finite population. Genet. Res., 22, $201-204$.

Prager EM, Wilson AC (1975) Slow evolutionary loss of potential for interspecific hybridization in birds: a manifestation of slow regulatory evolution. Proc. Natl. Acad. Sci. USA, 72, $200-204$.

Primmer CR, Raudsepp T, Chowdhary BP, Møller AP, Ellegren H (1997) Low frequency of microsatellites in the avian genome. Genome Research, 7, $471-482$.

Pritchard JK, Stephens M, Donnelly P (2000) Inference of population structure using multilocus genotype data. Genetics, 155, 945 - 959.

Raymond M, Rousset F (1995) GENEPOP (version 1.2): Population genetic software for the exact tests and ecumenicisms. J. Hered., 86, 248 -249 .

Rhymer JM, Simberloff D (1996) Extinction by hybridization and introgression. Annu. Rev. Ecol. Syst., 27, 83-109.

Robertson BC, Minot EO, Lambert DM (2000) Microsatellite primers for the kakapo (Strigops habroptilus) and their utility in other parrots. Conservation Genetics, 1, 93 - 95.

Russello M, Calcagnotto D, DeSalle R, Amato G (2001) Characterization of microsatellite loci in the endangered St. Vincent Parrot, Amazona guildingii, Molecular Ecology Notes, 1, 162 - 164. 
Ryder OA (1986) Species conservation and systematics: The dilemma of subspecies. TREE, 1, $9-10$.

Sainsbury JP, MacAvoy ES, Chambers GK (2004) Characterization of microsatellite loci in the Kaka, Nestor meridionalis. Molecular Ecology Notes, 4, $623-625$.

Saitou N, Nei M (1987) The neighbor-joining method: A new method for reconstructing phylogenetic trees. Mol. Bio. Evol., 4, 406-425.

Sambrook J, Fritsch EF, Maniatis T (1989) Molecular Cloning: $A$ Laboratory Manual, 2nd edn. Cold Spring Harbor Laboratory Press, New York.

Seehausen O (2004) Hybridization and adaptive radiation. TREE, 19, 198 $-207$.

Slatkin M (1995) A measure of population subdivision based on microsatellite allele frequencies. Genetics, 139, 457-462.

Taylor $\mathrm{RH}$ (1975) Some ideas on speciation in New Zealand parakeets. Notornis, 22, 110 - 121.

Thioulouse J, Chessel D, Dolédec S, Olivier JM (1997) ADE-4: a multivariate analysis and graphical display software. Statistics and Computing, 7, $75-83$.

Triggs SJ, Daugherty $\mathrm{CH}$ (1996) Conservation and genetics of New Zealand parakeets. Bird Conservation International, 6, 89 - 101. 
Valdes AM, Slatkin M, Freimer NB (1993) Allele frequencies at microsatellite loci: the stepwise mutation model revisited. Genetics, 133, $737-749$.

Weir BS, Cockerham CC (1984) Estimating F-statistics for the analysis of population structure. Evolution, 38, $1358-1370$.

Wolf DE, Takebayashi N, Rieseberg LH (2001) Predicting the risk of extinction through hybridization. Conservation Biology, 15, 1039 - 1053. 


\section{Chapter 4: $\quad$ Microsatellite Evolution in Parrots}

\subsection{Introduction}

Although isolating microsatellite loci can be tedious (see Zane et al. 2002), once developed, microsatellite primers can often be used productively across a range of more or less closely related species (Moore et al. 1991; Primmer et al. 1996) because the priming sites of some microsatellites can be conserved over millions of years, e.g. in turtles (FitzSimmons et al. 1995), birds (Primmer et al. 1996), fish (Rico et al. 1996), and wasps (Ezenwa et al. 1998).

Microsatellites are often highly polymorphic with respect to repeat number variations (Weber \& May 1989; Weber 1990). However, diversity in microsatellite alleles can also arise from indels and / or single base substitutions within repeats (Estoup et al. 1995; Angers \& Bernatchez 1997; Viard et al. 1998; Taylor et al. 1999) and from variations in the flanking sequences (FitzSimmons et al. 1995; Grimaldi \& Crouau-Roy 1997).

Variations observed in microsatellite loci are often caused by repeat number changes, and often conform to the infinite allele model (IAM; Kimura \& Crow 1964), the stepwise mutation model (SMM; Ohta \& Kimura 1973), or the two-phase model (TPM; Di Rienzo et al. 1994) at the population level. However, insertion or deletion events, and single nucleotide polymorphisms also occur frequently within some microsatellite loci, suggesting the existence of a more complex, and presently unknown pattern of evolution (reviewed by Chambers \& MacAvoy 2000).

The evolution of parrots has been studied fairly extensively. However, no consensus has yet been reached regarding their current global phylogeny. 
A wide range of characters has been employed in constructing parrot phylogenies, including morphological and anatomical features (Burton 1974; Smith 1975), karyotypes (Schmutz \& Prus 1987), protein electrophoresis (Christidis et al. 1991; Triggs \& Daugherty 1996), and mitochondrial DNA variation (Ovenden et al. 1987; Birt et al. 1992; Leeton et al. 1994; Miyaki et al. 1998; Boon et al. 2000; Groombridge et al. 2004; Ribas \& Miyaki 2004). One of the factors that has created practical difficulties in constructing a reliable global phylogeny for parrots is the rearrangement of the mitochondrial genome in some species (Eberhard et al. 2001). So far, it has been recognised that the global parrot biota is made up of three main vicariant lineages: African (AF), Australasian (AU), and Neotropical (NT), with subdivisions within each lineage (see Boon 2000). Amplification of conserved microsatellite loci across related species presents a possibility of constructing phylogenies based on these loci, either using distance methods (Bowcock et al. 1994), or using standard phylogenetic methods based on flanking region sequence changes between taxa (Zardoya et al. 1996; Sainsbury 2004).

With the aims of enhancing the understanding of parrot evolution and the evolutionary process of microsatellite loci, this chapter evaluates the use of flanking sequences of loci developed for Forbes' parakeet (see Chapter 2) for phylogenetic construction. Microsatellite repeat motif evolution is investigated through mapping changes on to a phylogeny derived from Boon (2000).

\subsection{Methods}

\subsubsection{Cross-species Amplification of Microsatellite Loci}

Genomic DNA from a range of parrot tissue samples (Table 4.1) was available in the IMS collection. These were extracted by Boon (2000) and Sainsbury (2004). For this study, DNA from Coracopsis nigra barkyli and 
Poicephalus senegalus (see Boon 2000) was extracted from feather samples available in the IMS collection with DNeasy Tissue Kit (Qiagen), following the manufacturer's protocol.

PCR amplification conditions were as described for Forbes' parakeet in Chapter 2, section 2.2.16, except that the primer annealing temperature was lowered from the optimal temperature (see Chapter 2, Table 2.1) for Forbes' parakeet to $50^{\circ} \mathrm{C}$ in some non-Cyanoramphus species (see Table 4.1). The criterion for successful amplification were as described by Ezenwa et al. (1998), namely, the detection by agarose gel electrophoresis of a clear band within $200 \mathrm{bp}$ of the expected length. PCR products judged to have been successfully amplified were characterised by DNA sequencing of both strands as described in Chapter 3 , section 3.2.1. The DNA sequences were aligned manually with the aid of the MacClade software (version 4.06; Maddison \& Maddison 2003).

\subsubsection{Species Examined in this Study}

Parrot taxa are classified following Boon (2000; see Table 4.1), recognising three major geographical groupings: African (AF), Australasian (AU), and Neotropical (NT). African parrot samples used in this study were: Coracopsis nigra barkyli (Seychelles black parrot), Poicephalus senegalus (Senegal parrot), Poicephalus meyeri (Meyer's parrot), and Psittacus erithacus (African grey parrot). Australasian parrots can be classified into four main lineages, AU-NZ (New Zealand Nestor and Strigops), AU-C (Cockatoos, Cockatiels and Galah), AU-L (Lorikeets), and AU-1 (all other Australasian parrots). AU-NZ parrots studied were: Strigops habroptilus (Kakapo), Nestor notabilis (Kea), and Nestor meridionalis (Kaka). AU-C species studied were: Nymphicus hollandicus (Cockatiel), Eolophus roseicapillus (Galah), and Cacatua haematuropygia (Red-vented cockatoo). AU-L species studied were: Glossopsitta pusilla 
(Little lorikeet), and Trichoglossus haematodus (Rainbow lorikeet). AU-1 parrots studied included: Cyanoramphus forbesi (Forbes' parakeet), Cyanoramphus novaezelandiae novaezelandiae (Red-crowned parakeet), and the Chatham Island subspecies Cyanoramphus novaezelandiae chathamensis (Chatham Island Red-crowned parakeet), Cyanoramphus auriceps (Yellow-crowned parakeet), Cyanoramphus malherbi (Orangefronted parakeet), Cyanoramphus hochstetteri (Reischek's parakeet), Cyanoramphus unicolor (Antipodes Island green parakeet), Cyanoramphus saisetti (New Caledonian Red-crowned parakeet), Eunymphicus cornutus (Horned parakeet), Eunymphicus uvaeensis (Ouvea parakeet), Barnardius barnardi (Mallee ringneck parrot), Micropsitta pusio (Buff-faced pygmy parrot), Platycercus eximius (Eastern rosella), Psittacula alexandri (Red-breasted parakeet), Psephotus varius (Mulga parrot), and Melopsittacus undulatus (Budgerigar). The Neotropical (NT) parrot studied was Ara ararauna (Blue-and-gold macaw).

\subsubsection{Characterization of Flanking Region Sequences}

The sequences obtained were searched for homology to published sequences at the Genbank/EMBL/DDBJ databases (http://www.ncbi.nlm.nih.gov) using the nucleotide BLAST tool. To determine whether the microsatellite loci contained coding regions, the entire $C$. forbesi loci sequences were checked for stop codons in all 6 possible reading frames using the MAPDRAW software (Lasergene version 4.0; DNASTAR Inc.). Non-triplet insertions or deletions that would result in frameshifts were checked in interspecies sequence alignments constructed with the MacClade software (version 4.06; Maddison \& Maddison 2003). 


\subsubsection{Phylogenetic Trees Construction Within Cyanoramphus}

Using the flanking sequences of microsatellite loci, phylogenetic trees were constructed between Cyanoramphus species. The microsatellite repeat arrays were excluded in the analysis to avoid confusion caused by repeat number mutations. Choice of loci was determined by the proportion of variable and informative sites in the flanking regions between the species of interest. The two loci with the largest number of variable sites, Cfor 1415 and Cfor 3031 (with respectively $3.87 \%$ and $2.33 \%$ of variable sites), were used.

Using the software PAUP (version 4.0b10PPC; Swofford 1998), phylogenies were constructed using the maximum parsimony (Camin \& Sokal 1965) and maximum likelihood (Felsenstein 1981) algorithms. All trees were unrooted. Confidence intervals of phylogenies were determined using the bootstrap method (Efron 1979; Felsenstein 1985) with 1000 replicates.

\subsubsection{Construction of Phylogeny Between Parrot Taxa}

The flanking sequences at most microsatellites do not show sufficient variation to produce well supported phylogenies for parrot taxa (see section 4.3.3). The matter is further complicated by the limited availability of other DNA sequences characterized across taxa (see Boon 2000 for instance). A neighbour-joining phylogeny (Saitou \& Nei 1987) can be constructed using the PAUP software (version 4.0b10PPC; Swofford 1998) from only $267 \mathrm{nt}$ available common mitochondrial cytochrome $b$ sequences (Boon 2000) between taxa in this study. Since mitochondrial cytochrome $b$ sequences are not available for all taxa examined in this microsatellite study, the original neighbour-joining tree has been expanded by incorporating some of the placements from mitochondrial 12S rRNA trees in Boon (2000) to allow mapping of microsatellite arrays in a wider 
range of taxa. Two loci, Cfor1819 and Cfor3031, were selected for the mapping exercise since these loci contain simple, comprehensible and variable repeat structures between parrot taxa.

\subsection{Results}

\subsubsection{Cross-species Microsatellite Amplifications}

All nine loci were amplified successfully from all Cyanoramphus species tested, but the results of amplification reactions varied in other parrots (Table 4.1). Sequencing of the PCR products confirmed that all successful cross-species PCRs amplified the same loci as in Cyanoramphus forbesi.

\subsubsection{Search for Coding Regions within Flanking Sequences}

Alignment searches of Cfor loci on GenBank/EMBL/DDBJ online databases showed no matches with non-Cfor entries (as at December 2004 ) with scores $>50$ bits or E-values $<0.001$. Translation of the Cfor sequences showed that all loci have stop codons in one or more reading frames, indicating the possibility of the presence of open reading frames. However, since all the loci have either di- or tetranucleotide repeat units, any repeat unit number mutations would disrupt open reading frames. The possibility is low that any of these loci contain an open reading frame or substantial part of one. 
Table 4.1 Amplification of Cfor loci in other parrot and cockatoo species. Symbols $+=$ amplification of a microsatellite, $-=$ no amplification. $\Delta$ indicates a reduction of annealing temperature to $50^{\circ} \mathrm{C}$ is required to achieve amplification.

\begin{tabular}{|c|c|c|c|c|c|c|c|c|c|c|}
\hline & Species & Loc & us & & & & & & & \\
\hline & & $\begin{array}{l}8 \\
\infty \\
0 \\
0 \\
0 \\
0\end{array}$ & $\frac{\frac{10}{d}}{\frac{d}{d}}$ & $\frac{\frac{N}{0}}{\frac{1}{0}}$ & $\begin{array}{l}\frac{0}{\infty} \\
\frac{0}{0} \\
0\end{array}$ & 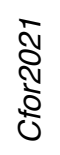 & 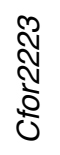 & 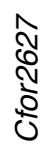 & 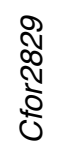 & 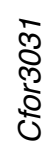 \\
\hline Australasian & Cyanoramphus novaezelandiae chathamensis & + & + & + & + & + & + & + & + & + \\
\hline & Cyanoramphus novaezelandiae novaezelandiae & + & + & + & + & + & + & + & + & + \\
\hline & Cyanoramphus auriceps & + & + & + & + & + & + & + & + & + \\
\hline & Cyanoramphus malherbi & + & + & + & + & + & + & + & + & + \\
\hline & Cyanoramphus hochstetteri & + & + & + & + & + & + & + & + & + \\
\hline & Cyanoramphus unicolor & + & + & + & + & + & + & + & + & + \\
\hline & Cyanoramphus saisetti & + & + & + & + & + & + & + & + & + \\
\hline & Eunymphicus cornutus & + & + & + & + & + & + & + & + & + \\
\hline & Eunymphicus uvaeensis & + & + & + & + & + & + & + & + & + \\
\hline & Platycercus eximius & $\Delta$ & + & + & + & - & $\Delta$ & - & - & + \\
\hline & Psephotus varius & - & + & $\Delta$ & - & - & - & + & - & + \\
\hline & Barnardius barnardi & + & + & + & + & - & $\Delta$ & + & + & - \\
\hline & Melopsittacus undulatus & - & - & - & $\Delta$ & - & - & + & - & - \\
\hline & Micropsitta pusio & + & - & + & + & + & - & + & - & + \\
\hline & Psittacula alexandri & + & + & + & + & - & - & + & - & + \\
\hline & Trichoglossus haematodus & + & - & + & - & + & - & + & - & + \\
\hline & Glossopsitta pusilla & $\Delta$ & - & + & + & + & - & + & - & + \\
\hline & Strigops habroptilus & - & - & - & $\Delta$ & - & $\Delta$ & - & - & - \\
\hline & Nestor notabilis & + & - & $\Delta$ & - & - & - & - & - & - \\
\hline & Nestor meridionalis & + & - & $\Delta$ & - & - & - & - & - & - \\
\hline African & Coracopsis nigra barkyli & + & - & - & + & + & - & + & - & + \\
\hline & Poicephalus senegalus & + & - & + & + & $\Delta$ & - & + & + & + \\
\hline & Poicephalus meyeri & + & - & + & + & - & - & + & - & - \\
\hline & Psittacus erithacus & + & - & + & + & $\Delta$ & - & + & - & + \\
\hline Neotropical & Ara ararauna & + & + & + & $\Delta$ & - & - & + & - & - \\
\hline Cacatuidae & Nymphicus hollandicus & + & + & + & + & + & + & + & + & - \\
\hline & Eolophus roseicapillus & $\Delta$ & - & + & - & - & - & + & - & - \\
\hline & Cacatua haematuropygia & $\Delta$ & - & - & - & - & - & + & - & - \\
\hline
\end{tabular}

\subsubsection{Within-Cyanoramphus Phylogenetic Relationships}

Phylogenetic trees for Cyanoramphus parakeets were constructed with the flanking sequences of Cfor1415 (181 bp) and Cfor3031 (215 bp) loci (Figure 4.1). Both trees showed a closer relationship between $C$. unicolor and $C$. hochstetteri than between other species. In the tree constructed based on flanking sequences of Cfor3031, the two subspecies of Red- 
crowned parakeets (C. novaezelandiae chathamensis, and C. $n$. novaezelandiae) did not cluster together as expected (Figure 4.1b). This reflects the fact that the use of short sequences for phylogenetic constructions may lead to errors in the resulting tree topologies. Resolution is generally lower than for phylogenies previously constructed by Triggs \& Daugherty (1996) and by Boon (2000) due to a lack of signal in the microsatellite flanking regions. Resolution did not improve when the flanking sequences from Cfor1415 and Cfor3031 were concatenated (data not shown). The trees obtained here do not have high bootstrap support for most branches. In Cfor1415 interruptions to the core repeat tract were observed in C. novaezelandiae chathamensis, C. auriceps, and $C$. malherbi (Figure 4.1a). A G to A substitution in the middle of the Cfor1415 repeats divides the TG repeats into two sections in $C$. novaezelandiae chathamensis, whereas in $C$. auriceps and C. malherbi, $G$ to $T$ substitutions were observed at the beginning of the tracts. These interruption patterns, however, may only be variation between individuals as the sample size screened is small. There is no major change of the microsatellite motif in Cfor3031 (Figure 4.1b). In other loci, repeat structure changes are minor across Cyanoramphus (see Table 4.2).

The poor resolution and low bootstrap support of the trees suggest that the flanking regions do not show high enough differentiation between Cyanoramphus parakeets to allow a detailed and reliable phylogeny to be constructed.

\subsubsection{Evolution of Cfor1819 in Parrots}

Polymorphism in this locus was in the form of variation in $(C A)_{n}$ repeats. A change of the theme is observed in the two Eunymphicus species, where a $(C C A)_{n}$ motif has replaced the $(C A)_{n}$ motif from the second repeat unit (Figure 4.2a; Table 4.2). Interruptions in the repeat tracts were observed 
in $C$. $n$. chathamensis and B. barnardi. In both species the interruptions were made up of $C$ mononucleotide repeats.

There is a clear pattern of microsatellite evolution in species related to Cyanoramphus (Figure 4.2a). Parrots of the AF, NT, AU-NZ, AU-L lineages and some AU-1 (Melopsittacus, Micropsitta, and Psittacula) species do not show dinucleotide $(C A)_{n}$ repeats at this locus.

Figure 4.1 Phylogeny of Cyanoramphus parakeets constructed using microsatellite flanking regions of (a) Cfor1415 and (b) Cfor3031. Maximum likelihood (ML) trees are positioned on the left, and maximum parsimony (MP) trees are positioned on the right. The core repeat motifs are mapped on the trees.

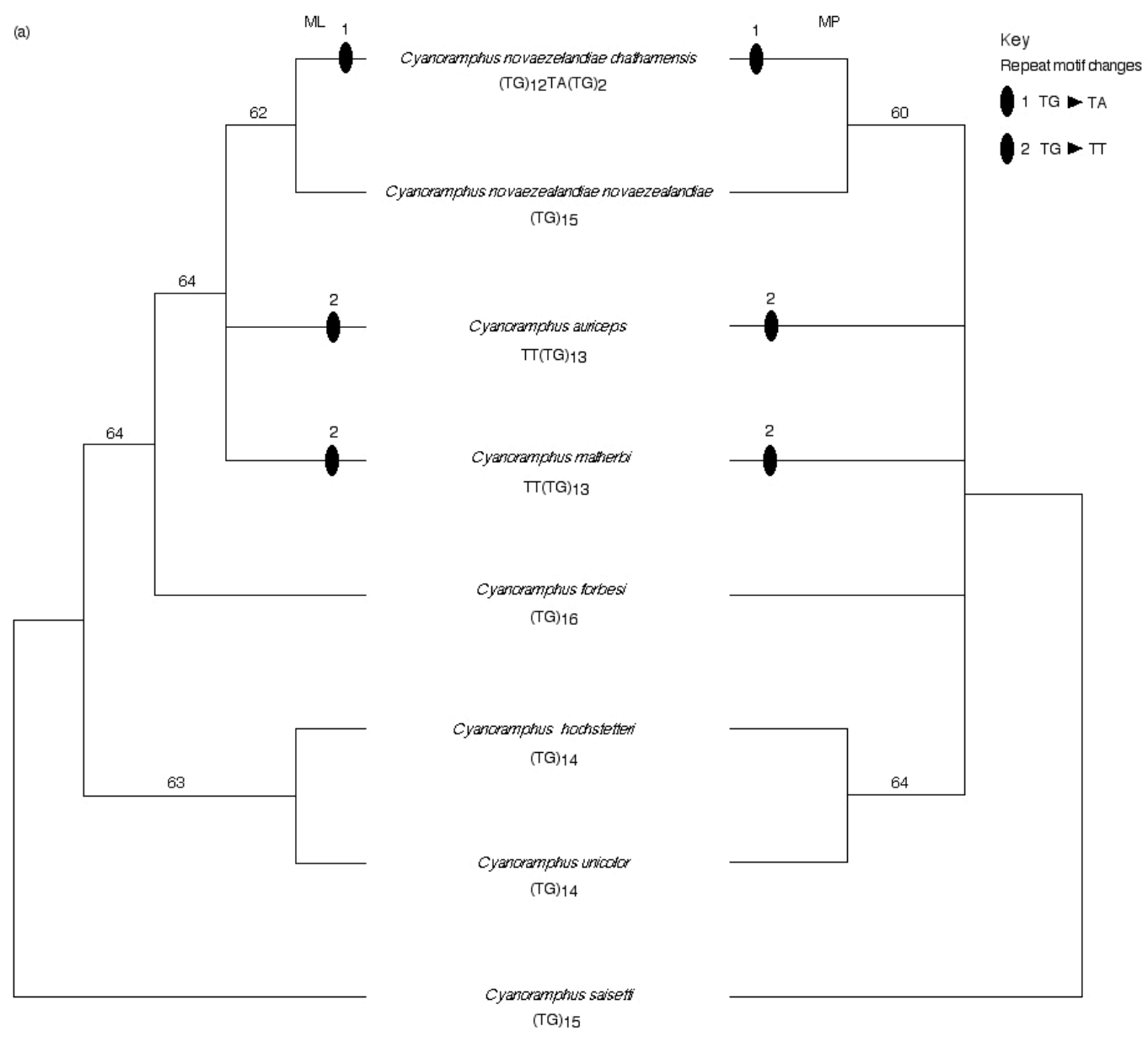




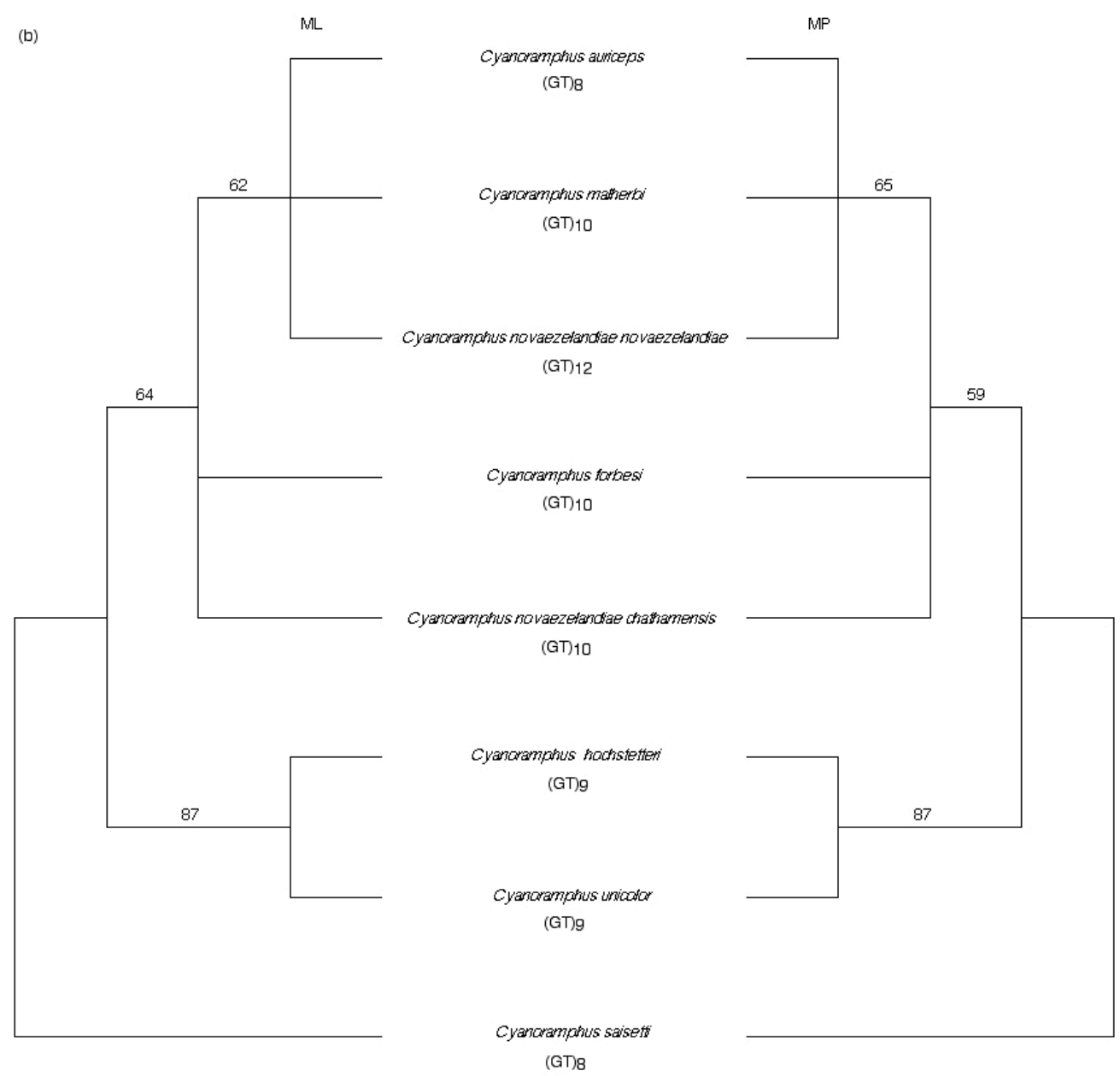

\subsubsection{Evolution of Cfor3031 in Parrots}

The repeat unit at this locus is $(G T)_{n}$. This locus is not very variable across species (Figure 4.2b; Table 4.2). Most groups have $(\mathrm{GT})_{3}$ repeat at this locus, except Poicephalus senegalus and Psittacula erithacus which had a $(\mathrm{GT})_{6}$ repeat, and Cyanoramphus and Eunymphicus species where larger number of repeats $(n>7)$ were observed. Groups with 3 or 6 GT repeats showed no within-species polymorphism in the individuals examined, while polymorphism was observed in Cyanoramphus and Eunymphiucs species. 
Figure 4.2 Diagrammatic representation of phylogeny of parrot species. Neighbour-joining (Saitou \& Nei 1987) phylogenetic constructions from 267 nt of cytochrome $b$ sequences data (Boon 2000) are shown in bold lines. Taxa from which cytochrome $b$ data are unavailable have been added onto the phylogeny and represented by finer lines based on phylogenetic analysis of $12 \mathrm{~S}$ rRNA data in Boon (2000). Repeat motif changes for (a) Cfor1819, and (b) Cfor3031 are mapped on the trees. N/A indicates non-amplification of the microsatellite locus in a taxon.

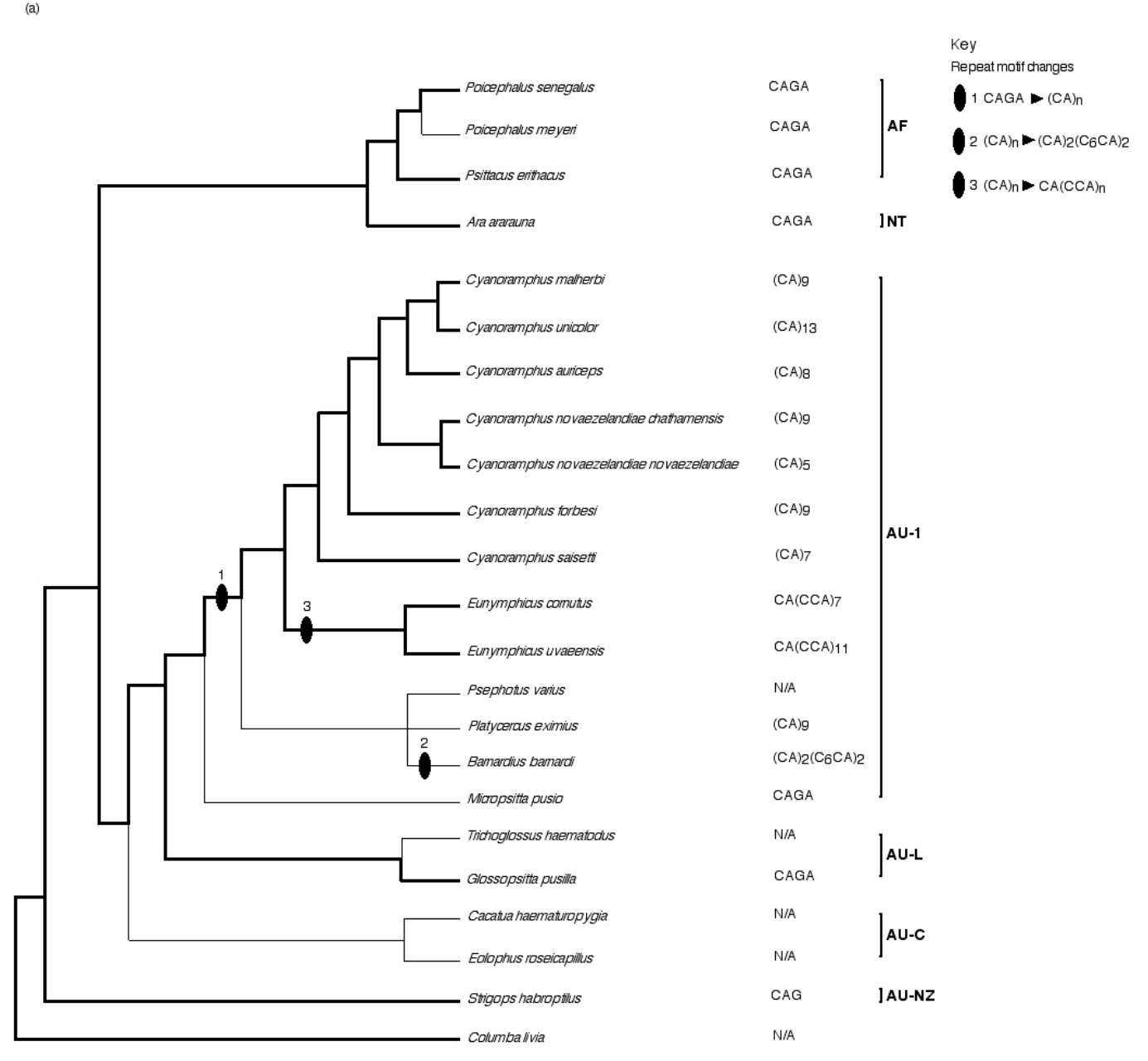




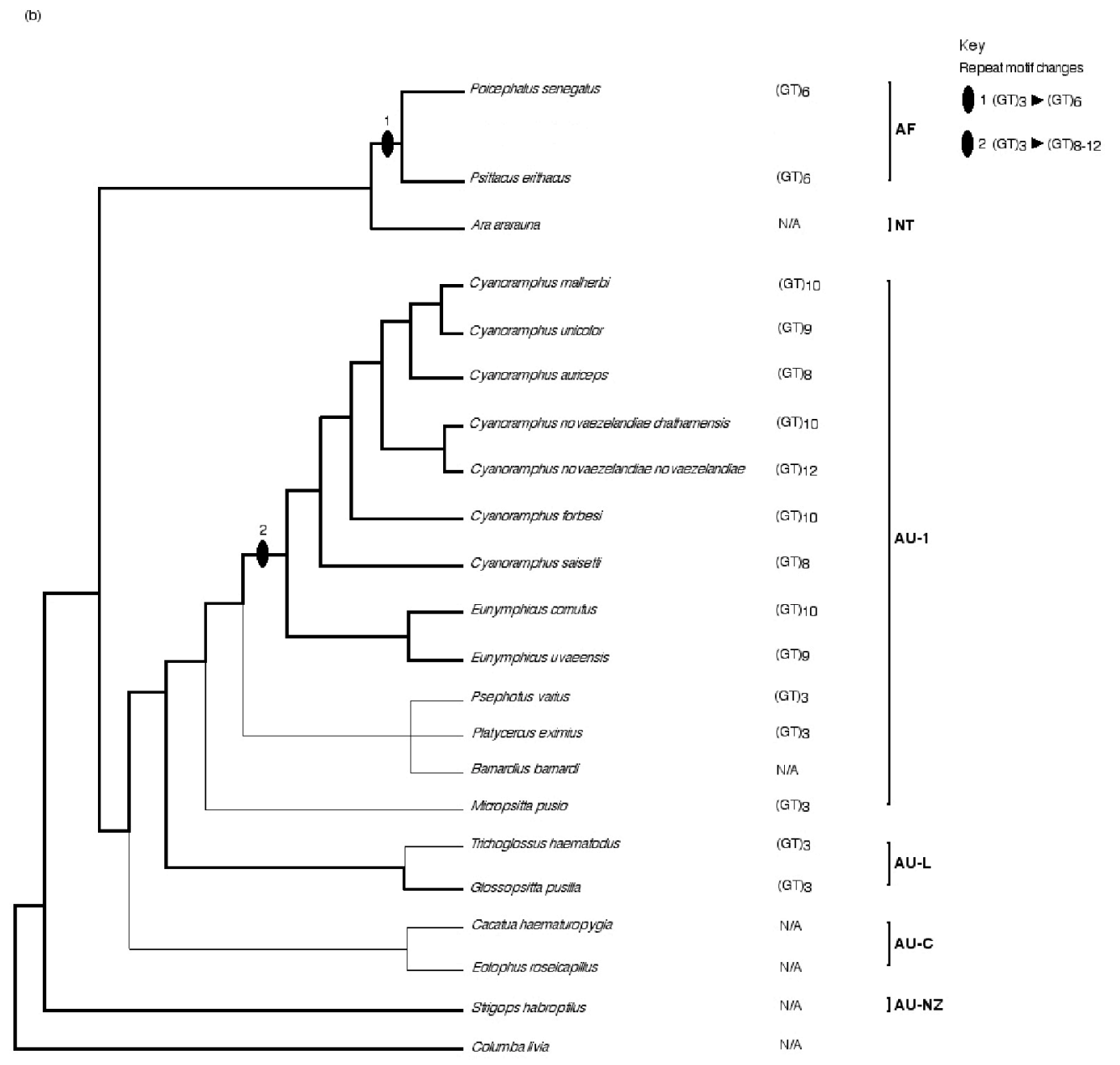

\subsubsection{General Pattern of Microsatellite Evolution between Parrots}

In loci Cfor1819, Cfor2021, Cfor2627 and Cfor3031, the dinucleotide repeat tracts are bordered at one end by tracts of $C_{n} / G_{n}$ mononucleotides (Table 4.2). The length of these mononucleotide tracts varied between species, and substitution or insertion mutations within these mononucleotide tracts can be observed in some species. Although in Cfor3031, species with longer dinucleotide repeats have less $G$ mononucleotide repeats in the immediate bordering sequences, such pattern was not observed in other loci. In some species, the dinucleotide repeat tracts were interrupted with runs of mononucleotides of the same bases as the bordering mononucleotide tracts. This suggests the 
bordering mononucleotides may play a role in the origin of the dinucleotide repeats.

Table 4.2 Association of dinucleotide microsatellite repeats with bordering mononucleotide repeat tracts.

\begin{tabular}{|c|c|c|}
\hline \multicolumn{2}{|c|}{ Locus / Species / Lineage } & \multirow[t]{2}{*}{ Repeat Structure of Microsatellite and Bordering Sequences } \\
\hline \multicolumn{2}{|l|}{ Cfor1819 } & \\
\hline C. nigra barkyli & $\mathrm{AF}$ & $\mathrm{CAGAC}_{4}$ \\
\hline P. senegalus & $\mathrm{AF}$ & $\mathrm{CAGAC}_{5}$ \\
\hline P. meyeri & $\mathrm{AF}$ & $\mathrm{CAGAC}_{5}$ \\
\hline P. erithacus & $\mathrm{AF}$ & $\mathrm{CAGAC}_{4}$ \\
\hline A. ararauna & NT & $\mathrm{CAGAC}_{5}$ \\
\hline C. n. chathamensis & AU-1 & $(\mathrm{CA})_{9} \mathrm{C}_{6}$ \\
\hline C. n. novaezelandiae & AU-1 & $(\mathrm{CA})_{5} \mathrm{C}_{4}$ \\
\hline C. auriceps & AU-1 & $(\mathrm{CA})_{8} \mathrm{C}_{4}$ \\
\hline C. malherbi & AU-1 & $(\mathrm{CA})_{9} \mathrm{C}_{7}$ \\
\hline C. hochstetteri & $A U-1$ & $(\mathrm{CA})_{12} \mathrm{C}_{4}$ \\
\hline C. unicolor & AU-1 & $(\mathrm{CA})_{13} \mathrm{C}_{4}$ \\
\hline C. forbesi & AU-1 & $(\mathrm{CA})_{9} \mathrm{C}_{4}$ \\
\hline C. saisetti & AU-1 & $(\mathrm{CA})_{7} \mathrm{C}_{6}$ \\
\hline E. cornutus & AU-1 & $\mathrm{CA}(\mathrm{CCA})_{7} \mathrm{C}_{6}$ \\
\hline E. uvaeensis & AU-1 & $\mathrm{CA}(\mathrm{CCA})_{11} \mathrm{C}_{3}$ \\
\hline P. eximius & AU-1 & $(\mathrm{CA})_{9} \mathrm{C}_{6}$ \\
\hline B. barnardi & AU-1 & $(\mathrm{CA})_{2}\left(\mathrm{C}_{6} \mathrm{CA}\right)_{2} \mathrm{CC}$ \\
\hline P. alexandri & AU-1 & $\mathrm{CAGAC}_{5}$ \\
\hline M. pusio & AU-1 & $\mathrm{CAGAC}_{5}$ \\
\hline M. undulatus & AU-1 & $\mathrm{CAGAC}_{4}$ \\
\hline G. pusilla & AU-L & $\mathrm{CAGAC}_{5}$ \\
\hline N. hollandicus & $A U-C$ & $(\mathrm{CA})_{10} \mathrm{C}_{6}$ \\
\hline S. habroptilus & AU-NZ & $\mathrm{CAGC}_{4} \mathrm{TC}$ \\
\hline \multicolumn{3}{|l|}{ Cfor2021 } \\
\hline C. nigra barkyli & $\mathrm{AF}$ & $\mathrm{G}_{6}(\mathrm{TG})_{2} \mathrm{G}(\mathrm{TG})_{2} \mathrm{G}(\mathrm{TG})_{2} \mathrm{G}(\mathrm{TG})_{4}$ \\
\hline$P$. senegalus & $\mathrm{AF}$ & $\mathrm{G}_{6} \mathrm{TGTAG}(\mathrm{TG})_{2} \mathrm{G}(\mathrm{TG})_{5}$ \\
\hline P. erithacus & $\mathrm{AF}$ & $\mathrm{G}_{6} \mathrm{TGTAG}(\mathrm{TG})_{2} \mathrm{G}(\mathrm{TG})_{3} \mathrm{CGTG}$ \\
\hline C. n. chathamensis & AU-1 & $\mathrm{G}_{4}(\mathrm{TG})_{2} \mathrm{CGG}(\mathrm{TG})_{2} \mathrm{G}(\mathrm{TG})_{6}$ \\
\hline C. n. novaezelandiae & AU-1 & $\mathrm{G}_{4}(\mathrm{TG})_{2} \mathrm{CGG}(\mathrm{TG})_{2} \mathrm{G}(\mathrm{TG})_{6}$ \\
\hline C. auriceps & AU-1 & $\mathrm{G}_{4}(\mathrm{TG})_{2} \mathrm{CGG}(\mathrm{TG})_{2} \mathrm{G}(\mathrm{TG})_{6}$ \\
\hline C. malherbi & AU-1 & $\mathrm{G}_{4}(\mathrm{TG})_{2} \mathrm{CGG}(\mathrm{TG})_{2} \mathrm{G}(\mathrm{TG})_{6}$ \\
\hline C. hochstetteri & AU-1 & $\mathrm{G}_{4}(\mathrm{TG})_{2} \mathrm{CGG}(\mathrm{TG})_{2} \mathrm{GG}(\mathrm{TG})_{3}$ \\
\hline C. unicolor & AU-1 & $\mathrm{G}_{4}(\mathrm{TG})_{2} \mathrm{CGG}(\mathrm{TG})_{2} \mathrm{GG}(\mathrm{TG})_{3}$ \\
\hline C. forbesi & AU-1 & $\mathrm{GAGG}(\mathrm{TG})_{2} \mathrm{CGG}(\mathrm{TG})_{2} \mathrm{G}(\mathrm{TG})_{9}$ \\
\hline C. saisetti & AU-1 & $\mathrm{G}_{4}(\mathrm{TG})_{2} \mathrm{CGG}(\mathrm{TG})_{2} \mathrm{G}(\mathrm{TG})_{6}$ \\
\hline E. cornutus & AU-1 & $\mathrm{G}_{4}(\mathrm{TG})_{2} \mathrm{CGG}(\mathrm{TG})_{2} \mathrm{G}(\mathrm{TG})_{4}$ \\
\hline E. uvaeensis & AU-1 & $\mathrm{G}_{4}(\mathrm{TG})_{2} \mathrm{CGG}(\mathrm{TG})_{2} \mathrm{G}(\mathrm{TG})_{7}$ \\
\hline M. pusio & AU-1 & $\mathrm{G}_{4}(\mathrm{TG})_{3} \mathrm{G}(\mathrm{TG})_{5}$ \\
\hline G. pusilla & AU-L & $\mathrm{G}_{6}(\mathrm{TG})_{2} \mathrm{G}(\mathrm{TG})_{4} \mathrm{TT}$ \\
\hline T. haematodus & AU-L & $\mathrm{G}_{6}(\mathrm{TG})_{2} \mathrm{G}(\mathrm{TG})_{2} \mathrm{G}(\mathrm{TG})_{2} \mathrm{G}(\mathrm{TG})_{4}$ \\
\hline N. hollandicus & $\mathrm{AU}-\mathrm{C}$ & $\mathrm{G}_{4}(\mathrm{TG})_{2} \mathrm{CGG}(\mathrm{TG})_{2} \mathrm{G}(\mathrm{TG})_{6}$ \\
\hline
\end{tabular}




\begin{tabular}{|c|c|c|}
\hline \multicolumn{3}{|l|}{ Cfor2627 } \\
\hline C. nigra barkyli & AF & $\mathrm{G}_{3} \mathrm{TG}_{4}(\mathrm{AG})_{2}(\mathrm{TGAG})_{2}(\mathrm{TG})_{6} \mathrm{~T}_{2}(\mathrm{TG})_{7} \mathrm{~T}_{2}(\mathrm{TG})_{3} \mathrm{AG}(\mathrm{TG})_{4} \mathrm{~T}_{2}(\mathrm{TG})_{7}$ \\
\hline P. senegalus & AF & $\left.\mathrm{G}_{3} \mathrm{ATGAGG}(\mathrm{AG})_{2} \mathrm{TGAGTTCA} \mathrm{TG}\right)_{4} \mathrm{CG}(\mathrm{TG})_{6}$ \\
\hline P. meyeri & $\mathrm{AF}$ & GAGATGAGG(AG) $)_{2}$ TGAGTTCA $(T G)_{4} \mathrm{CA}(\mathrm{TG})_{6}$ \\
\hline P. erithacus & AF & $\mathrm{G}_{3}$ ATGAGG(AG) $)_{2}$ TGAGTTCG $(\mathrm{TG})_{3} \mathrm{C}(\mathrm{TG})_{5}$ \\
\hline A. ararauna & NT & $\mathrm{G}_{3} \mathrm{TGAGA}(\mathrm{AG})_{2} \mathrm{TG}(\mathrm{AG})_{2}(\mathrm{TG})_{3} \mathrm{CAT}$ \\
\hline C. n. chathamensis & $A U-1$ & $\mathrm{G}_{4} \mathrm{TG}_{4}(\mathrm{AG})_{2}(\mathrm{TG})_{14}(\mathrm{CG})_{2}(\mathrm{CA})_{2} \mathrm{TG}$ \\
\hline C. n. novaezelandiae & $A U-1$ & $\mathrm{G}_{4} \mathrm{TG}_{4}(\mathrm{AG})_{3}(\mathrm{TG})_{7}(\mathrm{CA})_{2} \mathrm{TG}$ \\
\hline C. auriceps & $A U-1$ & $\mathrm{GCGGTG}_{4}(\mathrm{AG})_{3}(\mathrm{TG})_{12} \mathrm{CG}(\mathrm{TG})_{6}(\mathrm{CA})_{2} \mathrm{TG}$ \\
\hline C. malherbi & $A U-1$ & $\mathrm{GCGGTG}_{4}(\mathrm{AG})_{2}(\mathrm{TG})_{13} \mathrm{CACG}$ \\
\hline C. hochstetteri & $A U-1$ & $\mathrm{GCGGTG}_{4}(\mathrm{AG})_{3}(\mathrm{TG})_{15} \mathrm{CACG}$ \\
\hline C. unicolor & $A U-1$ & $\mathrm{G}_{4} \mathrm{TG}_{4}(\mathrm{AG})_{2}(\mathrm{TG})_{12} \mathrm{CACG}$ \\
\hline C. forbesi & $A U-1$ & $\mathrm{G}_{4} \mathrm{TG}_{4}(\mathrm{AG})_{2}(\mathrm{TG})_{20}(\mathrm{CA})_{2} \mathrm{TG}$ \\
\hline C. saisetti & $A U-1$ & $\mathrm{GCGGTG}_{4}(\mathrm{AG})_{3}(\mathrm{TG})_{17}(\mathrm{CA})_{2} \mathrm{TG}$ \\
\hline E. cornutus & $A U-1$ & $\mathrm{G}_{4} \mathrm{TG}_{4}(\mathrm{AG})_{2}(\mathrm{TG})_{10} \mathrm{TA}(\mathrm{TG})_{17}(\mathrm{CA})_{2} \mathrm{TG}$ \\
\hline E. uvaeensis & $A U-1$ & $\mathrm{G}_{4} \mathrm{TG}_{4}(\mathrm{AG})_{2}(\mathrm{TG})_{5} \mathrm{TA}(\mathrm{TG})_{4} \mathrm{TA}(\mathrm{TG})_{15}(\mathrm{CA})_{2} \mathrm{TG}$ \\
\hline$P$. varius & $A U-1$ & $\mathrm{G}_{3} \mathrm{TG}_{4} \mathrm{AG}(\mathrm{TG})_{12}$ \\
\hline B. barnardi & $A U-1$ & $\mathrm{G}_{3} \mathrm{TG}_{4}(\mathrm{AG})_{2} \mathrm{TGAG}(\mathrm{TG})_{10}$ \\
\hline P. alexandri & $A U-1$ & $\mathrm{G}_{4} \mathrm{TG}_{4}(\mathrm{AG})_{2} \mathrm{TGAG}(\mathrm{TG})_{2} \mathrm{AG}(\mathrm{TG})_{5}$ \\
\hline M. pusio & $A U-1$ & $\mathrm{GGAATG}_{4}(\mathrm{AG})_{2} \mathrm{TGAG}(\mathrm{TG})_{2}(\mathrm{AG})_{2} \mathrm{G}_{4}(\mathrm{TG})_{4} \mathrm{AG}(\mathrm{TG})_{3}$ \\
\hline M. undulatus & $A U-1$ & $\mathrm{G}_{4} \mathrm{TG}_{4} \mathrm{ACAGTGAG}(\mathrm{TG})_{2} \mathrm{AG}(\mathrm{TG})_{2}$ \\
\hline G. pusilla & AU-L & $\mathrm{G}_{4} \mathrm{TG}_{4} \mathrm{ACAGTGAG}(\mathrm{TG})_{2} \mathrm{AG}(\mathrm{TG})_{3}$ \\
\hline T. haematodus & AU-L & $\mathrm{G}_{4} \mathrm{TG}_{4} \mathrm{ACAGTGAG}(\mathrm{TG})_{2} \mathrm{AG}(\mathrm{TG})_{3}$ \\
\hline N. hollandicus & $A U-C$ & 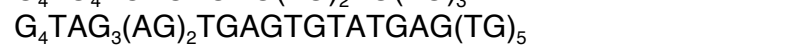 \\
\hline E. roseicapillus & $A U-C$ & $\mathrm{G}_{4} \mathrm{TG}_{4}(\mathrm{AG})_{2}(\mathrm{TGAGTGTA})_{2} \mathrm{TGAG}(\mathrm{TG})_{4}$ \\
\hline C. haematuropygia & $A U-C$ & $\mathrm{G}_{4} \mathrm{TG}_{4}(\mathrm{AG})_{2}(\mathrm{TGAGTGTA})_{2}(\mathrm{TG})_{4}$ \\
\hline \multicolumn{3}{|l|}{ Cfor3031 } \\
\hline C. nigra barkyli & AF & $\mathrm{GAGTG}_{7} \mathrm{CT}(\mathrm{GT})_{3} \mathrm{ATGT}$ \\
\hline P. senegalus & AF & $\mathrm{GAGTGGAG}_{4}(\mathrm{GT})_{6} \mathrm{ATGT}$ \\
\hline$P$. erithacus & AF & GAGTGGAGGCG $_{4}(\mathrm{GT})_{6}$ ATGT \\
\hline C. n. chathamensis & $A U-1$ & $\mathrm{G}_{4} \mathrm{TGG}(\mathrm{GT})_{10} \mathrm{ATGT}$ \\
\hline C. n. novaezelandiae & $A U-1$ & $\mathrm{G}(\mathrm{GT}){ }_{12}$ ATGT \\
\hline C. auriceps & $A U-1$ & $\mathrm{G}_{4} \mathrm{TGG}(\mathrm{GT})_{8} \mathrm{ATGT}$ \\
\hline C. malherbi & $A U-1$ & $\mathrm{G}_{4}(\mathrm{GT})_{10}$ ATGT \\
\hline C. e. hochstetteri & $A U-1$ & $\mathrm{GG}(\mathrm{GT})_{9} \mathrm{ATGT}$ \\
\hline C. unicolor & $A U-1$ & $\mathrm{GG}(\mathrm{GT})_{9} \mathrm{ATGT}$ \\
\hline C. forbesi & $A U-1$ & $\mathrm{G}_{4} \mathrm{TGG}(\mathrm{GT})_{10} \mathrm{ATGT}$ \\
\hline C. saisetti & $A U-1$ & $\mathrm{GG}(\mathrm{GT})_{8} \mathrm{ATGT}$ \\
\hline E. cornutus & $A U-1$ & $\mathrm{G}_{5}(\mathrm{GT})_{10} \mathrm{ATGT}$ \\
\hline E. uvaeensis & $A U-1$ & $\mathrm{G}_{6}(\mathrm{GT})_{9} \mathrm{ATGT}$ \\
\hline$P$. varius & $A U-1$ & $\mathrm{GAGGTG}_{8} \mathrm{AGCT}(\mathrm{GT})_{3} \mathrm{ATGT}$ \\
\hline P. eximius & $A U-1$ & $\mathrm{G}_{9} \mathrm{CGGTCT}(\mathrm{GT})_{3} \mathrm{ATGT}$ \\
\hline P. alexandri & $A U-1$ & $\mathrm{GAGTG}_{7} \mathrm{CT}(\mathrm{GT})_{3} \mathrm{ATGT}$ \\
\hline M. pusio & $A U-1$ & $\mathrm{GAGCG}_{7} \mathrm{CT}(\mathrm{GT})_{3} \mathrm{ATGT}$ \\
\hline G. pusilla & $A U-L$ & GAGTCTG $_{5} \mathrm{CT}(\mathrm{GT})_{3} \mathrm{ATGT}$ \\
\hline T. haematodus & $A U-L$ & GAGTCTG $_{5} \mathrm{CT}(\mathrm{GT})_{3}$ ATGT \\
\hline
\end{tabular}

\subsection{Discussion}

\subsubsection{Markers and Methods in Phylogenetic Constructions}

Since the first use of microsatellite flanking region sequences to construct phylogenies by Zardoya et al. (1996), an increasing number of studies 
have been published utilising this technique (for example, Ortí et al. 1997; Streelman et al. 1998; Makova et al. 2000; Zhu et al. 2000a).

Although the flanking region sequences of microsatellite loci isolated in this study generally show low resolving power (Figure 4.1), the microsatellite flanking region sequences do add to the number of loci available for construction of more accurate parrot phylogenies.

Compared with nuclear genes, mitochondrial markers have a higher rate of evolution, and evolve independently of chromosomal markers, making them popular tools for phylogenetic construction (Brown et al. 1979; Barton \& Jones 1983; Moore 1995). However, there has been concern that mitochondrial DNA represents only single-gene genealogy and may not always accurately represent the evolution of the organisms examined (Pamilo \& Nei 1988; Ball et al. 1990). To increase the probability of obtaining an accurate species phylogenetic tree, the use of DNA sequences from many independently evolving loci is preferred (Tajima 1983; Takahata \& Nei 1985; Pamilo \& Nei 1988).

The choice of algorithms for constructing phylogeny (see Felsenstein 1978; Kuhner \& Felsenstein 1994; Kolaczkowski \& Thornton 2004) and understanding of the most appropriate mutation model of the marker sequence (see Yang 1997; Takezaki \& Gojobori 1999) are important considerations in taxonomy and evolution. Maximum parsimony (MP; Camin \& Sokal 1965), maximum likelihood (ML; Felsenstein 1981), and neighbour-joining (NJ; Saitou \& Nei 1987) algorithms were chosen for phylogenetic constructions in this study because they are widely accepted (Saitou \& Imanishi 1989; Huelsenbeck \& Hillis 1993; Tateno et al. 1994; Russo et al. 1996; Huelsenbeck 1995; Yang 1996). Differences between $\mathrm{ML}$ and MP trees in the microsatellite phylogenies of Cyanoramphus 
parakeets are most likely to be caused by the differences in performance of the algorithms (Yang 1996) and lack of signal in the flanking sequences.

\subsubsection{Cross-species Microsatellite Amplifications in Parrots}

It has been suggested that the likelihood of successful cross-species microsatellite amplification correlates positively with phylogenetic distance in avian species (Primmer et al. 1996). The majority of the Cfor loci show no amplification in the AU-NZ lineage, which is believed to be the ancestral lineage of parrots, with greatest distance away from Cyanoramphus (Boon 2000). The amplification of these microsatellite loci generally conforms to the pattern of higher likelihood of amplification in more closely species, as predicted by Primmer et al. (1996) and Chambers \& MacAvoy (2000).

\subsubsection{Origin and Evolution of Microsatellites}

Few studies have addressed the origin of microsatellite repeats. Messier et al. (1996) proposed a substitution event in an existing dinucleotide repeat unit can give rise to a new tetranucleotide motif. However, an alternative mechanism was also proposed (Gordon 1997) which showed slippage replication alone (without substitution) could produce the results reported by Messier et al. (1996). Phylogenetic studies have reported that microsatellites with fewer than 5 repeat units are rarely polymorphic (Strassmann et al. 1997; Zhu et al. 2000a), supporting the view that there is a threshold for microsatellite expansion (Messier et al. 1996; Rose \& Falush 1998). Using data in the Human Gene Mutation Database (Krawczak \& Cooper 1997), Zhu et al. (2000b) found that insertions and substitutions are common in short repeat units, and may play a role in the origin of microsatellite repeats. However, it is still unclear whether slippage replication acts on small repeat arrays. Another mechanism in 
which A-rich microsatellites were generated by 3' extension of retrotranscripts was suggested as the origin of a microsatellite based on an observed association between microsatellites with retrotransposable elements (Nadir et al. 1996). The data obtained in the present study support a role for both substitutions and replication slippage in the genesis of microsatellite repeat arrays (see below).

The majority of lineages examined at locus Cfor1819 contained no microsatellite repeats, but have the simple sequence CAGA followed by a row of mononucleotide $C$ repeats (Figure 4.2a; Table 4.2). However in the AU-1 lineage associated with Cyanoramphus species and in Nymphicus hollandicus, the locus contains a $(\mathrm{CA})_{\mathrm{n}}$ microsatellite. If CAGA represents the ancestral state, then the simplest route by which $(C A)_{n}$ may arise is the substitution of a $\mathrm{G}$ for $\mathrm{C}$ in CAGA, forming $(\mathrm{CA})_{2}$. The subsequent expansion of $(C A)_{2}$ into larger numbers of repeats could be via slippage replication, perhaps facilitated by the presence of the row of flanking $C$ mononucleotides on the 3' side. The pattern of $\left(\mathrm{C}_{6} \mathrm{CA}\right)_{2}$ interruptions in $B$. barnardi may be explained by an independent, additional substitution or insertion event that introduced an $\mathrm{A}$ within the flanking mononucleotide $\mathrm{C}$ repeat tracts. Alternatively, a $\mathrm{C}$ substitution in $(\mathrm{CA})_{4}$ can turn the motif into $(\mathrm{CA})_{2} \mathrm{CCCA}$, and subsequent $\mathrm{C}$ expansion to $\mathrm{C}_{6} \mathrm{CA}$ and duplication of the motif will result in the $(C A)_{2}\left(C_{6} C A\right)_{2}$ motif observed. The $(C A)_{2}\left(C_{6} C A\right)_{2}$ pattern also suggested that slippage may act on larger templates like $\mathrm{C}_{6} \mathrm{CA}$. The $\mathrm{CA}(\mathrm{CCA})_{\mathrm{n}}$ pattern in Eunymphicus species could be explained by a $\mathrm{C}$ insertion that follows a $\mathrm{G}$ to $\mathrm{C}$ substitution in CAGA.

The proposed model of Cfor1819 evolution, where slippage replication expands a repeat unit after its generation through substitution or insertion, could be used to explain the origin of the repeat motifs in Cfor2021, Cfor2627, and Cfor3031, where substitutions and insertions can occur within the bordering strings of mononucleotides, generating new repeat 
motifs. The observations from these loci support the view of Zhu et al. (2000b) that both insertions and substitutions play important roles in the origin and development of a microsatellite locus. The mechanism which assists the elongation of repeats less than the proposed 5 units "threshold" is unclear, but in the case of the 4 loci studied here, the immediately adjacent mononucleotide repeats are highly likely to act as a template for slippage replication causing the growth of microsatellite repeats.

If slippage involving bordering mononucleotides as templates causes the elongation of di- or tri- nucleotide repeats, then one might also expect the mononucleotides to grow along with the microsatellites. Thus, longer microsatellites would be expected to be associated with longer mononucleotide repeats. This is however not what is observed. It also seems that long mononucleotide repeats may accumulate nucleotide substitutions or insertions readily (see Cfor2627 and Cfor3031; Table 4.2).

Two approaches are generally used to study genesis of microsatellites (reviewed by Bachtrog et al. 1999). The approach taken here follows the evolution of one or a few loci through a phylogeny (for example, Messier et al. 1996; Zhu et al. 2000a). This method relies heavily on how accurately the adopted phylogeny describes true phylogenetic relationships. It is also worth noting that shorter microsatellites may not necessarily represent young microsatellites (Streelman et al. 1998). The alternative approach, surveys the distribution of microsatellites in genomes to search for factors that influence microsatellite density. This requires knowledge from large genome projects, and assumes frequency of microsatellite genesis is directly reflected by observed microsatellite density (for example, Bachtrog et al. 1999). For parrots, neither a $100 \%$ reliable phylogeny is available, nor whole genomic information is available in parakeets. These factors remain as the present obstacles to further assess evolution models built 
on parrot microsatellites. Nonetheless, the findings from Cfor loci provide valuable empirical data on the origin and evolution of microsatellites.

\subsubsection{Future Research}

Subsequent to the submission of this thesis, de Kloet \& de Kloet (2005) published a global phylogeny of parrots based on spindlin gene sequences. Their study did not include many of the AU-1 lineage parrots studied in this chapter, but nevertheless provides an excellent opportunity to further investigate the evolution of Cfor loci when spindlin sequence data from more $\mathrm{AU}-1$ parrots are obtained and incorporated into the global parrot phylogeny.

\subsection{References}

Angers B, Bernatchez L (1997) Complex evolution of a Salmonid microsatellite locus and its consequences in inferring allelic divergence from size information. Mol. Biol. Evol., 14, 230 - 238.

Bachtrog D, Weiss S, Zangerl B, Brem G, Schlötterer C (1999) Distribution of dinucleotide microsatellites in the Drosophila melanogaster genome. Mol. Biol. Evol., 16, $602-610$.

Ball RM Jr, Neigel JE, Avise JC (1990) Gene genealogies within the organismal pedigrees of random-mating populations. Evolution, 44, $360-$ 370.

Barton N, Jones JS (1983) Mitochondrial DNA: New clues about evolution. Nature, 306, 317 - 318. 
Birt TP, Friesen VL, Green JM, Montevecchi WA, Davidson WS (1992) Cytochrome-b sequence among parrots. Hereditas, 117, 67 - 72.

Boon WM (2000) Molecular Systematics and Conservation of the Cyanoramphus Parakeet Complex and the Evolution of Parrots. PhD thesis, Victoria University of Wellington, Wellington, New Zealand.

Boon WM, Kearvell JC, Daugherty CH, Chambers GK (2000) Molecular systematics of New Zealand Cyanoramphus parakeets: Conservation of Orange-fronted and Forbes' Parakeets. Bird Conservation International, 10, $211-239$.

Bowcock AM, Ruiz-Linares A, Tomfohrde J, Minch E, Kidd JR, CavalliSforza LL (1994) High resolution of human evolutionary trees with polymorphic microsatellites. Nature, 368, $455-457$.

Brown WM, George M Jr, Wilson AC (1979) Rapid evolution of animal mitochondrial DNA. Proc. Natl. Acad. Sci., 76, $1967-1971$.

Burton PJK (1974) Jaw and tongue features in Psittaciformes and other orders with special reference to the anatomy of the Tooth-billed pigeon (Didunculus strigirostris). J. Zool. Lond., 174, 255 - 276.

Camin JH, Sokal RR (1965) A method for deducing branching sequences in phylogeny. Evolution, 19, $311-326$.

Chambers GK, MacAvoy ES (2000) Microsatellites: Consensus and controversy. Comparative Biochemistry and Physiology B, 126, 455 476. 
Christids L, Schodde R, Shaw DD, Maynes SF (1991) Relationships among the Australo-Papuan parrots, lorikeets, and cockatoos (Aves: Psittaciformes): Protein evidence. Condor, 93, 302-317.

de Kloet RS, de Kloet SR (2005) The evolution of the spindlin gene in birds: Sequence analysis of an intron of the spindlin $\mathrm{W}$ and $\mathrm{Z}$ gene reveals four major divisions of the Psittaciformes. Molecular Phylogenetics and Evolution, 36, $706-721$.

Di Rienzo A, Peterson AC, Garza JC, Valdes AM, Slatkin M, Freimer NB (1994) Mutational processes of simple-sequence repeat loci in human populations. Proc. Natl. Acad. Sci. USA, 91, 3166-3170.

Eberhard JR, Wright TF, Bermingham E (2001) Duplication and concerted evolution of the mitochondrial control region in the parrot genus Amazona. Mol. Biol. Evol., 18, 1330 - 1342.

Efron (1979) Bootstrap methods: Another look at the jackknife. Ann. Statist., 7, $1-26$.

Estoup A, Tailliez C, Cornuet JM, Solignac M (1995) Size homoplasy and mutational processes in two bee species, Apis mellifera and Bombus terrestris (Apidae). Mol. Biol. Evol., 12, 1074 - 1084.

Ezenwa VO, Peters JM, Zhu Y, Arévalo E, Hastings MD, Seppä P, Pedersen JS, Zacchi F, Queller DC, Strassmann JE (1998) Ancient conservation of trinucleotide microsatellite loci in Polistine wasps. Molecular Phylogenetics and Evolution, 10, 168 - 177.

Felsenstein J (1978) Cases in which parsimony or compatibility methods will be positively misleading. Syst. Zool., 27, $401-410$. 
Felsenstein J (1981) Evolutionary trees from DNA sequences: A maximum likelihood approach. J. Mol. Evol., 17, 368 - 376.

Felsenstein J (1985) Confidence limits on phylogenies: An approach using the bootstrap. Evolution, 39, $783-791$.

FitzSimmons NN, Moritz C, Moore SS (1995) Conservation and dynamics of microsatellite loci over 300 million years of marine turtle evolution. Mol. Biol. Evol., 12, 432 - 440.

Gordon AJE (1997) Microsatellite birth register. J. Mol. Evol., 45, 337 338.

Grimaldi MC, Crouau-Roy B (1997) Microsatellite allelic homoplasy due to variable flanking sequences. J. Mol. Evol., 44, 336 - 340.

Groombridge JJ, Jones CG, Nichols RA, Carlton M, Bruford MW (2004) Molecular phylogeny and morphological change in the Psittacula parakeets. Molecular Phylogenetics and Evolution, 31, 96-108.

Huelsenbeck JP (1995) Performance of phylogenetic methods in simulation. Syst. Biol., 44, 17 - 48.

Huelsenbeck JP, Hillis DM (1993) Success of phylogenetic methods in the four-taxon case. Syst. Biol., 42, $247-264$.

Kimura M, Crow JF (1964) The number of alleles that can be maintained in a finite population. Genetics, 49, $725-738$. 
Kolaczkowski B, Thornton JW (2004) Performance of maximum parsimony and likelihood phylogenetics when evolution is heterogeneous. Nature, 431, $980-984$.

Krawczak M, Cooper DN (1997) Human Gene Mutation Database. TIG, 13, $121-122$.

Kuhner MK, Felsenstein J (1994) A simulation comparison of phylogeny algorithms under equal and unequal evolutionary rates. Mol. Biol. Evol., 11, $459-468$.

Leeton PRJ, Christidis L, Westerman M, Boles WE (1994) Molecular phylogenetic affinities of the night parrot (Geopsittacus occidentalis) and the ground parrot (Pezoporus wallicus). Auk, 111, 833-843.

Maddison DR, Maddison WP (2003) MacClade 4: Analysis of phylogeny and character evolution. Version 4.06. Sinauer Associates, Sunderland, Massachusetts.

Makova KD, Nekrutenko A, Baker RJ (2000) Evolution of microsatellite alleles in four species of mice (Genus Apodemus). J. Mol. Evol., 51, $166-$ 172.

Messier W, Li SH, Stewart CB (1996) The birth of microsatellites. Nature, 381, 483.

Miyaki CY, Matioli SR, Burke T, Wajntal A (1998) Parrot evolution and paleogeographical events: Mitochondrial DNA evidence. Mol. Biol. Evol., $15,544-551$. 
Moore WS (1995) Inferring phylogenies from mtDNA variation: Mitochondrial-gene trees versus nuclear-gene trees. Evolution, 49, 718 726.

Moore SS, Sargeant LL, King TJ, Mattick JS, Georges M, Hetzel DJS (1991) The conservation of dinucleotide microsatellites among mammalian genomes allows the use of heterologous PCR primer pairs in closely related species. Genomics, 10, $654-660$.

Nadir E, Margalit H, Gallily T, Ben-Sasson SA (1996) Microsatellite spreading in the human genome: Evolutionary mechanisms and structural implications. Proc. Natl. Acad. Sci. USA, 93, 6470-6475.

Ohta T, Kimura M (1973) A model of mutation appropriate to estimate the number of electrophoretic detectable alleles in a finite population. Genet. Res., 22, $201-204$.

Ortí G, Pearse DE, Avise JC (1997) Phylogenetic assessment of length variation at a microsatellite locus. Proc. Natl. Acad. Sci. USA, 94, $10745-$ 10749.

Ovenden JR, Mackinlay AG, Crozier RH (1987) Systematics and mitochondrial genome evolution of Australian Rosellas (Aves: Platycercidae). Mol. Biol. Evol., 4, 526 - 543.

Pamilo P, Nei M (1988) Relationships between gene trees and species trees. Mol. Biol. Evol., 5, $568-583$.

Primmer CR, Møller AP, Ellegren H (1996) A wide-range survey of crossspecies microsatellite amplification in birds. Molecular Ecology, 5, $365-$ 378. 
Ribas CC, Miyaki CY (2004) Molecualr systematics in Aratinga parakeets: Species limits and historical biogeography in the 'solstitialis' group, and the systematic position of Nandayus nenday. Molecular Phylogenetics and Evolution, 30, $663-675$.

Rico C, Rico I, Hewitt G (1996) 470 million years of conservation of microsatellite loci among fish species. Proc. R. Soc. Lond. B, 263, $549-$ 557.

Rose O, Falush D (1998) A threshold size for microsatellite expansion. Mol. Biol. Evol., 15, $613-615$.

Russo CAM, Takezaki N, Nei M (1996) Efficiencies of different genes and different tree-building methods in recovering a known vertebrae phylogeny. Mol. Biol. Evol., 13, 525 - 536.

Sainsbury JP (2004) Population Structure, Conservation Genetics and Evolution of the Kaka (Nestor meridionalis): A Microsatellite Study. PhD thesis, Victoria University of Wellington, Wellington, New Zealand.

Saitou N, Imanishi T (1989) Relative efficiencies of the Fitch-Margoliash, maximum-parsimony, maximum-likelihood, minimum-evolution, and neighbor-joining methods of phylogenetic tree construction in obtaining the correct tree. Mol. Biol. Evol., 6, 514-525.

Saitou N, Nei M (1987) The neighbor-joining method: A new method for reconstructing phylogenetic trees. Mol. Bio. Evol., 4, 406- 425.

Schmutz SM, Prus SE (1987) A cytogenetic study of four species of cockatoos and Amazon parrots. Genetica, 74, 69- 71. 
Smith GA (1975) Systematics of parrots. Ibis, 117, $18-68$.

Strassmann JE, Barefield K, Solís CR, Hughes CR, Queller DC (1997) Trinucleotide microsatellite loci for a social wasp, Polistes. Molecular Ecology, 6, $97-100$.

Streelman JT, Zardoya R, Meyer A, Karl SA (1998) Multilocus phylogeny of cichild fishes (Pisces: Perciformes): Evolutionary comparison of microsatellite and single-copy nuclear loci. Mol. Biol. Evol., 15, 798 - 808.

Swofford DL (1998) PAUP*. Phylogenetic Analysis Using Parsimony ( ${ }^{*}$ and other methods). Version 4. Sinauer Associates, Sunderland, Massachusetts.

Tajima F (1983) Evolutionary relationship of DNA sequences in finite populations. Genetics, 105, $437-460$.

Takahata N, Nei M (1985) Gene genealogy and variance of interpopulational nucleotide differences. Genetics, 110, 325 - 344.

Takezaki N, Gojobori T (1999) Correct and incorrect vertebrate phylogenies obtained by the entire mitochondrial DNA sequences. Mol. Biol. Evol., 16, $590-601$.

Tateno Y, Takezaki N, Nei M (1994) Relative efficiencies of the maximumlikelihood, neighbor-joining, and maximum-parsimony methods when substitution rate varies with site. Mol. Biol. Evol., 11, $261-277$.

Taylor JS, Sanny JSP, Breden F (1999) Microsatellite allele homoplasy in the gruppy (Poecilia reticulata). J. Mol. Evol., 48, $245-247$. 
Triggs SJ, Daugherty CH (1996) Conservation and genetics of New Zealand parakeets. Bird Conservation International, 6, 89 - 101.

Viard F, Franck P, Dubois MP, Estoup A, Jarne P (1998) Variation of microsatellite size homoplasy across electromorphs, loci, and populations in three invertebrate species. J. Mol. Evol., 47, 42 - 51.

Weber JL (1990) Informativeness of human $(d C-d A)_{n} \cdot(d G-d T)_{n}$ polymorphisms. Genomics, 7, 524-530.

Weber JL, May PE (1989) Abundant class of human DNA polymorphisms which can be typed using the Polymerase Chain Reaction. Am. J. Hum. Genet., 44, 388 - 396.

Yang Z (1996) Phylogenetic analysis using parsimony and likelihood methods. J. Mol. Evol., 42, $294-307$.

Yang Z (1997) How often do wrong models produce better phylogenies? Mol. Biol. Evol., 14, 105 - 108.

Zane L, Bargelloni L, Patarnello T (2002) Strategies for microsatellite isolation: A review. Molecular Ecology, 11, 1-16.

Zardoya R, Vollmer DM, Craddock C, Streelman JT, Karl S, Meyer A (1996) Evolutionary conservation of microsatellite flanking regions and their use in resolving the phylogeny of cichlid fishes (Pisces: Perciformes). Proc. R. Soc. Lond. B, 263, $1589-1598$.

Zhu Y, Queller DC, Strassmann JE (2000a) A phylogenetic perspective on sequence evolution in microsatellite loci. J. Mol. Evol., 50, 324 - 338. 
Zhu Y, Strassmann JE, Queller DC (2000b) Insertions, substitutions, and the origin of microsatellites. Genet. Res., 76, 227-236. 


\section{Chapter 5: Does Crown Plumage Directly Reflect}

the Hybridisation Status of Parakeets? A Preliminary Study in Red-crowned Parakeets (Cyanoramphus novaezelandiae novaezelandiae) and Yellow-crowned Parakeets (C. auriceps) on New Zealand Mainland

\subsection{Introduction}

A situation that parallels the hybridisation of Forbes' parakeet with Chatham Island Red-crowned parakeet exists on the New Zealand mainland, where Red-crowned parakeets (Cyanoramphus novaezelandiae novaezelandiae) have been observed to pair with Yellow-crowned parakeets (C. auriceps; Veitch 1979; Butler 1986).

A parakeet was captured on Kapiti Island in early 2004, which had crown plumage patterns intermediate between a Red-crowned and a Yellowcrowned parakeet (Figure 5.1). The bird, which died in captivity, weighed $68 \mathrm{~g}$ and was banded with a metal band numbered D181961. Today, the Kapiti Island parakeet population consists solely of Red-crowned parakeets, however, Yellow-crowned parakeets are believed to have existed on Kapiti Island since the 1930s but have not been seen there since the 1960s (Colin Miskelly, NZ Department of Conservation, pers. comm.). The captured bird, D181961, could be either a hybrid between Red-crowned and Yellow-crowned parakeets, or have a mutation in the crown colour genes, representing natural variation in Red- or Yellowcrowned parakeets. 
Figure 5.1 Parakeet D181961 captured on Kapiti Island displaying crown plumage characteristics intermediate between a Red-crowned and a Yellow-crowned parakeet. Photograph courtesy of New Zealand Department of Conservation.

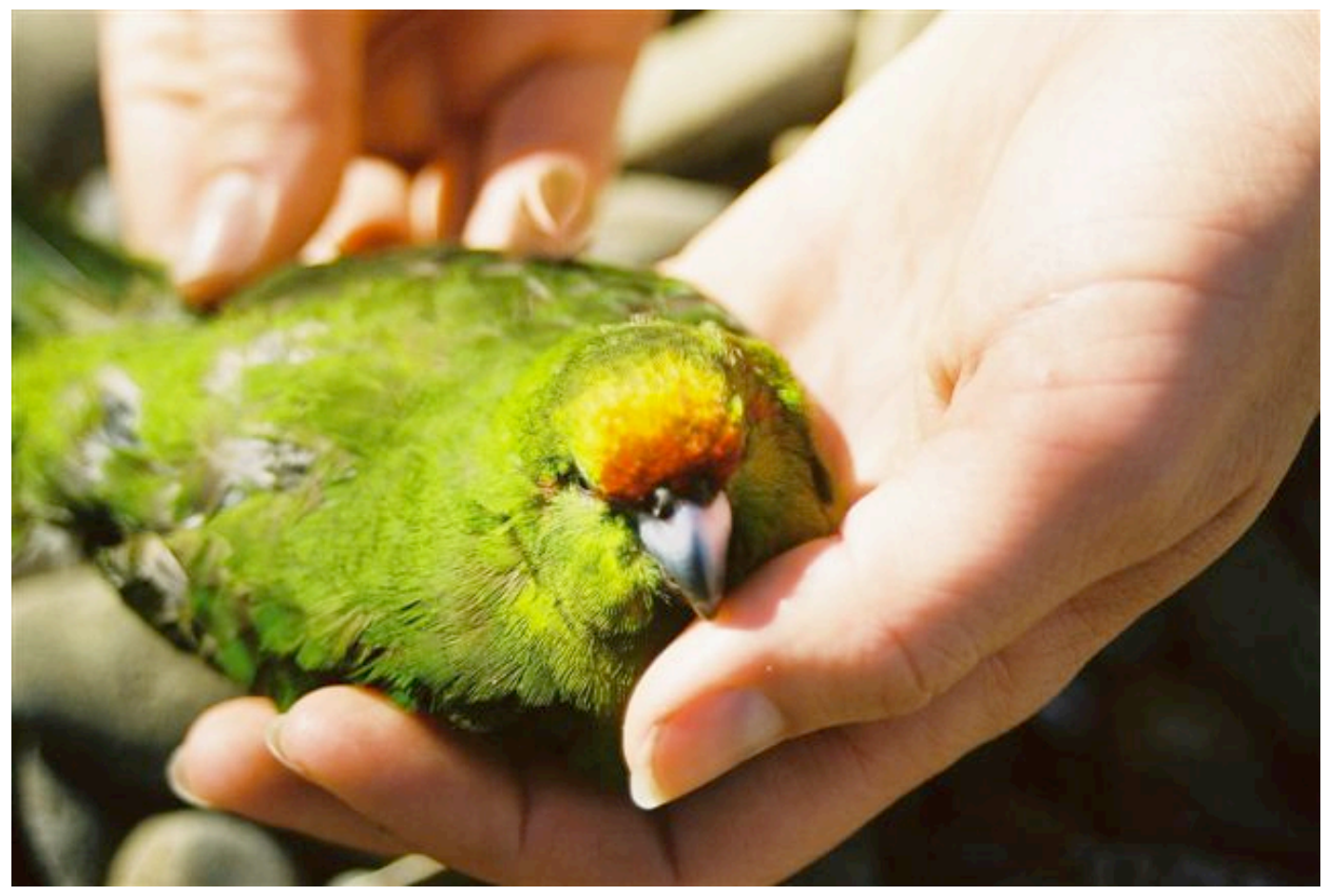

At the time of this study, samples from Kapiti Island were unavailable, but blood samples from a small number of Red-crowned parakeets from Poor Knights Islands, and of Yellow-crowned parakeets from Eglinton Valley were available (Boon 2000). These enabled a preliminary comparative study of the microsatellite genotypes to further test for correlation between morphology and genetics in mainland parakeets. The Eglinton population is believed to consist mainly of pure Yellow-crowned parakeets. The Poor Knights Islands population is made up of Red-crowned parakeets, but a small number of Yellow-crowned parakeets and possible hybrids between them had been reported there in the past (Chambers 1956; Sagar 1988). Therefore, the Poor Knights samples may not represent "pure" mainland Red-crowned parakeet genotypes. 
The objective of this chapter is to further explore the relationship between crown morphology and genetics in Cyanoramphus parakeets in species other than Forbes' parakeet.

\subsection{Methods}

\subsubsection{Extraction of DNA from Samples}

Total DNA was extracted from breast muscle dissected from the corpse of bird D181961 (courtesy of Kaye Ballantyne, Victoria University of Wellington), or $5 \mu \mathrm{l}$ of blood from 13 Poor Knights Islands Red-crowned parakeets and 16 Yellow-crowned parakeets from Eglinton Valley using High Pure DNA Template Preparation Kit (Roche), following the manufacturer's protocol.

\subsubsection{Amplification and Screening of Cfor Microlatellite Loci}

The target Cfor loci were amplified from the extracted DNA. PCRs were performed on an Eppendorf Mastercycler ep thermocycler using conditions described in Chapter 2, section 2.2.16. PCR products were genotyped and sequenced on an ABI Prism 377 sequencer (Applied Biosystems) as described in Chapter 3, section 3.2.1, and results were analysed with GeneScan Analysis and Sequencing Analysis software (Applied Biosystems) respectively.

\subsubsection{Analysis of Basic Population Characteristics}

Allele frequencies, expected and observed heterozygosities were calculated using the Microsatellite Analyser software (version M3.15; Dieringer \& Schlötterer 2002). Because sample size bias could affect the differences in heterozygosity, a resampling of 1000 random draws was performed to allow a more balanced comparison. Allele frequency 
distributions were compiled using AppleWorks (version 6; Apple Computer).

Tests for deviations from Hardy-Weinberg equilibrium (HWE) was by the Markov chain method (Guo \& Thompson 1992) as implemented in GENEPOP (version 3.4; Raymond \& Rousset 1995). The programme was run for 600 batches with 1000 iterations per batch, and dememorization was set at 1000. The same software was used to test for linkage disequilibrium between loci.

\subsubsection{Calculation of Genetic Differentiation}

Data from six loci, Cfor0809, Cfor1415, Cfor1617, Cfor2021, Cfor2829, and Cfor3031 were selected for further analysis (see Chapter 3, section 3.3.3). The estimator $\square_{S T}$ (Weir \& Cockerham 1984) of $F_{S T}$ (Wright 1951) and the estimator $\square_{\text {ST }}$ (Rousset 1996) of $R_{\text {ST }}$ (Slatkin 1995) were calculated using the GENEPOP software (version 3.4; Raymond \& Rousset 1995). Differentiation between Poor Knights Red-crowned parakeets and Eglinton Yellow-crowned parakeets was assessed by Analysis of Molecular Variance (AMOVA; Excoffier et al. 1992) as implemented in the GeneticStudio software (version 2.01; Dyer \& Sork 2001).

\subsubsection{Assignment of Individuals Using Microsatellite Allele Frequencies} Assignment of individuals to populations was made using the test implemented in the Doh software (Paetkau et al. 1995). The programme was run for $10^{6}$ runs to assign individual D181961 into the population with the closest genotypes. Poor Knights Islands Red-crowned parakeet and Eglinton Valley Yellow-crowned parakeet samples screened in this chapter were included in the analysis together with 30 "pure" Forbes' parakeet and 
13 "pure" Chatham Island Red-crowned parakeet samples (see Chapter 3, Appendix 3.2).

\subsubsection{Genetic Distances Calculations}

A genetic distance matrix of chord distance $\left(D_{c}\right.$; Cavalli-Sforza \& Edwards 1967), a statistic which makes no assumption about models of microsatellite evolution, was calculated by the Microsatellite Analyser software (version M3.15; Dieringer \& Schlötterer 2002). The genetic distance matrix was then ordinated in multidimensional space by Principal Coordinate Analysis (Gower 1966) using the software PCO (Anderson 2003).

\subsubsection{Mitochondrial DNA Data}

The mitochondrial DNA data is kindly provided by Kaye Ballantyne (Victoria University of Wellington). The $2.5 \mathrm{~kb}$ mitochondrial control region was amplified using primers L16518 and H1800 (Boon et al. 2001) in 1x Expand High Fidelity PCR buffer (Roche), $1.5 \mathrm{mM} \mathrm{MgCl}, 0.2 \mathrm{mM}$ dNTPs, $0.5 \mu \mathrm{M}$ of each primer, and $0.05 \mathrm{U}$ Expand High Fidelity DNA polymerase (Roche). The cycling profile, consisting of $95^{\circ} \mathrm{C}-3 \mathrm{~min}, 35$ cycles at $\left(95^{\circ} \mathrm{C}-15 \mathrm{sec}, 55^{\circ} \mathrm{C}-30 \mathrm{sec}, 68^{\circ} \mathrm{C}-2 \mathrm{~min}\right.$ with a cumulative increase of extension time at $20 \mathrm{sec}$ per cycle), $68^{\circ} \mathrm{C}-7 \mathrm{~min}$, was run on a PerkinElmer model 480 thermocycler. The products were sequenced on an $\mathrm{ABI}$ Prism 377 sequencer (Applied Biosystems).

\subsection{Results}

\subsubsection{HWE, Linkage Disequilibrium, and Genetic Differentiation}

Most loci conformed to HWE ( $P \geq 0.05$; Table 5.1), except Cfor1415 and Cfor3031 in the Poor Knights population, and Cfor0809 in the Eglinton 
population $(P<0.05)$. Among the loci which deviated from HWE, Cfor1415 showed heterozygote excess, while Cfor0809 and Cfor3031 showed heterozygote deficiencies. Calculated expected heterozygosity values were similar with or without resampling, indicating that bias due to small population size was minimal (Table 5.1). Allele frequencies were charted in Figure 5.2. Linkage disequilibrium between loci was not observed after sequential Bonferroni correction (Rice 1989). The estimators of $F_{S T}$ and $R_{S T}$ were calculated to be 0.0878 and 0.1190 respectively, indicating about $9 \%$ genetic differentiation between Poor Knights Red-crowned parakeets and Eglinton Yellow-crowned parakeets. AMOVA also showed $10.2 \%$ of the genetic differentiation could be attributed to the differences between the two populations examined $(P=$ $0.001)$.

\subsubsection{Assignment of Individuals}

Parakeet D181961 was assigned as a Red-crowned parakeet, similar to other members in the Poor Knights Islands Red-crowned parakeet population (Table 5.2). The probability of assigning D181961 as a Yellowcrowned parakeet was $7.15 \times 10^{-10}$, magnitudes lower than that of Redcrowned parakeet. Analysis of mitochondrial DNA control region sequences also showed that parakeet D181961 has Red-crowned parakeet maternal ancestors. Therefore, it is rather unlikely that D181961 has a recent interspecific hybridisation history. 
Table 5.1 Population genetic characteristics at variable Cfor loci in Poor Knights and Eglinton parakeet populations. The number of alleles observed is represented by $n ; H_{\mathrm{O}}$ and $H_{\mathrm{E}}$ represent observed and expected heterozygosities respectively. HWE $(P)$ represents the $P$-value in HWE test, HWE (S.E.) represents the standard error, and $H_{\mathrm{E}}$ (R.S.) shows the mean expected heterozygosity after 1000 resamplings.

\begin{tabular}{cccccccc}
\hline Locus & Population & $n$ & HWE $(P)$ & HWE (S.E.) & $H_{\mathrm{O}}$ & $H_{\mathrm{E}}$ & $H_{\mathrm{E}}$ (R.S.) \\
\hline Cfor0809 & Poor Knights Is. & 3 & 0.8208 & 0.0011 & 0.6923 & 0.5938 & 0.6086 \\
& Eglinton Valley & 4 & 0.0250 & 0.0011 & 0.3750 & 0.5907 & 0.5470 \\
& & & & & & & \\
Cfor1415 & Poor Knights Is. & 9 & 0.0427 & 0.0036 & 1.0000 & 0.8554 & 0.8449 \\
& Eglinton Valley & 6 & 0.1041 & 0.0027 & 1.0000 & 0.8226 & 0.8219 \\
& & & & & & & \\
Cfor1617 & Poor Knights Is. & 3 & 0.3743 & 0.0025 & 0.2308 & 0.3354 & 0.3918 \\
& Eglinton Valley & 2 & - & - & 0.0625 & 0.0625 & 0.1350 \\
Cfor1819 & Poor Knights Is. & 5 & 0.1914 & 0.0028 & 0.7692 & 0.7908 & 0.7678 \\
& Eglinton Valley & 7 & 0.5798 & 0.0058 & 0.8125 & 0.8206 & 0.7633 \\
& & & & & & & \\
Cfor2021 & Poor Knights Is. & 3 & 0.2848 & 0.0020 & 0.3077 & 0.3938 & 0.4984 \\
& Eglinton Valley & 3 & 0.2846 & 0.0019 & 0.5625 & 0.5262 & 0.5351 \\
& Poor Knights Is. & 12 & 0.1465 & 0.0090 & 0.7692 & 0.9046 & 0.8683 \\
& Eglinton Valley & 9 & 0.4787 & 0.0093 & 0.7500 & 0.8266 & 0.7532 \\
& & & & & & & \\
Cfor2829 & Poor Knights Is. & 3 & 0.4955 & 0.0019 & 0.6154 & 0.5569 & 0.5461 \\
& Eglinton Valley & 5 & 0.2765 & 0.0039 & 0.6875 & 0.7117 & 0.7174 \\
& & & & & & & \\
Cfor3031 & Poor Knights Is. & 7 & 0.0176 & 0.0016 & 0.6923 & 0.8369 & 0.8135 \\
& Eglinton Valley & 6 & 0.2826 & 0.0068 & 0.5000 & 0.5907 & 0.6826 \\
\hline
\end{tabular}

Out of all 72 assignment tests (excluding D181961), three cases of misassignments were observed in the microsatellite assignment: 1) Poor Knights Islands individual CD2070 as a Yellow-crowned parakeet, 2) South-East Island individual D171531 as a Yellow-crowned parakeet, and 3) Mangere Island individual D172022 as a Red-crowned parakeet. The error rate of the microsatellite assignment is about $4.2 \%$. The major cause of these misassignments is likely to be the birds' individual genotypes being more similar to that found in the populations they are misassigned to. No Eglinton Valley Yellow-crowned parakeet was misassigned. 
Figure 5.2 Allele frequency distributions of $\mathrm{Cfor}$ loci in two populations of parakeets. Solid bars represent Poor Knights Islands population (13 individuals), shaded bars represent Eglinton population (16 individuals), and the numbers above bars represent the number of times an allele is observed.
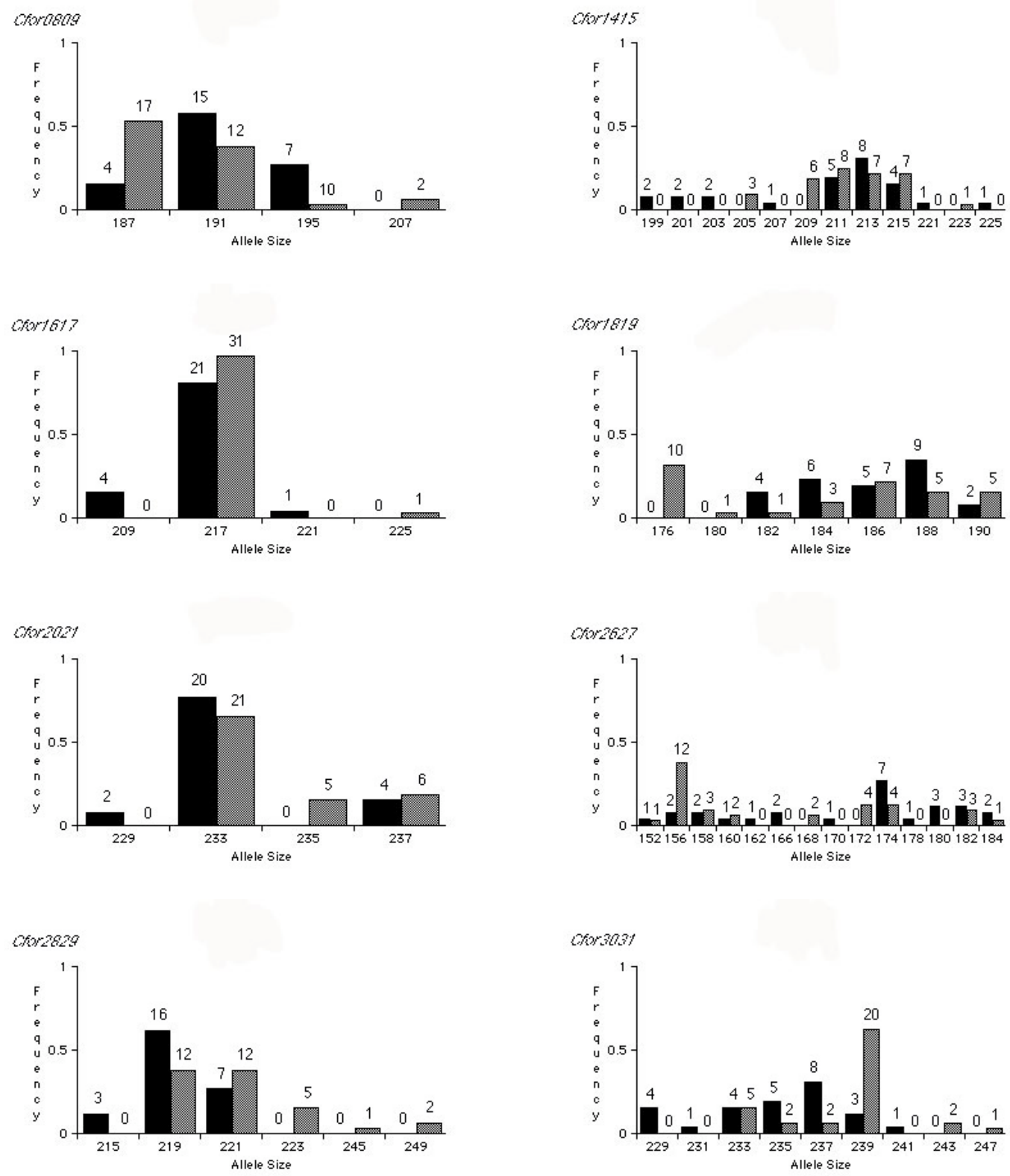


\subsubsection{Genetic Distances Between Individuals}

A principal coordinates plot of $D_{c}$ distance values (Figure 5.3) shows that the Kapiti Island bird D181961 was more closely grouped to Poor Knights Islands Red-crowned parakeets than Eglinton Yellow-crowned parakeets. The first axis, PCO 1, represents $23.4 \%$ of the total variation, while the second axis, PCO 2, represents $16.8 \%$ of the total variation. Cumulatively, $40.2 \%$ of the total genetic variation was represented in the first two axes. These results supported the outcome of the assignment test.

Table 5.2 Assignment of individuals using microsatellite allele frequency and mitochondrial control region data. RCP = Red-crowned parakeet, $\mathrm{YCP}=$ Yellow-crowned parakeet, $\mathrm{CIRCP}=$ Chatham Island Red-crowned parakeet, and FBP = Forbes' parakeet. Mitochondrial DNA data was provided courtesy of Kaye Ballantyne (Victoria University of Wellington).

\begin{tabular}{|c|c|c|c|c|}
\hline \multirow{2}{*}{ Population } & \multirow{2}{*}{ Sample } & \multicolumn{2}{|c|}{ Microsatellite Assignment } & \multirow[t]{2}{*}{ mtDNA Assignment } \\
\hline & & Assignment & Assignment Probability & \\
\hline \multirow[t]{13}{*}{ Poor Knights } & CD2063 & $\mathrm{RCP}$ & $2.56 \times 10^{-6}$ & $\mathrm{RCP}$ \\
\hline & CD2067 & RCP & $1.18 \times 10^{-7}$ & $\mathrm{RCP}$ \\
\hline & CD2068 & $\mathrm{RCP}$ & $7.34 \times 10^{-5}$ & $\mathrm{RCP}$ \\
\hline & CD2070 & YCP & $4.07 \times 10^{-5}$ & $\mathrm{RCP}$ \\
\hline & CD2071 & $\mathrm{RCP}$ & $3.59 \times 10^{-6}$ & RCP \\
\hline & CD2073 & $\mathrm{RCP}$ & $8.51 \times 10^{-11}$ & $\mathrm{RCP}$ \\
\hline & CD2075 & $\mathrm{RCP}$ & $4.14 \times 10^{-6}$ & $\mathrm{RCP}$ \\
\hline & CD2078 & $\mathrm{RCP}$ & $4.95 \times 10^{-10}$ & $\mathrm{RCP}$ \\
\hline & CD2080 & $\mathrm{RCP}$ & $5.22 \times 10^{-6}$ & $\mathrm{RCP}$ \\
\hline & CD2087 & RCP & $1.63 \times 10^{-6}$ & $\mathrm{RCP}$ \\
\hline & CD2091 & RCP & $1.33 \times 10^{-6}$ & $\mathrm{RCP}$ \\
\hline & CD2093 & RCP & $9.37 \times 10^{-5}$ & $\mathrm{RCP}$ \\
\hline & CD2113 & $\mathrm{RCP}$ & $2.79 \times 10^{-7}$ & - \\
\hline \multirow[t]{11}{*}{ Eglinton } & FT3323 & YCP & $8.53 \times 10^{-10}$ & YCP \\
\hline & FT3325 & YCP & $7.17 \times 10^{-6}$ & YCP \\
\hline & FT3326 & YCP & $1.08 \times 10^{-6}$ & YCP \\
\hline & FT3327 & YCP & $1.99 \times 10^{-4}$ & YCP \\
\hline & FT3328 & YCP & $6.42 \times 10^{-6}$ & YCP \\
\hline & FT3329 & YCP & $6.07 \times 10^{-5}$ & YCP \\
\hline & FT3330 & YCP & $1.12 \times 10^{-9}$ & YCP \\
\hline & FT3331 & YCP & $6.51 \times 10^{-5}$ & YCP \\
\hline & FT3334 & YCP & $5.24 \times 10^{-6}$ & YCP \\
\hline & FT3336 & YCP & $2.55 \times 10^{-7}$ & - \\
\hline & FT3337 & YCP & $2.67 \times 10^{-4}$ & YCP \\
\hline
\end{tabular}




\begin{tabular}{|c|c|c|c|c|}
\hline & FT3339 & YCP & $3.50 \times 10^{-4}$ & YCP \\
\hline & FT3346 & YCP & $5.78 \times 10^{-6}$ & YCP \\
\hline & FT3347 & YCP & $1.45 \times 10^{-5}$ & YCP \\
\hline & FT3348 & YCP & $3.22 \times 10^{-4}$ & YCP \\
\hline & FT3349 & YCP & $5.17 \times 10^{-7}$ & YCP \\
\hline \multirow[t]{13}{*}{ South-East Is. } & D171526 & CIRCP & $2.22 \times 10^{-4}$ & CIRCP \\
\hline & D171527 & CIRCP & $6.53 \times 10^{-3}$ & CIRCP \\
\hline & D171531 & YCP & $1.50 \times 10^{-3}$ & $\mathrm{CIRCP}$ \\
\hline & D171533 & CIRCP & $1.24 \times 10^{-2}$ & CIRCP \\
\hline & D171535 & CIRCP & $6.56 \times 10^{-4}$ & CIRCP \\
\hline & D171536 & CIRCP & $4.69 \times 10^{-3}$ & CIRCP \\
\hline & D171586 & CIRCP & $1.79 \times 10^{-3}$ & CIRCP \\
\hline & D171587 & CIRCP & $7.93 \times 10^{-6}$ & CIRCP \\
\hline & D171588 & CIRCP & $1.84 \times 10^{-3}$ & CIRCP \\
\hline & D171589 & CIRCP & $7.07 \times 10^{-5}$ & CIRCP \\
\hline & D171593 & CIRCP & $4.99 \times 10^{-4}$ & CIRCP \\
\hline & D171596 & CIRCP & $1.01 \times 10^{-4}$ & CIRCP \\
\hline & D171597 & CIRCP & $5.13 \times 10^{-6}$ & CIRCP \\
\hline \multirow[t]{30}{*}{ Mangere Is. } & $B W-G$ & FBP & $1.56 \times 10^{-4}$ & FBP \\
\hline & G-BO & FBP & $5.87 \times 10^{-3}$ & FBP \\
\hline & G-BR & FBP & $6.03 \times 10^{-2}$ & FBP \\
\hline & G-RY & FBP & $1.25 \times 10^{-2}$ & FBP \\
\hline & GW-W & FBP & $6.03 \times 10^{-2}$ & FBP \\
\hline & OY-G & FBP & $3.09 \times 10^{-3}$ & FBP \\
\hline & $R G-G$ & FBP & $5.05 \times 10^{-4}$ & FBP \\
\hline & WO-G & FBP & $1.56 \times 10^{-4}$ & FBP \\
\hline & WR-G & FBP & $6.02 \times 10^{-2}$ & FBP \\
\hline & W-WB & FBP & $1.21 \times 10^{-4}$ & FBP \\
\hline & D171514 & FBP & $3.01 \times 10^{-3}$ & FBP \\
\hline & D172011 & FBP & $1.25 \times 10^{-2}$ & FBP \\
\hline & D172022 & $\mathrm{RCP}$ & $3.77 \times 10^{-6}$ & FBP \\
\hline & D172042 & FBP & $6.03 \times 10^{-2}$ & FBP \\
\hline & D174714 & FBP & $7.00 \times 10^{-3}$ & FBP \\
\hline & D174717 & FBP & $7.01 \times 10^{-3}$ & FBP \\
\hline & D174718 & FBP & $2.66 \times 10^{-2}$ & FBP \\
\hline & D175003 & FBP & $4.37 \times 10^{-2}$ & FBP \\
\hline & D175013 & FBP & $5.32 \times 10^{-4}$ & FBP \\
\hline & D175103 & FBP & $4.14 \times 10^{-4}$ & FBP \\
\hline & D175104 & FBP & $6.42 \times 10^{-3}$ & FBP \\
\hline & D175111 & FBP & $6.02 \times 10^{-2}$ & FBP \\
\hline & D175114 & FBP & $2.83 \times 10^{-3}$ & FBP \\
\hline & D175128 & FBP & $2.66 \times 10^{-2}$ & FBP \\
\hline & D175135 & FBP & $1.25 \times 10^{-2}$ & FBP \\
\hline & D175181 & FBP & $1.31 \times 10^{-3}$ & FBP \\
\hline & D175187 & FBP & $6.02 \times 10^{-2}$ & FBP \\
\hline & D175190 & FBP & $6.03 \times 10^{-2}$ & FBP \\
\hline & D175207 & FBP & $6.02 \times 10^{-2}$ & FBP \\
\hline & D175214 & FBP & $6.02 \times 10^{-2}$ & FBP \\
\hline Kapiti & D181961 & $\mathrm{RCP}$ & $2.89 \times 10^{-7}$ & $\mathrm{RCP}$ \\
\hline
\end{tabular}


Figure 5.3 Principal coordinate analysis of Cavalli-Sforza \& Edwards (1967) chord distances between individual parakeets.

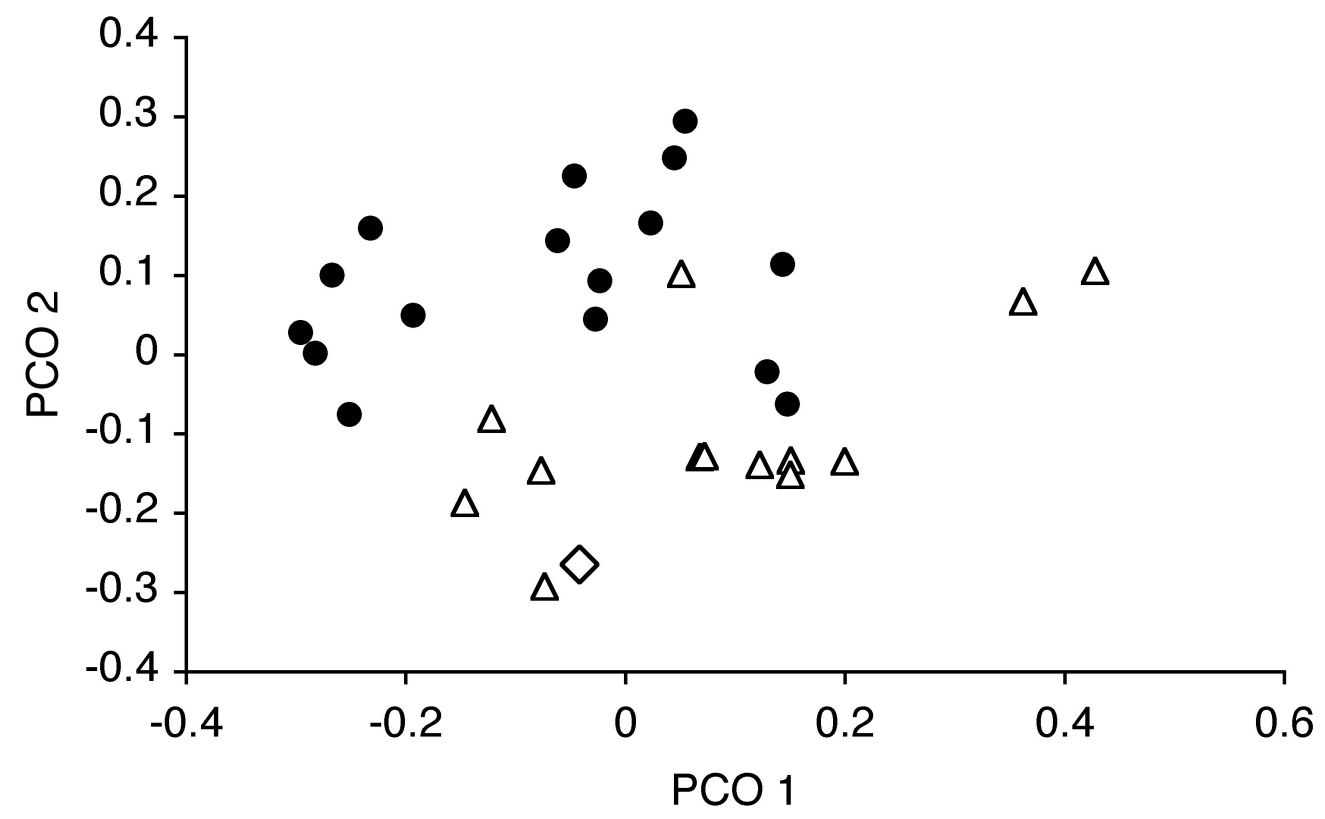

$\Delta$ Poor Knights $\bullet$ Eglinton $\diamond$ Kapiti Island

\subsection{Discussion}

\subsubsection{Relationship Between Morphological Characteristics and Genetics}

There is no empirical genetic evidence that the crown plumage pattern observed in parakeet D181961 is the result of hybridisation. The bird has typical Red-crowned parakeet mitochondrial control region sequence (Kaye Ballantyne, Victoria University of Wellington, pers. comm.; Table 5.2), and the mitochondrial DNA data rules out the further possibility that this bird represents a new species. If hybridisation had occurred in recent generations, then one would expect microsatellite allele frequencies of sample D181961 to be shifted towards the Yellow-crowned parakeet end of the genotype spectrum and to a degree directly related to how recently the hybridisation took place. However, neither microsatellite assignment test nor the genetic distance data for microsatellites suggest that this is the case. Although rather unlikely, it cannot be ruled out that D181961 may 
have retained Yellow-crowned parakeet type crown morphology alleles inherited from a very ancient hybridisation event. A more detailed study of the situation would require samples from the Kapiti Island population, which are currently unavailable.

Taylor et al. (1986) performed breeding experiments between Yellowcrowned parakeets and Orange-fronted parakeets (C. malherbi). They showed that hybrids can display intermediate crown plumage patterns as well as parental phenotypes. Therefore, hybrids can be morphologically identical to parental species (see also Chapter 3).

An alternative explanation of the crown morphology observed in bird D181961 is a mutation occurring in the crown colour control pathway genes on Red-crowned parakeet genotype background. It has also been suggested that production of red carotenoid pigments in birds, which give red colouration on feathers, may be related to environmental factors such as diet, and the metabolic abilities of the birds (Hill 1996). Therefore, crown colouration could be affected by both genetic and environmental factors, and may not be a very reliable indicator of species identities in parakeets.

\subsubsection{Genetic Variation in Island and Mainland Parakeet Populations} Comparing the number of observed alleles between the Poor Knights Islands and Eglinton Valley populations with the Mangere Island and South-East Island populations studied in Chapter 3, equal or higher number of alleles are observed in Poor Knights Islands and Eglinton Valley populations at all loci (Table 5.3). These differences may be species differences, or they may represent lower diversity in isolated island populations, consistent with the literature survey by Frankham (1997) that showed most island populations have less genetic variation 
than mainland populations as measured by allele diversity and heterozygosities using various nuclear genetic markers.

Although the Poor Knights Islands are about $20 \mathrm{~km}$ from the adjacent mainland, genetic exchange with mainland populations is possible (Sagar 1988).

Increased genetic variation may increase the adaptive potential of populations to changing environments. Ayala (1965) suggested that preexisting genetic variation is critical for short-term evolutionary changes. Compared to Yellow-crowned and mainland Red-crowned parakeets, Forbes' and Chatham Island Red-crowned parakeets may be more vulnerable to environmental changes, and thus the Chatham Islands species may require more attention in management.

Table 5.3 Comparison of number of observed alleles between Chatham Islands, Poor Knights Islands and New Zealand mainland parakeet populations.

\begin{tabular}{ccccc}
\hline Locus & $\begin{array}{c}\text { Mangere Is. } \\
\text { (250 samples) }\end{array}$ & $\begin{array}{c}\text { South-East Is. } \\
\text { (35 samples) }\end{array}$ & $\begin{array}{c}\text { Poor Knights Is. } \\
\text { (13 samples) }\end{array}$ & $\begin{array}{c}\text { Eglinton Valley } \\
\text { (16 samples) }\end{array}$ \\
\hline Cfor0809 & 4 & 3 & 3 & 4 \\
Cfor1415 & 7 & 5 & 9 & 6 \\
Cfor1617 & 2 & 2 & 3 & 2 \\
Cfor1819 & 4 & 4 & 5 & 7 \\
Cfor2021 & 2 & 1 & 3 & 3 \\
Cfor2627 & 5 & 4 & 12 & 9 \\
Cfor2829 & 3 & 2 & 3 & 5 \\
Cfor3031 & 7 & 5 & 7 & 6 \\
\hline
\end{tabular}




\subsection{References}

Anderson MJ (2003) PCO: a FORTRAN computer program for principal coordinate analysis. Department of Statistics, University of Auckland, New Zealand.

Ayala FJ (1965) Evolution of fitness in experimental populations of Drosophila serrata. Science, 150, $903-905$.

Boon WM (2000) Molecular Systematics and Conservation of the Cyanoramphus Parakeet Complex and the Evolution of Parrots. PhD thesis, Victoria University of Wellington, Wellington, New Zealand.

Boon WM, Kearvell JC, Daugherty CH, Chambers GK (2001) Molecular systematics and conservation of kakariki (Cyanoramphus spp.): Science for Conservation 176. Department of Conservation, Wellington.

Butler DJ (1986) Hybrid parakeet on mainland. Notornis, 33, 58 - 62.

Cavalli-Sforza LL, Edwards AWF (1967) Phylogenetic analysis: models and estimation procedures. Amer. J. Hum. Genet., 19, 233 - 257.

Chambers BS (1956) Birds of the Poor Knights Island. Tane, 7, 66 - 67.

Dieringer D, Schlötterer C (2002) Microsatellite analyser (MSA): a platform independent analysis tool for large microsatellite data sets. Molecular Ecology Notes, 3, $167-169$.

Dyer R, Sork VL (2001) Pollen pool heterogeneity in shortleaf pine, Pinus echinate Mill. Molecular Ecology, 10, 859 - 866. 
Excoffier L, Smouse PE, Quattro JM (1992) Analysis of molecular variance inferred from metric distances among DNA haplotypes: application to human mitochondrial DNA restriction data. Genetics, 131, 479 - 491.

Frankham R (1997) Do island populations have less genetic variation than mainland populations? Heredity, 78, $311-327$.

Gower JC (1966) Some distance properties of latent root and vector methods used in multivariate analysis. Biometrika, 53, 325-338.

Guo SW, Thompson EA (1992) Performing the exact test of HardyWeinberg proportions for multiple alleles. Biometrics, 48, 361-372.

Hill GE (1996) Redness as a measure of the production cost of ornamental coloration. Ethology Ecology \& Evolution, 8, 157 - 175.

Paetkau D, Calvert W, Stirling I, Strobeck C (1995) Microsatellite analysis of population structure in Canadian polar bears. Molecular Ecology, 4, $347-354$.

Raymond M, Rousset F (1995) GENEPOP (version 1.2): Population genetic software for the exact tests and ecumenicisms. J. Hered., 86, 248 -249 .

Rice WR (1989) Analyzing tables of statistical tests. Evolution, 43, 223 225.

Rousset $F$ (1996) Equilibrium values of measures of population subdivision for stepwise mutation processes. Genetics, 142, $1357-1362$. 
Sagar PM (1988) Some characteristics of Red-crowned parakeets on the Poor Knights Islands. Notornis, 35, 1 - 8.

Slatkin M (1995) A measure of population subdivision based on microsatellite allele frequencies. Genetics, 139, $457-462$.

Taylor RH, Heatherbell EG, Heatherbell EM (1986) The Orange-fronted Parakeet (Cyanoramphus malherbi) is a colour morph of the Yellowcrowned Parakeet (C. auriceps). Notornis, 33, 17- 22.

Veitch CR (1979) Parakeet hybridisation. Notornis, 26, 395.

Weir BS, Cockerham CC (1984) Estimating F-statistics for the analysis of population structure. Evolution, 38, $1358-1370$.

Wright S (1951) The genetical structure of populations. Annals of Eugenics, 15, $323-354$. 


\section{Chapter 6: Conservation of Forbes' Parakeet - Present and Outlook}

\subsection{Summary}

Results from this study clearly show that Forbes' parakeets have hybridised extensively with the Chatham Island Red-crowned parakeets (see Chapter 3). Despite the extensive hybridisation, genetic differentiation studies using microsatellite markers showed a morphological class of birds that is still genetically distinct from Chatham Islands Red-crowned parakeets. Therefore, "pure" or near-"pure" Forbes' parakeets and a lot of their original genetic variation still remain to be conserved in the Mangere Island parakeet population. Cryptic hybrids (comprising $F_{n}$ hybrids and backcrosses) with Forbes' parakeet morphology exist in large proportions $(77.9 \%$ of all Forbes' parakeet morphotype birds tested), and are by definition impossible to identify based solely on crown plumage. In contrast, all of the clear morphological hybrids show their genetic hybridisation history.

Using both genetic and morphological criteria, a Forbes' parakeet is defined as a bird which has morphological score MP1 (morphological true Forbes' parakeet), mitochondrial DNA haplotype 3 (MT3), and assigned as a Forbes' parakeet (MS1) in microsatellite assignment tests (see Chapter 3 , section 3.3.6). Of 203 birds tested in this study, $17.8 \%$ of birds fall into this category. Being able to establish guidelines for defining a "true" Forbes' parakeet ("pure" or near-"pure") greatly facilitates identification of parakeets and associated management efforts.

Microsatellites isolated in this study are believed to evolve through either a SMM (Ohta \& Kimura 1973) or a TPM (Di Rienzo et al. 1994) mode. This 
indicates mutation patterns vary for different microsatellite loci, and no single universal model exists to date. The origin of four of the dinucleotide microsatellite loci isolated appears to be linked to flanking single nucleotide repeat tracts. The data support slippage-replication as the main mechanism that generates polymorphisms in microsatellites (Schlötterer \& Tautz 1992), and a role played by substitutions and insertions in generation of new repeat themes (Messier et al. 1996; Zhu et al. 2000).

The tools developed in this study are also widely applicable in other parakeets and parrots. The microsatellite markers isolated here will very likely contribute to the study of various population genetics aspects in other parrots in the future.

\subsection{Present Status of Forbes' Parakeet}

\subsubsection{Inbreeding and Genetic Bottlenecks}

Many New Zealand land birds have experienced substantial decline over the last millennium, with many endemics already lost (such as the moa), or facing extinction (McDowall 1969). Inbreeding depression and genetic bottlenecks have been extensively studied by conservation geneticists because of the associated risk of extinction (for example, Frankham \& Ralls, 1998; Saccheri et al. 1998). Worldwide, many small island populations are significantly inbred, and are more prone to the undesirable effects of inbreeding depression (Frankham 1998). Conversely, it has also been noted that while some abundant species have minimal variability, some endangered species have high levels of genetic variability comparable with healthy populations (Amos \& Harwood 1998). Therefore, genetic variability, though important in enhancing the potential in adaptation, may not necessarily enhance the survival of a population (Lande \& Shannon 1996). Inbreeding coefficients are defined in terms of 
the probability of identity in state of different pairs of genes (Rousset 2002). Departures from HWE and homozygote excesses have been frequently used as a sign of possible inbreeding (Robertson \& Hill 1984). However, a recent simulation study has suggested that correlation between heterozygosity and inbreeding is strong only when a large number of microsatellite loci $(\sim 200)$ can be used in estimating heterozygosity (Balloux et al. 2004). Inbreeding depression has been suggested as a cause of reduced fitness and juvenile mortality, for example, in the Japanese quail and ungulates (see Sittmann et al. 1966; Ralls et al. 1979; Ralls \& Ballou 1982). Studies with experimental Drosophila populations also show that inbreeding and loss of genetic diversity are related to decrease in disease resistance (Spielman et al. 2004).

Field studies of the Mangere Island Forbes' parakeet population showed morphological Forbes' parakeet pairs have smaller clutch size and considerably lower hatching rate than hybrids and Chatham Island Redcrowned parakeet pairs (Denise Fastier, NZ Department of Conservation, pers. comm.). Inbreeding in the Forbes' parakeet population (see Chapter 3, section 3.3.5) may be a plausible explanation for the apparent reduction in fitness. In addition, the Mangere Island parakeets have a lower microsatellite allelic diversity compared to mainland New Zealand parakeets (see Chapter 5, section 5.4.2). The reduced genetic diversity could be attributed to founder effects, inbreeding, or past genetic bottlenecks. Because of the low genetic diversity in the Mangere Island population, it may be more susceptible to newly introduced diseases (Spielman et al. 2004). Therefore, increasing attention in preventing disease in this population is vital to its survival. The present situtation where all of the world's remaining Forbes' parakeets exist in one single population on Mangere Island has also put this species in high risk of extinction. 
A sharp loss in genetic diversity can sometimes be detected in bottlenecked populations (Nei et al. 1975), for example, in the Cheetah (O'Brien et al. 1985). The severe loss of genetic diversity may increase the vulnerability of the population to extinction (O'Brien et al. 1985). The Forbes' parakeet population is believed to have experienced a reduction in population size when Mangere Island was cleared for farming (Taylor 1975), but the exact population numbers immediately before and after clearing of Mangere Island have not been documented. The results of the microsatellite bottleneck tests do not suggest a recent genetic bottleneck in the Mangere Island parakeet population (Chapter 3, section 3.3.5). Despite the fact that there is no detectable genetic bottleneck the Forbes' parakeet population is very likely to have experienced a population bottleneck judging by the low numbers observed (Taylor 1975).

\subsubsection{Hybridisation}

Although hybridisation may have helped to sustain the Forbes' parakeet morphotype during times with low population numbers, the proportion of hybrids at present has certainly outnumbered Forbes' or near-Forbes' parakeet types (Chapter 3, section 3.3.6). It has been proposed that factors bringing ecologically divergent parental species together often change the environment to form habitats for hybridisation (Templeton 1981). Long term coexistence of parent species and hybrids may be explained by adaptive advantages of hybrids in temporally changing environments (Lewontin \& Birch 1966; Spaak \& Hoekstra 1997). The hypothesis that hybrids perform better in a modified environment (Anderson 1948) suggests the present Mangere Island habitat may not be one that confers advantages to "pure" Forbes' parakeets.

Hybridisation can be a route to introduce genetic variability for adaptive radiation (Seehausen 2004) and can make a positive contribution to 
evolution (Barton 2001). However, further hybridisation, which is likely to result in more extensive mixing of the gene pool, does not appear to help the conservation of "pure" Forbes' parakeets and may eventually lead to the extinction of Forbes' parakeet genotypes. The rarity of "pure" Forbes' parakeet types also suggests hybridisation is slowly displacing the parental genotypes, and constitutes a threat to the long-term survival of the parent species as in other cases documented (see Rhymer \& Simberloff 1996; Huxel 1999; Wolf et al. 2001).

Past cullings of hybrid and Chatham Island Red-crowned parakeets without genetic testing have not eliminated "pure" Forbes' parakeets, but the measure failed to stop hybridisation involving cryptic hybrids. At present, it is uncertain whether crown colouration plays a role in mating choice in parakeets. By eliminating parakeets with extra red feathers in the crown, the culling practice essentially encourages matings between any surviving Chatham Island Red-crowned parakeets or hybrid parakeets with morphological Forbes' parakeets, and consequently increasing the number of cryptic hybrids in the population. Therefore, hybrid culling may not be an optimal solution to the problem.

\subsection{Conservation Considerations}

6.3.1 How Many Evolutionarily Significant Units Make Up the Mangere Island Parakeet Population?

Since the recognition of Forbes' parakeet as a full species (Triggs \& Daugherty 1996; Boon et al. 2000), increasing efforts have been directed towards its conservation (see Greene 2000). Whether the mix of Forbes' parakeets and its hybrids on Mangere and Little Mangere Islands represent a single unit for conservation will need to be considered. 
With the increasing need of conserving natural genetic diversity and resources (Frankel 1974), the Evolutionarily Significant Unit (ESU) concept was proposed to provide a rational basis for setting priorities in conservation that reflect underlying genetic diversity (Ryder 1986). Among numerous definitions proposed for ESU (for example, Moritz 1994; Vogler \& DeSalle 1994; Crandall et al. 2000), the definition of Moritz (1994) is most clearly based on the use of molecular techniques.

Boon et al. (2001) showed that the Mangere Island parakeet population is made up of birds from four different mitochondrial haplogroups: Forbes' parakeet haplogroups (MT1 - 3), and Chatham Island Red-crowned parakeet haplogroup (MT4), with Forbes' parakeet haplogroup MT3 apparently monophyletic to other parakeet species. Birds with haplogroup MT3 makes up about 55\% of the Mangere Island population sampled (Chapter 3, section 3.3.8).

Significant divergence of microsatellite allele frequencies was observed between "pure" Forbes' parakeets and Chatham Island Red-crowned parakeets in this study. The combined mtDNA, microsatellite, and morphological data suggest that Forbes' parakeets are genetically distinct from Chatham Island Red-crowned parakeets, and "pure" or near-"pure" mitochondrial haplogroup MT3 Forbes' parakeets certainly form a single genetically distinct ESU. Both mitochondrial and nuclear genetic data also suggest non-hybrid birds of Chatham Island Red-crowned parakeet haplotype form another distinct ESU.

The origin of mitochondrial haplotype MT2 birds is unknown. MT2 birds on South-East Island all showed morphology of Chatham Island Redcrowned parakeets, while those on Mangere Island can have Forbes' parakeet crown morphology. The data support the view of Boon (2000) that the presence of MT2 birds with Forbes' parakeet morphotype is a 
result of recent hybridisation. Haplotype MT2 birds may originally have been part of the Mangere Island population and some members have migrated to South-East Island (Ballantyne et al. 2004), or they may be originally part of Chatham Island Red-crowned parakeet population on South-East Island. Evaluation of these contrasting hypotheses will require larger scale haplotype screening of parakeets from South-East Island and the main Chatham Island.

Mitochondrial haplogroup MT1 birds have not been found on South-East Island, and all MT1 parakeets screened showed either Forbes' parakeet or hybrid crown morphologies (Chapter 3 , section 3.3.8). This group of birds, found within the Red-crowned parakeet clade in mitochondrial control region phylogeny (Boon 2000), has apparently hybridised with Forbes' parakeet in the past as Boon (2000) suggested.

\subsubsection{Management of Hybrids}

The main aim of managing hybridisation is to minimise the harmful effects caused to the parental species (Rhymer \& Simberloff 1996). However, the positive role of hybridisation in evolution should also be taken into account when making conservation management policies (Dowling \& Secor 1997). Because hybridisation can be an important source of genetic variation (Lewontin \& Birch 1966), different management strategies are recommended for natural and human induced hybrids, and natural hybrids may deserve some form of protection (Allendorf et al. 2001).

Consideration should also be given to the effects of the presence of a large number of hybrids on the parent species. While maintaining hybrids may preserve genetic diversity on the island, ultimately it could also lead to the total loss of the remaining Forbes' parakeet types. On the other hand, if all hybrids are removed (removal of $81 \%$ of the population), a 
substantial decline in the population will occur, and there will also be a genetic diversity loss through another human induced bottleneck. Therefore, a strategy needs to be developed to control the number of hybrids in the population while maintaining a maximum amount of existing genetic variation.

Management of hybrid parakeets is also subject to practical constraints. Genetic testing of every bird on the island may not be an economically favourable prospect and would certainly require a large investment in human resources. Field studies, therefore, can best rely on morphological identification in most cases. The main problem faced here is that morphological intermediacy does not always infer hybridity. This is also a problem frequently encountered by plant taxonomists (Wilson 1992). This study has shown that parakeets with morphological types MP2 and MP3 can have Forbes' parakeet genetics, and the MP1 class consists of a proportion of cryptic hybrids (Chapter 3, section 3.3.8). Past culling of mostly MP3 - MP5 parakeets without genetic testing has not eliminated "pure" Forbes' parakeets, but has not efficiently eliminated hybrids either, especially cryptic hybrids showing Forbes' parakeet morphology MP1.

The immigration of Chatham Island Red-crowned parakeets also poses a major problem in the conservation of Forbes' parakeets. Immigration of Chatham Island Red-crowned parakeets to Mangere Island is usually from the neighbouring Pitt Island and South-East Island. Although the main Chatham Island is about $40 \mathrm{~km}$ from Mangere Island, possibly within the dispersal range of parakeets, no birds have been observed flying from that direction. Another consideration is whether Chatham Island Red-crowned parakeets should be removed from Mangere Island. Existing Chatham Island Red-crowned parakeets on Mangere Island could breed with Forbes' parakeet types and hybrids, but they could also mate with Chatham Island Red-crowned parakeet immigrants, lowering the chance 
of formation of new Forbes' parakeet and Chatham Island Red-Crowned parakeet pairs. Eliminating existing Chatham Island Red-crowned parakeets on Mangere Island would mean all new migrants would have to breed with Forbes' parakeets or hybrids. Instead of hybrid culling, a preferred long-term solution would be reforestation of the habitat to favour Forbes' parakeets.

\subsubsection{Prospect for the Longer Term Survival of Forbes' Parakeet} Considering genetic implications and practical limitations, the following strategies are suggested for future conservation of Forbes' parakeets:

A proportion of hybrids, especially those in morphological groups MP1 and 2 , should be maintained to preserve genetic diversity in the population and to avoid accidental removal of predominantly Forbes' parakeet genotypes. To minimise the threat of losing Forbes' parakeet genotypes through hybridisation, a threshold of hybrid proportion should be decided for restarting of hybrid removal or when hybrid numbers increase quickly. A consensus was reached in a technical meeting at the Wellington conservancy of the New Zealand Department of Conservation in November 2004 that culling of hybrids will resume if morphological hybrids (MP3 and MP4) and Chatham Island Red-crowned parakeets make up more than $25 \%$ of the Mangere Island population, or when morphological hybrids (MP3 and MP4) reach $10 \%$ of the population, or when Forbes' parakeet x Chatham Island Red-crowned parakeet pairs are observed.

If culling is resumed, genetic assessment of culled birds should be carried out to assess the effectiveness of culling.

Birds with unclear morphological identities should be genetically tested before they are culled. 
Establishing new populations of Forbes' parakeet will greatly reduce the risk of extinction of this species. Founding of new Forbes' parakeet populations elsewhere should only include parakeets which are genetically tested as Forbes' parakeets, and a sufficient number to represent reasonable amount of genetic variation.

Periodical genetic testing (for example, every 5 years) should be carried out on a subsample of the Mangere Island population to monitor the changes in genetic proportions. This is particularly important if hybrids have been eliminated during the period, because the effects of hybrids removal to the remaining population could be assessed.

Reforestation of the Mangere Island habitat is urgently needed to favour Forbes' parakeets.

\subsection{Future Research}

\subsubsection{Chatham Island Parakeets}

With the presently available molecular tools, various other ecological problems in the Chatham Islands parakeet populations could be studied. Knowledge of the mating system of Mangere Island parakeets would certainly help to inform management decisions in lowering hybridisation rates. Being Mendelian markers, microsatellites could be used to analyse pedigree and kinship through the study of the pattern of allelic inheritance (Blouin 2003). Also of interest is the correlation between genetic variation and offspring viability. Along with blood or feather samples from viable offspring, tissues from non-viable offspring, such as eggs that failed to hatch, can be used as a source of DNA for genetic testing to determine whether hybrids are more or less fit than their parents. Data from fitness studies can be used to assess post-mating barriers between the two species. 
The origin of various mitochondrial DNA haplogroups (Boon et al. 2001) has not been determined. Of most concern is haplogroup MT2, which is found on both Mangere and South-East Islands. Haplogroup MT2 birds on South-East Island are morphologically indistinguishable from Chatham Island Red-crowned parakeets. A larger scale survey of Chatham Island Red-crowned parakeets from the main Chatham Island and South-East Island would help resolve the mystery. If MT2 birds originate from pure Chatham Island Red-crowned parakeet populations, then the suggestion by Boon (2000) that MT2 parakeets with Forbes' parakeet morphotypes are the results of recent hybridisations can be confirmed.

\subsubsection{Other Parakeets and Parrots}

There has been a suggestion that genetic difference between parents predicts reproductive compatibility (Edmands 2002). Since Forbes' parakeets and Chatham Island Red-crowned parakeets are the most divergent pairing in all New Zealand parakeets (Boon et al. 2001), then one would expect all pairs of New Zealand Cyanoramphus parakeets to have the potential to hybridise. Hybrids between other New Zealand Cyanoramphus parakeets have been observed, for example, hybrids between mainland Red-crowned and Yellow-crowned parakeets (Butler 1986). The markers developed in this study along with mitochondrial DNA markers from Boon et al. (2001) could be used to identify genetic hybrids, and to assess correlation between morphotypes and genotypes in other Cyanoramphus species.

It appears that some of the microsatellite loci isolated in this study are present in a wide range of parrot species (see Chapter 4, section 4.3.1). There are many more parrot species in the world that have not been surveyed in this study due to unavailability of samples. Adding more taxa into the existing collection would enhance the phylogenetic trees built and 
offer more insights on the origin and evolution of microsatellites and parrots.

\subsection{References}

Allendorf FW, Leary RF, Spruell P, Wenburg JK (2001) The problems with hybrids: Setting conservation guidelines. TREE, 16, 613-622.

Amos W, Harwood J (1998) Factors affecting levels of genetic diversity in natural populations. Phil. Trans. R. Soc. Lond. B, 353, $177-186$.

Anderson E (1948) Hybridization of the habitat. Evolution, 2, 1 - 9.

Ballantyne KN, Chan C-H, Chambers GK (2004) A PCR-RFLP based method for assigning mitochondrial control region haplogroups in hybridizing Chatham Islands Cyanoramphus parakeets. New Zealand Natural Sciences, 29, $33-38$.

Balloux F, Amos W, Coulson T (2004) Does heterozygosity estimate inbreeding in real populations? Molecular Ecology, 13, 3021 - 3031.

Barton NH (2001) The role of hybridization in evolution. Molecular Ecology, 10, $551-568$.

Blouin MS (2003) DNA-based methods for pedigree reconstruction and kinship analysis in natural populations. TREE, 18, $503-511$.

Boon WM (2000) Molecular Systematics and Conservation of the Cyanoramphus Parakeet Complex and the Evolution of Parrots. PhD thesis, Victoria University of Wellington, Wellington, New Zealand. 
Boon WM, Kearvell JC, Daugherty CH, Chambers GK (2000) Molecular systematics of New Zealand Cyanoramphus parakeets: Conservation of Orange-fronted and Forbes' Parakeets. Bird Conservation International, 10, $211-239$.

Boon WM, Kearvell JC, Daugherty CH, Chambers GK (2001) Molecular systematics and conservation of kakariki (Cyanoramphus spp.). Science for Conservation 176. Department of Conservation. Wellington.

Butler DJ (1986) Hybrid parakeet on mainland. Notornis, 33, 58 - 62.

Crandall KA, Bininda-Edmonds ORP, Mace GM, Wayne RK (2000) Considering evolutionary processes in conservation biology. TREE, 15, $290-295$.

Di Rienzo A, Peterson AC, Garza JC, Valdes AM, Slatkin M, Freimer NB (1994) Mutational processes of simple-sequence repeat loci in human populations. Proc. Natl. Acad. Sci. USA, 91, $3166-3170$.

Dowling TE, Secor CL (1997) The role of hybridization and introgression in the diversification of animals. Annu. Rev. Ecol. Syst., 28, 593-619.

Edmands S (2002) Does parental divergence predict reproductive compatibility? TREE, 17, $520-527$.

Frankel OH (1974) Genetic conservation: Our evolutionary responsibility. Genetics, 78, $53-65$.

Frankham R (1998) Inbreeding and extinction: island populations. Conservation Biology, 12, $665-675$. 
Frankham R, Ralls K (1998) Inbreeding leads to extinction. Nature, 392 , $441-442$.

Greene TC (2000) Forbes' parakeet (Cyanoramphus forbesi) population on Mangere Island, Chatham Islands. Conservation Advisory Science Notes 319. Department of Conservation, Wellington.

Huxel GR (1999) Rapid displacement of native species by invasive species: Effects of hybridization. Biological Conservation, 89, 143-152.

Lande R, Shannon S (1996) The role of genetic variation in adaptation and population persistence in a changing environment. Evolution, 50, 434 437.

Lewontin RC, Birch LC (1966) Hybridization as a source of variation for adaptation to new environments. Evolution, 20, $315-336$.

McDowall RM (1969) Extinction and endemism in New Zealand land birds. Tuatara, 17, $1-12$.

Messier W, Li SH, Stewart CB (1996) The birth of microsatellites. Nature, 381, 483.

Moritz C (1994) Defining 'Evolutionarily Significant Units' for conservation. TREE, 9, 373 - 375.

Nei M, Maruyama T, Chakraborty R (1975) The bottleneck effect and genetic variability in populations. Evolution, 29, $1-10$. 
O’Brien SJ, Roelke ME, Marker L, Newman A, Winkler CA, Meltzer D, Colly L, Evermann JF, Bush M, Wildt DE (1985) Genetic basis for species vulnerability in the Cheetah. Science, 227, $1428-1434$.

Ohta T, Kimura M (1973) A model of mutation appropriate to estimate the number of electrophoretically detectable alleles in a finite population. Genet. Res., 22, $201-204$.

Ralls K, Ballou J (1982) Effect of inbreeding on juvenile mortality in some small mammal species. Laboratory Animals, 16, 159 - 166.

Ralls K, Brugger K, Ballou J (1979) Inbreeding and juvenile mortality in small populations of Ungulates. Science, 206, 1101-1103.

Rhymer JM, Simberloff D (1996) Extinction by hybridization and introgression. Annu. Rev. Ecol. Syst., 27, 83-109.

Robertson A, Hill WG (1984) Deviations from Hardy-Weinberg proportions: sampling variances and use in estimation of inbreeding coefficients. Genetics, 107, $703-718$.

Rousset F (2002) Inbreeding and relatedness coefficients: what do they measure? Heredity, 88, $371-380$.

Ryder OA (1986) Species conservation and systematics: The dilemma of subspecies. TREE, 1, 9-10.

Saccheri I, Kuussaari M, Kankare M, Vikman P, Fortelius W, Hanski I (1998) Inbreeding and extinction in a butterfly metapopulation. Nature, 392, 491 - 494. 
Schlötterer C, Tautz D (1992) Slippage synthesis of simple sequence DNA. Nucleic Acids Research, 20, 211-215.

Seehausen O (2004) Hybridization and adaptive radiation. TREE, 19, 198 $-207$.

Sittmann K, Abplanalp H, Fraser RA (1966) Inbreeding depression in Japanese quail. Genetics, 54, $371-379$.

Spaak P, Hoekstra JR (1997) Fish predation on a Daphnia hybrid species complex: A factor explaining species coexistence? Limnol. Oceanogr., 42, $753-762$.

Spielman D, Brook BW, Briscoe DA, Frankham R (2004) Does inbreeding and loss of genetic diversity decrease disease resistance? Conservation Genetics, 5, 439 - 448.

Taylor RH (1975) Some ideas on speciation in New Zealand parakeets. Notornis, 22, $110-121$.

Templeton AR (1981) Mechanisms of speciation - a population genetic approach. Annu. Rev. Ecol. Syst., 12, $23-48$.

Triggs SJ, Daugherty CH (1996) Conservation and genetics of New Zealand parakeets. Bird Conservation International, 6, 89-101.

Vogler AP, DeSalle R (1994) Diagnosing units of conservation management. Conservation Biology, 8, $354-363$.

Wilson P (1992) On inferring hybridity from morphological intermediacy. Taxon, 41, 11- 23. 
Wolf DE, Takebayashi N, Rieseberg LH (2001) Predicting the risk of extinction through hybridization. Conservation Biology, 15, 1039 - 1053.

Zhu Y, Strassmann JE, Queller DC (2000) Insertions, substitutions, and the origin of microsatellites. Genet. Res., 76, $227-236$ 